\title{
Modelling the Fire Performance of Hybrid Steel-Timber Connections
}

\author{
by \\ Aaron Akotuah Ohene \\ A thesis submitted to \\ the Faculty of Graduate and Postdoctoral Affairs \\ in partial fulfillment of the requirements for the degree of \\ Master of Applied Science \\ in \\ Civil Engineering \\ Department of Civil and Environmental Engineering \\ Carleton University \\ Ottawa, Ontario
}

(C) 2014

Aaron Akotuah Ohene 


\begin{abstract}
In a building structure, wood can be used in conjunction with steel or concrete material to form what is known as a hybrid building system. A hybrid system combines the efficient properties of the different materials to achieve design requirements such as structural or fire safety.
\end{abstract}

In this research, a typical steel-timber hybrid system is considered. This steel-timber hybrid system consists of a glulam wooden beam connected to a steel column. The connection of the beam to the column is composed of three different types of shear tab connections: concealed, exposed and seated connections. These connections transfer vertical loads between the beams and columns in a hybrid structure. The fire resistance of these connections is evaluated using a finite element model and compared with the full-scale experimental fire resistance tests which had been conducted earlier in a separate project. The major parameters studied included load ratio, heat transfer, charring properties of wood, failure mode of the wood, and their influence on the time to failure of the connections.

The finite element model results were in good agreement with the observations made from the experimental tests. The variation between the test and the model results was within a $\pm 11 \%$ envelope. In conclusion, the seated connection had a better fire resistance as compared to the concealed and exposed connections. 


\section{Acknowledgements}

I want to thank God for the grace, courage and wisdom in seeing me through this Master's program. I want to extend my gratitude to Prof. George Hadjisophocleous for inviting me to undertake this research. Thank you for the entrusting me with this and for your support throughout my program. I would like to thank Prof. Jeffrey Erochko for his guidance and advice during this research study. My appreciation also goes to the collaborators and partners of this research; FP Innovations, NewBuildS and FIBRE network for the funding support.

I would also want to thank Prof. Heng-Aik Khoo and Mr. Sabah Ali for their assistance in conducting this research. Many thanks to the members of my research group and all friends for their support, encouragement and ideas. I finally thank my family back home in Ghana for their invaluable support throughout my program. 


\section{Table of Contents}

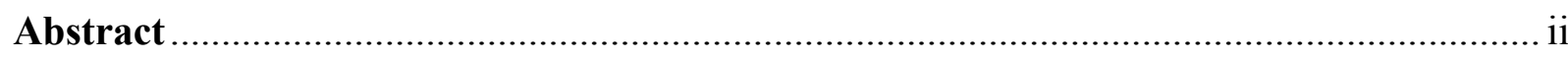

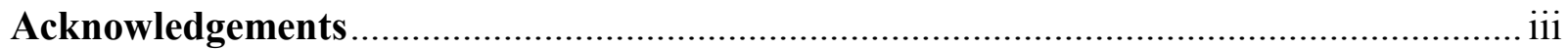

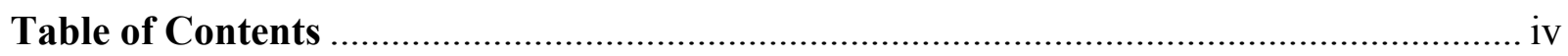

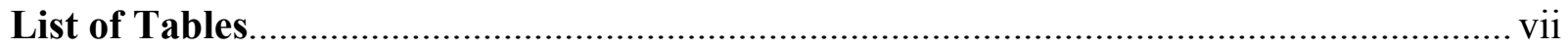

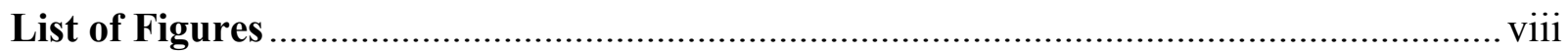

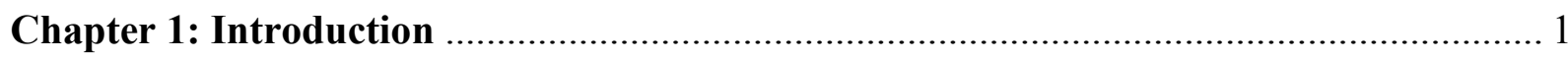

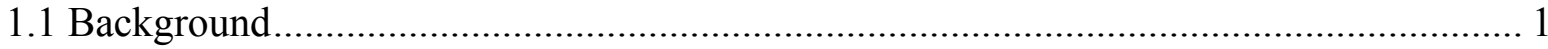

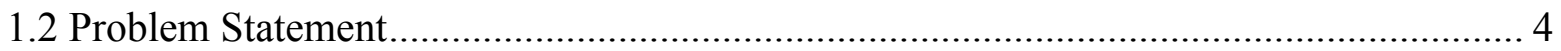

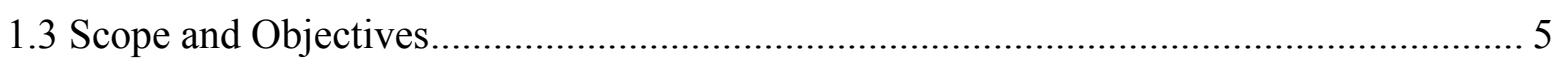

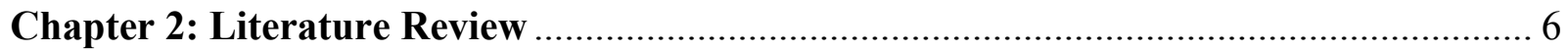

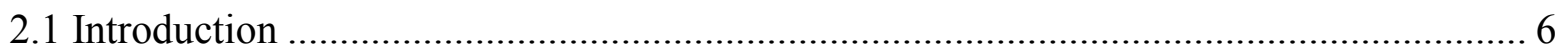

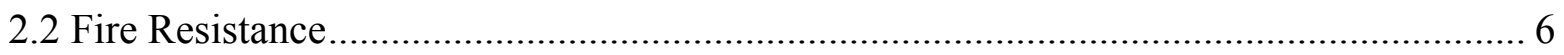

2.2.1 Assessment of Fire Resistance ………................................................................. 7

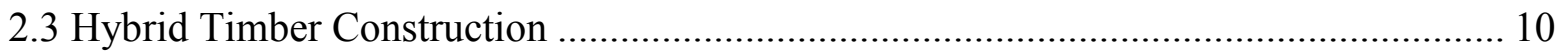

2.3.1 Hybrid Timber Connections ................................................................................. 12



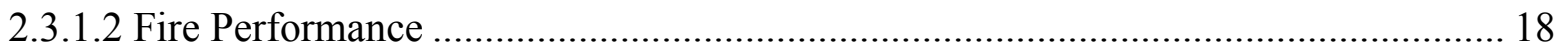

2.3.1.3 Embedment Strength and Fire Resistance Level ...................................................... 20

2.4 Mechanical Properties of Wood and Steel ……………………................................ 25

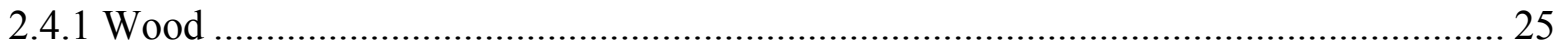

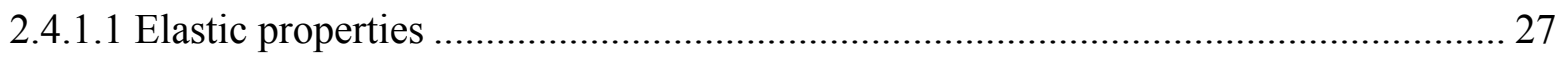

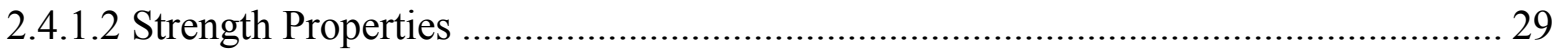

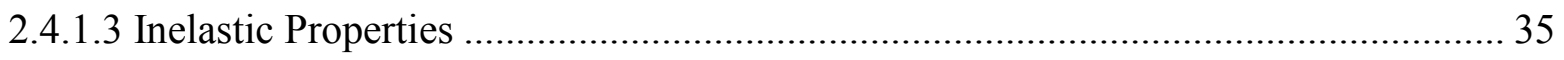

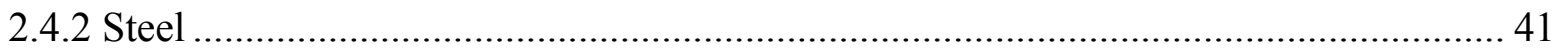

2.5 Mechanical Properties at Elevated Temperatures ........................................................ 42

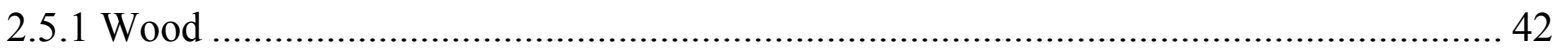

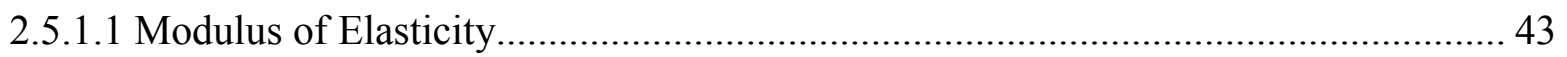

2.5.1.2 Strength Properties ........................................................................................... 44

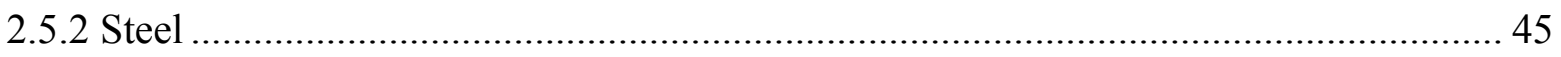




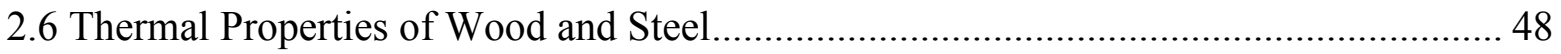

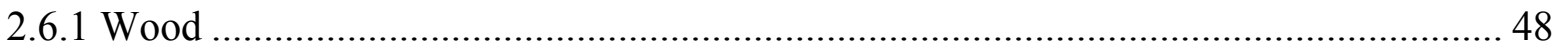

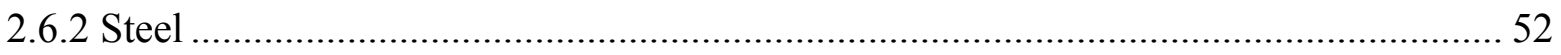

2.7 Numerical Modelling of Steel-Timber Connections ..................................................... 53

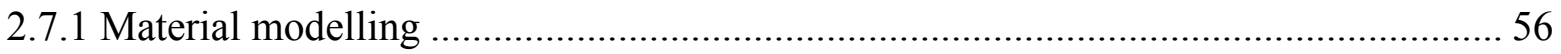

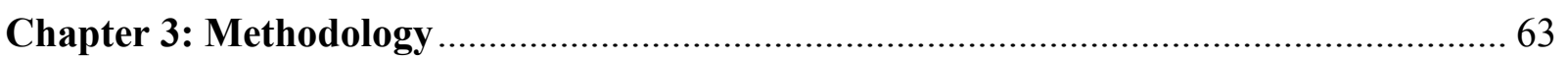

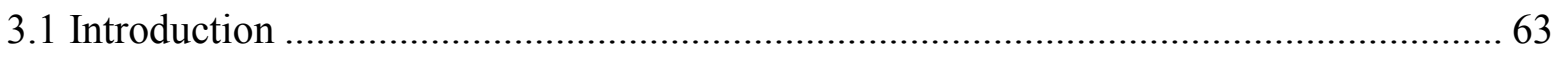

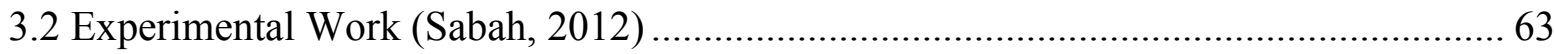

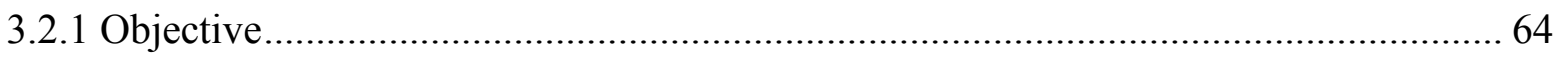

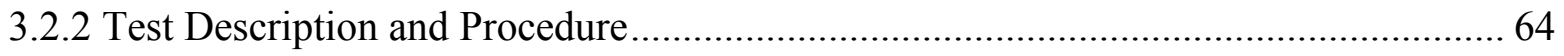



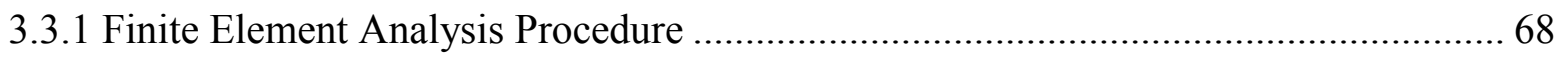

3.3.2 Finite Element Discretization and Meshing ………............................................... 70

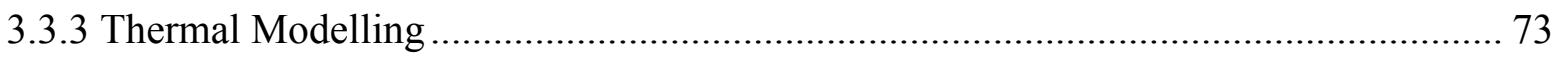

3.3.3.1 Assigning Finite Elements and Material Properties ............................................... 73

3.3.3.2 Fire Model and Heat Transfer Analysis .............................................................. 74

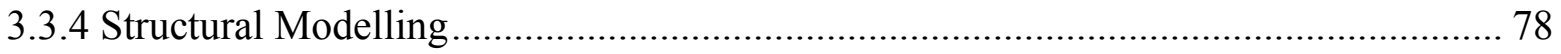

3.3.4.1 Assigning Finite Elements and Material properties ............................................... 78

3.3.4.2 Structural Damage and Failure Modelling .......................................................... 83

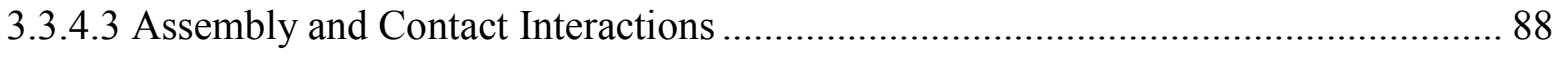

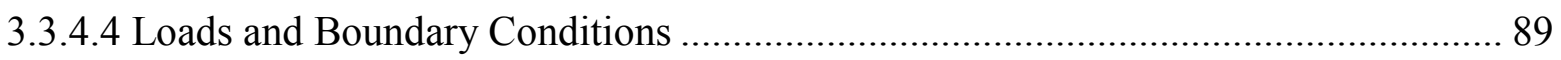

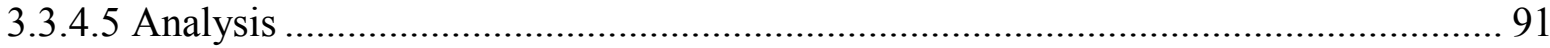



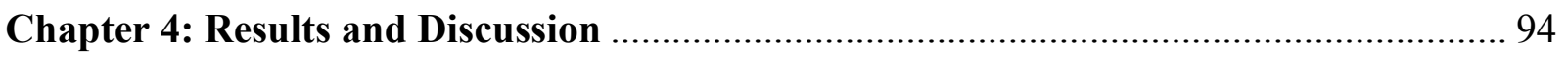

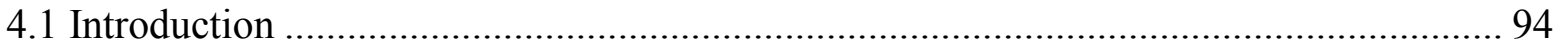

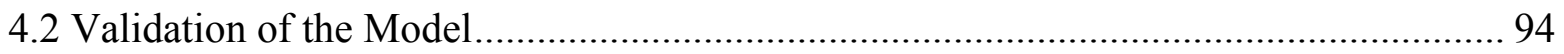

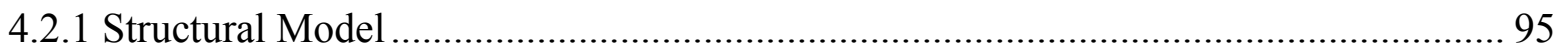

4.2.1.1 Estimation of the Ultimate Capacity from the Structural Model............................... 96

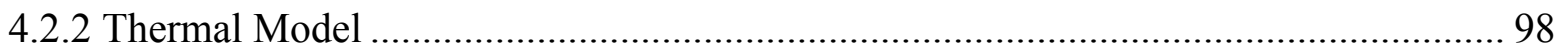

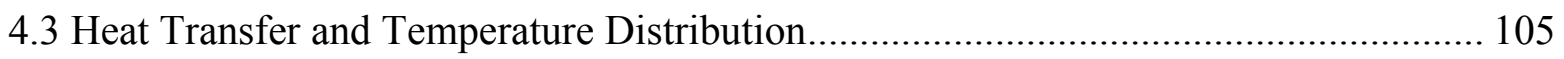

4.3.1 Concealed Connection $(\mathrm{CN})$.................................................................................. 105 


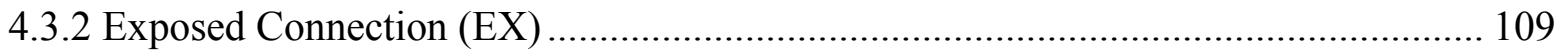

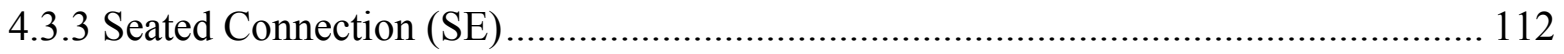



4.5 Estimation of the Fire Resistance ………………................................................... 120

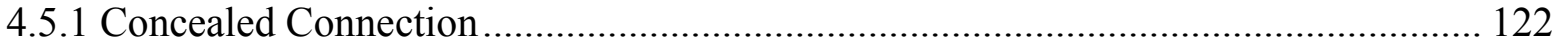

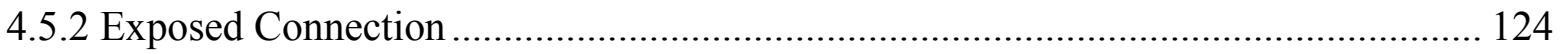

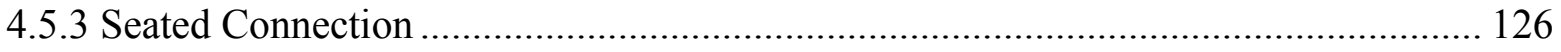

4.5.4 Relative Fire Resistance of the Connections ........................................................ 128

4.6 Structural Damage and Failure ................................................................................. 134

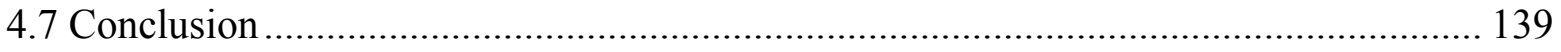

Chapter 5: Summary, Conclusions and Recommendations........................................... 140

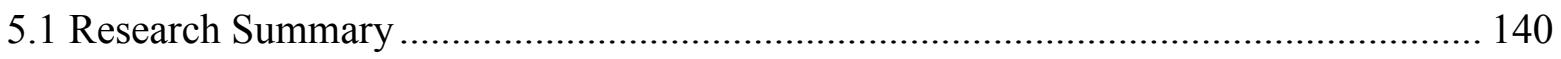

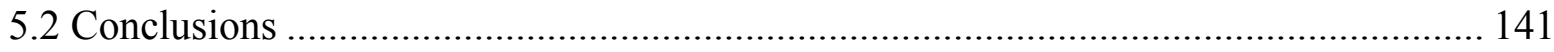

5.3 Recommendations for Future Work …………....................................................... 143



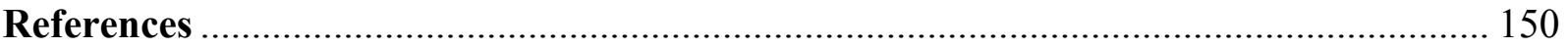




\section{List of Tables}

Table 2.1 Influence of knots on tension strength (Kollmann and Côtè, 1984) ............................. 30

Table 2.2 Influence of knots on compression strength (Kollmann and Côtè, 1984) .................... 30

Table 3.1 Elastic ratios of wood species (12\% moisture content) (Wood Handbook, 2010) ........ 81

Table 3.2 Approximate Elastic constant values used in the model.............................................. 83

Table 4.1 Applied Load and Load ratio of Test connections (Sabah, 2012) ................................ 96

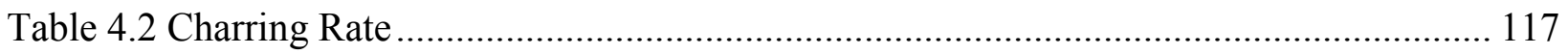

Table 4.3 Fire Resistance of the Connections ........................................................................ 130 


\section{List of Figures}

Fig. 1.1 Wooden Beam-Steel Column Connections ......................................................................... 4

Fig. 2.1 Standard time-temperature curves for CAN/ULC-S101 and ISO 834 (Peng, 2010) .................... 8

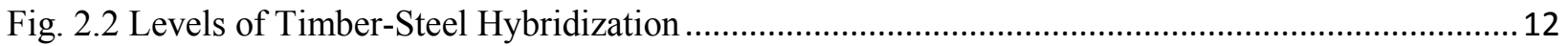

Fig. 2.3 Typical Failure modes in Timber Connections (Peng, 2010) ................................................... 14

Fig. 2.4 Load-Displacement of a designed ductile connection (Johansson and Stehn, 2002) ................... 15

Fig. 2.5 Load-slip relationship against bolt diameter and timber thickness (Ballerini et al., 2006) ............16

Fig. 2.6 Reduction factor for strength versus time of fire resistance (Racher et al., 2010)....................... 25

Fig. 2.7 Macroscopic view of the transverse section of a Quercus Alba trunk (Wiedenhoeft, 2010) .........26

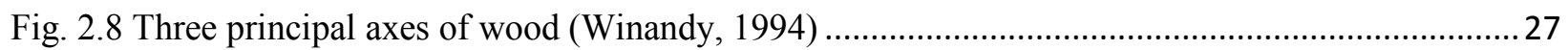

Fig. 2.9 Compressive stress-strain relation of wood parallel-to-grain showing progressive kinking of

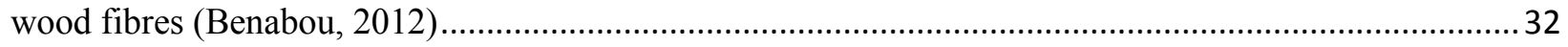

Fig. 2.10 Stress-strain relation of clear wood (Buchanan, 2002) ............................................................... 33

Fig. 2.11 Failure types in tension parallel to grain (a) splinter failure (b) shear and tension failure (c)

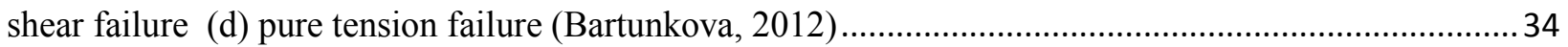

Fig. 2.12 Stress intensity derivation (a) Elliptical hole in a flat infinite plate (Inglis, 1913) (b) Stress state

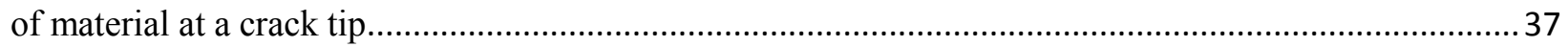

Fig. 2.13 Six Principal Systems of Crack Propagation by a Schematic Block View (Barrett, 1981) ......... 39

Fig. 2.14 Three Modes of Crack Loading and Failure (Irwin, 1958).................................................... 40

Fig. 2.15 Typical Stress-Strain Curve of Steel...................................................................................... 42

Fig. 2.16 Modulus of Elasticity of Wood Parallel to the Grain versus Temperature (Buchanan, 2002) .... 43

Fig. 2.17 Modulus of Elasticity of Wood Parallel to the Grain versus Temperature for Softwoods

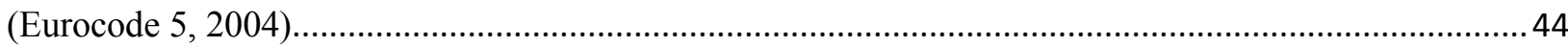

Fig. 2.18 Strength of Wood Parallel to the Grain versus Temperature for Softwoods (Eurocode 5, 2004) 45

Fig. 2.19 Reduction of Steel Strength with Temperature (Adapted from Buchanan (2002) as quoted from

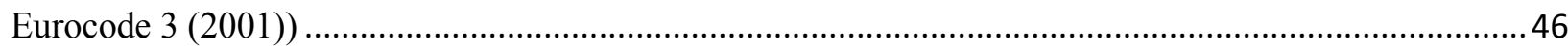

Fig. 2.20 Reduction of Different Types of Steel Strength with Temperature (Buchanan, 2002) ..............47

Fig. 2.21 Charring Distribution on a wooden beam (Adapted from Buchanan, 2002 as quoted from

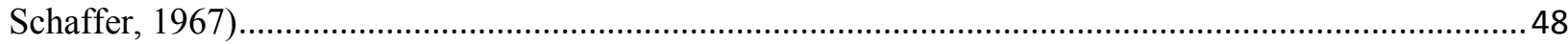

Fig. 2.22 Temperature-Thermal Conductivity for Wood and the Char layer (Eurocode 5, 2004)..............50

Fig. 2.23 Temperature-Specific Heat Capacity for Wood and the Char layer (Eurocode 5, 2004) ............ 50

Fig. 2.24 Temperature-Density Ratio for Softwood with an initial moisture content of 12\% (Eurocode 5,

$2004)$

Fig. 2.25 Variation of Steel Thermal Conductivity with Temperature (Eurocode 3 (2001)).....................52

Fig. 2.26 Variation of Steel Specific Heat Capacity with Temperature (Eurocode 3 (2001)) ....................53

Fig. 2.27 The Process of Finite Element Analysis (Bathe, 1996) .............................................................55

Fig. 3.1 Schematic of Test Configuration (Adapted from Sabah, 2012) ................................................65

Fig. 3.2 Connection Configurations in Test (Adapted from Sabah, 2012) .............................................66 
Fig. 3.3 Calibration of Furnace Temperatures with Time-Temperature curve of CAN/ULC-S101 (Adapted

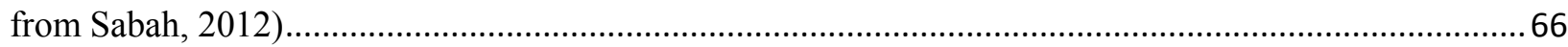

Fig. 3.4 Test Assembly before and after testing (Adapted from Sabah, 2012) .....................................67

Fig. 3.5 Modelling Individual Components of the Assembly ................................................................ 71

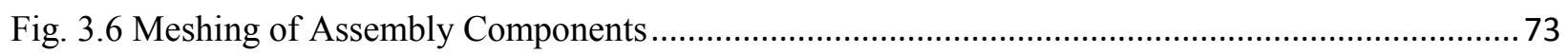

Fig. 3.7 Time-temperature Curves from Test and Standard (Sabah, 2012) ............................................ 76

Fig. 3.8 Assembled Model with Heat Flux Boundary Condition (Concealed Connection)........................78

Fig. 3.9 Bilinear Approximation of the Elastic-plastic curve of Steel ..................................................... 80

Fig. 3.10 Material Orientation of Wood (Adapted from Sandhaas, 2012) ............................................. 81

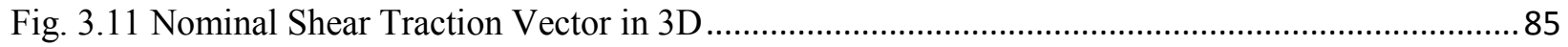

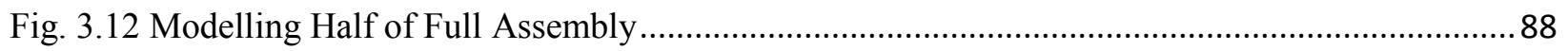

Fig. 3.13 Boundary Condition on a Concealed Connection Assembly ..................................................90

Fig. 4.1 Damage Energy (ALLDMD) against Time Increment ......................................................... 98

Fig. 4.2 Cross-section of Test Assembly with Thermocouple locations.................................................99

Fig. 4.3 Schematic of the Connection Test Assembly ........................................................................... 99

Fig. 4.4 Temperature-depth variation with time; bolt and concealed plate ..............................................101

Fig. 4.5 Temperature-depth variation with time; beam mid-span ......................................................... 102

Fig. 4.6 Temperature-depth Distribution against Time from the Test and Model ................................. 104

Fig. 4.7 Temperature Distribution at the $\mathrm{CN}$ connection after 35 minutes of fire exposure..................... 105

Fig. 4.8 Test vs Model Temperature T16 and T17 ......................................................................... 106

Fig. 4.9 Test vs Model Temperature T21 .................................................................................... 107

Fig. 4.10 Test vs Model Temperature T22 .................................................................................... 108

Fig. 4.11 Model Temperature T16, T19 and T24 .......................................................................... 109

Fig. 4.12 Temperature Distribution at the EX Connection after 30 minutes of Fire Exposure ................110

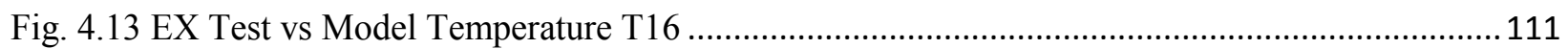

Fig. 4.14 Test vs Model Temperature T18 and T20 ........................................................................ 112

Fig. 4.15 Temperature Distribution at the SE Connection after 35 minutes of Fire Exposure .................113

Fig. 4.16 Test vs Model Temperature T18 and T20 .................................................................... 114

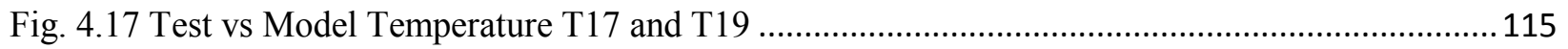

Fig. 4.18 Typical charred section at beam mid-span after 35 minutes.................................................116

Fig. 4.19 Typical charred section at the $\mathrm{CN}$ connection region after 35 minutes of fire exposure........... 117

Fig. 4.20 Typical charred section at the EX connection region .......................................................... 119

Fig. 4.21 Typical charred section at the SE connection region........................................................... 120

Fig. 4.22 A Typical Damage Energy curve (ALLDMD) ................................................................ 122

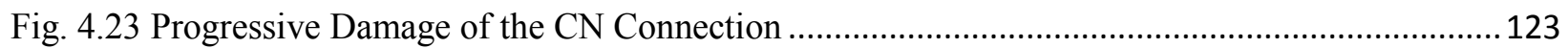

Fig. 4.24 Fire Resistance of the CN Connection................................................................................. 124

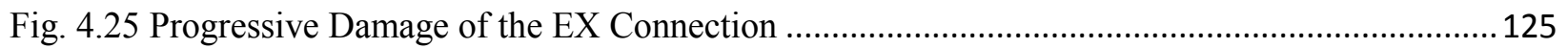

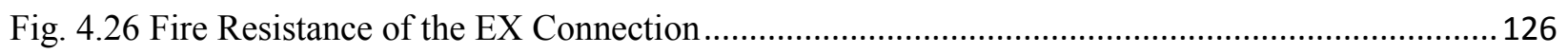

Fig. 4.27 Progressive Damage of the SE Connection ...................................................................... 127

Fig. 4.28 Fire Resistance of the SE Connection............................................................................ 127

Fig. 4.29 Relative Fire Resistance of the Connections ..................................................................... 129 
Fig. 4.30 Effect of Load Ratio on the Relative Fire Resistance of the Connections................................ 131

Fig. 4.31 Progressive Damage of the SE Boltless Connection ................................................................133

Fig. 4.32 Midspan deflection of beam against time of fire exposure................................................... 135

Fig. 4.33 Origination of Failure from the bolted regions ................................................................. 136

Fig. 4.34 Splitting at the beam mid-span for the SE connection........................................................ 137

Fig. 4.35 Stress concentration at the mid-span and mid-height of the half symmetry beam section........ 137

Fig. 4.36 Damage and Failure at the mid-span and mid-height of the half symmetry beam section........137

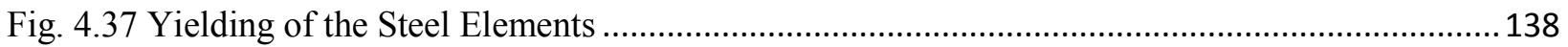




\section{Chapter 1: Introduction}

\subsection{Background}

Wood manufacturing and construction form a principal part of the Canadian forest industry. Wood product manufacturing is known to generate about $41 \%$ of the economic impact from the forest industry (Surprenant, 2010) and has become the backbone of the North American residential construction.

The use of wood in residential buildings in Canada is very common but with the introduction of performance-based concepts in the National Building Code of Canada (NBCC 2005), its use has started to expand beyond the confines of traditional residential construction. The cost, labour and energy efficiency of timber buildings tend to stand out among normal concrete and steel buildings (Surprenant, 2010) and architects, engineers and stakeholders are beginning to use timber more often in non-residential buildings. Timber construction basically fall under two main categories: light timber frame and heavy timber frame construction (Buchanan, 2002). Light timber frame involves the use of small size of timber as studs, joists and panels of wood in construction. The heavy timber frame utilizes bigger sizes of timber in the main members of a building such as columns, beams and decks (Buchanan, 2002). The use of timber in non-residential buildings necessitates a heavy timber construction instead of the light framing since such buildings are normally taller or need larger spans, which the light frame construction can't provide. The current aim of building designers in Canada is to achieve higher heights beyond the present four-storey limit of wood construction and this requires practical application of performance-based concepts. The four concerned objectives in the NBCC (2005) are Safety, Health, Accessibility and Fire and Structural protection of buildings (Surprenant, 2010). Since wood is a combustible material, there 
has been a significant amount of research in recent years on the fire resistance of the plain solid wood and engineered wood products which are used in the construction industry.

Most of the heavy timber construction in Canada now uses wood in conjunction with other building materials such as steel and concrete in what is called a hybrid building system. Hybrid building systems have been in practice to enhance the application of wood in much taller structures. In some hybrid systems, wood may be used as beams, floors or decks in combination with concrete or steel columns. The utilisation of two or more materials in a building system hence requires a critical connection between the various building elements. Connections are crucial areas in a building framework and are responsible for the overall integrity of the structure. One such heavy timber connection consists of connecting steel and timber elements with steel plates and bolts or dowels.

Timber connections have been widely investigated to ensure their structural integrity. In timber connections, ductility has been a major issue of concern since wood, unlike steel, can fail in a brittle manner which is undesirable. At elevated temperatures from fire conditions, both steel and wood materials behave differently and their interaction at a connection level is even more complex. Fire safety principles require that all structural members of a building including connections meet a certain fire resistance rating. Fire resistance is commonly rated in terms of the time for timber connections to resist structural failure when subjected to fire conditions. Adequate fire resistance of these connections will ensure the overall integrity of the building and prevent structural collapse in a fire scenario. 
The NBCC does not provide a direct way of assessing the fire resistance of timber connections except for general design guidelines which are prescriptive-based. Such guidelines include minimum thickness of timber members, spacing between fasteners and size of fasteners. With the recent drive for performance-based design in fire, a number of research works have been conducted on the fire resistance of timber connections (Buchanan and King 1991; Noren 1996; Peng and Hadjisophocleous, 2009; Racher et al., 2010; Erchinger, 2010) with aim of fulfilling the fire design objectives. Through experimental and numerical investigations, analytical relations have also been developed to estimate the fire resistance of timber connections. Most of the research on the fire performance of heavy timber connections in the recent years have focused on connections subjected to tensile loading (Noren, 1996; Moss et al., 2009; Peng and Hadjisophocleous, 2009; Erchinger et al., 2010; Racher et al., 2010). Results obtained for such type of connections in fire conditions are applicable to structural members such as roof trusses (where tension forces are significant) but not for beam-column connections. With the application of gravity loads on a beam member, these connections transfer shear to the connected columns. The mechanism of shear transfer from the beam to column in these connections is different from the direct shear (in tensionloaded connections) which is imposed on the timber material within the connection.

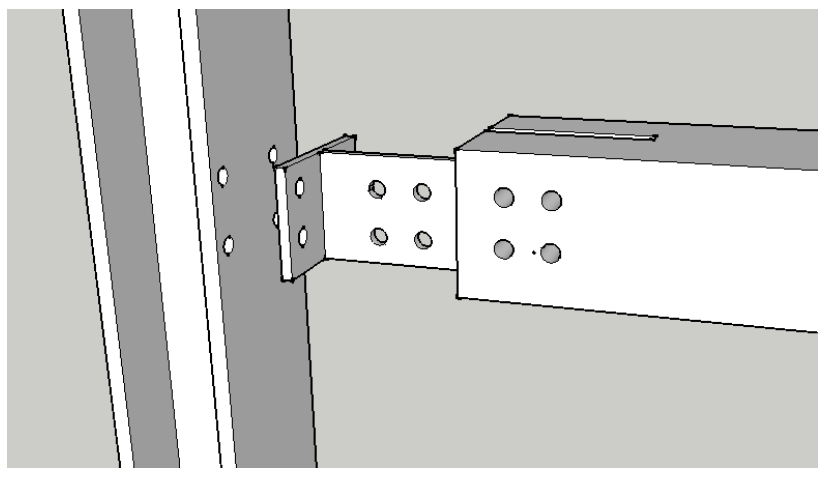

(a) Concealed

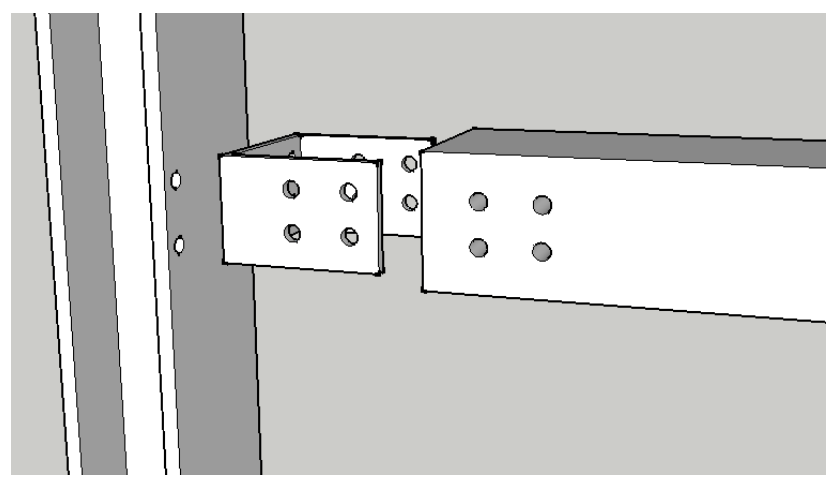

(b) Exposed 

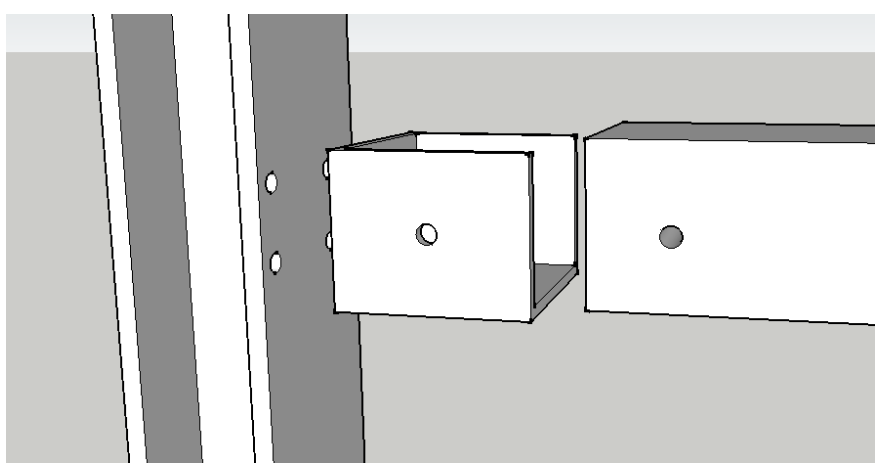

(c) Seated

Fig. 1.1 Wooden Beam-Steel Column Connections

The performance of concealed, exposed and seated shear tab connectors under standard fire conditions is examined in this thesis by a numerical simulation and also validated with test results. Three common types of beam-column connections, concealed, exposed and seated connections (see Fig. 1.1) are investigated in this research.

\subsection{Problem Statement}

Hybrid timber connections involve the interaction of both steel and timber materials at the joint region. The structural and thermal behaviour of the materials are different hence leading to a complex behaviour at the connections. Steel is ductile while wood exhibits a ductile-brittle behaviour. In response to heat, steel heats up quickly and expands due to high thermal conductivity whereas wood heats up and begins to char at relatively lower temperatures compared to steel. Charred wood has negligible strength to withstand stresses from externally applied loads.

The underlying challenge is to predict the behaviour of hybrid timber connections in response to elevated temperatures from a fire scenario. It is necessary to model the gradual reduction in the capacity of the connection with time of fire exposure in order to determine the connection's fire 
resistance level (time to failure in fire). According to the NBCC (2005), connections must demonstrate a similar fire resistance level to that of connected members, which is approximately 45 minutes to 1 hour for combustible construction. The work by Peng and Hadjisophocleous (2009) and other researchers have been directed towards fulfilling this goal where tension connections were investigated. The results obtained are applicable in structural members like roof trusses, roof beams and girders where connections are subjected to a significant amount of tension or compression stresses. Beam-column connections may not demonstrate the fire resistance level obtained by Peng and Hadjisophocleous (2009) since the applied loading conditions in both cases are different. Factors which might contribute to the difference in the connections' fire performance are investigated in this research with the aim of providing practical design guidelines.

\subsection{Scope and Objectives}

The first part of the research program involved full-scale fire resistance tests which were conducted previously by Sabah (2012). His test setup was a prototype of a hybrid building frame (glulam beam connected to steel columns). Three different shear connections of beam to column were investigated for their fire performance. The second part of the research, which is presented in this thesis, is a numerical investigation of the tested connections with the following objectives:

- To develop a finite element model for simulating the fire resistance of hybrid steel-timber connections

- To validate this model using test results

- To determine the relative fire resistance of the different connections 


\section{Chapter 2: Literature Review}

\subsection{Introduction}

In this part of the thesis, preliminary studies on the behaviour of steel-timber connections in fire are summarized. The fire performance of timber connections is quantified in terms of what is known as "fire resistance" in Fire Engineering Science. Steel-timber connections normally arise from a hybrid building system, which is formed by a combination of steel and timber building elements. The fire resistance of such connections, just like other building elements is assessed by various means which are presented and discussed from the work of other researchers. Steel and wood materials behave differently in both ambient and fire temperature conditions hence a comprehensive review of their fire performance is presented to properly characterize their influence on a connection's performance. The mechanical and thermal properties of both materials at elevated temperatures are examined since they are necessary inputs in any analytical or numerical model. This chapter finally closes with a discussion of the potential methods of modelling steel-timber connection behaviour for a numerical simulation.

\subsection{Fire Resistance}

Fire resistance is a measure of the ability of a building element to resist fire (Buchanan 2002). Building elements are normally tested and rated based on their ability to perform intended functions under exposure to standard fires, commonly referred to as "fire resistance rating". Fire resistance is mostly quantified as the time for that particular element or assembly to perform its "fire barrier and separation" and/or load bearing function in the building. 


\subsubsection{Assessment of Fire Resistance}

Fire resistance is a design parameter which is specific to building elements and assemblies such as columns, beams, walls, composite floors and ceilings. Fire resistance ratings of an element is determined by conducting full-scale fire resistance tests. Standards for fire resistance like the International Standard ISO 834 (1975) and ASTM E119 (1988) are used by most countries in Europe and North America respectively. Other standards include the CAN/ULC-S101 (2007), which is based on ASTM E119 (1988) and also the British standards BS 476 (1987), Parts 20 23. Fig. 2.1 below shows the time-temperature curve used by some standard fire tests.

Depending on the type of element in question, design standards specify the procedure, geometry, loads, support conditions and fire severity required to determine its fire resistance rating. The fire resistance determined through these tests and the required ratings in the standards provide a platform for meeting the fire design needs. An adequate fire design of a building element is one which satisfies a specified failure criterion for fire resistance.

The three failure criteria for fire resistance testing are stability, integrity and insulation (Buchanan 2002). Buchanan (2002) explains the failure criteria as follows. The stability criterion deals with the ability of load bearing elements such as columns, beams, floors and some particular walls to withstand applied loads up to a certain level in the occasion of fire. Integrity on the other hand ensures that mostly non-structural elements like partitions, doors and glazing do not develop cracks or fissures. This criterion hinders the transmission of hot gases and flames to adjacent rooms for fire spread. The insulation criterion, just like the integrity is to ensure the containment of room 
fires. This is achieved by providing an adequate level of insulation on room boundaries such that the heat transferred to the adjacent rooms do not initiate fire.



Fig. 2.1 Standard time-temperature curves for CAN/ULC-S101 and ISO 834 (Peng, 2010)

Apart from full-scale tests to determine the fire resistance of building elements, various empirical calculations have been developed to achieve the same purpose. A simple approach of determining the fire resistance of wooden frame assemblies is through the Component Additive Method (CAM) (Peng, 2010). This method involves a summation of the fire resistance ratings of individual elements of walls, floors or ceiling assemblies, which results in a resistance rating assigned to the whole assembly for design. Section 721.6 of the International Building Code (ICC IBC, 2012) outlines procedures for this approach and the National Building Code of Canada (NBCC, 2005 Section D-2) also adopts this as an alternative to fire resistance tests. 
One empirical approach for assessing the fire resistance of wooden elements was the formulae developed by Lie (1977). This has gained acceptance in various building codes especially in North America. This process for calculating the fire resistance of wooden beams and columns depends on the severity of fire exposure, geometry of the wood and the load ratio. The charring rate of wood and its insulating effect have been factored in this method and verified against test results.

An analytical method of determining the fire resistance of building elements involves a fire model, a heat transfer model and a structural response model (Buchanan, 2002). Using this method, described by Buchanan (2002), the fire model is obtained from standard fires as prescribed in various building codes and is needed as a basic input in such analysis. This leads to the transfer of heat from the fire to the element boundaries and within. The resulting thermal gradients, if conducted successfully, can be enough to determine the fire resistance of such building elements with respect to the integrity and insulation criteria. For the stability criterion fire resistance rating, the thermal gradients are used as input to the structural response model. The analytical approach eventually lends itself to computer-based modelling due to complexities of transient non-uniform temperature distribution, thermal expansion of materials, temperature-dependent properties of materials and the combination of different materials in an assembly.

Determining the fire resistance of building elements continues to evolve with time, from timeconsuming and costly standard fire resistance tests to developing simple fire resistance calculations. Relatively simple empirical equations are gaining popularity in order to resolve such drawbacks among contemporary architects and engineers 


\subsection{Hybrid Timber Construction}

A hybrid construction system is the combination of two or more building elements which is made up of different construction materials in a structure. The mixture of materials can be steelwood, steel-concrete or concrete-wood. Modern timber framing of buildings has evolved from the "Post and beam" construction which was common in the nineteenth century. This consisted of the connection of one timber to another with simple nails, metal plates and bolts and has previously been used in traditional wooden buildings around the world.

The use of wood as construction material has increased in the North American residential construction. This consists of light timber frame and heavy timber frame construction. Light timber frames are used in residential houses while heavy timber frames are used in mid-rise public and industrial buildings. Steel-timber hybrid structures have also become very popular in many other countries around the world such as USA, New Zealand, England and Japan (Khorasani, 2011). This has necessitated a significant amount of recent research and experimental work aimed at developing some innovative ways of utilising the combined efficient properties of wood and steel.

Khorasani (2011), who investigated the current construction of hybrid structures, noted two main levels of hybridization in timber-steel construction: the component level and the building system level. A component level hybridization involves the combination of steel and wood to form structural elements such as hybrid beams (Fig. 2.2a), hybrid columns, hybrid braces, hybrid bridge decks, hybrid slabs / diaphragms and hybrid connections or joints (Fig. 2.2b). This type of hybridization is effective in its composite action since the two materials complement each other for various design considerations such as strength, ductility and fire resistance. 
The building system level hybridization on the other hand is when the main structural framework of the building is a network of steel and wood elements. Typical building level hybridization implementations include the hybrid frame and the vertical mixed system. The hybrid frame is normally assembled from timber beams which are connected to steel columns with timber panels and partitions while the vertical mixed system typically consists of a steel structure for the main level and wood framing at the upper levels of buildings (Fig. 2.2c). Other types of hybrid systems include hybrid trusses, tube systems and steel frames with wood infill walls and floor joists (Fig.

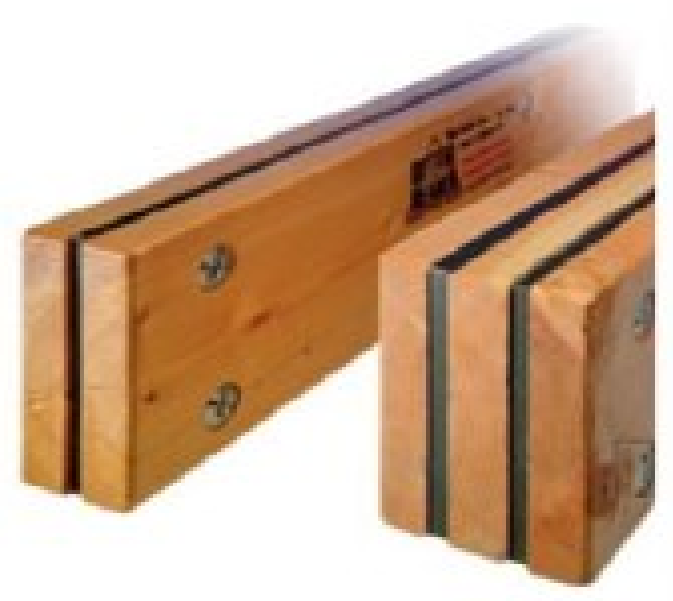

(a) hybrid beam (Stiemer et al., 2013)

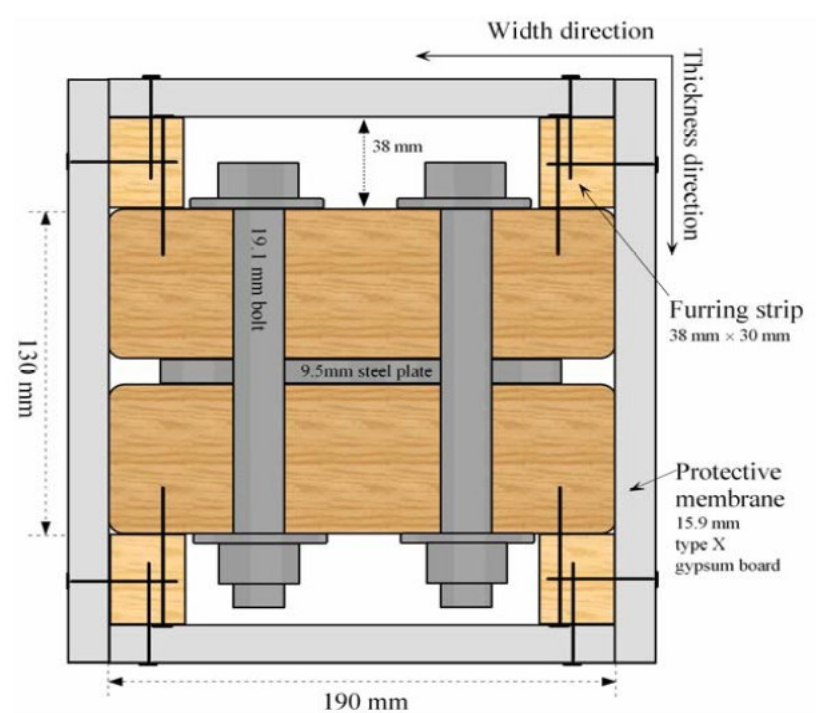

(b) hybrid wood-steel-wood connection

(Peng, 2010) 


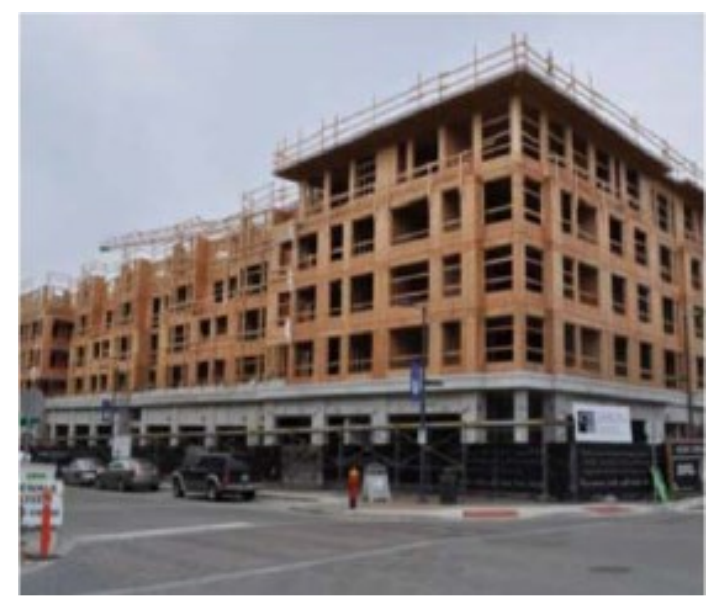

(c) Vertical mixed system (Stiemer et al., 2013)

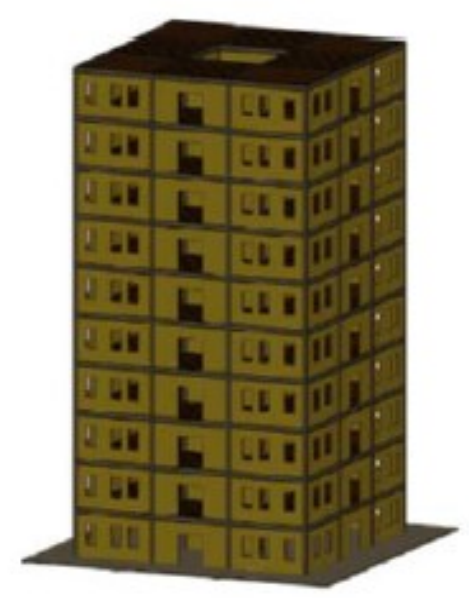

(d) Steel frame, wood infill, timber floor joists

(Stiemer et al., 2013)

Fig. 2.2 Levels of Timber-Steel Hybridization

\subsubsection{Hybrid Timber Connections}

\subsubsection{Structural Performance}

The structural integrity of building elements can be assessed under a wide number of design criteria of which strength, stiffness and ductility are examples. Timber construction involves a framework of interconnected structural members. Connections are very critical regions since they are responsible for the transfer of forces between main structural members, hence the structural capacity normally required of main members are also needed at the connection regions as well.

Ductility is an important requirement in structural design. It is also a common requirement in both static and dynamic design of structures. For structures to be able to redistribute internal forces through connections, the European code allows for an elastic-plastic analysis (Eurocode 5 (2004), Section 5.1). Ductility is defined as the ratio of the ultimate to the yield displacement attainable by 
a structure. However, adequate ductility requires that there is no brittle failure in the member or connections prior to the yielding of the structure.

Timber connections fail in three main modes; embedment (bearing) failure, splitting or shear-plug failure (Johansson and Stehn, 2002) as seen in Fig. 2.3. These failure modes occur predominantly in timber connections due to the susceptibility of brittle wood to high stress concentrations present at the joint regions. Ductile timber connections can be achieved if they are designed and detailed properly to avoid premature brittle failure by splitting (Jorissen and Fragiacomo, 2011). Jorissen and Fragiacomo (2011) investigated what is called the "overstrength factor". Overstrength factor is the ratio of the 95 th percentile of the connection strength distribution to the analytical prediction of the design connection strength. The strength of splice timber dowelled connections, from experiments loaded parallel to grain, was calculated according to the European Yielding Model. An overstrength ratio ranging from 1.2 to 2.1 , depending on the joint configuration, was obtained and a value of 1.6 was recommended for the ductile design of timber connections.

The European Yielding Model in Eurocode 5 (2004) for predicting the load carrying capacity of timber joints is based on Johansen's equations which were developed in 1949. It is a rigid-plastic theory which provides a good approximation of the load capacity of timber connections provided that brittle failure modes of splitting, block shear or plug shear are avoided (Ballerini et al., 2006) 

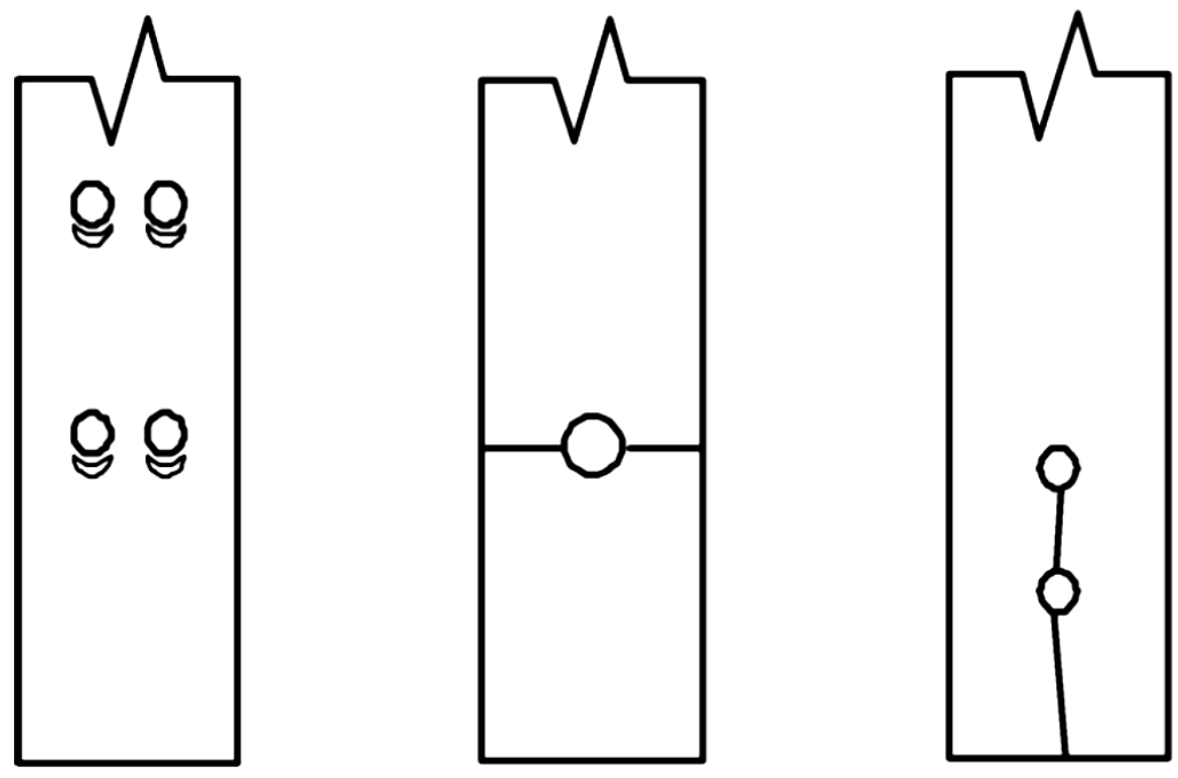

a) Bearing

b) Net Tension

c) Splitting
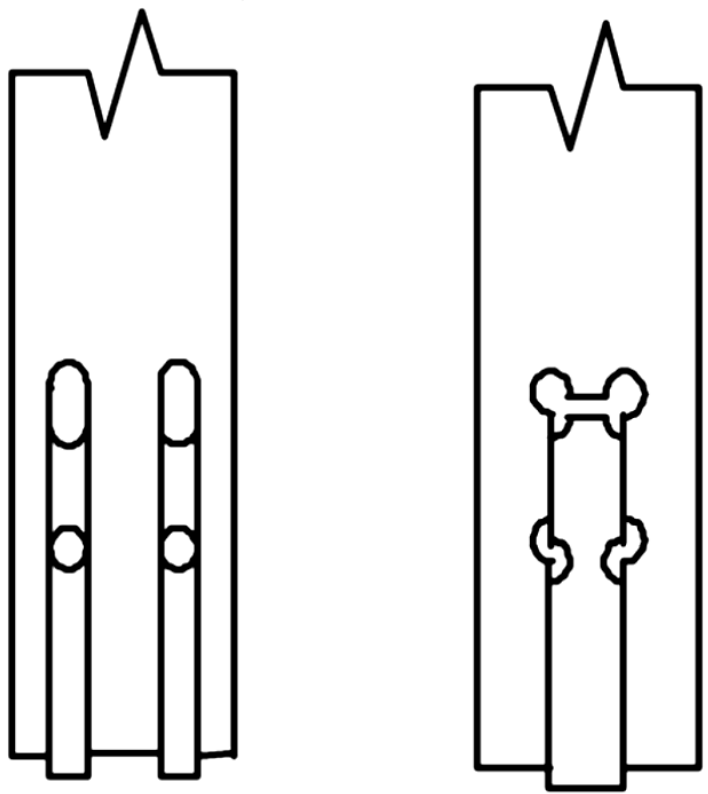

d) Shear-out

e) Group Shear-out

Fig. 2.3 Typical Failure modes in Timber Connections (Peng, 2010) 
On the contrary, the ductile assumptions of Johansens's popular theory do not always characterise most timber connections. The ductile embedment behaviour of such joints depend on the timber thickness, load-grain angle, spacing as well as the end and edge distances of dowel-type fasteners and their slenderness ratio (Blass and Shädle, 2011). The influence of fastener number and its influence on ductility have been well addressed in the recent Eurocode 5 (2004). The factor $n_{e f}$, the effective number of fasteners (parallel to grain), and the minimum values of end or edge distances are current modifications to enhance the ductile performance of timber connections.

In investigating the effect of fastener group layout on the development of shear-plug failure in timber connections, Johansson and Stehn (2002) noted a significant ductility for one test specimen (Fig. 2.4) which was specially designed according to Johansens's equations (Johansson and Stehn 2002).

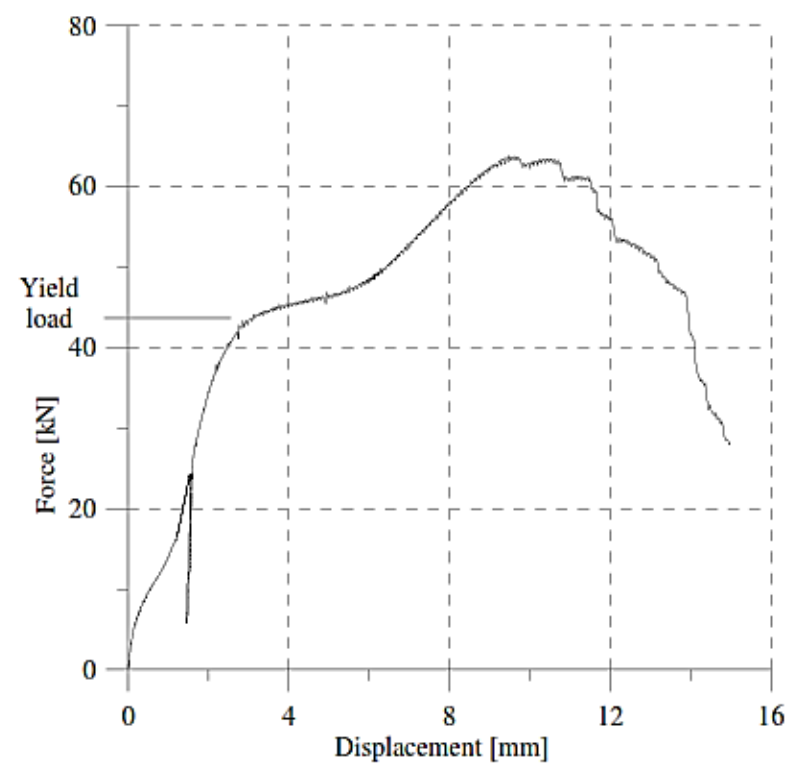

Fig. 2.4 Load-Displacement of a designed ductile connection (Johansson and Stehn, 2002) 


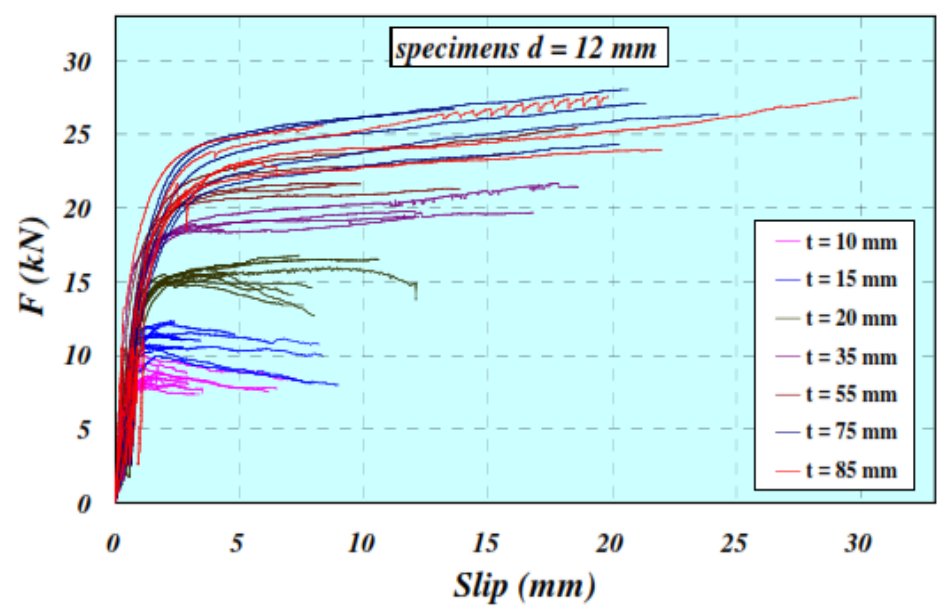

(a) dowel diameter $=12 \mathrm{~mm}$

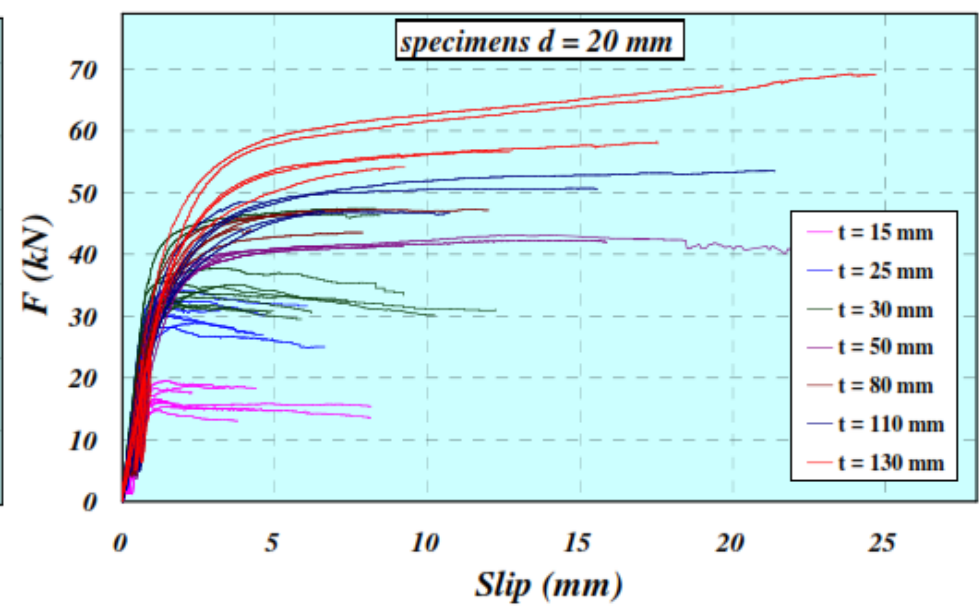

(b) dowel diameter $=20 \mathrm{~mm}$

\section{Fig. 2.5 Load-slip relationship against bolt diameter and timber thickness (Ballerini et al., 2006)}

Ballerini et al. (2006) also observed from experimental results the impact of dowel diameter, $d$ and timber thicknesses, $t$ on the ductility and the load carrying capacity of dowel-type connections according to Johansens's equations (Ballerini et al., 2006). Fig. 2.5 (a-b) shows the significant improvement of both the load capacity and the ductility by increasing dowel diameters and timber thickness. The European yield model was also verified which demonstrated a reasonable approximation of the load carrying capacity of the timber connections.

Due to inadequate ductility in some timber connections, innovative ways of reinforcing such connections can be achieved with reinforcing screws, glued-on-wood-based panels and punched metal plate fasteners. Experimental results of both non-reinforced and reinforced timber connections, which were compared, showed that brittle failure can be avoided by reinforcing with self-tapping screws (Blass and Shädle, 2011). Apart from counteracting brittle failure, improved strength, stiffness and ductility were also observed by increasing the number of reinforcing screws. 
Ductility improved on average from 1.6 to 5.3 through this method of reinforcement. Moreover, non-reinforced cross laminated timber (CLT) was also tested by Blass and Shädle (2011) and seen to exhibit even higher ductility at joints as compared to the screw-reinforced timber. An average ductility higher than 7.0 was obtained from experimental results. The crosswise lamination of layers in CLT was noted to contribute to its natural reinforcement against brittle failure.

The relevance of hybrid steel-timber connections has been demonstrated by quite a number of research works in Canada, New Zealand and Japan recently. It has been noted that, using steel and timber elements in a building can enhance its seismic performance (Stiemer, 2010) compared to conventional concrete buildings. This is because wood has a relatively high strength to weight ratio, hence timber buildings can be lighter compared to some other building types. Since earthquake forces are proportional to the weight of the structure, the use of lightweight wood can be an advantage.

An innovative ductile connection for Laminated Veneer Lumber (LVL) timber buildings was investigated for its seismic performance (Palermo et al., 2010). Three different connections, beamcolumn, wall-to-foundation and column-to-foundation were tested, where yielding-type dissipaters were also adopted at the connection levels. It was realised that post-tensioning of the connections can control the seismic performance of the assembly within acceptable drifts while the introduction of dissipaters enhanced both the overall strength and energy dissipation of the connections.

In the research of Dickof et al. (2012), a wood-steel hybrid system was examined for its resistance to seismic forces. The hybrid system consisted of steel frames with infill Cross Laminated Timber 
(CLT) walls. It was observed that the connections of the shear walls to the steel frame played a very important role in the system ductility. Two major features characterized the connections: bracket connectors of wall to the frame and the confinement of the wall by the frame. After conducting a pushover analysis on some designed six and nine storeys, it was observed that the hybrid frame with just the confinement resulted in a ductility ranging from $1.5-2.2$ and an overstrength factor of about $50 \%-100 \%$ higher than the design value. Overstrength factor is the ratio of the maximum base shear resistance to the design base shear of the frame. The introduction of the bracket connectors enhanced the seismic design ultimate limit state of the system; the connectors yielded before the rest of the system. The addition of the connectors improved the system performance under seismic action and the connectors could be replaced while the remaining steel frame remain undamaged after a seismic event.

The work of He and Li (2012) on the lateral performance of steel hybrid system also involved a steel frame with an infill of light wood frame shear walls. It was observed that the lateral resistance could be improved by 2.5 times with the inclusion of infill walls as compared to the open steel frame structure. The wood panels were connected with nails to side studs which were in turn bolted to the steel frame. During testing, no failure was recorded in the wood frame-steel frame joint but the failure of edge nail connections resulted in the damage of the whole hybrid frame system.

\subsubsection{Fire Performance}

As already discussed in the foregoing paragraphs, the fire performance of structural elements is mostly rated according to their structural integrity under fire exposure hence their fire resistance is measured in terms of their capacity when subjected to fire. This is obviously dependent on the exposure time to fire, which eventually results in the time to failure as a fire 
rating criteria for structural members as well. This concept is well captured by Lie (1977) whose fire resistance equation of wooden members is strongly dependent on the load ratio.

The structural fire design concept of building elements requires that Equation (2.1) below is satisfied (Buchanan, 2002).

$$
U_{\text {fire }}^{*} \leq R_{\text {fire }} \ldots \ldots \ldots \ldots \ldots \ldots \ldots \text { Equation (2.1) }
$$

where: $U_{\text {fire }}^{*}=$ the design force resulting from applied load at the time of fire

$$
R_{\text {fire }}=\text { the load capacity during the fire situation }
$$

The design force can be a resulting axial force, bending moment or shear force. The capacity or resistance of any structural member is primarily a function of its inherent material property and member geometry as well as existing restraints and boundary conditions. For the same geometry and boundary conditions, material properties chiefly govern the entire behaviour of the structural member when exposed to fire.

In a typical steel-timber hybrid connection, wood provides a good fire resistance contribution which is attributed to its low conductivity and charring property (Buchanan, 2002). On the other hand, the high conductivity of steel strongly undermines the fire resistance of such connections because bolts, dowels, nails, screws and metal plates transfer heat to the wood interior. Buchanan (2002) noted that the fire behaviour of bolt and dowel connections depends on the amount of heat able to enter the wood via the bolts. 


\subsubsection{Embedment Strength and Fire Resistance Level}

The significant difference in the thermal behaviour of steel and wood materials affects the embedment strength of connections and, hence, the fire resistance level. This has attracted experimental investigations in the recent years.

Buchanan and King (1991) investigated the fire performance of nailed wood and steel gusset joints of glue-laminated timber. Both loaded and unloaded gusset connections were tested, with and without protection. Solid wood, plywood, gypsum plaster board and intumescent paint were the types of protection employed on the gusset plates. Without loading, solid wood and gypsum plaster board were observed to provide very good protection to the gusset plates (both plywood and steel plates). A low rise in temperature over one-hour duration was observed in the gusset plates underneath the protection of solid wood and gypsum plaster. Loaded beam tests were tested in fire under a constant applied moment. Results indicated that, two layers of gypsum plaster board could provide adequate protection for 50 minutes of fire exposure before failure. An appreciable amount of deflection was also sustained by the beams. Buchanan and King (1991) further extended the above observation to the resistance of a simple portal frame. Calculations were done for the moment-rotation relationship of the frame. This showed that one layer of $19 \mathrm{~mm}$ gypsum board protection on both the plywood and the steel gusset connections can ensure a fire resistance level of one hour under applied loads.

Noren (1996) also investigated an alternative to side protection of side members by increasing the thickness of the side members. Tests to investigate the influence of side member thickness on the fire performance of nailed single-shear joints were also conducted under constant load. It was 
proved that when the side member thickness increased from $28 \mathrm{~mm}$ to $40 \mathrm{~mm}$, the additional time to failure was about 13.4 minutes whereas an increase from $28 \mathrm{~mm}$ to $45 \mathrm{~mm}$ improved the failure time by 14.8 minutes (for $30 \%$ load ratio test). The improvement of the time to failure due to the increase of the side member thickness was in the range of $89 \%$ to $99 \%$.

The need for adequate protection on connections cannot be over-emphasized. This is further demonstrated by the experimental work of Moss et al. (2009). Different configurations of wood and steel splice plate connections were investigated for their fire performance. They were woodwood-wood (W-W-W), wood-steel-wood (W-S-W) and steel-wood-steel (S-W-S) bolted connections. Results showed that under a constant load in fire testing, specimens with mostly exposed wood to fire i.e. the W-W-W and W-S-W had higher time to failure as compared to the S-W-S connections, which have the steel components directly exposed to fire. This observation was attributed to the higher heat transfer into the connection through the steel splice plates. Specimens with the wood side members recorded an average fire resistance duration of 18.5 minutes which is more than twice the 8.8 minutes recorded for the S-W-S connection.

Various empirical equations have been proposed for the fire resistance of different steel-timber connection types based on both experimental and numerical investigations. The aim of these researchers was to predict the time to failure of such connections with simple equations and also modifications to existing equations.

Noren's (1996) experimental fire resistance tests, which were done for various single-shear nailed joints under different load ratios, led to a simple exponential relationship (Equation 2.2) as follows: 


$$
\frac{F_{f}}{F_{0}}=e^{-k t} \ldots \ldots \ldots \ldots \ldots \ldots \ldots \ldots \text { Equation }(2.2)
$$

where: $F_{f}=$ applied tensile load under fire conditions

$F_{0}=$ tensile load capacity under ambient conditions, $t=$ time to failure in minutes

$k=\mathrm{a}$ characteristic coefficent, averaging 0.077

Under normal temperatures, the capacity and behaviour of steel-timber connections strongly depends on the embedment strength of wood and the yield strength of the fasteners. The effect of nail distribution and diameter on the connection capacity wasn't well represented in Noren's tests. However, an assumed embedment strength reduction relation was found to be in good agreement with the results from Noren's experiment.

Peng and Hadjisophocleous (2009) investigated the fire performance of wood-steel-wood bolted connections by varying wood member thickness and bolt diameter at different load levels. A heat transfer model was developed in ABAQUS and validated with test results. Peng and Hadjisophocleous (2009) extended Noren's approach of reducing the embedment strength of wood at the connections. The temperature distribution from the heat transfer model was used to determine the embedment strength of wood along fastener regions and the yield moment of fasteners. This resulted in the following proposed formula for calculating the time to failure of wood-steel-wood connections:

$$
t_{f}=-0.0042 \ln \left(\frac{R_{f}}{R_{0}}\right)\left(t_{1}^{2}+2 d^{2}\right) \ldots \ldots \ldots \ldots \ldots \ldots \text { Equation }(2.3)
$$


Analytical predictions using Equation (2.3) for various tests were done. The tests involved varying the bolt diameter and side member thickness under different tensile load ratios. The experimental results compared well with the analytical predictions.

The above proposed formula by Peng and Hadjisophocleous (2009) captures the effect of load ratio i.e. $\left(\frac{R_{f}}{R_{0}}\right)$ as suggested earlier by Noren (1996). This parameter is promising for design purposes since the structural capacity under fire conditions can easily be related to the corresponding ambient capacity in various codes. Peng's proposed formula also reflects the need for adequate protection of steel plates and members in a connection through the consideration of wood side member thickness $\left(t_{1}\right)$.

Erchinger et al. (2010) developed analytical methods for predicting the fire resistance of multiple shear steel-timber connections with slotted-in steel plates and steel dowels. Several tensile tests were performed on such connections by varying the number of slotted-in steel plates, number of dowels and thickness of side members under different load ratios. It was noted that increasing the number of dowels did not increase significantly the fire resistance as compared to increasing the thickness of the side members and the application of additional protection on the connections. The influence of steel plates on the temperature distribution within the connection was studied from test observations and numerical verifications. This was important since it affects the charring depth in the wood. The reduced section properties method according to Eurocode 5 was eventually used to develop an analytical approach to determine the fire resistance up to 60 minutes. An effective charring depth was determined, which included the nominal charring depth as prescribed in the Eurocode 5 (2004) and an additional layer. This layer takes into account the temperature- 
dependent reduction of timber strength and the effects of corner roundings from char. Experimental test results showed that this layer is dependent on three main factors, which were included in the proposed equations: ratio of initial width of cross-section to width of residual crosssection, time of fire exposure and the number of dowels. Hence, the knowledge of the reduced cross-sectional area enabled the computation of the load capacity of such connections. Analytical predictions of both the additional char layer and the load capacity compared very well with the numerical results. An analytical-numerical ratio value ranging between $1.00-1.18$ was obtained among the various test configurations.

Racher et al. (2010) also noted a direct correlation of the fire resistance of dowelled connections to the side member thickness of wood. They developed a 3D thermo-mechanical finite element model for dowelled timber connections. The model was validated with experimental results and could predict the fire resistance of such connections with $2 \%-11 \%$ variation. The experimental tests involved both timber-to-timber and timber-to-steel connections which had different dowel diameters, side member thickness and varying load ratios. Racher et al. (2010) noted that the failure of timber connections was mostly influenced by the reduction in the timber properties rather than those of the fastener properties. This was evident in the test results as well as the numerical predictions. It was also noted from numerical investigations that predicting the fire resistance of a single fastener joint by Johansen's theory could be uncertain at times. Hence, this led to the proposal of equation (2.4) for calculating the fire resistance of such connections and the introduction of $k_{1, f i}\left(t_{1}\right)$, an influential fire resistance factor as shown in Fig. 2.6.

$$
R_{1, f i}=k_{1, f i}\left(t_{1}\right) R_{1} \ldots \ldots \ldots \ldots \ldots \ldots \ldots \ldots \text { Equation }(2.4)
$$

where; $R_{1, f i}=$ fire resistance of a single fastener $\quad t_{1}=$ side member thickness 
$R_{1}=$ capacity of single fastener in normal conditions

$k_{1, f i}\left(t_{1}\right)=$ a coefficient dependent on time of fire exposure and member thickness

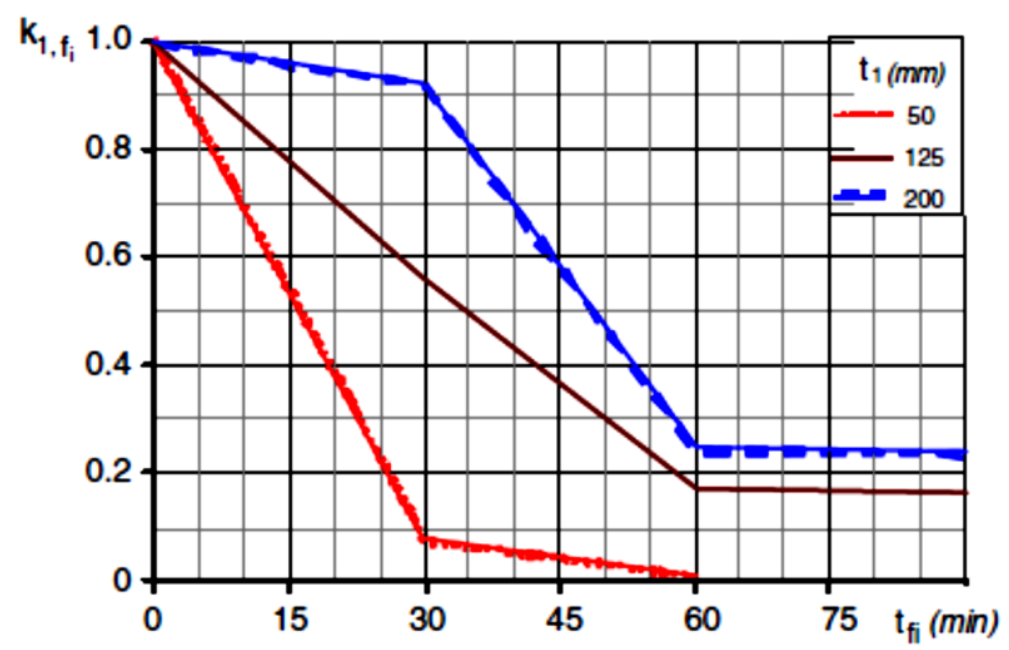

Fig. 2.6 Reduction factor for strength versus time of fire resistance (Racher et al., 2010)

\subsection{Mechanical Properties of Wood and Steel}

\subsubsection{Wood}

Wood is a strong and versatile natural material. Structural timbers are obtained from logs of selected trees. Trees are very diverse in nature, growth and composition, hence broadly categorised as Hardwood (e.g. Maple, Birch, Oak) or Softwood (e.g. Spruce, Pine). The solid wood and engineered wood products used for timber construction are typically Softwood.

The microscopic anatomy of wood is that of a cellular structure comprising cellulose, hemicellulose and lignin within the numerous cell walls (Wiedenhoeft, 2010). Cellulose accumulate as long thread-like microfibrils with high tensile strength and are known to be linked by the hemicellulose to the brittle lignin matrix to form a unified composition in each cell wall layer. 
The macroscopic level of wood is easily visualized by cutting the cross-section of a tree. It consists of the outer bark (ob), inner bark (ib), vascular cambium (vc), sapwood, heartwood and pith (p) as shown in Fig. 2.7. The concentric bands of material, as observed at the macroscopic level, are representative of discrete cells interconnected and oriented specifically in two main separate systems of cells; the axial system and the radial system.

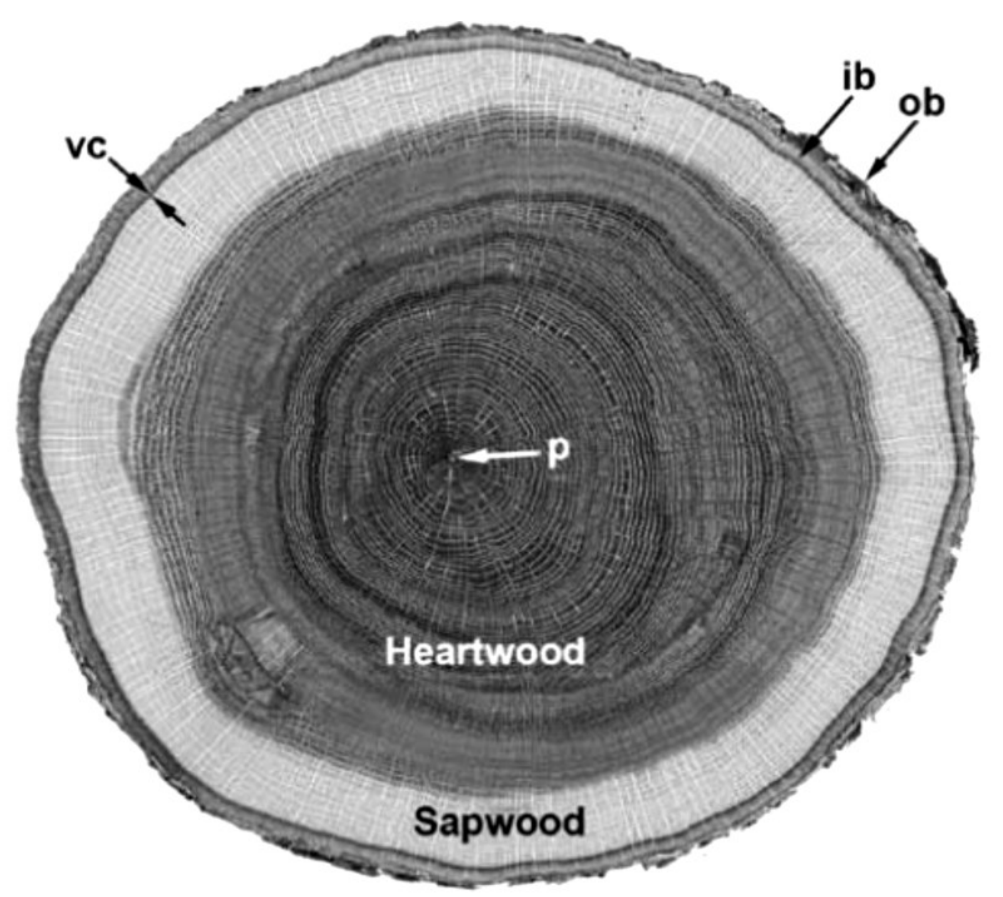

Fig. 2.7 Macroscopic view of the transverse section of a Quercus Alba trunk (Wiedenhoeft, 2010)

The orientation of the fibers and the addition of growth rings give rise to three main mutually perpendicular axes namely Longitudinal (L), Radial (R) and Tangential (T) in any sawn timber (see Fig. 2.8). The longitudinal axis lies parallel to the fibre or grain while both the radial and tangential axes are perpendicular to the direction of the grain. The main difference in the radial and tangential directions is their relative orientation to the growth rings; the radial axis is normal to the growth rings while the tangential axis is a tangent to the growth rings (Winandy, 1994). 


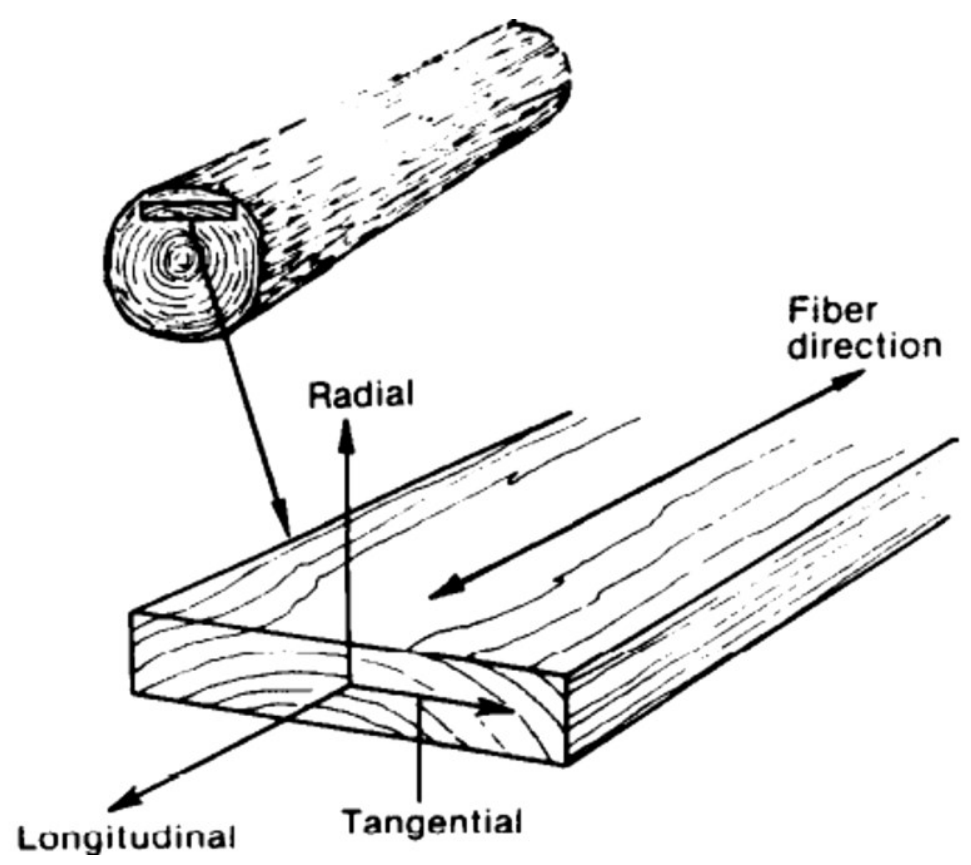

Fig. 2.8 Three principal axes of wood (Winandy, 1994)

The mechanical behaviour and properties of wood can be summarized under three main headings, which are as follows:

1. Elastic properties

2. Strength properties

3. Non-elastic properties

\subsubsection{Elastic properties}

The elasticity of a material defines its deformation or strain response to applied stresses. This determines a unique constitutive model of any material. Wood is an example of a material with different elastic properties in different directions because of the nature of growth of trees and the orientation of the resulting fibres. This makes wood a highly anisotropic material. Its elastic 
properties for design, analytical and modelling purposes are often simplified in the form of orthotropic elasticity.

Wood has unique and independent elastic parameters in the directions of three mutually perpendicular axes: longitudinal (L, parallel to fiber), radial ( $\mathrm{R}$, normal to the growth rings in the radial direction), and tangential ( $\mathrm{T}$, perpendicular to grain and tangent to the growth rings) (Bartunkova, 2012). If wood is considered as an orthotropic material, nine independent material parameters are needed to define its orthotropy, which include three young moduli $\left(E_{L}, E_{R}\right.$ and $\left.E_{T}\right)$, three shear moduli $\left(G_{L R}, G_{L T}\right.$ and $\left.G_{R T}\right)$ and three Poisson ratios $\left(v_{L R}, v_{L T}\right.$ and $\left.v_{R T}\right)$. These parameters together define a constitutive relation for wood in the form of the three-dimensional generalized Hooke's law as seen in equation 2.5 (Sandhaas, 2012). The six Poisson ratios as shown in equation 2.5 include three which are dependent and they are related as follows $\frac{v_{i j}}{E_{i}}=\frac{v_{j i}}{E_{j}}$ but $v_{i j} \neq v_{j i}$. The two subscripts, $i$ and $j$ stand for the transverse strain in the $\mathrm{j}$-direction, when the material is stressed in the i-direction.

$$
\left(\begin{array}{c}
\varepsilon_{\mathrm{LL}} \\
\varepsilon_{\mathrm{RR}} \\
\varepsilon_{\mathrm{TT}} \\
\gamma_{\mathrm{RT}} \\
\gamma_{\mathrm{LT}} \\
\gamma_{\mathrm{LR}}
\end{array}\right)=\left(\begin{array}{cccccc}
\frac{1}{E_{\mathrm{L}}} & \frac{-v_{\mathrm{LR}}}{E_{\mathrm{R}}} & \frac{-v_{\mathrm{LT}}}{E_{\mathrm{T}}} & & & \\
\frac{-v_{\mathrm{RL}}}{E_{\mathrm{L}}} & \frac{1}{E_{\mathrm{R}}} & \frac{-v_{\mathrm{RT}}}{E_{\mathrm{T}}} & & 0 & \\
\frac{-v_{\mathrm{TL}}}{E_{\mathrm{L}}} & \frac{-v_{\mathrm{TR}}}{E_{\mathrm{R}}} & \frac{1}{E_{\mathrm{T}}} & & & \\
& & & \frac{1}{G_{\mathrm{RT}}} & 0 & 0 \\
& & & 0 & \frac{1}{G_{\mathrm{LT}}} & 0 \\
& 0 & & 0 & 0 & \frac{1}{G_{\mathrm{LR}}}
\end{array}\right)\left(\begin{array}{c}
\sigma_{\mathrm{LL}} \\
\sigma_{\mathrm{RR}} \\
\tau_{\mathrm{TT}} \\
\tau_{\mathrm{LT}} \\
\tau_{\mathrm{LR}}
\end{array}\right)
$$


It can be written for short in the form of:

$$
\varepsilon=C \sigma \ldots \ldots . . \text { Equation (2.6) }
$$

where: $\mathrm{C}$ is the Compliance matrix relating the strains $(\varepsilon)$ to the corresponding applied stresses $(\sigma)$

These stiffness parameters of wood vary greatly among reported structural wood properties. Wood anatomy (species), environmental factors, test-setup and geometry are among the contributing factors to this variation. This large variation is present even when experimental tests to determine these properties are conducted on clear and defect-free specimens in a particular environmental condition. Environmental conditions make the elastic properties of wood directly dependent on density, moisture content and temperature only to mention a few. Sandhaas (2012) also highlighted the applicability of wood structural properties for computer modelling purposes and noted that the kind of test; uniaxial or biaxial directly influences the outcome of measured material parameters.

\subsubsection{Strength Properties}

The ultimate resistance of wood to applied loads is a measure of its strength (Winandy, 1994). The inherent anisotropic nature of wood makes its strength properties direction-dependent. The strength is significantly different in the longitudinal, radial and tangential directions. The strength in the longitudinal direction is greater than that in the radial and tangential directions. Radial and tangential strengths are generally similar, hence wood is normally referred to as transversely isotropic. Longitudinal strength is popularly known as the parallel-to-grain strength whereas radial and tangential strengths are generally categorised as the perpendicular-to-grain strength (Winandy, 1994). 
Different species of wood present a wide range of strength values. The environmental conditions and processing of wood also affect its mechanical properties (Winandy, 1994). Density, moisture content and defects are all directly influenced by the growth conditions for any particular timber and this eventually has a bearing on the strength of the final wood logs used in construction. Density is a function of moisture content and since wood is a hygroscopic material, it tends to establish an equilibrium moisture content with its surrounding. Uneven and uncontrolled drying can result in shrinkage defects such as bow, twist, crook or cup. Hence, controlled seasoning of timber logs is normally done to prevent these shrinkage issues in order to achieve optimum structural capacity. Defects of wood also come naturally in the form of natural irregularities such as cracks, knots and undesirable slope of grains. Such natural defects may reduce the strength of wood by as much as $50 \%$ on average (Sandhaas, 2012) and this observation is also demonstrated in Tables 2.1 and 2.2 (Kollman and Côtè, 1984) below.

Table 2.1 Influence of knots on tension strength (Kollmann and Côtè, 1984)

\begin{tabular}{|l|l|l|l|}
\hline \multirow{2}{*}{ Pinewood } & $\begin{array}{l}\text { Density } \\
\left(\mathrm{kg} / \mathrm{m}^{3}\right)\end{array}$ & Tensile strength \\
\cline { 3 - 4 } & 500 & $(\mathrm{MPa})$ & Reduction \\
\hline Clear & 530 & 76.5 & \\
\hline Few, small knots & 37.7 & $51 \%$ \\
\hline Many, large knots & 570 & 11.7 & $85 \%$ \\
\hline
\end{tabular}

Table 2.2 Influence of knots on compression strength (Kollmann and Côtè, 1984)

\begin{tabular}{|l|l|l|l|}
\hline \multirow{2}{*}{ Pinewood } & $\begin{array}{l}\text { Density } \\
\left(\mathrm{kg} / \mathrm{m}^{3}\right)\end{array}$ & Compressive strength \\
\cline { 3 - 4 } & 500 & $(\mathrm{MPa})$ & Reduction \\
\hline Clear & 530 & 39.5 & $10 \%$ \\
\hline Few, small knots & 35.4 & $22 \%$ \\
\hline Many, large knots & 570 & 30.8 & \multicolumn{2}{|l}{} \\
\hline
\end{tabular}


The loading condition on a wood specimen also determines the resulting stress interactions, failure mode and eventually its capacity which can be utilised. In developing a constitutive model, Sandhaas (2012) emphasised the type of test methods and their delivery of the needed material properties as an input to the model. It was noted that although uniaxial test setups normally deliver strengths for mathematical models, multiaxial stresses and strains may be already developed in the wood which are not measured during the test. The complexity increases as researchers over the years propose and use biaxial test setups with the aim of capturing these stress interactions. (Sandhaas, 2012).

\section{Compression Strength}

In compression parallel to grain, wood cells deform along the longitudinal direction and are shortened by compressive stresses (Winandy, 1994). Wood cells act as columns of tubes, supported laterally by each other to resist the imposed stresses. The ideal compressive strength is achieved when the buckling of the test specimens is prevented, hence small and stocky specimens are normally used in compression testing to prevent bending and instability (Benabou, 2012). An axial compressive test of a wood specimen gives a typical stress-strain relationship as seen in Fig. 2.9 below. It shows a ductile behaviour consisting of an initial linear elastic relationship, followed by a distinct plastic behaviour. The wood is initially compressed to its ultimate stress. The peak stress attained initiates a kink which results in a yield drop after reaching the maximum stress. This marks the first stage of failure by kinking across the wood fibre, which is barely visible. Propagation of the crushed fibre continues, spreading across the entire wood specimen and results in a further drop in the compressive capacity. The last stage of the kink failure is marked by a steady state of the stresses as the kink bands widen laterally by further crushing of the wood fibres. 


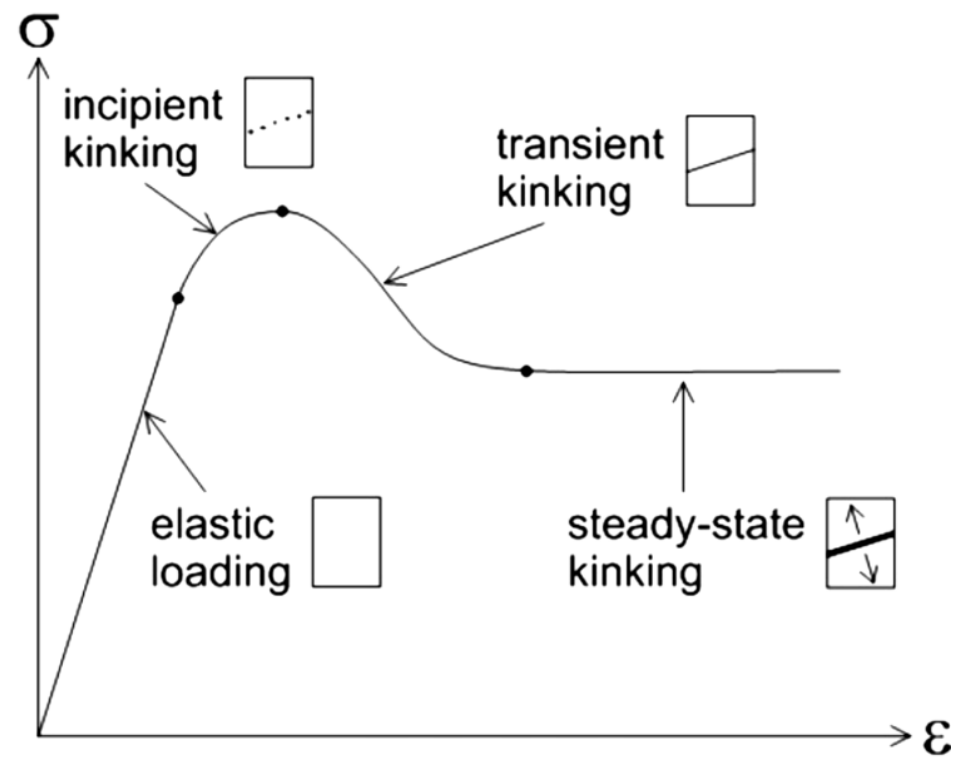

Fig. 2.9 Compressive stress-strain relation of wood parallel-to-grain showing progressive kinking of wood fibres (Benabou, 2012)

Perpendicular-to-grain of wood, compression stresses increase until fibres fold together with little or no cavity in-between them (Winandy, 1994). The peak compressive capacity of wood is normally significantly less in this case compared to compressing parallel to grain. A more stable post-peak compressive stress is obtained as compared to the parallel-to-grain compression. Notwithstanding, the overall ductility of wood is much higher in the parallel direction as opposed to the perpendicular direction.

For compression at any inclined angle to the wood fibre, the ultimate strength of wood is generally known to be an intermediate strength value between parallel and perpendicular to grain compressive strengths (Winandy, 1994). 


\section{Tension Strength}

Tensile strength of wood is quite difficult to determine as compared to its compressive strength (Winandy, 1994). This is because of the brittle failure behaviour of wood under such stresses. Unlike compressive stress development in wood, tensile stresses tend to split and fracture wood after a small deformation and, therefore, this behaviour is less ductile. The sudden fracture point of wood under tension in both parallel and perpendicular-to-grain is summarised in Fig. 2.10 below.

For tension parallel to grain, two main failure modes are possible. The first type of failure occurs when the wood cell walls rupture across the fibre, hence producing the splinter and pure tension fracture patterns as seen in Fig. 2.11 (a) and Fig. 2.11 (d) respectively.

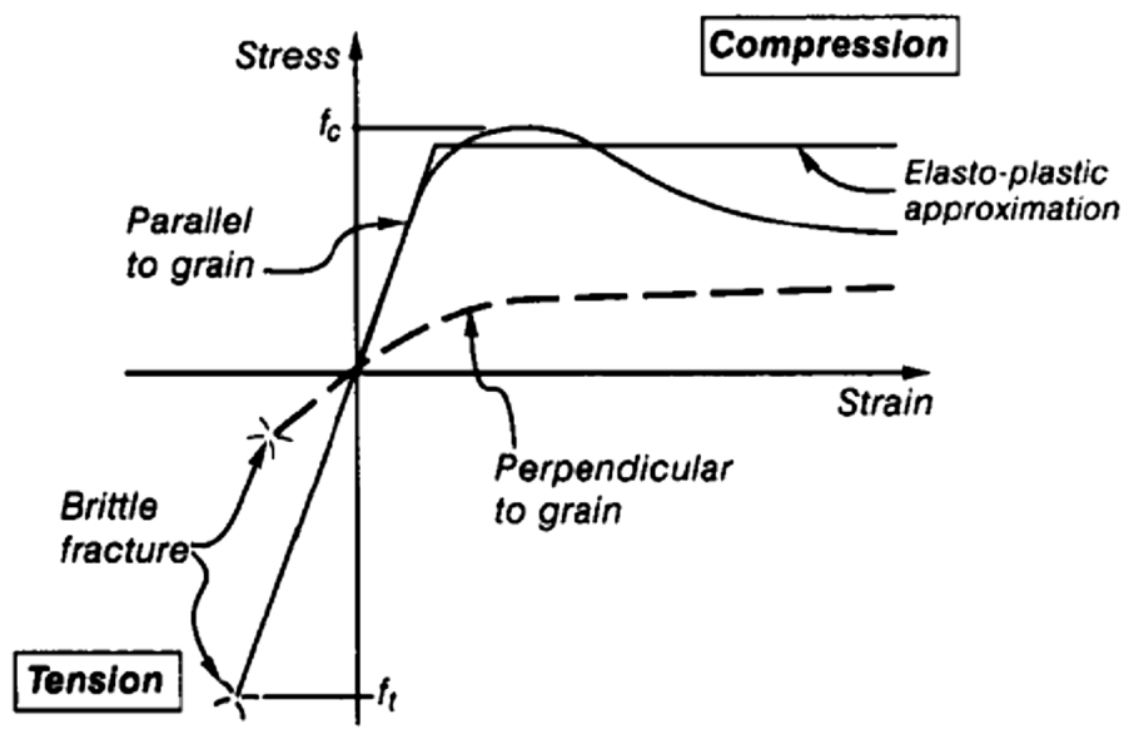

Fig. 2.10 Stress-strain relation of clear wood (Buchanan, 2002) 
In the other failure mode, tensile stresses together with the influences of shear stresses result in a diagonal fracture pattern as seen in Fig. 2.11 (b) and Fig. 2.11 (c).

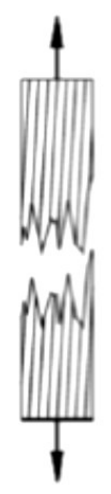

(a)

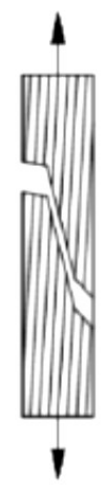

(b)

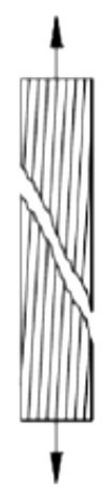

(c)

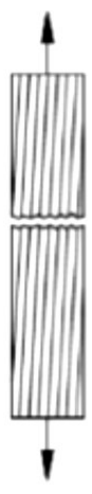

(d)

Fig. 2.11 Failure types in tension parallel to grain (a) splinter failure (b) shear and tension failure (c) shear failure (d) pure tension failure (Bartunkova, 2012)

For the tensile strength perpendicular to grain, minimal stresses are required to cause interfacial split between adjacent cell walls of wood (Winandy, 1994). The applied tensile stresses directly separate the bonds between wood fibres, hence after a slight plastic deformation, the ultimate strength is reached which is much lesser than the parallel-to-grain strength. The tensile strength of wood in the perpendicular-to-grain direction is within the range of $1 \%$ to $5 \%$ of its longitudinal direction (CEN, 2009)

\section{Shear Strength}

Shear is a complex phenomenon which proceeds from the bending action on a wood section. Bending induces tensile and compressive stresses on the opposite sides of the section. The resulting shear action is normally parallel to the wood grain and is referred to as longitudinal shear. Longitudinal shear tends to split wood fibres along the grain in a brittle manner as one would 
observe in a perpendicular tensile loading condition (Winandy, 1994). Another type of shear is known as rolling shear. Rolling shear is known to occur when shear stress is applied perpendicular to wood grain, a manner which causes the 'rolling' of wood fibres over one another. Rolling failure modes occur in the RT plane of wood and is not normally common in practice. The average rolling shear strength is about $18 \%$ to $28 \%$ of the longitudinal shear value (Winandy, 1994).

It is also important to mention that shear strength of wood is directly dependent on the depth of wood section considered. The depth of wood section determines the shear span to depth ratio which can be mobilised in transmitting shear stresses to the supports. Higher shear span to depth ratios decrease the shear capacity of the wood section.

\subsubsection{Inelastic Properties}

Wood as a material is strained when subjected to stresses gradually. The level of proportionality of the stress to strain which takes place defines the elastic regime. Because of the directionality of wood and the stress interactions, the relationship of strains to stresses is normally non-linear. Beyond the elastic yield point, wood becomes inelastic and can experience plastic deformation and fracture.

Depending on the type of applied stress and its direction of application, the stress-strain curves differ significantly. The difference is clearly distinguished in Fig. 2.10: compressive stresses in both longitudinal and perpendicular directions to grain produce a more ductile relation as opposed to tensile stresses which give away a premature brittle failure. 
The post-elastic behaviour of wood determines its ultimate capacity in terms of strength and the most important factor is the failure mode which ensues during loading.

\section{Fracture Toughness and Failure Modes}

Fracture and ultimate failure of wood is investigated by the fracture mechanics theory. According to the fracture mechanics principles, three important parameters; applied stress, flaw size and fracture toughness (Bartunkova, 2012) are of relevance, which eventually determine the final failure mode. Beyond critical stresses in the elastic regime, flaws in the form of cracks are initiated in the material which finally lead to its ultimate failure. Wood, since it is structurally anisotropic, possesses natural cleavage planes from which cracks can easily originate (Barrett, 1981). Longitudinal-radial and longitudinal-tangential planes are natural planes of weakness where cracks normally form and propagate. It takes a relatively higher energy to create cracks across wood fibres and such perpendicular-to-grain cracks are the least common in practice.

Fracture toughness is basically the response of a material to plastic deformation as cracks (flaws) initiate and extend, tending towards ultimate failure. Fracture toughness of a material can be analysed by two main criteria: the critical stress intensity factor $\left(K_{c}\right)$ or critical strain energy release rate $\left(G_{c}\right)$.

In 1913, Inglis pioneered the study of crack propagation in a material by examining the stress intensity factors. This was done by analysing elliptical holes in a flat infinite plate as seen in Fig. 2.12a. The state of stress at a point A can be derived by assuming a linear elastic material behaviour. Point A symbolizes the tip of a crack (see Fig. 2.12b) and the stresses present there 
depend on the stress intensity function $K$, polar coordinate $(\theta, r)$ and a function of angular coordinate $f_{i j}$ as expressed in equation 2.7 .

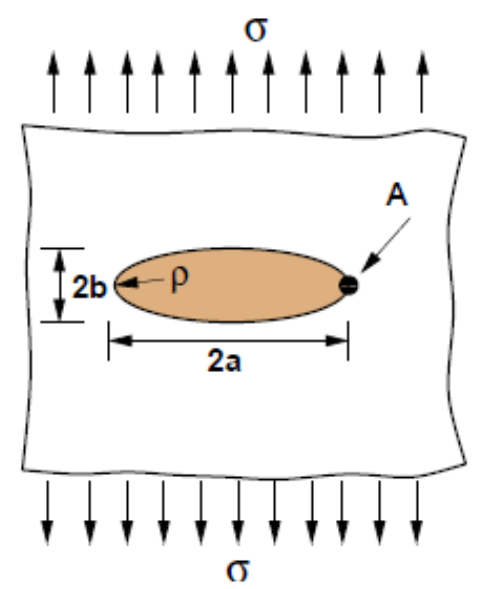

(a)

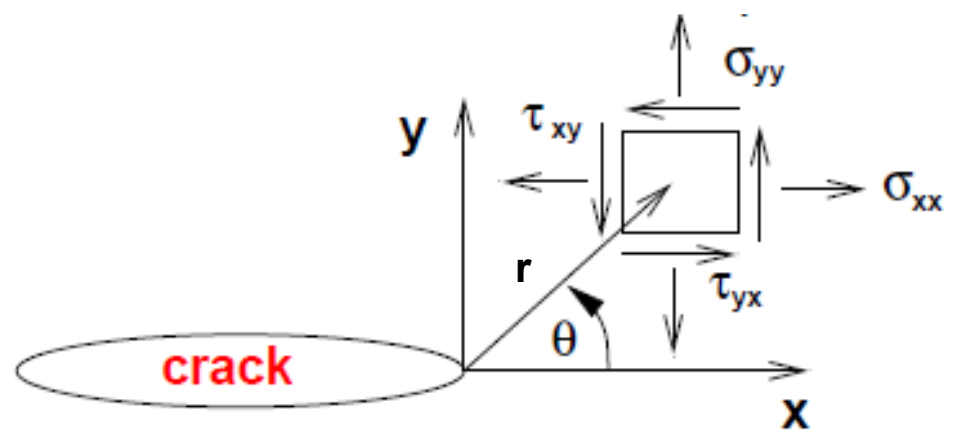

(b)

Fig. 2.12 Stress intensity derivation (a) Elliptical hole in a flat infinite plate (Inglis, 1913) (b) Stress state of material at a crack tip

$$
\sigma_{i j}=\frac{K}{\sqrt{2 \pi r}} f_{i j}(\theta) \ldots \ldots \ldots \ldots \ldots \text { Equation }(2.7)
$$

From this relation, the stress intensity factor can be related to crack length $(a)$ in equation 2.8 as follows:

$$
K=\sigma \sqrt{\pi a}\left(\mathrm{kN} \mathrm{m}^{-3 / 2}\right)
$$

As it can be seen from the above relations, the magnitude of the stress is driven by the stress intensity factor. As the stresses in the material increase, they reach a certain critical stress $\left(\sigma_{c}\right)$ beyond which fracture occurs. The stress intensity factor, $\mathrm{K}$ is a measure of the material's resistance to fracture. 
Griffith (1921) extended the work of Inglis on fracture theory based on strain energy rather than local stresses. It was observed that for a linear elastic material in a fracture mode, a decrease in the potential energy results in an increase of the surface energy which creates new crack surfaces. This is summarised in equation 2.9 as the decrease in potential energy which is also the energy release rate during crack formation.

$$
\frac{d \Pi}{d a}=-\frac{\pi \sigma^{2} a B}{E} \ldots \ldots \ldots \ldots \ldots \text { Equation }(2.9)
$$

Where, $B=$ the thickness of the crack plane structure, $E=$ modulus of Elasticity, $\Pi=$ potential energy

Equation 2.9 was slightly modified by Irwin (1958) to suit engineering problems as seen in equation 2.10 below.

$$
G=-\frac{d \Pi}{d A}=-\frac{1}{B} \frac{d \Pi}{d a}=\frac{\pi \sigma^{2} a}{E}(N / m) \ldots \ldots \ldots \ldots \ldots \ldots \text { Equation }(2.10)
$$

$G$ is the rate of change in potential energy with respect to crack area $(A)$ and it directly corresponds to the energy available for crack extension. Just like the stress intensity factor, $G$ is also a measure of the fracture toughness of the material. $G$ has been found to be a constant material property which is independent of the geometry of the structure, size of the crack and the applied load (Khorasan, 2012).

Whereas the stress intensity factor $K$ describes the stresses, strains and displacements near the crack tip, the critical strain energy release rate $G$ on the other hand measures the potential energy change caused by crack propagation. $K$ is a localised parameter whereas $G$ considers the overall energy change in the system, hence a global parameter. The basic assumption in deriving both $K$ 
and $G$, however, is a linear elastic material response. In fracture mechanics $G$ and $K$ are related by equation 2.11 (Bartunkova, 2012).

$$
G=\frac{K^{2}}{E}
$$

During loading in the material, $\mathrm{G}$ increases up to a critical strain energy release rate, $G_{c}$ beyond which fracture occurs. In linear elastic fracture mechanics (LEFM), $G_{c}$ is equal to the fracture energy, $G_{f}$ (Bartunkova, 2012). Fracture energy, $G_{f}$ is referred to as the amount of energy needed to form a unit area of a new crack in the material.

Depending on the loading and internal stresses developed, fracture occurs when the critical strain energy release rate is exceeded. Cracks can lie and propagate in about six distinct ways (see Fig. 2.13). The first of the letter pairs indicates the direction normal to the crack surface while the second letter denotes the direction of crack propagation in the plane.

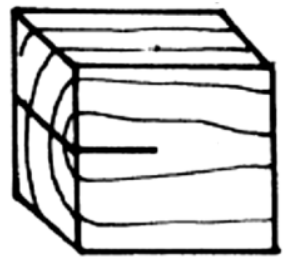

t.l.

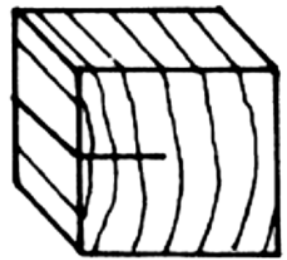

t.r.

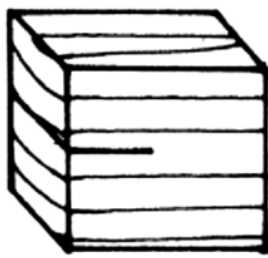

r.l.

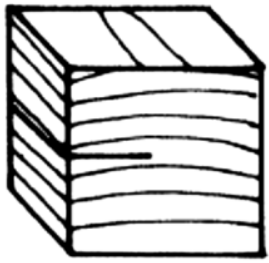

r.t.

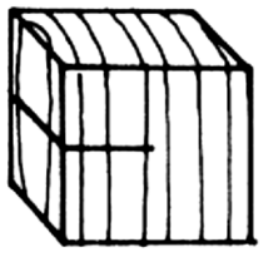

l.r.

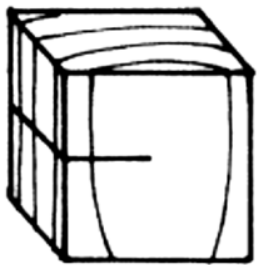

l.t.

Fig. 2.13 Six Principal Systems of Crack Propagation by a Schematic Block View (Barrett, 1981) 
The most common form of crack propagation in practice are t.l, r.l, t.r and r.t, which normally occur in weak natural cleavages of the wood aligned with grain direction. The most critical among the crack propagation systems are t.l and r.l. This is due to the fact that t.l and r.l cracks open along the tangential and radial directions respectively as they respond to tensile stresses perpendicularto-grain direction. Since wood has a lower strength and stiffness in response to such stresses, t.l and $r .1$ crack propagation dominate.

The three ways of crack loading associated with each of the crack propagation systems are described by Irwin (1958). These represent the possible modes of failure wood can experience under loading and are as follows (See Fig. 2.14):

1. Mode I- Pure principal tensile stresses are applied perpendicular to the wood grain which tend to open the crack. This is normally referred to as the opening mode.

2. Mode II - This mode is due to in-plane shear stresses which causes sliding along the crack surfaces in the same plane. This mode of failure is normally referred to as the sliding mode.

3. Mode III - In this mode of failure, transverse shear stresses cause out-of-plane shearing of one crack surface over another. This mode is also known as the tearing mode.

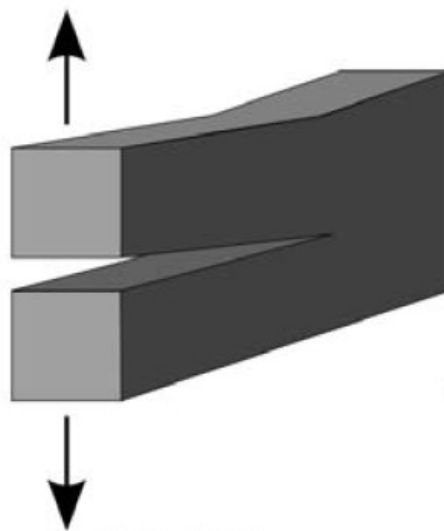

Mode I:

Opening

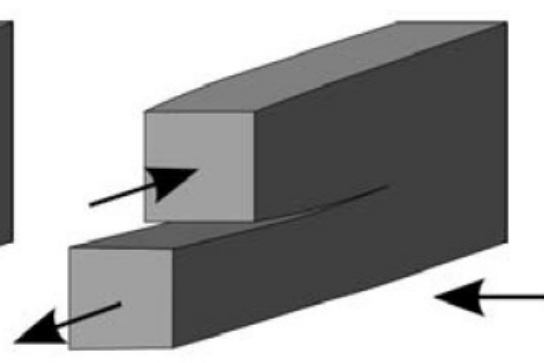

Mode II: Sliding

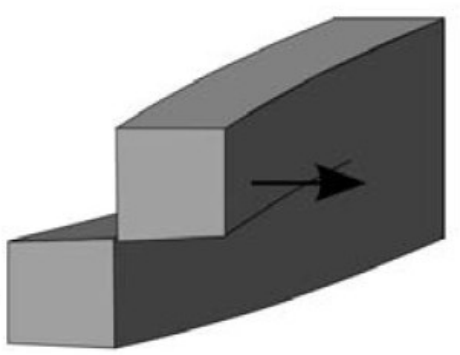

Fig. 2.14 Three Modes of Crack Loading and Failure (Irwin, 1958) 
Each crack loading mode has fracture toughness associated with it. Stress intensity factors and fracture energies are therefore determined with respect to any of the three failure modes which could occur during crack propagation. Depending on the type of loading applied on the crack surface, three different critical energy release rates $\mathrm{G}_{\mathrm{I}}, \mathrm{G}_{\mathrm{II}}, \mathrm{G}_{\text {III }}$ values arise for the respective failure modes. Nevertheless, the failure in the wood can occur through a combination of all the three modes, which is known as the mixed-mode failure (Khorasan, 2012).

\subsubsection{Steel}

Steel material unlike wood is homogenous and possesses the same mechanical properties in all directions (isotropic). Single values of elastic modulus, $E$ and Poisson ratio, $v$ are enough to completely define the elastic response of the steel material to stresses. The typical values of $E$ and $v$ for steel are $207 \mathrm{GPa}$ and 0.3 respectively.

Under both pure tensile and compressive stresses, steel exhibits an elasto-plastic behaviour which is indicated by three distinct phases (see Fig. 2.15). The first stage depicts a linear response of strains in the steel to applied stresses. This marks the elastic region up to the proportional limit within which equation 2.12 is valid for steel subjected to uniaxial stress.

$$
\left\{\begin{array}{c}
\varepsilon_{11} \\
\varepsilon_{22} \\
\varepsilon_{33} \\
\gamma_{12} \\
\gamma_{13} \\
\gamma_{23}
\end{array}\right\}=\left[\begin{array}{cccccc}
1 / E & -\nu / E & -\nu / E & 0 & 0 & 0 \\
-\nu / E & 1 / E & -\nu / E & 0 & 0 & 0 \\
-\nu / E & -\nu / E & 1 / E & 0 & 0 & 0 \\
0 & 0 & 0 & 1 / G & 0 & 0 \\
0 & 0 & 0 & 0 & 1 / G & 0 \\
0 & 0 & 0 & 0 & 0 & 1 / G
\end{array}\right]\left\{\begin{array}{c}
\sigma_{11} \\
\sigma_{22} \\
\sigma_{33} \\
\sigma_{12} \\
\sigma_{13} \\
\sigma_{23}
\end{array}\right\} \ldots \ldots \ldots \ldots \text { Equation (2. 12) }
$$

In the elastic range, withdrawal of the applied stresses returns steel to its original state with no permanent deformation. Beyond the elastic limit, steel yields $\left(f_{y}\right)$ and the plastic region is initiated. 
When the applied load is removed after the yield point, complete recovery to its original state is impossible and a permanent deformation results which is known as plastic deformation. The second stage lies within the plastic region where strains continually increase with negligible increase in the stresses forming yield plateau. After the yield plateau, stresses increase significantly against increasing strains over a range called the strain-hardening range.

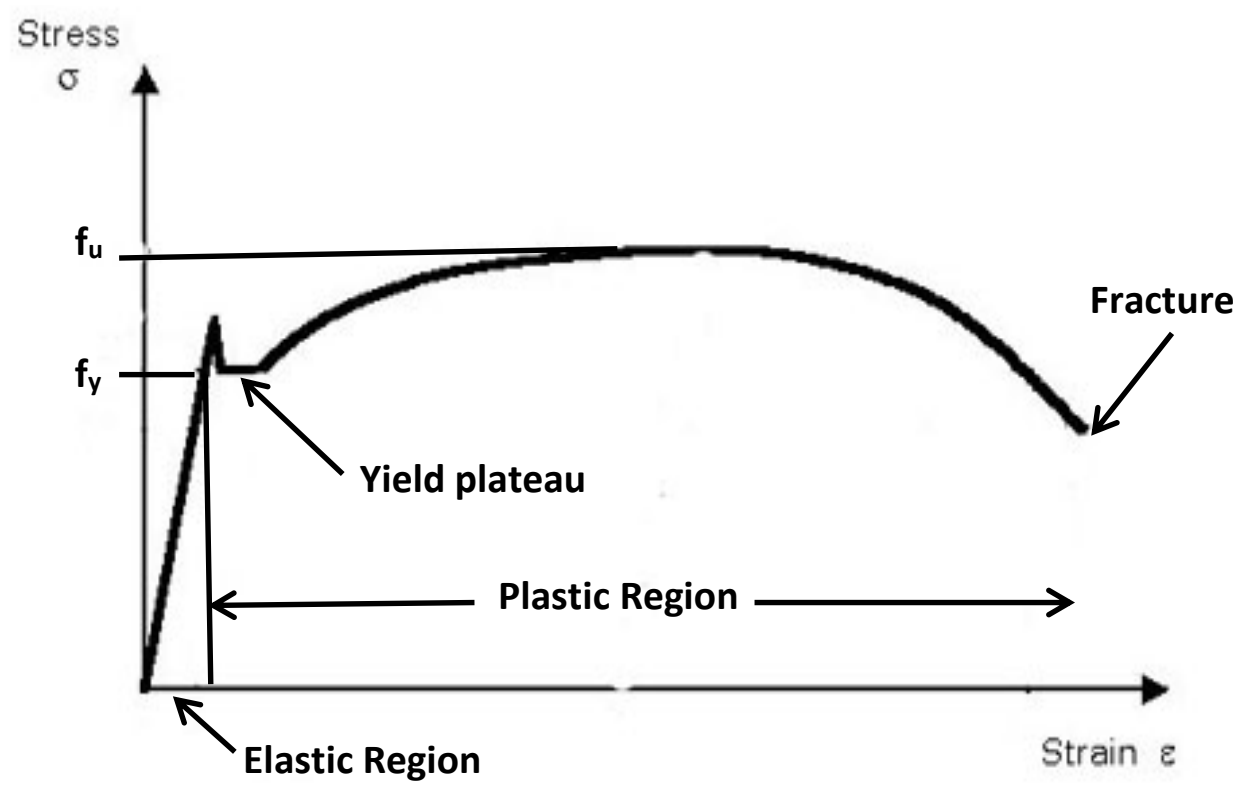

Fig. 2.15 Typical Stress-Strain Curve of Steel

The strain-hardening of steel enhances its capacity beyond the yield strength $f_{y}$ until its ultimate strength $f_{u}$ is reached. The ultimate strength is the maximum strength of steel which can be utilised after which the steel material will eventually failure by fracture.

\subsection{Mechanical Properties at Elevated Temperatures}

\subsubsection{Wood}

Mechanical properties of wood are highly dependent on temperature. Increase in temperature heats up the moisture in wood till it turns to steam around $100^{\circ} \mathrm{C}$. Other significant 
changes are pyrolysis of wood around $200^{\circ} \mathrm{C}$ and subsequent charring at $300^{\circ} \mathrm{C}$ (Buchanan, 2002). Pyrolysis is the thermal decomposition of solid wood to gaseous volatiles (Buchanan, 2002). The movement of moisture in wood and its charring characteristics are the major factors which affect its strength and elasticity at elevated temperatures.

\subsubsection{Modulus of Elasticity}

In the Wood Handbook (2010), a wide range of experimental values for the elastic modulus is provided for different temperatures and moisture content of wood. Fig. 2.16 shows the relative modulus of elasticity varying with temperature as adopted from Buchanan (2002).



Fig. 2.16 Modulus of Elasticity of Wood Parallel to the Grain versus Temperature (Buchanan, 2002)

Fig. 2.16 shows a gradual reduction of elasticity from the ambient value as temperature in the wood increases. The curve with a significant initial moisture content of $12 \%$ records the gradual reduction in the elastic modulus for a range of temperatures up to $100^{\circ} \mathrm{C}$. The other one with a negligible moisture content $(0 \%)$ however continues beyond $100^{\circ} \mathrm{C}$ until about $200^{\circ} \mathrm{C}$ where there is a slight sudden drop probably because wood approaches the charring zone. 


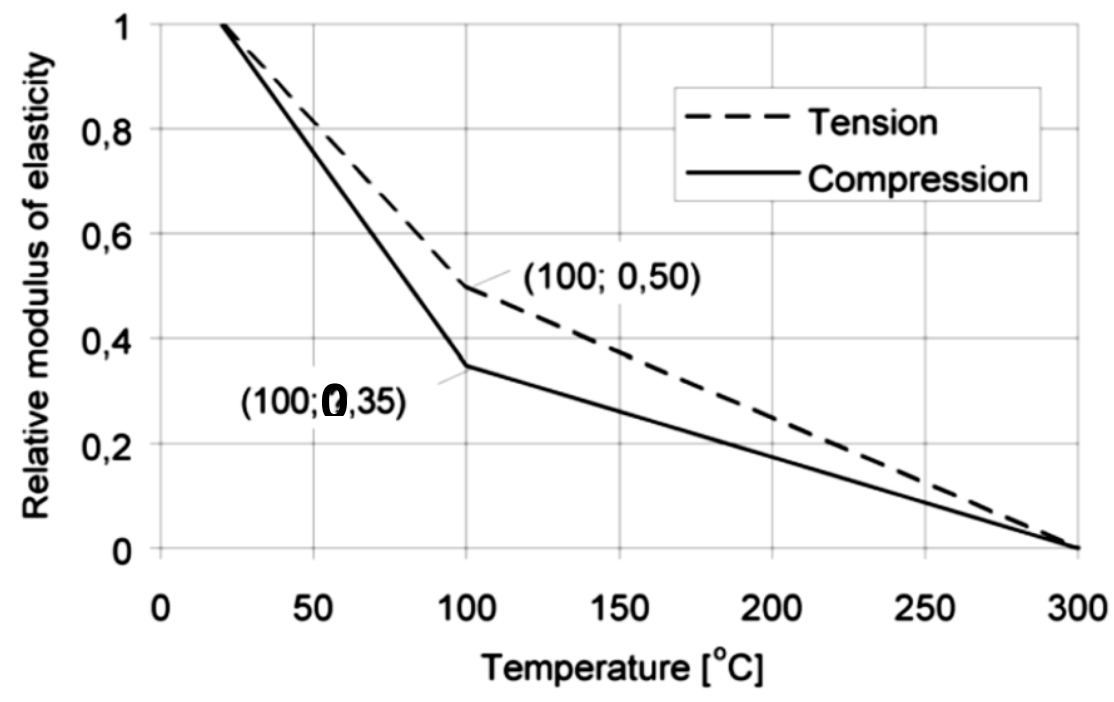

Fig. 2.17 Modulus of Elasticity of Wood Parallel to the Grain versus

Temperature for Softwoods (Eurocode 5, 2004)

Values from other researchers like Nyman (1980), Ostman (1985), Schaffer (1970) and Preusser (1968) are reported to fit well into the $0 \%$ moisture content bracket as shown in Fig. 2.16. A significant difference in the relative modulus of elasticity is seen in Fig. 2.17 as it varies with temperature for typical softwoods. The effect of moisture evaporation is however demonstrated for Softwoods as a bilinear curve is obtained with a gradient change at $100^{\circ} \mathrm{C}$ (Eurocode 5,2004 ).

\subsubsection{Strength Properties}

The significant wood strength properties which can adversely change with increasing temperatures are compressive, tension and shear. The variation of each strength with increasing temperature is summarised in Fig. 2.18 as provided by Eurocode 5 (2004). 
For compression parallel to grain, the reduction in strength is quite rapid as moisture in the wood is heated up and driven off gradually. Compressive strength is more sensitive to elevated temperatures as compared to tension and shear.

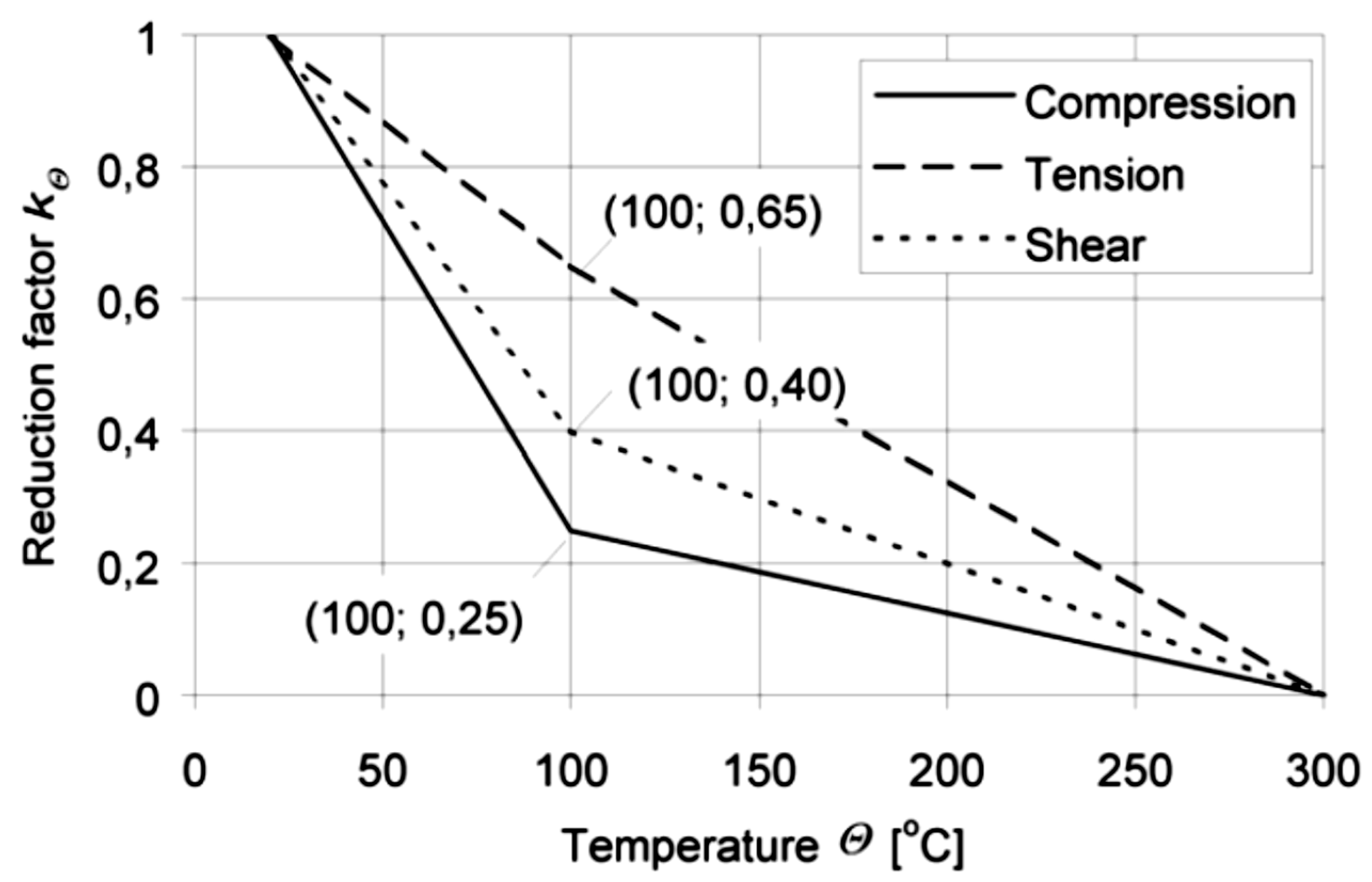

Fig. 2.18 Strength of Wood Parallel to the Grain versus Temperature for Softwoods (Eurocode 5, 2004)

\subsubsection{Steel}

Steel has a high thermal conductivity, hence it is heated up quickly and its strength and stiffness deteriorate rapidly in high temperatures. As the yield strength and elastic modulus of steel decrease with temperature, significant deformations occur which may not be acceptable especially for steel structures subjected to structural loads. 
Deterioration of strength and elasticity of steel in elevated temperatures is accounted for by introducing reduction factors in design calculations. Fig. 2.19 summarizes both the yield strength and elastic modulus reduction with elevated temperatures depicting a similar variation. Strength and stiffness reduction define the stress-strain relation of steel at various temperatures and has been documented in literature (Buchanan, 2002 and Eurocode 3, 2001).

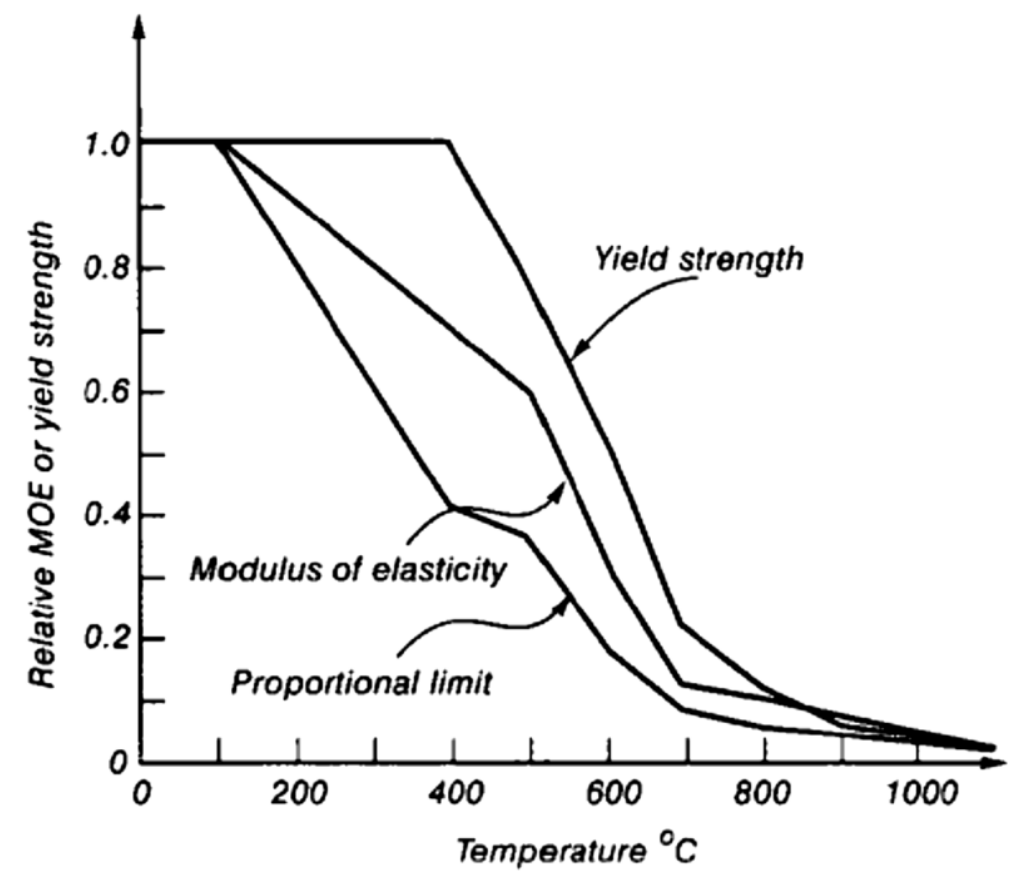

Fig. 2.19 Reduction of Steel Strength with Temperature (Adapted from Buchanan (2002) as quoted from Eurocode 3 (2001))

Reduction factors for structural, reinforcing and prestressing steel are shown in Fig. 2.20. These are typical relationships extracted from Australian, New Zealand and British Standards (AS 4100, NZS 3404, BS 8110 and AS 3600) as quoted by Buchanan (2002). Test results of both hot-rolled and cold-worked steel have been reported by Harmathy (1993) which also show a similar trend. 
A critical temperature for steel can be seen in both Fig. 2.19 and 2.20 which lies approximately in the range of $200^{\circ} \mathrm{C}-400^{\circ} \mathrm{C}$. In this range of temperature and beyond, both strength and stiffness of steel decrease significantly.

Apart from stress-related strain, thermal and creep strain in steel are also known to occur. Thermal strain results from the expansion of steel as it is heated up. Creep strain on the other hand is due to accumulated stress which induces strains during the time of steel exposure to high temperatures (Buchanan, 2002). Thermal and creep strains are mostly negligible for simple structures but for complex and restrained structural members, their effect can be quite significant (Buchanan, 2002).

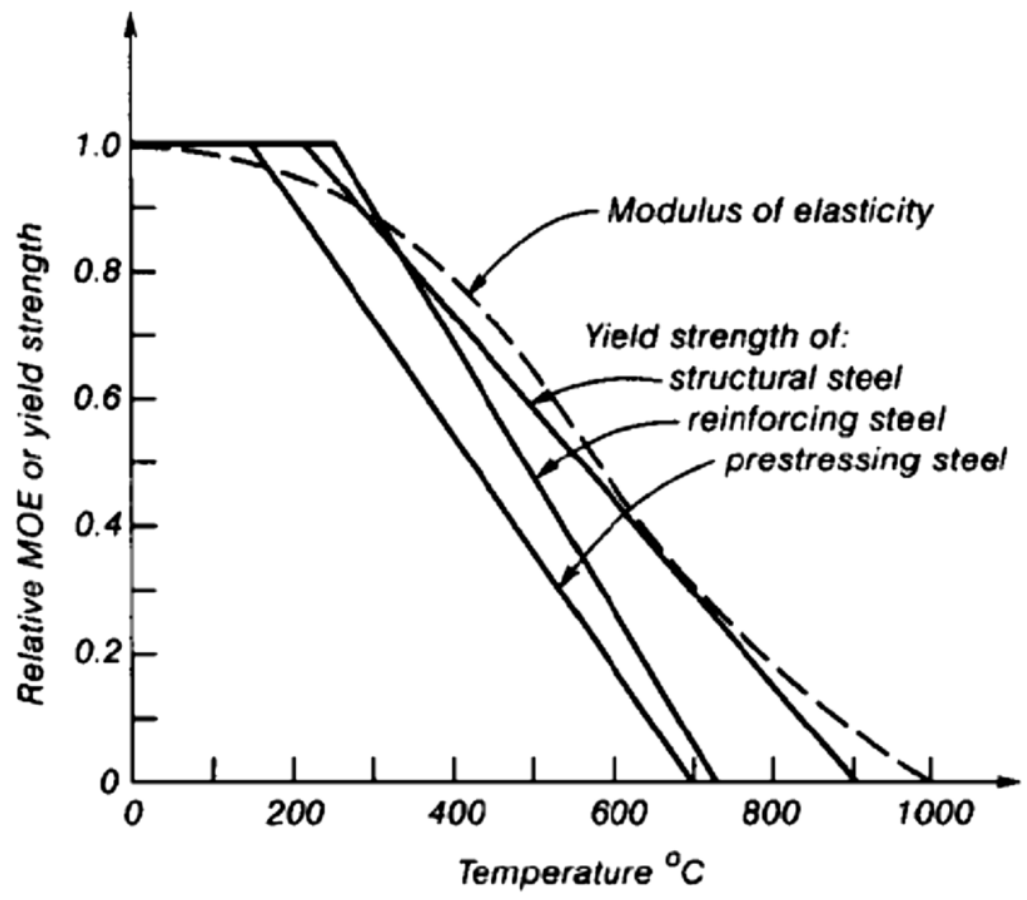

Fig. 2.20 Reduction of Different Types of Steel Strength with Temperature (Buchanan, 2002) 


\subsection{Thermal Properties of Wood and Steel}

\subsubsection{Wood}

Unlike steel, wood is a combustible material hence it turns to char beyond a certain temperature. The rate at which wood turns to char during heat exposure is known as charring rate. Heat transfer within wood is dependent on its charring characteristics and vice versa. The charring distribution of wood exposed to fire is shown in Fig. 2.21. Buchanan (2002) identifies the three main distinct zones of a heated wood as, char layer, pyrolysis zone and normal wood. Buchanan (2002) noted that as wood is heated up, its moisture turns to steam around $100^{\circ} \mathrm{C}$ and begins to evaporate. At about $200^{\circ} \mathrm{C}$, the pyrolysis of wood takes place and combustibles are generated; this produces the pyrolysis zone and this continues until wood finally turns to char at about $300^{\circ} \mathrm{C}$ (Buchanan, 2002).

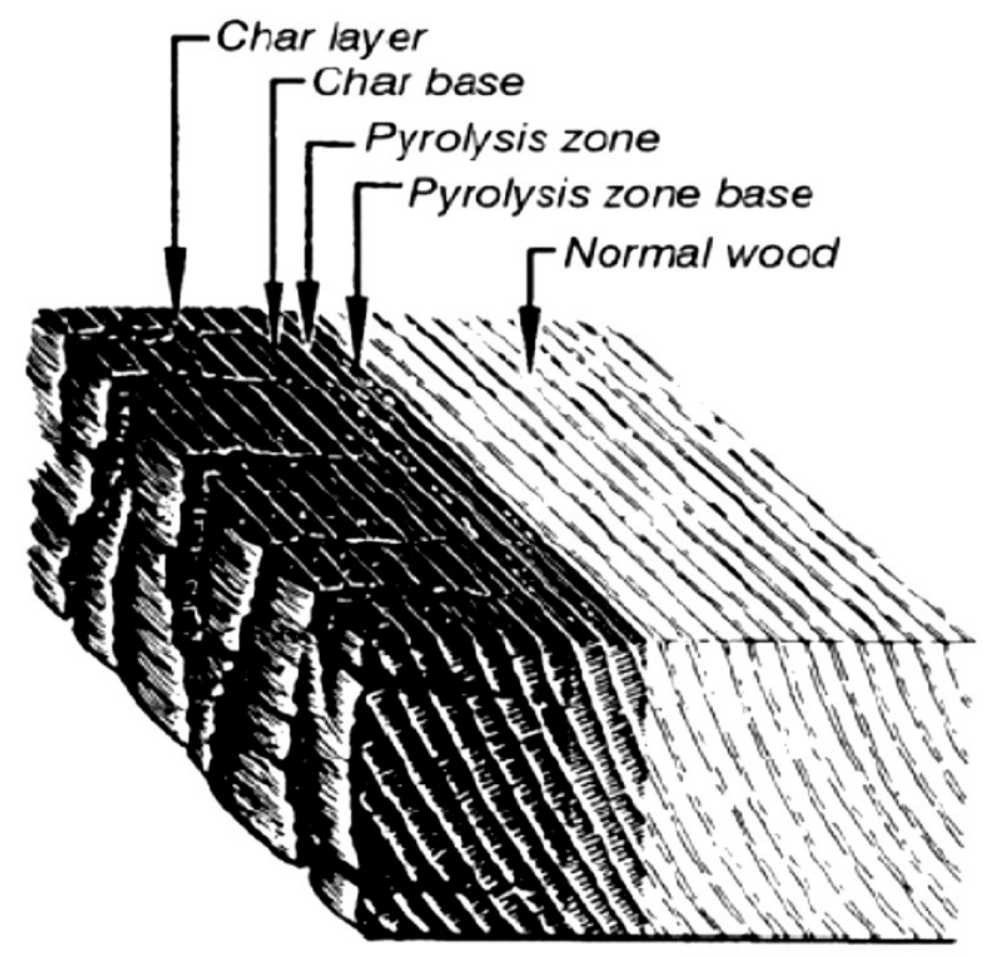

Fig. 2.21 Charring Distribution on a wooden beam (Adapted from Buchanan, 2002 as quoted from Schaffer, 1967) 
The charred layer of wood has negligible strength and stiffness hence the charring rate of wood has been the basis of structural design of heavy timber members in fire conditions (Buchanan, 2002). The residual section of the timber section which is not charred is what is effective in resisting structural loads in case of fire exposure. The charring characteristics of wood also affects its heat transfer as described by the thermal properties of conductivity, density and specific heat capacity in the following paragraphs.

Thermal conductivity is the extent to which heat is conducted through a material, measured normally in $\mathrm{W} / \mathrm{m} / \mathrm{K}$. Thermal conductivity of wood has been documented by various researchers with some scatter. Peng (2010) noted that the different wood species, densities, moisture contents and test methods used by researchers contribute significantly to this variation. However, similar trends can be noted when wood begins to combust. At pyrolysis temperatures of wood, the char material produced provides a partial insulation protection during the time of fire exposure hence hindering the penetration of heat to the wood underneath. The pyrolysis effect decreases the thermal conductivity over a range of temperatures up to a point where significant cracks occur in the char layer. The shrinkage and cracks in the charred wood then tend to increase the thermal conductivity beyond temperatures of $350^{\circ} \mathrm{C}-400^{\circ} \mathrm{C}$ (Peng, 2010). Fig. 2.22 shows the variation of thermal conductivity with temperature as adapted in Eurocode 5 (2004) for design purposes. The graph captures the influence of charring and reflects the general trend reported by various researchers. 




Fig. 2.22 Temperature-Thermal Conductivity for Wood and the Char layer (Eurocode 5, 2004)

A typical variation of specific heat capacity with temperature is reported in Eurocode 5, 2004 (see Fig. 2.23). The large spike of the specific heat value around $100^{\circ} \mathrm{C}$ is a result of the extra energy needed to evaporate the moisture in the wood (Buchanan, 2002).

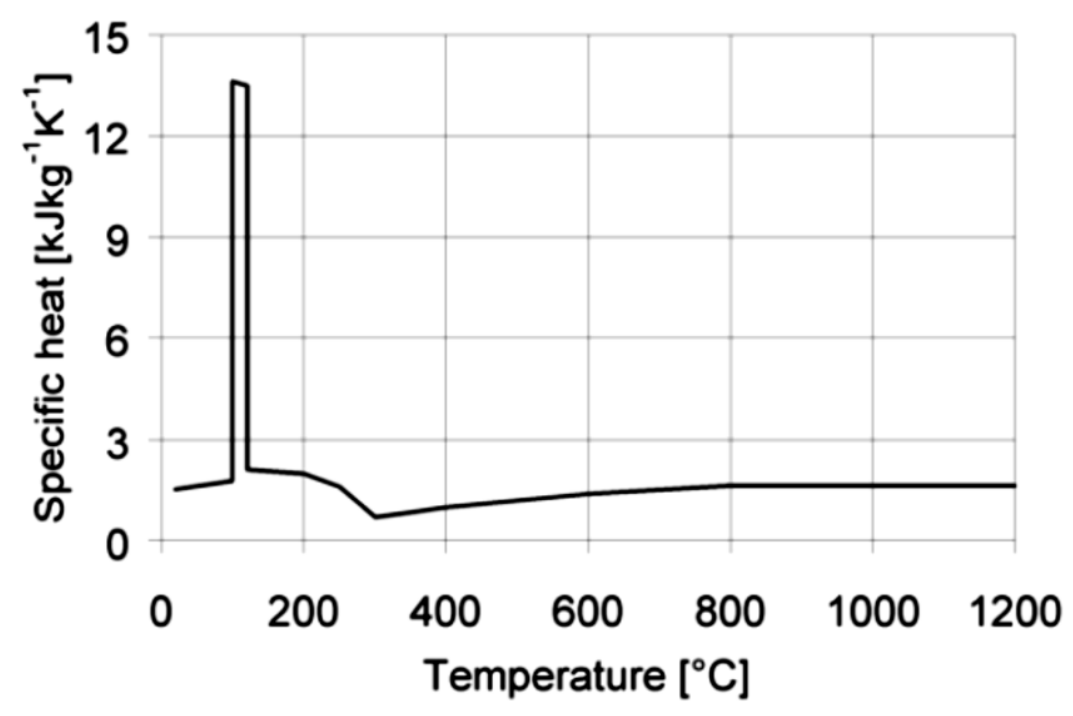

Fig. 2.23 Temperature-Specific Heat Capacity for Wood and the Char layer (Eurocode 5, 2004) 
Density of wood is a major function of its moisture content. As wood is heated up, moisture within it evaporates hence its weight is reduced. Evaporated moisture leaves the wood dry and wood begins to undergo combustion. Increased pyrolysis leads to a rapid degradation of wood density since it is progressively turned to light charred layers. Different wood species have varying densities and Fig. 2.24 shows the variation of density ratio rather than actual wood densities. Density ratio is the ratio of wood density in high temperature conditions to its ambient values $\left(20^{\circ} \mathrm{C}\right)$. Density ratio is adapted as a reduction factor by Eurocode $5(2004)$ as seen in Fig. 2.24 to generally indicate the influence of moisture content and the charring on wood density. The value of the density ratio could be slightly higher than unity because of the initial moisture content of wood (see Fig. 2.24).

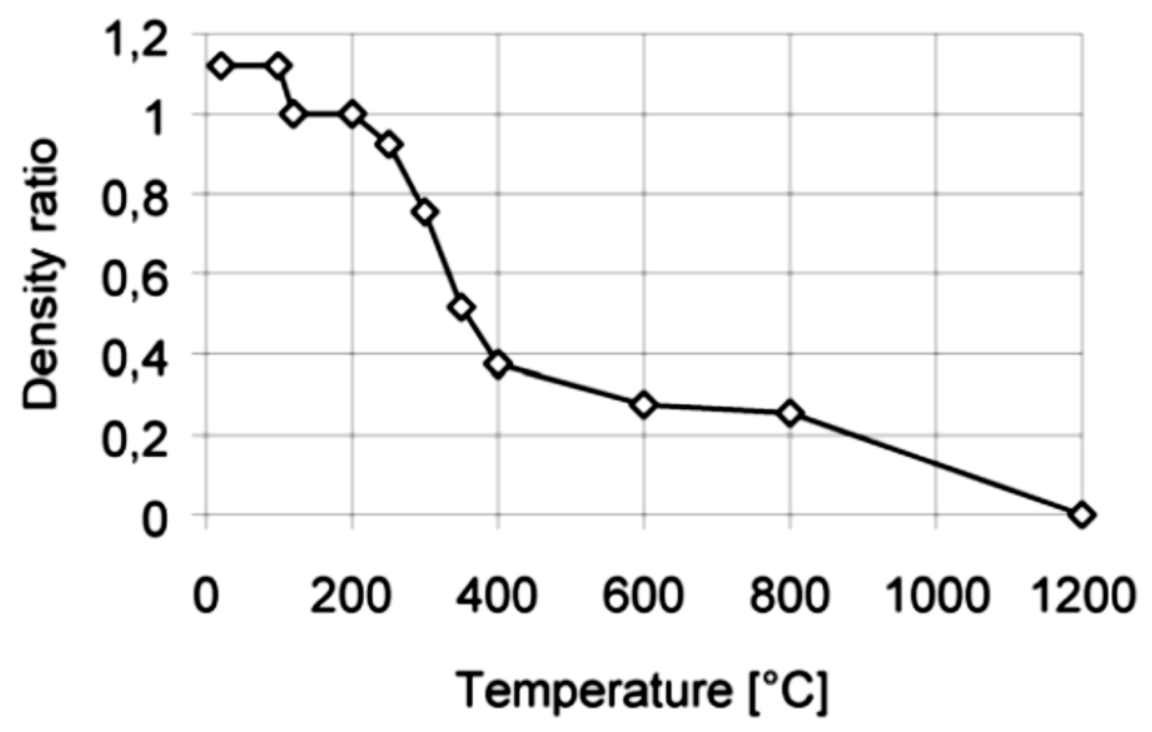

Fig. 2.24 Temperature-Density Ratio for Softwood with an initial moisture content of 12\% (Eurocode 5, 2004) 


\subsubsection{Steel}

Steel possesses a very high thermal conductivity as compared to wood. Thermal conductivity of steel is about $50 \mathrm{~W} / \mathrm{m} / \mathrm{K}$ as opposed to wood which is $0.12 \mathrm{~W} / \mathrm{m} / \mathrm{K}$ at ambient conditions (Peng, 2010). The difference in thermal conductivity is very significant and therefore, steel is normally protected against elevated temperatures. The variation of steel conductivity with temperature is well described by Eurocode 3 (2001) as seen in Fig. 2.25. The response of steel specific heat capacity to high temperatures is also shown in Fig.2.26. The large spike in specific heat capacity at a temperature around $723{ }^{\circ} \mathrm{C}$ is due to the phase change which occurs in carbon steel. The density of steel however is known to remain at an almost constant value of $7850 \mathrm{~kg} / \mathrm{m}^{3}$ even with increasing temperatures (Peng, 2010).

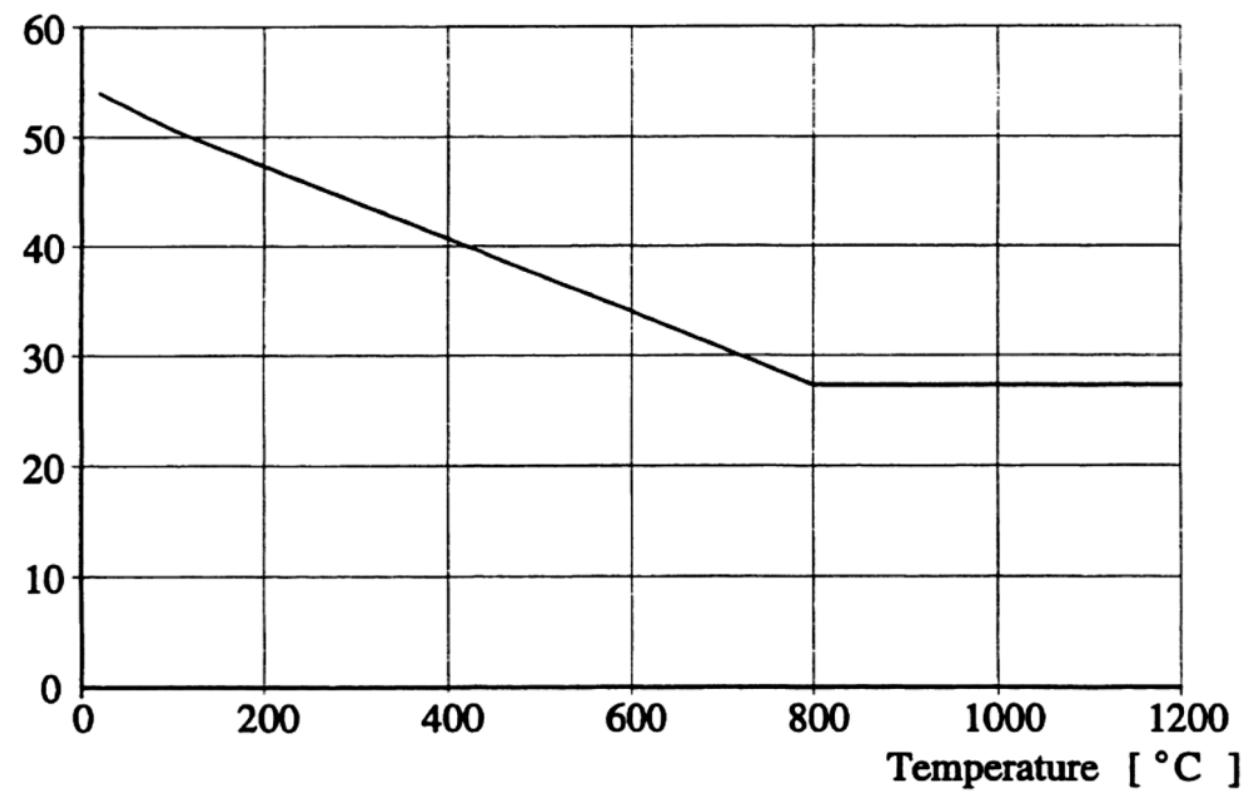

Fig. 2.25 Variation of Steel Thermal Conductivity with Temperature

(Eurocode 3 (2001)) 


\section{Specific heat [ J / kg K ]}

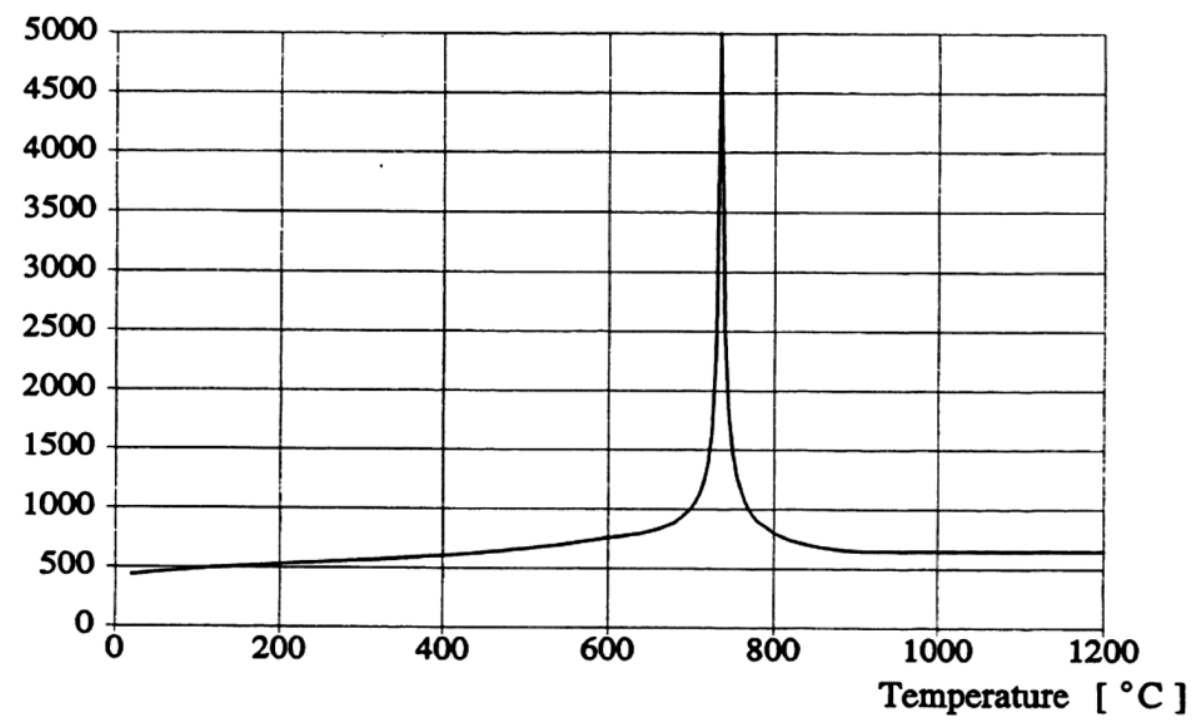

Fig. 2.26 Variation of Steel Specific Heat Capacity with Temperature (Eurocode 3 (2001))

\subsection{Numerical Modelling of Steel-Timber Connections}

Typical timber connections consist of steel members connected to timber members through steel plates and bolts or dowels. The performance of these connections is important for the overall integrity of the building structure even though individual members may be adequate in structural performance.

The structural and fire performance of these connections have been previously discussed in section 2.3.1. Ductility and fire resistance are important requirements at the connection level to ensure that the structural-fire performance of such connections are reliable during design. Reliable methods of assessing the structural-fire integrity of such a hybrid system are therefore needed. Experimental investigation of the performance of connections is the first approach of researchers where the prototype of connections are built and tested in the laboratory. In addition, analytical methods have 
been developed through correlation with test results and computer models with the aim of predicting the connection behaviour. A popular analytical method is the European Yield Model in Eurocode 5 (2004) which is based on Johansen's work in 1949 which has been previously discussed. Apart from experimental and analytical means, a numerical modelling is another powerful way to assess the performance of connections. Previous numerical investigations of the hybrid timber connections by others are presented in this section.

Numerical simulation of any engineering or science problem involves two major tasks (Reddy, 1993):

1. Mathematical formulation of the physical problem

2. Numerical analysis of the mathematical model

The mathematical formulation breaks down the problem into a system of differential equations and the numerical simulation is performed by applying the appropriate numerical methods to solve the given problem. Various numerical procedures exist which can be used to solve diverse engineering problems. The most common one for solving solid mechanical engineering problems is the Finite Element Method (or normally referred to as Finite Element Analysis).

The finite element method (FEM) is a numerical procedure which is used to simulate and solve a physical problem governed by differential equations. The term "finite element" is derived from simple sub-domains which have been broken down from the main domain of the problem (Reddy, 1993). The general finite element analysis process is as shown in Fig. 2.27 as described by Bathe (1996). It comprises of applying the system of mathematical equations to the finite elements. An approximate value of the solution variable is obtained at nodal points on the element and inter- 
element continuity functions can be used to obtain equilibrium of the nodal forces at the local level. The local solution of the problem is then extended to the entire system through a global matrix and appropriate boundary conditions are applied to obtain the final global solution of the system.

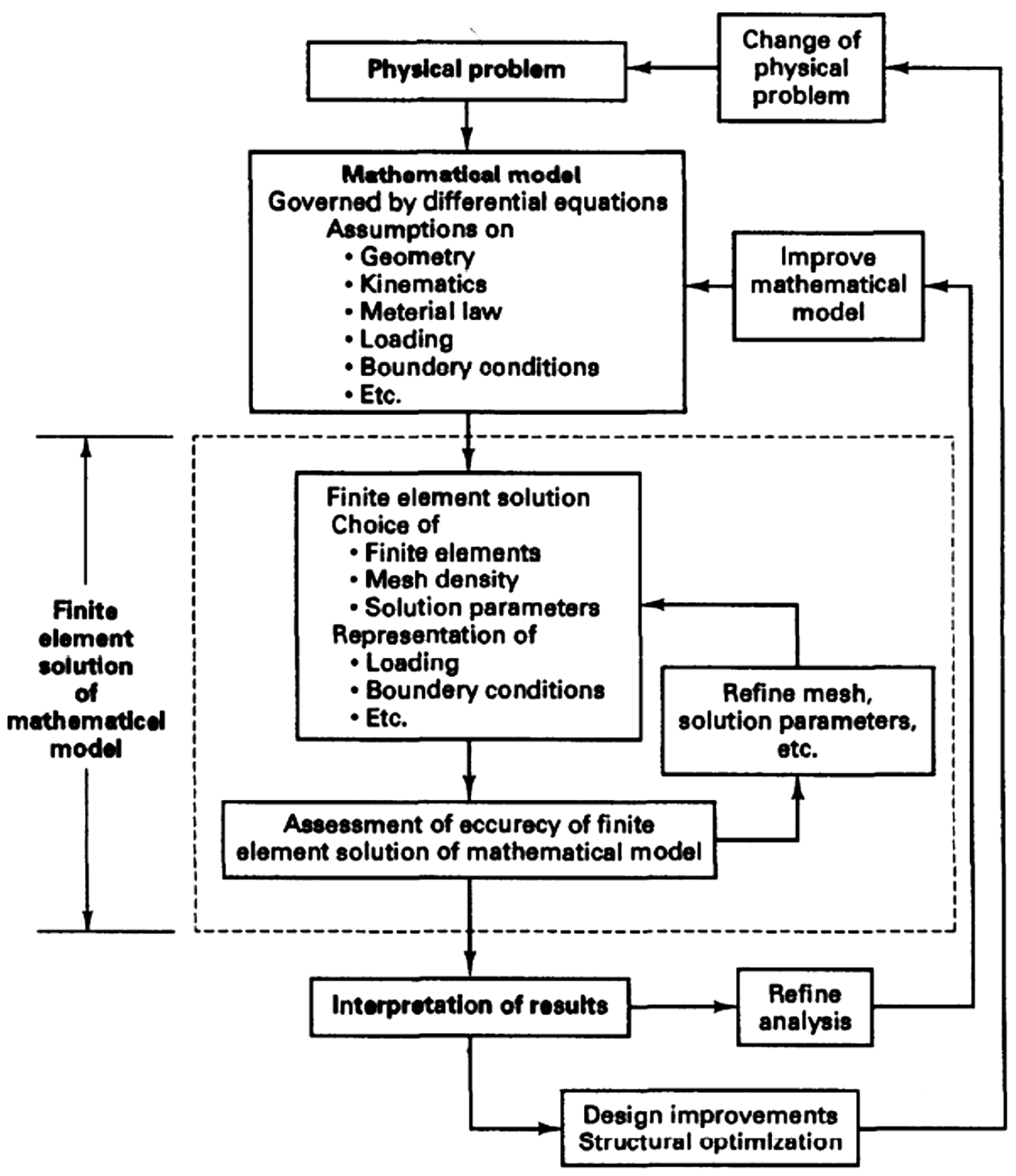

Fig. 2.27 The Process of Finite Element Analysis (Bathe, 1996) 
Finite element analysis has been packaged in many commercial computer programs such as Algor, ABAQUS, ANSYS, COSMOS, MARC, MSC/NASTRAN, SAP2000, OpenSees, etc. The standard capabilities of these programs include the availability of the different element types, analysis procedures, material models and various load types. The choice of the finite element software package depends on the kind of problem at hand and the capability of the program to handle that given problem.

Modelling the behaviour of connections entails good material models for wood and steel as well as contact simulation to ensure the transfer of forces across the joint. Wood and steel behave differently in both ambient and elevated temperature conditions hence a complex behaviour at the joint level is usually expected. Accurate material models for both wood and steel are therefore the major determining factors.

\subsubsection{Material modelling}

Finite element modelling of a material requires a good understanding of how the material behaves in response to loads. The mechanical response of wood and steel materials has been described previously in sections 2.4 .1 and 2.4.2 respectively. Wood is a highly anisotropic material while steel is isotropic. The directional dependency of wood behaviour makes it quite complex to model but steel is fairly easy to model.

Sandhaas (2012) clearly identifies that a good mathematical model of any structural material is dependent on four main concepts which are namely:

1. A valid constitutive law which governs the strain response to applied stresses 
2. Failure/yield criteria which will characterise the material damage

3. Non-linear response of the material by a hardening or softening rule

4. Good test results to serve as input to the finite element model

Both wood and steel exhibit elastic properties hence obey Hooke's law up to their elastic limit beyond which inelastic properties set in. The elastic stiffness matrix is the constitutive relation between stresses and strains in elastic materials. The elastic matrix can remain constant or vary during the elastic response hence resulting in either a linear or non-linear elastic material respectively. Comparing the stress-strain relations, steel typically depicts an almost linear elasticity whereas wood has a non-linear response. Wood is known to have a ductile response in compression but brittle in tension and shear (see Fig. 2.10).

Modelling steel involves defining its elastic-plastic behaviour as seen previously in Fig. 2.15. The elastic-plastic response is generally tested experimentally to characterise steel irrespective of the direction of loading provided instabilities are avoided in the test specimen. The isotropy of steel makes it easier to model in finite element programs. This is done by defining the Modulus of Elasticity $(E)$ which determines the resulting strains from stresses in the elastic region. Specifying a Poisson ratio $(v)$ enables the computation of corresponding lateral strains from applied stresses in the direction of loading. To include the plastic behaviour of steel in the model, the yield stress of steel $\left(f_{y}\right)$, post-elastic stresses and their corresponding strains are needed inputs which can easily be obtained from literature. The post-elastic behaviour of steel should normally be modelled to include the strain-hardening effect, which is typical of the stress-strain relation of the steel material 
Wood, on the other hand is highly anisotropic and therefore must be modelled to include its ductile and brittle response in the different directions. A comprehensive wood model is one which can entirely represent both the ductile and brittle behaviours. Accurate prediction of wood failure is even more critical at timber connections where either embedment, splitting or shear-plug failures can occur (see Fig. 2.3). The high compressive stresses imposed by steel on wood at the joint are ductile and lead to bearing failure, however, excessive shear or tensile stresses result in a more sudden and catastrophic brittle failure. Various modelling approaches have been adopted by researchers in attempt to simulate the mechanical behaviour of wood which are discussed here.

Modelling the anisotropic plasticity of wood can be achieved by using Hill's yield criterion (1950). Hill's criteria were developed as a modification of von Mises yield criteria for anisotropic materials. The criteria can be expressed in either $2 \mathrm{D}$ or $3 \mathrm{D}$ form and also in a simplified version when wood is modelled as orthotropic. Yield strength values for compression predominantly characterise the failure using Hill's formula and the different behaviour of wood in compression and tension is not accounted for (Audebert et al., 2011). The advanced version of original Hill's yield criteria is Tsai-Wu's criteria (1971), which can predict the brittle failure of wood in tension and shear. By the Tsai-Wu criteria, the resulting stresses in wood under loading can be used to evaluate regions of potential failure (Smith I. et al., 2006).

In examining the behaviour of a timber bolted joint, Bouchair (1995) modelled the elastic-plastic behaviour of wood with a plastic flow rule after Tsai-Wu's criteria. The case study was a timbersteel connection which was loaded in tension parallel to wood grain. A two-dimensional orthotropic wood model was verified to be good enough to predict the areas of potential failure as 
defined by the yield criteria. To include the effect of different bolt and connection geometries, a three-dimensional model was recommended. Remarkable in Bouchair's work is the influence of grain angle on the stress distribution at the joint. It was observed that even for loading in the direction of grain, the extent of wood grain angle can introduce significant plastic strains which eventually lead to unexpected failures at the joint level.

When wood joints are loaded in tension, wood around fasteners are predominantly loaded in compression and Hill's yield criteria, which was initially adapted to compressive yield stresses (Audebert et al., 2011) can perform well. This is demonstrated by the work of Kharouf et al. (2003) who applied Hill's criteria to predict the behaviour of a single bolted wood joint. Two models of wood; linear elastic and elastic-plastic orthotropic materials were applied to determine their relative suitability in wood modelling by correlation with experimental results. The bi-axial compression which wood experiences in the vicinity of the bolt hole was well represented by Hill's yield criteria. The elastic-plastic wood orthotropy model was found to have better accuracy in predicting the post-elastic deformation as opposed to the simple linear elastic orthotropy. Elasticplastic wood orthotropy also stood a better chance of predicting the failure load and failure mode observed in the experiment, hence a preferable choice over linear-elastic model when it comes to post-elastic deformation as wood crushes locally under bolts.

The behaviour of wood in the region of bolted connections is an important concept which needs critical examination as high stress concentrations develop in the fastener-wood area. Low loads on wood connections result in plastic deformation in the surrounding wood, but at high load-levels, the compressed wood zone increases which triggers tensile stresses perpendicular to grain 
(Kharouf et al., 2003). The high tension zones which develop result in brittle failures such as shear plug-outs of wood at the connection. The compressed wood zone at the connections can have a significant impact on the elastic-plastic response of wood (Oudjene and Khelifa, 2009). Oudjene and Khelifa (2009) by numerical modelling of a single bolted joint and correlation with published test results discovered that a coupling of anisotropic ductility with the densification of wood could simulate the non-linearity of wood until failure is reached. This approach was later extended by the same authors to include brittle failure. Correlation of the model with a three-point bending test result showed the possibility of predicting the load carrying capacity of wood with the inclusion of the brittle failure criterion (Oudjene and Khelifa, 2009).

Foregoing discussions on wood modelling have focused on the failure of continuum elements. Brittle modelling in continuum elements is relevant to capture the practical failure modes in wood and this can be done by incorporating the concepts of fracture mechanics or damage mechanics (Sandhaas, 2012).

A common fracture mechanics approach in material modelling is the Linear Elastic Fracture Mechanics (LEFM) method. Fundamental to the LEFM method is the presence of pre-existing cracks and a knowledge of their positions in the wood section (Smith I. et al., 2006). Khorassan (2012) applied LEFM to see the effects of natural cracks on the load carrying capacity of glulam beams. The finite element model was able to simulate well the influence of pre-existing cracks and how their propagation strongly affects the bending and shear capacities of beams.

The major limitation of the continuum element modelling lies in its inability to capture the nonlinearity of wood (Smith I. et al., 2006). Continuum Damage Mechanics (CDM) is one option for 
overcoming this limitation since it can by theory manipulate the stiffness matrix of wood to represent its non-linear behaviour (Sandhaas, 2012). A simplified 3D orthotropic model of wood was done by Cofer (1999) which included the concept of CDM. This was a preliminary assessment of the approach and it was demonstrated to have the potential of predicting the failure mechanisms. In Sandhaas' approach of CDM modelling of wood, a single surface of failure (normally adopted in continuum models) was considered inadequate to predict the mixed failure modes which are typical of a wood structure. Hence, the interaction between stresses was accounted for by introducing some respective damage variables of the possible failure modes. The stress interactions were modelled quite well and this was reflected in the load-slip curves which correlated well in the test and model results. Using the CDM approach, Sandhaas (2012) captured the non-linearity of wood and the failure modes well except for some inaccuracy which was found in the prediction of brittle failure within the embedment model. The densification effects of compressed wood, which wasn't included in Sandhaas' model, can make a significant difference in the plastic deformations and brittle failure prediction as Oudjene and Khelifa (2009) already observed. This is probably due to the high compressive zones of wood in the bolted regions which may eventually lead to brittle failure through densification effects as observed by Kharouf et al. (2003).

Contrary to the continuum modelling approach, the discrete modelling of wood accounts for the high heterogeneity of wood. In discrete modelling, the morphological features of the wood material are represented since strength and stiffness are assigned to the individual elements. Discrete models popularly known as lattice models consist of a lattice structure of longitudinal, lateral and diagonal elements which have a distinct stress-strain response (Reichert, 2009). Reichert (2009) in his lattice model of wood recorded a good comparison to test data for the load-slip response, 
brittle failure and crack development. This was modelled for wood in different load conditions and also joint configurations. The limitation of the discrete lattice model is the high computational demand since it requires a much larger number of numerical elements than the other modelling approaches.

In order to avoid the limitations of both the continuum and discrete models of wood, an innovative approach of hybrid modelling is currently being considered by other researchers. The hybrid modelling approach basically combines both continuum and discrete elements in a single model. This idea was adopted by Racher and Bocquet (2005) in examining the embedment behaviour of wood in dowelled connections. The wood material just underneath the dowel was modelled in two layers; the first layer consists of bar elements in the direction parallel to the grain which takes into account the elastic-plastic behaviour in compression parallel to grain and the second layer consists of joint elements to model the brittle tension perpendicular to grain. Other areas of the wood away from the fasteners were modelled using a linear orthotropic material. The model results agreed well with the test results for both stiffness and the load-carrying capacity of the connections in parallel and perpendicular to grain loadings. It was noted that the model result could be significantly affected by friction and shear strength especially in the post-elastic region where brittle effects dominate. The fundamental concept of the hybrid approach is to represent regions of high stress concentrations in wood by a lattice structure while other regions are considered as solid elements (Smith I. et al., 2006). 


\section{Chapter 3: Methodology}

\subsection{Introduction}

This chapter describes the numerical simulations which were conducted to determine the fire performance of the studied timber connections. A finite element model was developed to simulate the standard fire resistance tests which had been conducted by Sabah (2012) to assess the fire resistance of three different types of connections. Numerical simulations were performed using ABAQUS/Standard V6.112 (Hibbitt, 2011), a commercial finite element software. A threedimensional finite element model was developed to simulate the structural and fire behaviour of the connections as observed in the experimental work. A sequentially coupled thermal-stress analysis procedure was employed to simulate the mechanical and thermal behaviour of the modelled assembly in fire conditions. Experimental results served as the means of validating the developed model.

\subsection{Experimental Work (Sabah, 2012)}

To examine the fire performance of the timber connections, several fire resistance tests have been conducted at the Fire Research Facility of Carleton University. The research facility is located in Almonte, Ontario. Sabah (2012) examined the performance of typical steel-timber connections (beam-to-column connection) used in the timber construction industry by using fire resistance tests. The test setup was a glulam beam connected to steel columns as shown in Fig. 3.1. Three different types of connections were tested to see their relative performance under fire conditions: Concealed shear tab (CN), Exposed (EX) and Seated (SE) connections (see Fig 3.2). 


\subsubsection{Objective}

The main objective of the experimental work was to determine the key parameters which govern the fire performance of these connections.

\subsubsection{Test Description and Procedure}

A typical hybrid steel-timber frame of a building structure was built and used as case study. It consisted of two structural steel columns (W150 x 37) which were connected to a glulam beam of dimension 140x191x1900 mm (see Fig. 3.1). The connection of the beam to the columns comprised of three different configurations which are Concealed shear tab (CN), Exposed (EX) and Seated (SE) connections as seen in Fig. 3.2.

Assessing the fire resistance of the test configuration described above involved observing its structural resistance when subjected to fire. The whole structure was inserted in a furnace and subjected to a standard-time temperature curve (as described in Fig. 2.1 in Chapter 2). The standard time-temperature curve used was according to CAN/ULC-S101 (2007). The furnace was equipped with several thermocouples (TC) used to regulate the furnace temperature to follow the standard time-temperature curve and this is illustrated in Fig. 3.3. Plate thermometers (PT) were also installed to record temperatures near the assembly surface. Plate thermometer readings was used as the temperature boundary condition in the model.

The test was done by first loading the assembly at one-third points along the beam span. The load was maintained on the assembly for about 20 minutes prior to the beginning of the test, and then the assembly was subjected to elevated temperatures (following the standard time-temperature 
curve discussed previously) until failure was reached. The load applied was a ratio of the connections' design load capacity under ambient temperatures according to CAN/CSA-O86-09 (2009). This applied load was maintained while the whole assembly heats up to simulate the effect of dead loads present in the building during fire occurrence.

The experimental test setup was repeated with a variation of the bolt sizes at the connections and the load ratio on the assembly. A bolt size of $12.7 \mathrm{~mm}$ was used for the seated connection and a $19.1 \mathrm{~mm}$ was used for the other two connections. Corresponding load ratios $30 \%, 60 \%$ and $100 \%$ were applied on the assembly.

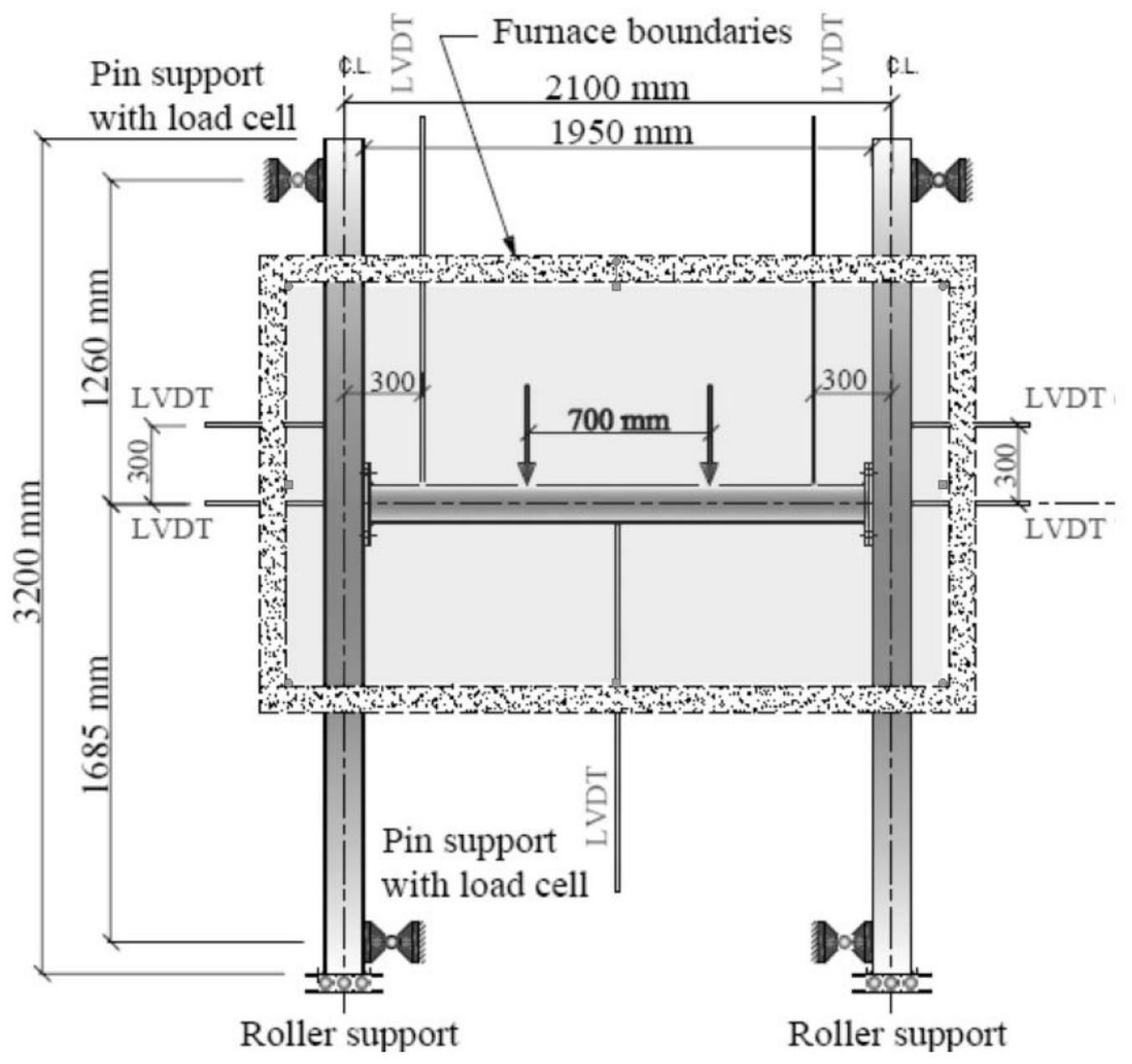

Fig. 3.1 Schematic of Test Configuration (Adapted from Sabah, 2012) 


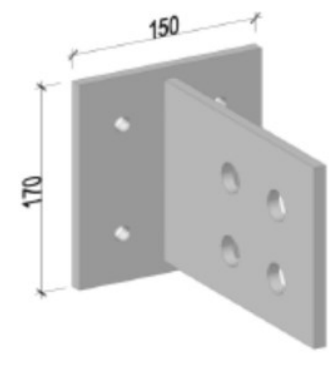

(a) Concealed ( $\mathrm{CN})$

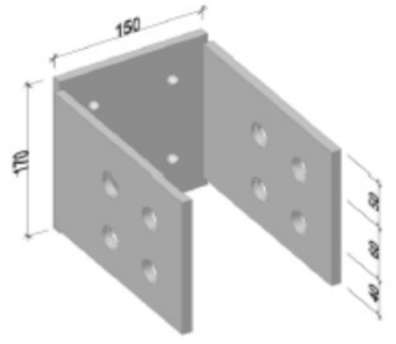

(b) Exposed (EX)

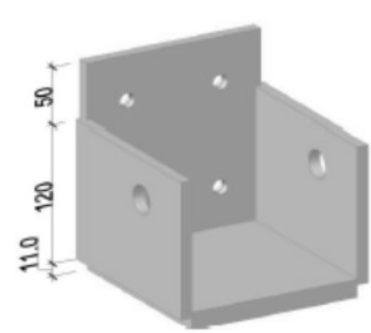

(c) Seated (SE)

Fig. 3.2 Connection Configurations in Test (Adapted from Sabah, 2012)

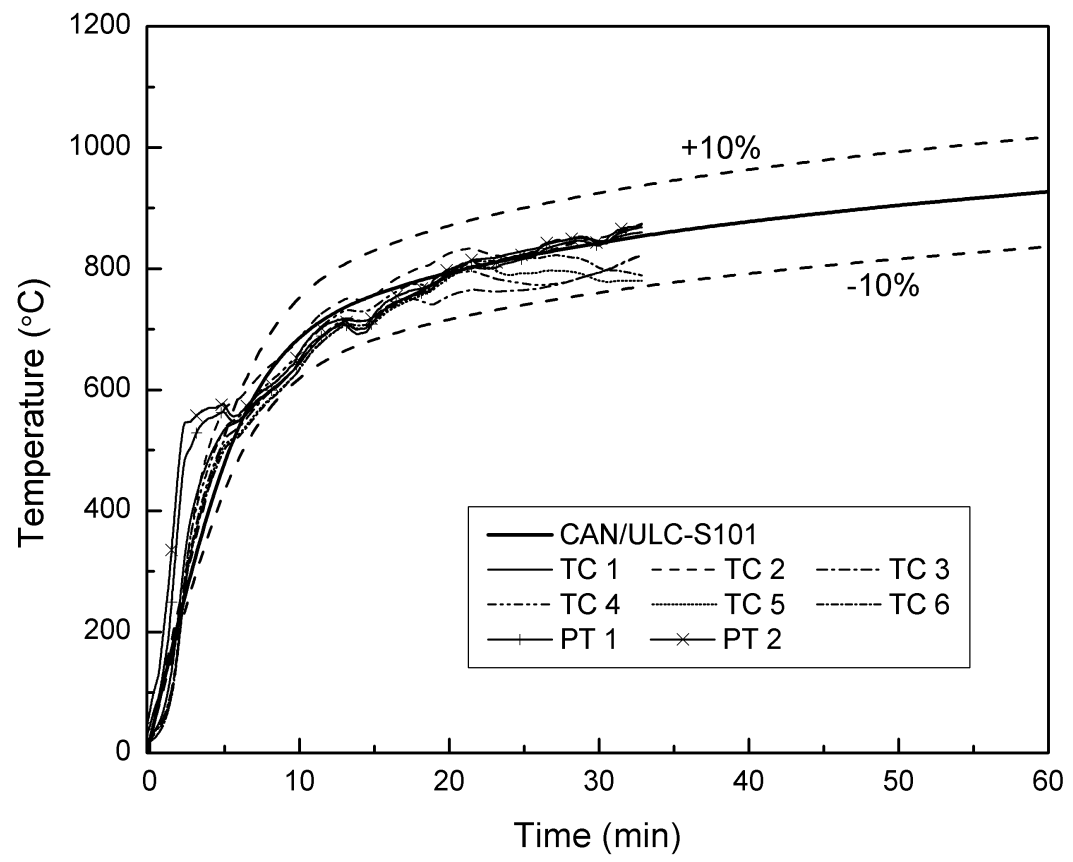

Fig. 3.3 Calibration of Furnace Temperatures with Time-Temperature curve of CAN/ULC-S101 (Adapted from Sabah, 2012)

During the test, under a constant load ratio, the assembly heats up when exposed to fire, causing its strength and stiffness to degrade until it loses its capacity to resist the load. The time to reach the ultimate failure of the assembly is termed as its fire resistance and was the main output. Other parameters such as time-temperature distribution within the glulam beam, charring characteristics 
of wood and the displacement of the test assembly were also measured. Fig. 3.4 shows the concealed connection assembly before and after the fire resistance test.

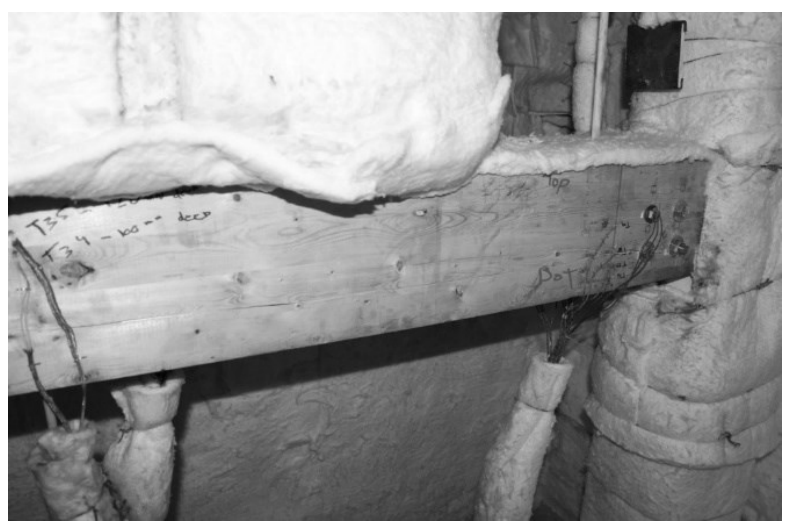

(a) Before testing

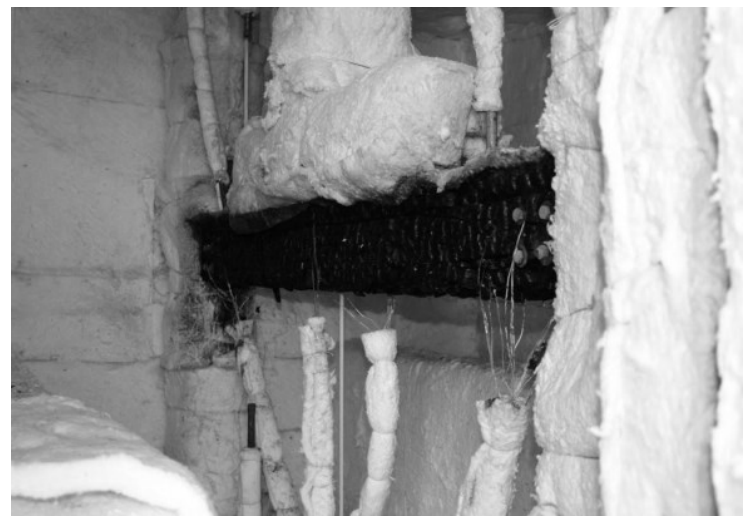

(b) After testing

Fig. 3.4 Test Assembly before and after testing (Adapted from Sabah, 2012)

\subsection{Numerical Modelling}

Connections are critical links in a building structure and necessary for maintaining the overall integrity of the structure. The behaviour of these connections in ambient conditions is well addressed in structural design codes but their behaviour at elevated temperatures has not been thoroughly studied. Once the behaviour of individual materials (steel and wood) at elevated temperatures are known, their complex interaction at the connection level could be well understood.

An alternative approach to full-scale fire resistance test of an assembly is numerical analysis for fire resistance assessment. Useful design equations to calculate the fire resistance of the connections can be derived when numerical simulations are validated with experimental results 
and this is demonstrated by the work of researchers (Peng, 2009; Racher et al., 2010; Audebert, 2011) in recent years. Experimental tests accompanied with numerical results have been able to highlight the effect of key design parameters such as bolt diameter, thickness of wood members, load capacity and protections, on the fire resistance of timber connections. It is the main objective of this research to simulate the fire resistance tests as described in the foregoing section 3.2 and also to confirm the various influencing parameters which have been portrayed in the experimental test results.

The finite element method will be used to simulate the fire resistance tests. Simulating a structuralfire resistance test will involve modelling three main components:

1. Fire model

2. Heat transfer model

3. Structural model

The fire model and heat transfer models are required to simulate the thermal effects from the fire while the structural model simulates the mechanical behaviour of the connections. The finite element software package used in this research is ABAQUS 6.112/Cae which has the capability of modelling both thermal and mechanical effects on a structure.

\subsubsection{Finite Element Analysis Procedure}

Simulating the overall behaviour of the fire resistance test requires a procedure which incorporates the mutual dependence of the thermal and mechanical behaviour of individual member materials. Coupling of the thermal effects and the mechanical stresses can be achieved in 
ABAQUS, using one of the two alternative procedures (Abaqus 6.112 Manual, 2011): fully coupled thermal-stress analysis or sequentially coupled thermal-stress analysis.

The fully coupled thermal-stress analysis is suitable for systems where the thermal and mechanical solutions affect each other significantly. Examples include systems in which friction can serve as a source of heating and the effect of gap variation at contact areas, which affect the conductance of heat in the system (Abaqus 6.112 Manual, 2011). The fully coupled thermal-stress procedure can be used for such analyses to obtain simultaneous stress/displacement and temperature field solutions of the system. Sequentially coupled thermal-stress on the other hand is a simplified version of the coupled thermal-stress procedure where the stress solution is dependent on the temperature solution with negligible or no inverse dependency. A fully coupled thermal-stress procedure can be very complex and time consuming especially for complicated systems which may lead to non-convergence or inaccurate solutions. Conducting a sequentially coupled thermalstress analysis is less complex and is done in two stages: an uncoupled heat transfer analysis is first performed to obtain the time-varying temperature field in the system, then those time-varying temperature field results are input into a stress analysis as a predefined field.

The sequentially coupled thermal-stress procedure was adopted in this research since the effects of stress (in the hybrid timber steel connection) on the thermal solution are negligible. The following sections describe the modelling approach for both the thermal and structural analysis in detail. 


\subsubsection{Finite Element Discretization and Meshing}

In the discretization process, all parts of the assembly were first created before they could be assembled. In ABAQUS, the 3D deformable base feature was used for modelling each part. Extrusion and cut features were employed to model all components as well as their discontinuous regions. Welded regions in the individual connection brackets were modelled as monolithic with the steel plates. Fastener components such as bolts, nuts and washers were lumped together as a single part in the model for simplicity (see Fig. 3.5). This was done to reduce numerous contact interactions which would otherwise be present when the several parts are modelled separately. The glulam beam was partitioned into several lamellae (4 layers about $48 \mathrm{~mm}$ thick) in all the numerical simulations. This simulates the natural discontinuities which are found in the manufactured glulam beams. Fig. 3.5 also shows a manufactured glulam beam with several lamellae as compared to its finite element model.

After partitioning the glulam beam, a local material orientation was assigned to each lamella. In the layers of the glulam beam tested, the growth rings from the wood log followed a similar pattern depicted in Fig. 2.8, in which the origin of the growth rings is located at centre of the lamella width. Hence, a cylindrical coordinate system in ABAQUS was used to define the orientation of the wood fiber in each of the lamella. The cylindrical coordinate system has three major principal axes (Radial, R, Tangential, T and Longitudinal, L), which was used to describe the orientation of the numerous discretized material points in the glulam layer. The strength and elastic properties of the wood material were then assigned to each lamella 


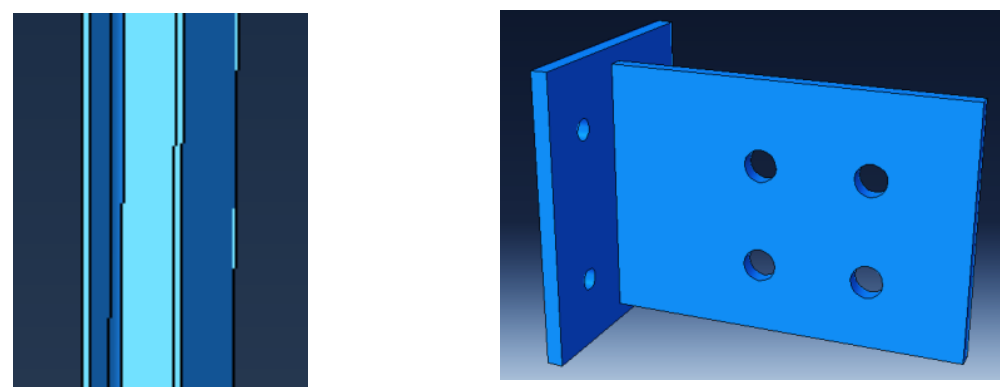

Concealed plate

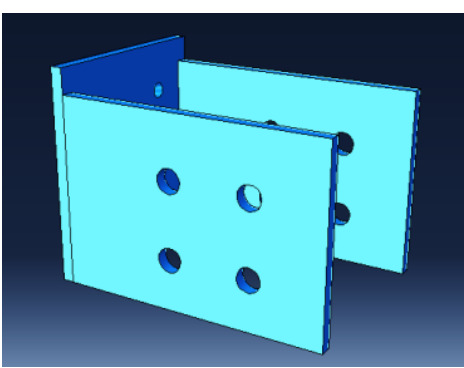

Exposed plate

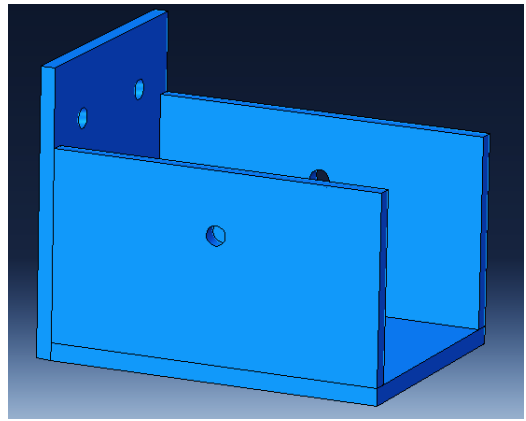

Seated plate

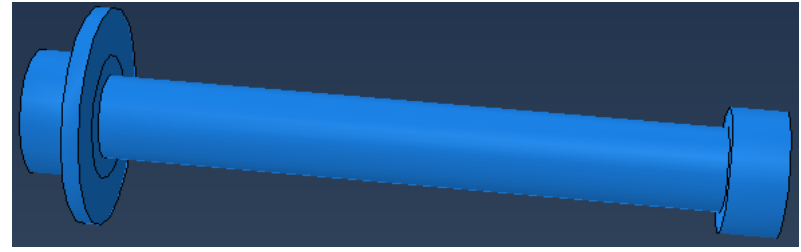

Bolt

Column
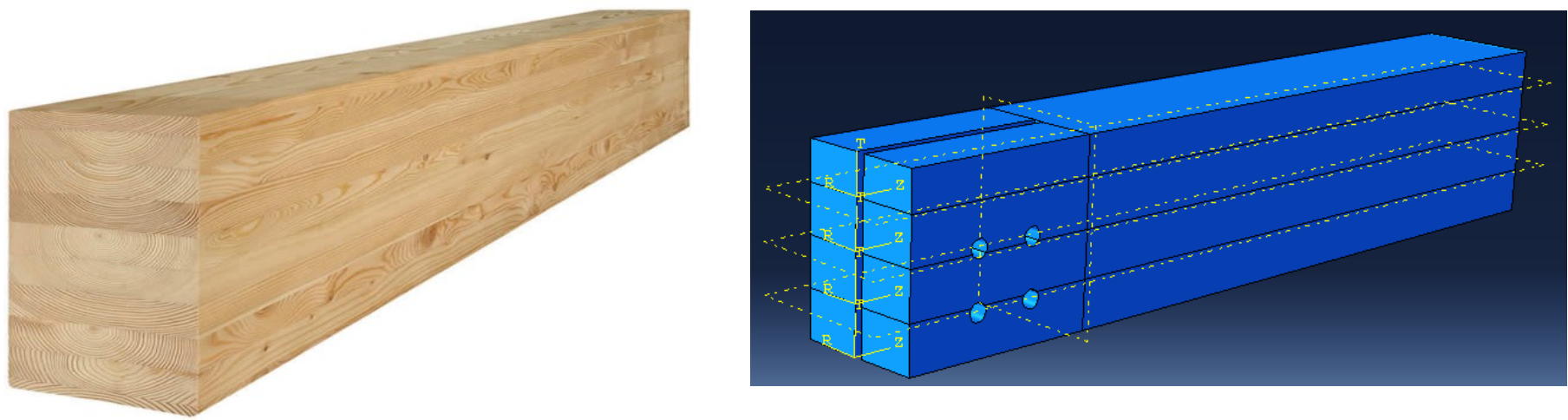

Glulam beam

Fig. 3.5 Modelling Individual Components of the Assembly 
The mesh geometry of any component was generally controlled by geometry, discontinuities and contact interactions of the assembly. Mesh sizes were adopted to suit the smoothness of each component's geometry. The discontinuous and critical contact areas such as bolt-hole regions were carefully meshed to ensure accuracy of the model. The contact interaction formulation in ABAQUS requires that the master surface has a coarser mesh compared to the slave surface (Abaqus 6.112 Manual, 2011). Master and slave surfaces are roles which are assigned to surfaces in the contact interaction formulation of a numerical simulation (Abaqus 6.112 Manual, 2011). Smaller mesh sizes were used in the stress-concentrated regions to capture stress distribution and transfer while coarser mesh sizes were used in the other regions of the assembly (see Fig. 3.6).

The mesh size used for the assembly was the same for both the heat transfer and structural models. This was done so that the finite element nodes were coincident in order to facilitate the transfer of temperature-time history field data from the heat transfer model to the structural model. Significant deformations in the model's structural behaviour could interrupt the transfer of temperature results from the heat transfer model at various points in the assembly. The structural model was adapted after the dominating brittle response observed in the test, hence deformations resulting from a more ductile response were negligible in the assembly's response. This means a similar mesh size which was adopted for both the heat transfer and structural models can be considered an adequate representation.

The size of the meshes is very important since it determines the time for completing an analysis as well as the accuracy of the solution. Several simulations were done with different mesh sizes in order to choose the mesh that gives good results during the validation of the model. 


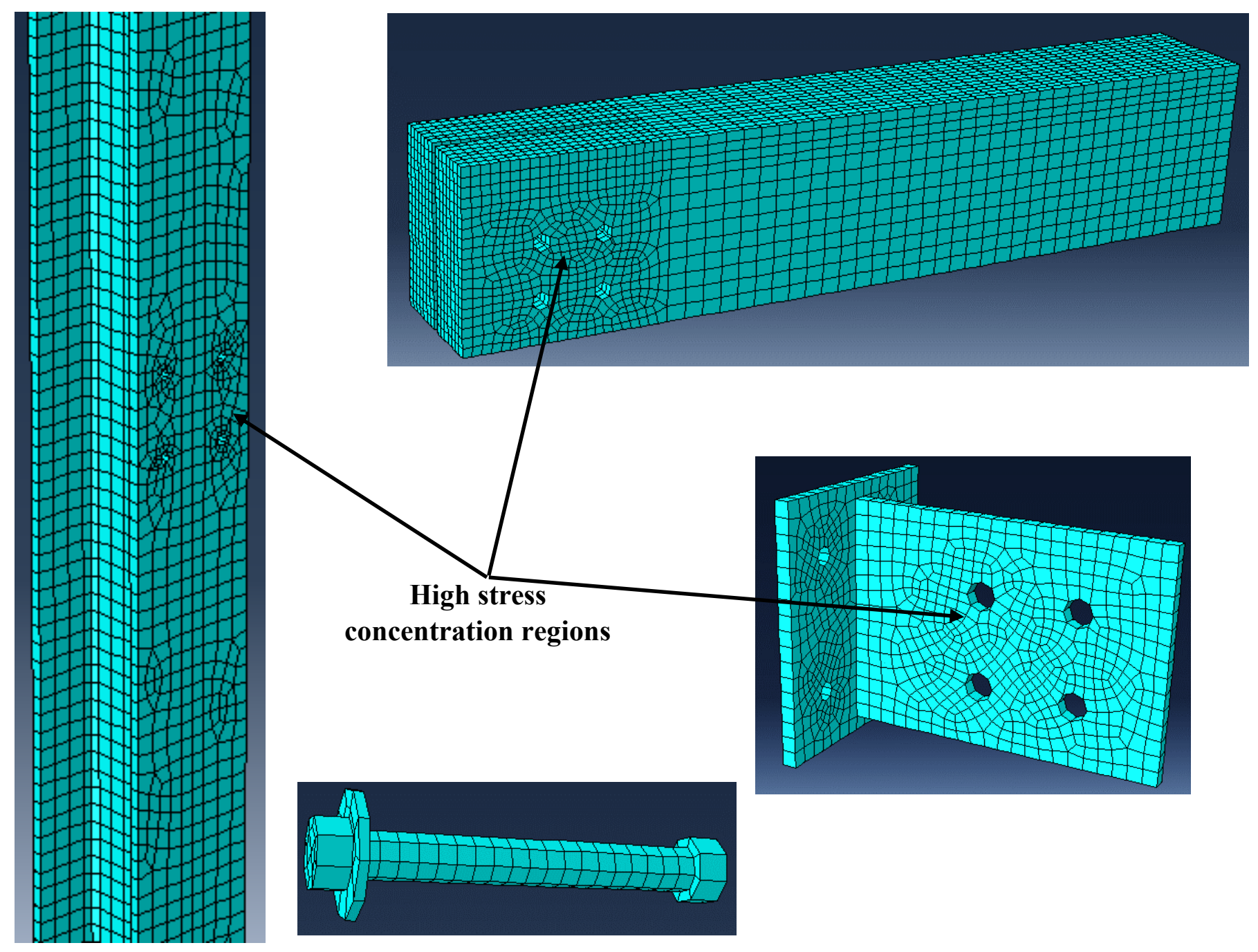

Fig. 3.6 Meshing of Assembly Components

\subsubsection{Thermal Modelling}

\subsubsection{Assigning Finite Elements and Material Properties}

Three-dimensional solid diffusive elements (DC3D8) in ABAQUS were used to define all components of the assembly for the heat transfer model (Abaqus 6.112 Manual, 2011). DC3D8 are eight-node brick elements that have only nodal temperature degrees of freedom in a heat transfer analysis. 
Thermal properties of Density $(\rho)$, Conductivity $(k)$ and Specific heat capacity $\left(C_{p}\right)$ were assigned to the respective materials. The temperature dependence of $k, \rho$ and $C_{p}$ were computed for steel and timber materials using reduction factors from literature as described in section 2.6 and are tabulated in the Appendix. The density of steel is taken as a known value of $7850 \mathrm{~kg} / \mathrm{m}^{3}$ and that of the glulam beam was obtained from the manufacturer as $560 \mathrm{~kg} / \mathrm{m}^{3}$.

\subsubsection{Fire Model and Heat Transfer Analysis}

In the experimental fire resistance test, the heat source in the furnace was a propane burner. The heat from the propane burner increases the temperature of air in the furnace and the furnace boundaries beyond ambient conditions. The furnace enclosure and its boundaries, which are at high temperatures, supply heat to the boundaries of the test assembly through convective and radiative heating. The top of the beam was protected in the test to simulate the presence of a floor system that would be found in a typical building. The steel columns were also protected.

The heat to the exposed surfaces of the assembly was therefore modelled as a uniform heat flux, $\dot{q}^{\prime \prime}\left(\mathrm{W} / \mathrm{m}^{2}\right)$ according to equation 3.1 which is made up of the components of both convective and radiative heat.

$$
\dot{q}^{\prime \prime}=h_{c}\left(T_{f}-T_{s}\right)+\emptyset \varepsilon_{f f} \sigma\left(T_{f}^{4}-T_{s}^{4}\right)
$$

Where: $h_{c}=$ convection coefficient $\quad T_{f}=$ furnace temperature

$T_{S}=$ surface temperature of assembly $\quad \emptyset=$ configuration factor

$$
\varepsilon_{f f}=\text { effective emissivity } \sigma=\text { Stefan }- \text { Boltzman constant, } 5.67 \times 10^{8} \mathrm{~W} / \mathrm{m}^{2} \mathrm{~K}^{4}
$$


In the ABAQUS model, the estimated heat flux was incorporated as a boundary condition to the modelled assembly surface through a user DFLUX subroutine developed by Peng, 2010 (see Appendix). The DFLUX subroutine is a set of computer programming instructions which is incorporated in an ABAQUS simulation for applying thermal loads on a model assembly. With the DFLUX subroutine, the heat flux to the boundary of a model can be applied as a distributed flux to the exposed surfaces. The heat flux can be applied non-uniformly as a function of position, time, temperature, element number and integration point number of the assembly during the heat transfer analysis (Abaqus 6.112 Manual, 2011).

In Fig. 3.7, a sample of time-temperature curves obtained from four plate thermometers (PT1, PT2, PT3 and PT4) in the fire resistance test are compared with the CAN/ULC S101 (2007) standard time-temperature curve. The temperature variation recorded by the plate thermometers shows a similar pattern to the standard time-temperature curve. This is because the boundary temperature of the test assembly was regulated in order to be in close approximation to the standard fire curve (Sabah, 2012). The average of the plate thermometer temperatures recorded from the test were the values of $T_{f}$ in equation 3.1. The value of $T_{f}$ varied during the exposure time of the assembly to fire and it was necessary to compute the heat flux to the assembly boundaries at every point in time. The plate thermometer temperatures (see Fig. 3.7) shows that the distribution of heat on the assembly boundary is quite non-uniform even though the furnace temperature was regulated to closely follow the CAN/ULC S101 standard time-temperature curve. To simplify the non-uniform distribution of heat flux on the assembly boundary, the CAN/ULC S101 (2007) standard fire curve (as seen in Fig. 3.7) was taken as an average approximation of the plate thermometer temperatures 
that were recorded. These temperatures were applied as a uniform distribution on the assembly and used as the variation of $T_{f}$ values in equation 3.1 for the heat transfer model.

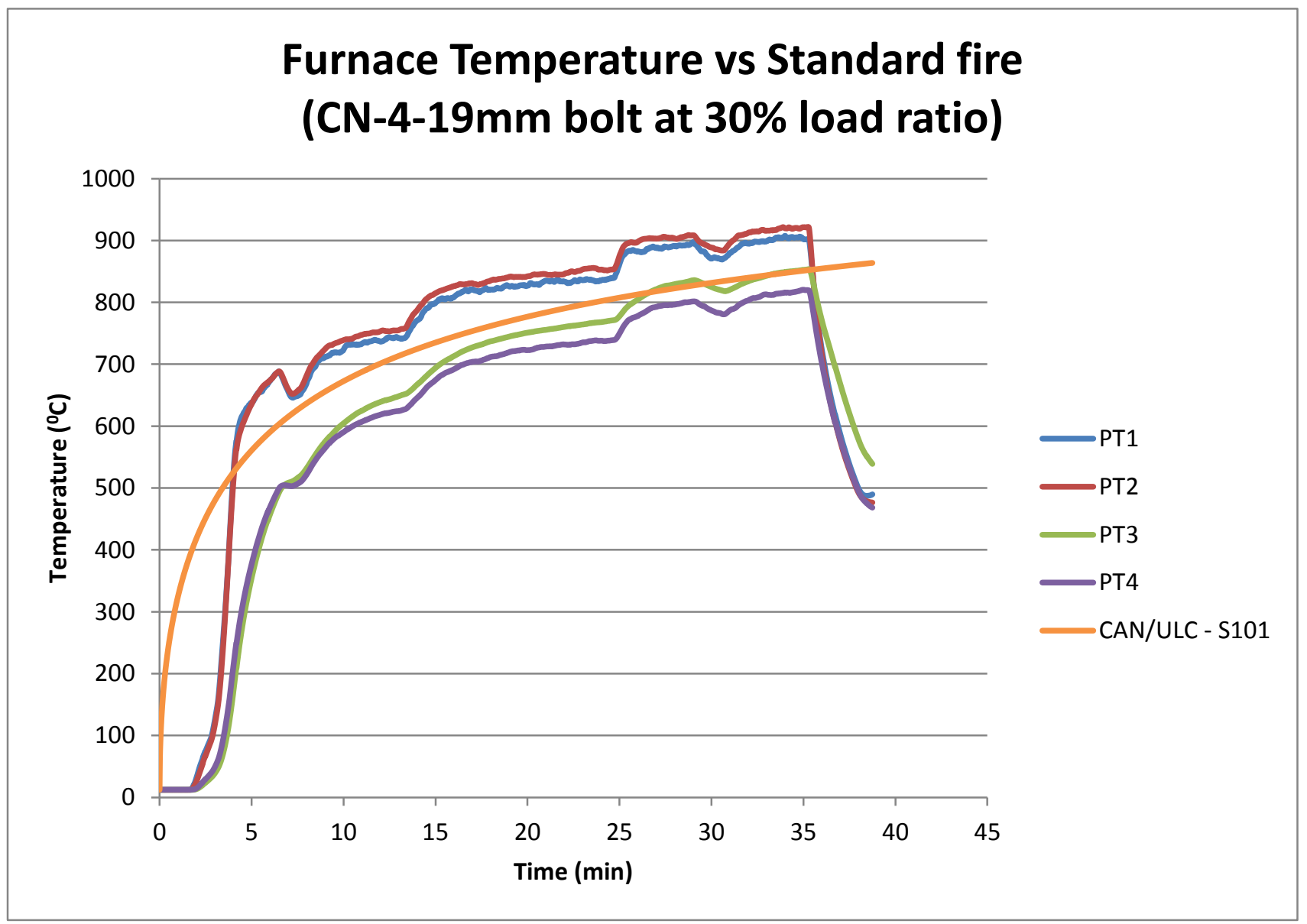

Fig. 3.7 Time-temperature Curves from Test and Standard (Sabah, 2012)

The transient conduction of heat within the assembly is governed by the three dimensional heat transfer equation as shown in equation 3.2.

$$
\rho c \frac{\partial T}{\partial t}=\frac{\partial}{\partial x}\left(k \frac{\partial T}{\partial x}\right)+\frac{\partial}{\partial y}\left(k \frac{\partial T}{\partial y}\right)+\frac{\partial}{\partial z}\left(k \frac{\partial T}{\partial z}\right)+\mathrm{S}
$$

Where, $\rho=\operatorname{density}\left(\mathrm{kg} / \mathrm{m}^{3}\right) \quad c=$ specific heat capacity $(\mathrm{J} / \mathrm{kg} / \mathrm{K}) \quad t=$ time $(\mathrm{s})$

$$
k=\text { conductivity }(\mathrm{W} / \mathrm{m} / \mathrm{K}) \quad S=\text { source of heat }\left(\mathrm{W} / \mathrm{m}^{3}\right) \text { and } T=\text { temperature }(\mathrm{K})
$$


Individual elements consisting of the steel column, glulam beam, bolts and plate were assembled together in ABAQUS and their relative connectivity was defined. Contact surfaces in the assembly were present at the bolt-wood, bolt-plate and wood-plate contact areas. Heat transfer between contacting members of the assembly was achieved through the thermal conductance feature, which is a surface interaction property in ABAQUS.

An uncoupled heat transfer analysis was conducted on the entire assembly. Before the analysis, it was necessary to prescribe the ambient temperature of the entire modelled assembly prior to the start of the test. This initial condition was defined using the "predefined field" feature in ABAQUS. An initial predefined temperature of $20{ }^{\circ} \mathrm{C}$ was applied to the whole assembly before the start of the analysis. During the analysis, heat flux was supplied to the exposed surfaces of the assembly (see Fig. 3.8) and the heat penetrated into the modelled test assembly over time. The full Newton method was adopted in ABAQUS/Standard for the three dimensional transient heat transfer analysis. The Newton method is an iterative scheme which is capable of resolving potential nonlinearities during the heat transfer analysis. The sources of such non-linearities include the nonlinear temperature-dependent properties of the materials (thermal properties) and radiation heat flux effects (Abaqus 6.112 Manual, 2011).

The output from the analysis was a nodal temperature-time history at all points in the assembly during the duration of the fire exposure. The temperature-time distribution within the assembly was then applied as a predefined time-varying field in the subsequent structural model 


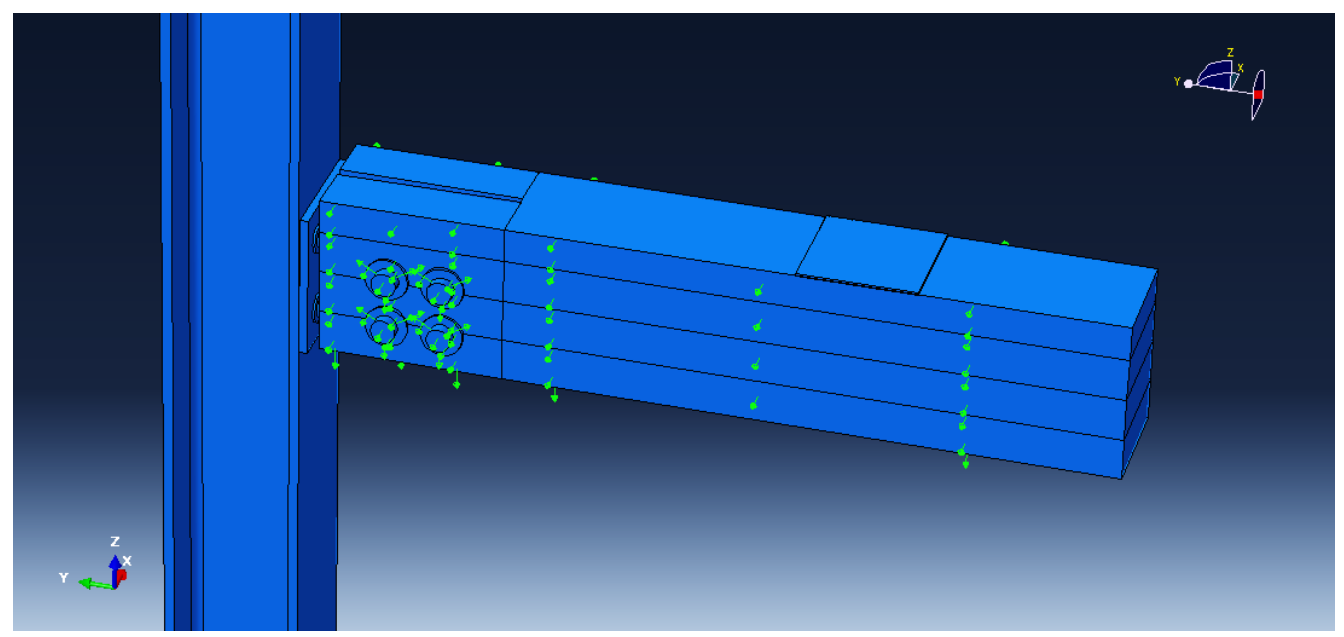

Fig. 3.8 Assembled Model with Heat Flux Boundary Condition (Concealed Connection)

\subsubsection{Structural Modelling}

\subsubsection{Assigning Finite Elements and Material properties}

Three dimensional continuum elements (C3D8R) were assigned to all the components of the assembly. C3D8R are eight-node brick elements in ABAQUS which are capable of capturing the deformations in a mechanical system with a reduced integration formulation. The ABAQUS "hourglass control" feature of these element types was used to prevent excessive deformations during the analysis process.

The selection and definition of appropriate material properties is critical to obtain results and observations in the finite element model which correlate well with the experimental results. Strength and elastic properties are the important parameters for stress/displacement analysis in a structural model. The elastic properties determine the stiffness response of the material to applied stresses while the strength properties define the onset of damage and failure in the material. In a 
coupled thermal-stress analysis procedure, the temperature dependence of the material properties is necessary for the structural model because it enables the material properties at their corresponding temperatures to be used in the model during the analysis. This allows the applied time-varying temperature field from the heat transfer analysis to effect the stiffness and strength of the structural analysis. A sequentially coupled thermal-stress analysis is adopted in this numerical simulation, hence the temperature dependence of the stress solution was needed.

There are two main ways of determining the temperature-dependence of strength and elastic properties namely, transient or steady state thermal equilibrium of a loaded specimen (Salem, 2012). The transient type of results are obtained by maintaining a constant load on the element while subjected to elevated temperatures. The steady state type on the other hand involves testing specimens which have been pre-heated to a certain temperature. The results obtained from both tests can be quite different (Salem, 2012). The results from the transient type of test are reported in Eurocode 3 (2001) and Eurocode 5 (2004) for steel and wood materials respectively (Salem, 2012), which are used in the model of this thesis.

The temperature dependence of both steel and wood materials have been discussed in section 2.4. Reduction factors at elevated temperatures for both materials were adopted from various literature (Buchanan, 2002; Eurocode 5, 2004; Eurocode 3, 2001; Wood Handbook, 2010) and applied accordingly to the material properties as given in the Appendix.

Steel is an inelastic material which depicts both elastic and plastic behaviour when subjected to stresses. The elastic-plastic behaviour of steel was idealized as bilinear curve with strain hardening 
of steel (see Fig. 3.9) and used in the model. The elastic-plastic response of steel was defined to calculate its elastic deformations, yielding and permanent deformations during analysis. The model input values for the steel material was obtained from literature and are shown in the Appendix.

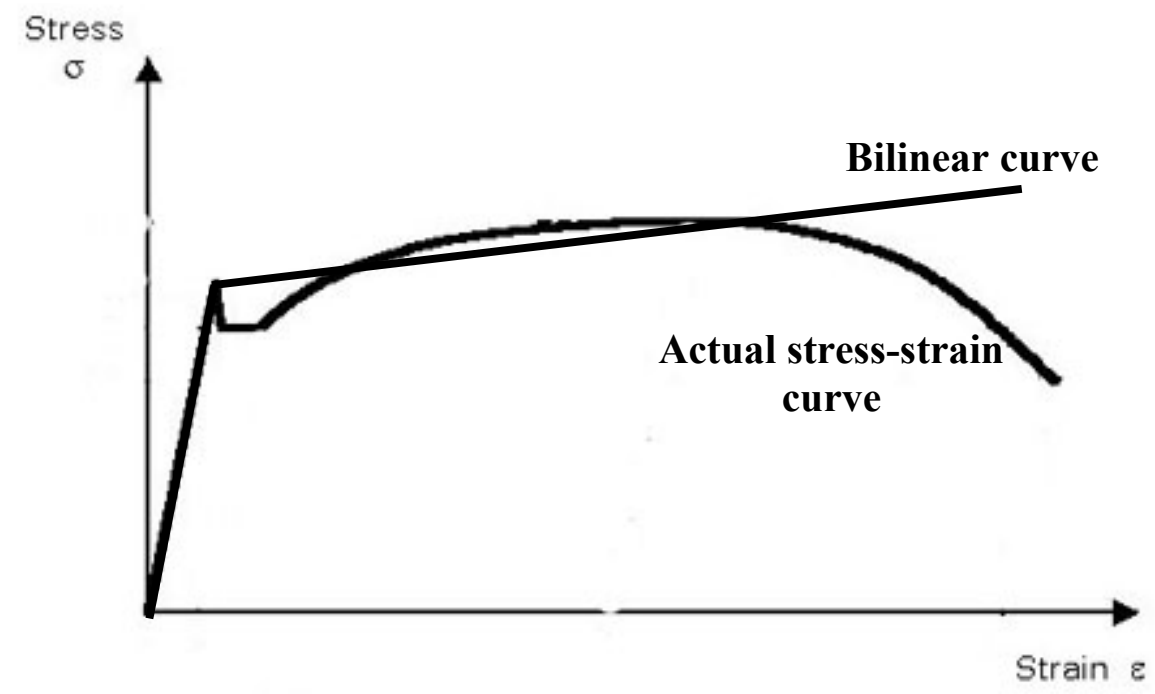

Fig. 3.9 Bilinear Approximation of the Elastic-plastic curve of Steel

Wood unlike steel is a highly anisotropic material with directional dependence of its strength and elastic properties. Twenty-one independent elastic (21) constants would be required to define the anisotropy of wood but the glulam beam in this model was simplified as an orthotropic material where nine (9) elastic constants were used to define its orthotropy. It is important at this stage to define the material orientation for the elastic properties as they relate to the Longitudinal (L), Radial (R) and Tangential (T) directions of wood. Fig. 3.10 shows the directionality of wood which was used to define the local material orientation of each glulam lamella (see Fig. 3.5). 


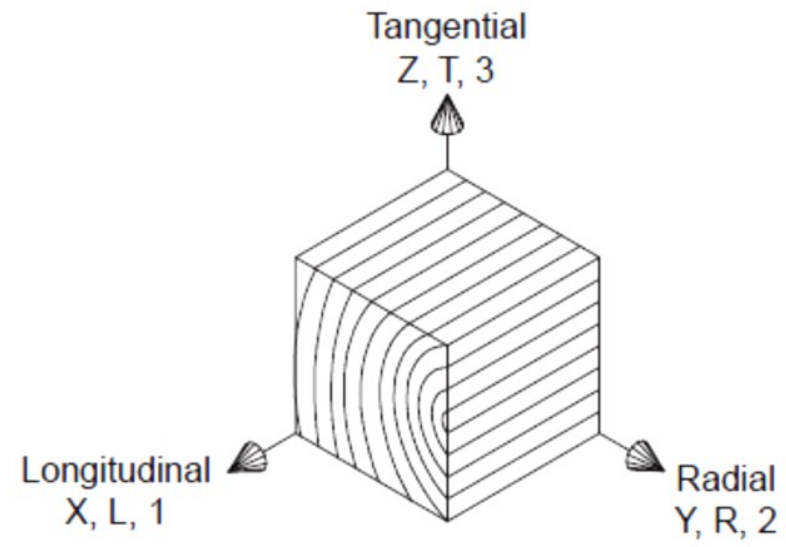

Fig. 3.10 Material Orientation of Wood (Adapted from Sandhaas, 2012)

The choice of the elastic properties of glulam wood is based on data from the manufacturer, reported values in the wood handbook (Wood Handbook, 2010) and literature (Sandhaas, 2012). In Table 3.1, values of some selected wood species are summarized in the form of ratios of wood elastic properties. These values were adapted from the Wood Handbook (2010) for some wood species which are normally used to manufacture glulam in Canada (Wood Design Manual, 2005).

Table 3.1 Elastic ratios of wood species (12\% moisture content) (Wood Handbook, 2010)

\begin{tabular}{|l|l|l|l|l|l|}
\hline Wood Species & $\boldsymbol{E}_{\mathbf{2}} / \boldsymbol{E}_{\mathbf{3}}$ & $\boldsymbol{E}_{\mathbf{1}} / \boldsymbol{E}_{\mathbf{3}}$ & $\boldsymbol{G}_{\mathbf{1 3}} / \boldsymbol{E}_{\mathbf{3}}$ & $\boldsymbol{G}_{\mathbf{2 3}} / \boldsymbol{E}_{\mathbf{3}}$ & $\boldsymbol{G}_{\mathbf{1 2}} / \boldsymbol{E}_{\mathbf{3}}$ \\
\hline Douglas-fir & 0.05 & 0.068 & 0.064 & 0.078 & 0.007 \\
\hline Fir, subalpine & 0.039 & 0.102 & 0.07 & 0.058 & 0.006 \\
\hline Hemlock, Western & 0.031 & 0.058 & 0.038 & 0.032 & 0.003 \\
\hline Larch, Western & 0.065 & 0.079 & 0.063 & 0.069 & 0.007 \\
\hline Average value & 0.046 & 0.077 & 0.059 & 0.059 & 0.0058 \\
\hline
\end{tabular}


The local orientation of the glulam parallel-to-grain axis coincides with the global z-axis of the ABAQUS model, which is also conventionally labelled axis 3 in the model, hence was used when defining the material elastic properties in terms of axes 1, 2 and 3 (see Table 3.1). The average values of the respective ratios were adopted from Table 3.1 to estimate the other values for $E_{2}, E_{3}$, $G_{13}, G_{23}$ and $G_{12}$ The value of the longitudinal elastic modulus obtained from the manufacturer was $E_{3}=13,000 \mathrm{MPa}$. The other elastic constants were then computed based on their ratios to $E_{3}$.

The glulam beam in this model was further considered to be transversely isotropic, in which the same elastic values were used in both directions perpendicular to grain of wood (i.e. the radial and tangential directions). These directions typically have similar properties (Sandhaas, 2012). This effectively reduces the elastic parameters of wood to about six (6) independent constants. An average of the perpendicular-to-grain values, which was computed using the values in Table 3.1, was in close approximation to what Sandhaas (2012) used in her model, hence her values were used for the glulam wood in this model as shown in Table 3.2.

The orthotropic elastic properties of wood were assigned to each glulam lamella through ABAQUS material engineering constants in their respective directions. The elastic properties and their temperature dependence are given in the Appendix.

The plasticity of wood wasn't incorporated in this model. This is because, the approach adopted in modelling the structural damage and failure of the wood accommodates only linear elastic material properties (see discussion in section 3.3.4.2). 
Table 3.2 Approximate Elastic constant values used in the model

\begin{tabular}{|c|c|c|c|c|c|}
\hline \multicolumn{6}{|c|}{ Average Elastic ratio (Wood Handbook, 2010) } \\
\hline & $E_{2} / E_{3}$ & $E_{1} / E_{3}$ & $G_{13} / E_{3}$ & $G_{23} / E_{3}$ & $G_{12} / E_{3}$ \\
\hline & 0.046 & 0.077 & 0.059 & 0.059 & 0.0058 \\
\hline \multicolumn{6}{|c|}{ Elastic constants computed based on Table 3.1 and the manufacturer value for $E_{3}$} \\
\hline$E_{3}{ }^{*}(\mathrm{MPa})$ & $E_{2}(\mathrm{MPa})$ & $E_{1}(\mathrm{MPa})$ & $G_{13}(\mathrm{MPa})$ & $G_{23}(\mathrm{MPa})$ & $G_{12}(\mathrm{MPa})$ \\
\hline 13,000 & 598 & 1,001 & 767 & 767 & 75.4 \\
\hline \multicolumn{6}{|c|}{ Elastic constants from Sandhaas (2012) } \\
\hline 13,000 & 860 & 860 & 810 & 810 & 59 \\
\hline
\end{tabular}

* value from manufacturer

\subsubsection{Structural Damage and Failure Modelling}

As previously discussed in chapter 2, the modelling of wood should include the progressive damage and subsequent failure under applied stresses. The Linear Elastic Fracture Mechanics (LEFM) approach was adopted in modelling the glulam beam. This approach was used to model brittle failure in the continuum finite element model of wood. The modelling approach accommodates only the linear elastic material properties of wood and the wood material fails in a brittle manner after sustaining a level of elastic deformations. In ABAQUS, the Extended Finite Element Method (XFEM) applies the principles of LEFM to model crack initiation and propagation in the wood. The method used by XFEM is similar to the Virtual Crack Closure Technique (VCCT), which models the separation of lamina that are partially bonded together (Abaqus 6.112 Manual, 2011). XFEM-LEFM by default requires the presence of a crack. The 
crack can be one which is pre-existing or forms during the analysis. Crack development in the wood is governed by the damage initiation criteria and damage evolution laws.

Damage initiation is needed first to prescribe the onset of cracks at any position in the wood material under stress. The glulam beam in this model is subjected to concentrated loads perpendicular to the beam's span. This type of loading induces bending stresses at any section in the beam which comprise mainly of compressive and tensile forces. Between the loads and the supports, the coupling of compressive and tensile stresses triggers diagonal tension shear stresses which eventually form cracks. In the wooden beam, the shear span is the region between the loads and the supports. This region is susceptible to the formation of cracks due to dominant shear stresses. The stress concentration at the wood-bolt contact area makes that area particularly susceptible to crack development.

Shear failure can be more catastrophic as compared to bending failure in wooden beams. This can be attributed to brittle lignin matrix in the wood cell wall, which introduces natural planes of weakness along the grain of the wood fibres. The predominant type of shear failure in wood is the longitudinal shear (see Section 2.4.1.2), which occurs parallel to the wood grain. In ABAQUS, the damage criteria used for the initiation of cracks is the Maximum Nominal Stress (MAXS), which is a shear stress damage criterion. The fracture criterion, $f$ is given in equation 3.3 and it defines the onset of damage in the wood. It is a ratio of the respective shear stresses resulting from applied forces to the shear capacities of the material in their respective directions.

$$
f=\max \left\{\frac{\left\langle t_{n}\right\rangle}{t_{n}^{o}}, \frac{t_{s}}{t_{s}^{o}}, \frac{t_{t}}{t_{t}^{o}}\right\} \ldots \ldots \ldots \ldots \ldots \text { Equation }(3.3)
$$


The parameters $t_{n}, t_{s}, t_{t}$ are components of the nominal shear traction vector, $t$ in a threedimensional form (see Fig. 3.11). They represent the normal and shear separations of a cracked element as obtained from the solution field during analysis. The component $t_{n}$ is normal to the cracked surface while $t_{s}$ and $t_{t}$ are values of the two shear components which lie in the plane of the cracked surface (Abaqus 6.112 Manual, 2011).

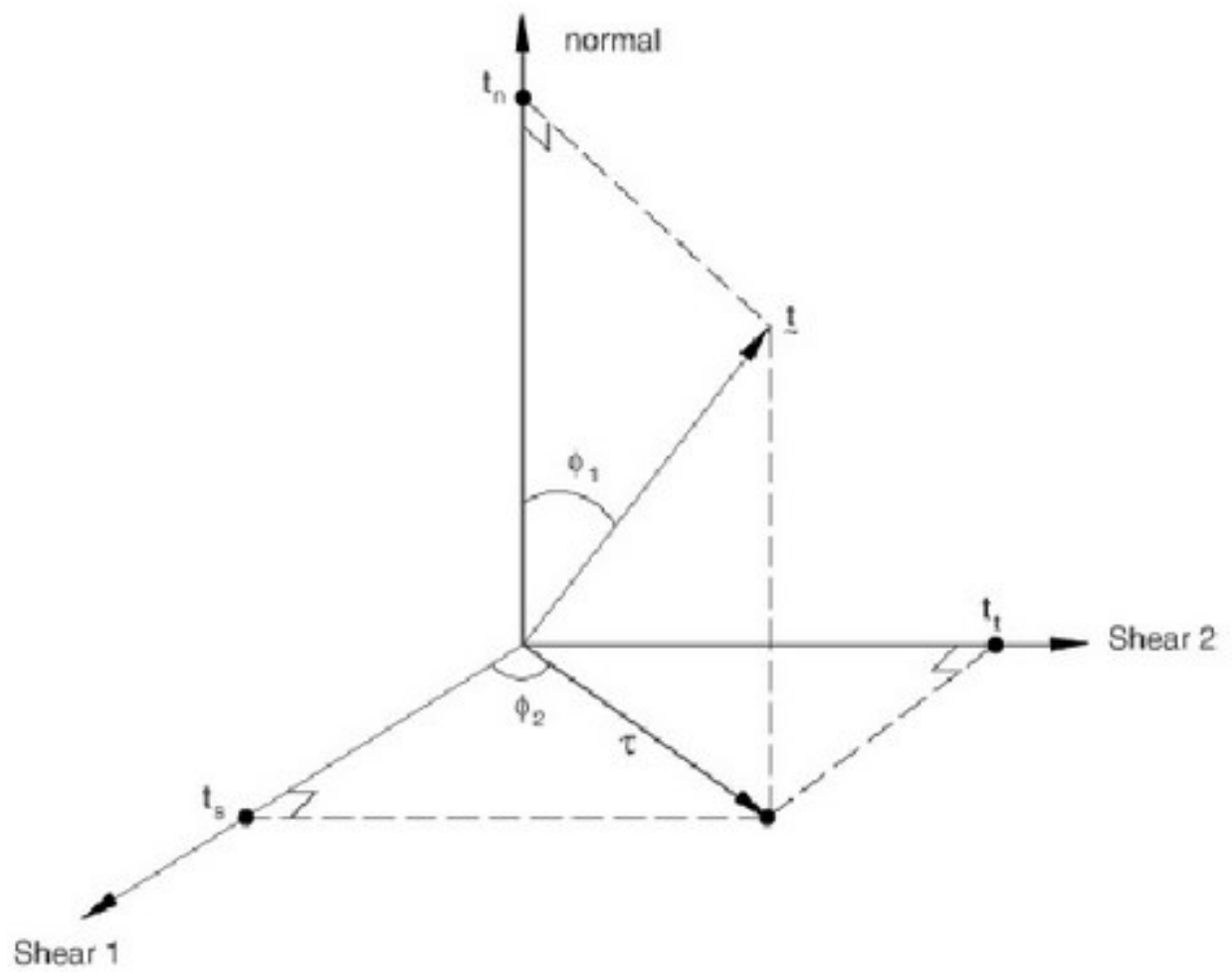

Fig. 3.11 Nominal Shear Traction Vector in 3D

The peak values of the nominal stresses are $t_{n}^{o}, t_{s}^{o}, t_{t}^{o}$ (see Appendix). These values are defined based on the characteristic strength of the wood material from the manufacturer. The critical one of them is $t_{t}^{o}$, which is equivalent to the longitudinal shear strength of the glulam wooden beam. A crack is continually extended in the direction parallel to wood grain once the value of $t_{t}^{o}$ is exceeded. The longitudinal shear strength of the wood material is critical since it gives away to splitting in the direction parallel to the wood grain once the strength value is exceeded (Aghayere and Vigil, 2007). 
The fracture criterion causes cracks to form at locations where the applied shear stresses exceed the longitudinal shear strength of wood. Damage occurs when the maximum nominal stress ratio reaches a value of one (given in Equation 3.3). The extension of a crack (damage evolution) is governed by the technique similar to VCCT which is adopted by the XFEM. The VCCT criterion is based on the assumption that the amount of strain energy released when a crack is extended is the same amount of energy required to close it by the same level of extension (Abaqus 6.112 Manual, 2011). This principle is used to form new crack surfaces from existing cracks. The criterion governing the debonding of surfaces at a crack-tip is given by equation 3.4. Extension occurs when this criterion reaches a value of one.

$$
f=\frac{G_{\text {equiv }}}{G_{\text {equiv } C}} \geq 1.0 \ldots \ldots \ldots \ldots \ldots \text { Equation }(3.4)
$$

Where, $G_{\text {equiv }}=$ equivalent strain release rate calculated at a crack node tip

$$
\begin{gathered}
G_{\text {equivc }}=\text { critical equivalent strain release rate calculated based on user }- \text { specified mode } \\
- \text { mix criterion }
\end{gathered}
$$

In determining $G_{\text {equivc }}$, three common mode-mix formulae can be used in ABAQUS: the BK law, the Power law and the Reeder law models. The choice of the mode-mix formula in a model is uncertain at the beginning of the simulation, hence all three were investigated to determine the one which best suits the problem at hand. The Power law was finally chosen since it produced the crack pattern as observed in the experimental test. The Power law used in the model is defined in equation 3.5 below.

$$
\frac{G_{\text {equiv }}}{G_{\text {equivC }}}=\left(\frac{G_{I}}{G_{I C}}\right)^{a_{m}}+\left(\frac{G_{I I}}{G_{I I C}}\right)^{a_{n}}+\left(\frac{G_{I I I}}{G_{I I I C}}\right)^{a_{o}} \ldots \ldots \ldots \ldots \ldots \text { Equation }(3.5)
$$

Where: $G_{I}, G_{I I}$ and $G_{I I I}$ are calculated strain energies in the three modes of crack propagation 
$G_{I C}, G_{I I C}$ and $G_{I I I C}$ are critical fracture energies associated with the three modes

The computed value from equation 3.5 determines the extension of cracks during the analysis. It is based on the strain energies released at crack tips and how critical they are in forming new crack surfaces. The values of $G_{I}, G_{I I}$ and $G_{I I I}$ are calculated strain energies from the analysis during the simulation. Three critical fracture energies $G_{I C}, G_{I I C}$ and $G_{I I I C}$ were defined, which are associated with the crack propagation systems described in Fig. 2.14. These critical fracture energies, as discussed previously in Section 2.4.1.3, are constant properties of a material which are independent of the size of the geometry of the structure, size of crack and applied load. The critical fracture energies of $G_{I C}$ and $G_{I I C}$ are reported by Haller and Putzger (2006) for Spruce wood. These reported values which correspond to the fracture propagation in mode I and mode II respectively (see Fig. 2.14), were used in the model (see Appendix). The third value, $G_{I I I C}$ correspond to the crack propagation system which is unlikely due to the boundary restraints on the model of this research. Hence a relatively high value of $G_{I I I C}$, which was adopted by Khorasan (2012) was used in the model (see Appendix).

The definition of the critical fracture energies captures the possibility of having any of the propagation systems during the crack development. Once a crack forms, the interaction of the crack surfaces is determined through an "Interaction property" in ABAQUS. The "Interaction property" contains fracture criterion parameters in their respective failure modes. Critical fracture energies used in the model are given in the Appendix. In XFEM, an area where cracks are likely to form and propagate is known as an "enriched area". The layers of glulam were defined as the enriched areas in order to capture the possible local crack developments, which eventually accumulate as the global failure of the assembly. 


\subsubsection{Assembly and Contact Interactions}

All components were assembled together in the "Assembly Module" of ABAQUS. Due to geometrical symmetry, half of the full assembly was modelled to reduce computational time. A symmetrical boundary condition was later prescribed at the truncated section. Fig. 3.12 shows the final assembled model for simulation.

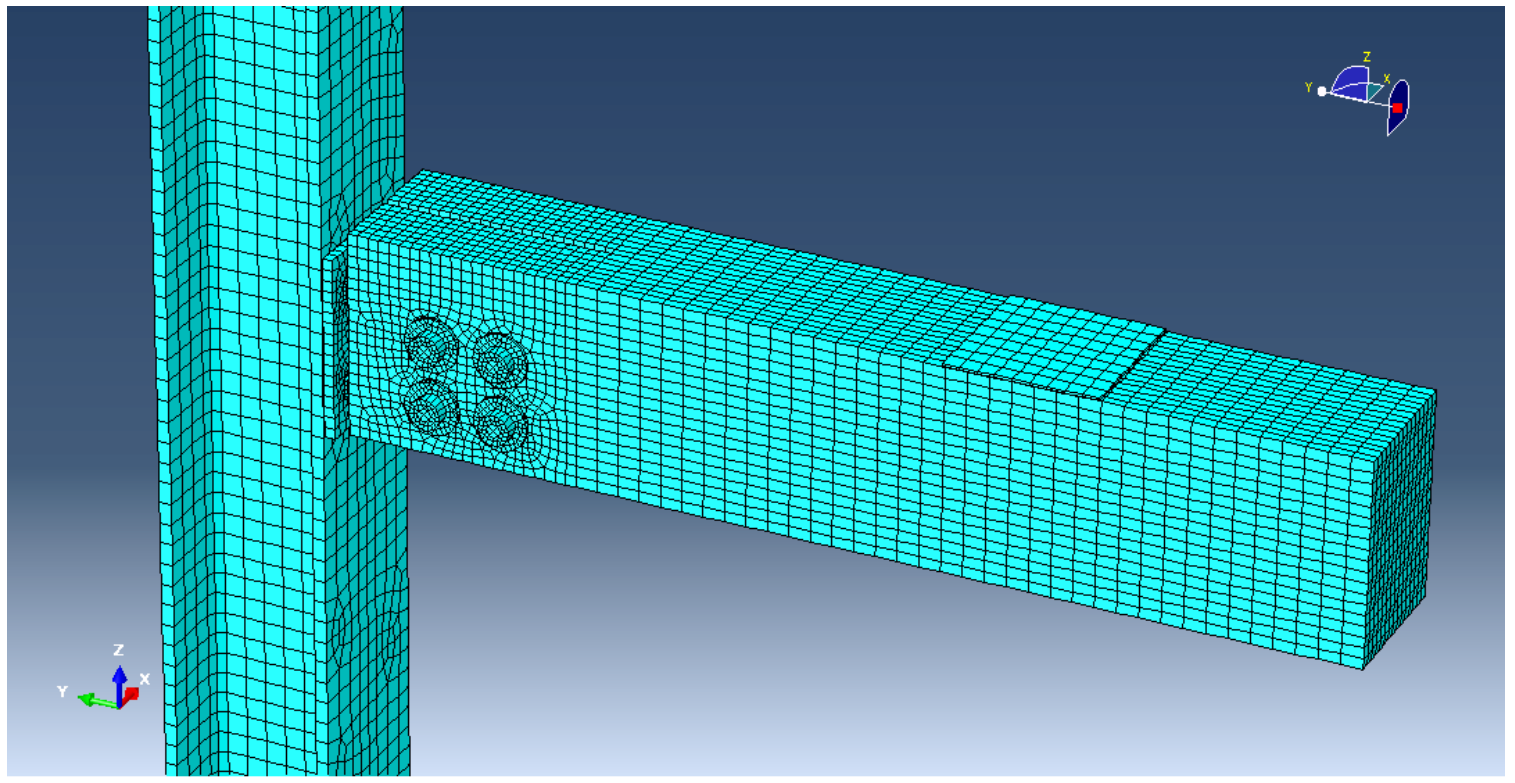

Fig. 3.12 Modelling Half of Full Assembly

In the assembly, many contacts occur between surfaces such as the bolt-bolt hole and wood-steel plate interactions. The interactions of these surfaces are points of discontinuities in the model, hence critical during the analysis process. Contact elements and contact algorithms are needed to cater for these discontinuities during numerical simulation. ABAQUS implicitly introduces these contact elements and algorithms through the "Contact interaction" and "Interaction properties" features. Contact interaction definition begins with identifying surfaces in the assembly which are in contact or likely to be in contact during the simulation. These pairs of surfaces are known as "contact pairs", which can be generated automatically or manually. Major and influential contact areas, such as bolt-bolt holes were carefully defined in the model. Other minor contact areas for 
the structural analysis, such as the plate-beam side surface and the plate-column surface were also automatically included during the model simulation. The contact definitions which were manually defined include bolt shank-wood bolt hole, bolt shank-plate bolt hole and steel plate-wood. These potential contacting surfaces were assigned "master" and "slave" surface roles. Assignment of surface roles is based on the contact formulation requirement that, the master surfaces would have coarser mesh densities than slave surfaces. The discretization method and sliding formulation were additional contact definition features which were specified for each contact pair. Both features control the contact elements and their associated algorithms during the analysis.

In addition, each contact pair definition was assigned an "interaction property". The interaction property defines the behaviour of the contacting surfaces for a mechanical analysis. The properties of interest are the tangential and normal behaviour of the surfaces relative to each other. A friction coefficient of 0.3 was used for the tangential behaviour. This value is based on the coefficient of static friction value for wood and metals as reported by the ASM Handbook (1992). A "hard contact" relationship was defined for the normal behaviour of all the contact pairs. All contact interactions were defined at the initial stage of the analysis.

\subsubsection{Loads and Boundary Conditions}

The loads applied during the experimental tests were two point loads at one-third points along the beam span. Point loads are loads which are concentrated over a relatively small surface area. The load jack in the test was used to apply a concentrated pressure to the top of the steel plates which in turn spreads the load to the beam and eventually to the entire assembly. In the model, the load is applied as a concentrated pressure on $140 \mathrm{~mm}$ square plates. The total pressure 
applied on the plate is computed to match its corresponding applied load in each test. The square plates were constrained to remain on top of the beam during the analysis. The load feature in ABAQUS is dependent on the analysis step, hence can be modified at any step of the analysis.

Fig. 3.13 shows the boundary condition of the assembly at the beam and the connection region. Pinned conditions were also applied as boundary conditions to simulate the hinge supports at the top and bottom of the columns in the test. Pinned conditions allow rotations but restrain displacements in the $\mathrm{X}, \mathrm{Y}$ and $\mathrm{Z}$ directions of the model. The assembly of the model implicitly imposes some level of restraints on the individual components at their contact regions. Some selected ends of the steel plate and bolts were also restrained to prevent any undesirable motion of them during the analysis. Restraining some loose ends of the assembly prevents rigid body motion, which can cause instability in the model during analysis. Such instabilities can affect the model results or terminate the analysis during simulation.

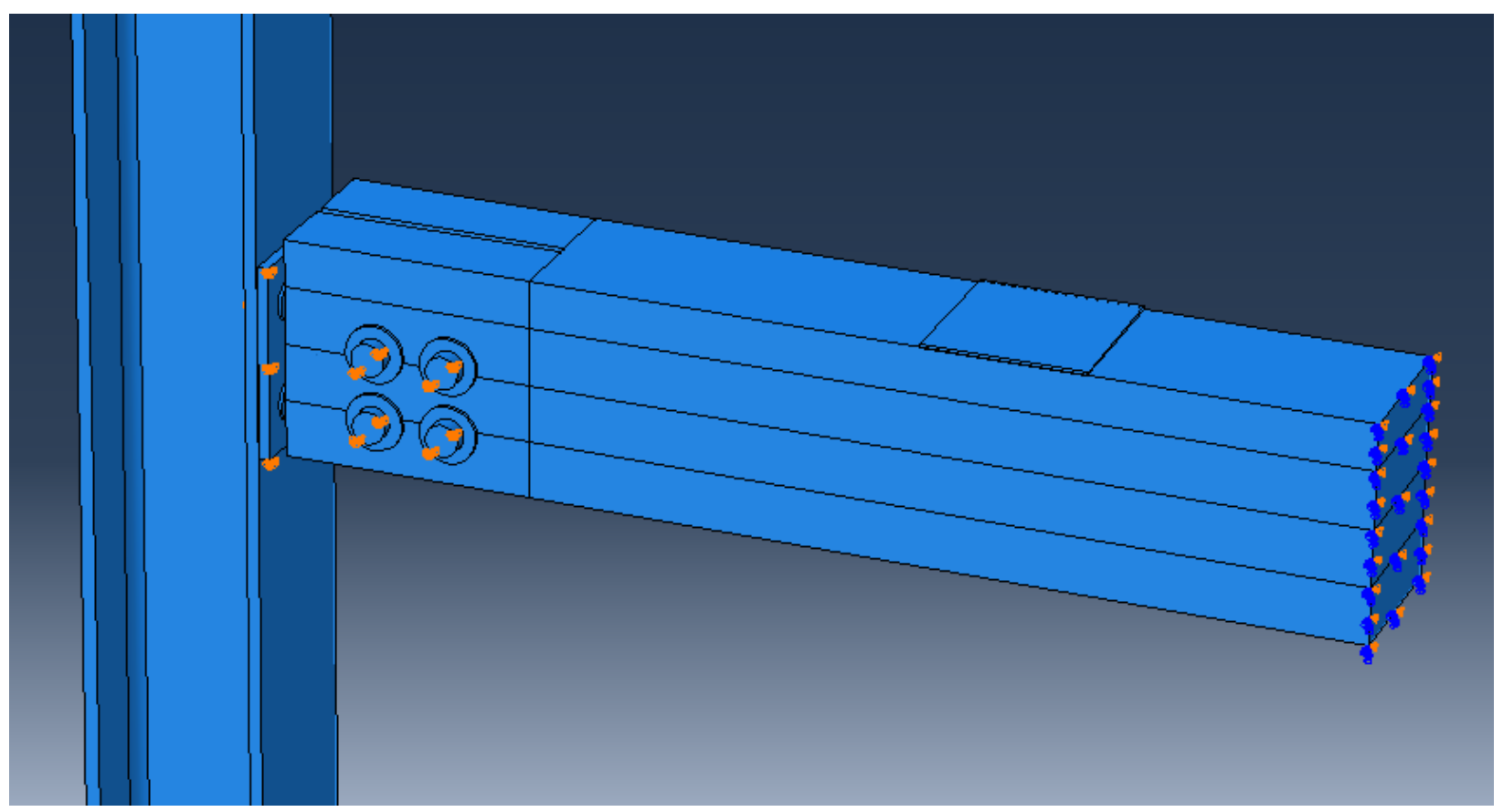

Fig. 3.13 Boundary Condition on a Concealed Connection Assembly 
Since the test specimen is fully symmetric, a symmetric boundary condition was applied at the truncated section of the beam (see Fig. 3.13) to simulate the symmetry in geometry, loads and boundary conditions. This symmetric boundary condition allows half of the test assembly to be modelled yet still represent the behaviour of the full system. All the boundary conditions were defined at the initial step of the analysis and their effect were propagated in the subsequent steps.

\subsubsection{Analysis}

The analysis procedure in ABAQUS starts off with an initial step followed by the userdefined subsequent steps. The default initial step cannot be modified but can be used to initiate boundary conditions and contact interactions before the start of the actual analysis. Subsequent steps are defined by the user to analyse the finite element model when simulating the physical problem. Each defined step of the analysis contains a procedure which is appropriate to solve the problem at hand.

The overall fire resistance test was simulated in two main steps of the analysis. In the first step, a static analysis was conducted, where the load was applied in increments until the full load on the assembly was reached. The incremental load is determined by the time increments in the analysis step. During the analysis, the time increment is adjusted automatically to enable convergence of the solution. This is because the convergence of the solution depends on the equilibrium of the system, and the system equilibrates with the level of load applied on the assembly. The second step of the analysis involved maintaining a constant load on the assembly while the effects of fire are included to simulate the fire resistance test itself. This was achieved by reading the transient temperature solution on the entire assembly as already computed by the heat transfer model. The 
nodal temperatures in the assembly were read from the heat transfer analysis results file as a "predefined field" in ABAQUS. Associated temperature time histories were applied to all the elements in the model to simulate the effect of fire exposure.

Due to the temperature dependence of the strength and elastic properties of the assembly materials, the structural and thermal effects are coupled in the second step of the analysis. Elevated temperatures in the elements continually degrade the strength and stiffness of the assembly. At any time increment in this step of the analysis, the strength and stiffness of the assembly change and the system is analysed until equilibrium is achieved to obtain a converged solution. The applied load from the first stage still remains constant and the assembly becomes more flexible with increasing temperatures. The decay of the strength and stiffness causes the assembly to experience elastic and plastic deformations until damage and failure eventually occur. The time to failure of the assembly during fire exposure is tracked as an output and estimated as the recorded fire resistance from the model.

The major shortcoming which could arise in a sequentially coupled thermal-stress analysis used in modelling this problem is the likely mismatch of mesh between the heat transfer model and the structural model which follows it during the analysis. For the heat transfer model, the mesh was fixed in space with no concept of mechanical deformations, hence the transfer of temperature results to the subsequent structural model could be suffer some inconsistency especially when the deformations resulting from the structural model are quite significant. In such a situation, the fully coupled thermal-stress procedure can resolve the inconsistency since it can simultaneously update the mesh deformations along with the temperature results during the analysis. The choice of the 
sequentially coupled procedure over the fully coupled procedure is based on the concept of brittle failure model of the wooden beam which was adopted. Large deformations hardly characterize brittle failures and this was evident in the test observations (Sabah, 2012). On condition that resulting deformations from the structural model are not high, the sequentially coupled thermalstress procedure is sufficient for simulating the fire resistance tests.

\subsection{Conclusion}

A finite element model has been developed, and will be used to simulate the structural and fire effects on a connection assembly. The overall behaviour in a fire resistance test includes the transient heat transfer on the assembly, the gradual strength degradation, progressive damage of the connection assembly and eventually the ultimate failure of the connection. The analysis approach which will used is a sequentially coupled thermal-stress analysis procedure. The fire resistance of the connections can then be estimated as the time to failure under the constant applied loads after being affected by the elevated temperatures from the fire. 


\section{Chapter 4: Results and Discussion}

\subsection{Introduction}

The model discussed in the preceding chapter was used to simulate the behaviour of three different connection assemblies from the experimental fire resistance tests. Concealed $(\mathrm{CN})$, Exposed (EX) and Seated (SE) connections were simulated in ABAQUS under three different load ratios; $30 \%, 60 \%$ and $100 \%$ while subjected to a time-temperature curve from the fire. The model was first validated to ensure its reliability in simulating the actual test connections. The heat transfer and temperature distribution in the assembly over the duration of fire exposure are discussed and compared with test results. The charring properties of the glulam beam are also examined considering the exposure of wood in the different connection regions. Following the heat transfer calculations, the response of the assembly to fire temperatures was simulated in the form of progressive structural damage and failure in order to provide an estimate of the fire resistance of these connections.

\subsection{Validation of the Model}

To simulate the fire resistance test, a sequentially coupled thermal-stress procedure was employed to predict the thermal and mechanical response of the assembly as already discussed in Chapter 3. Prior to the coupled analysis procedure, both the thermal and structural models require validation. The validation of the model is needed to ascertain the reliability of inputs like material properties, modelling approach, analysis procedure and other factors which could significantly impact the final results from the model. 


\subsubsection{Structural Model}

For the structural model, the material strength and elastic properties are the major determining factors to obtain desired results of the structural capacity, damage and failure. Material properties were partly obtained from the manufacturer and literature. An average of the widely distributed properties from literature may be chosen carefully to avoid the need for laboratory tests to determine the strength and elastic properties of the materials. For the wood material, even experimental tests would have a great deal of scatter between different test specimens due to the natural variability of the material. Moreover, the temperature-dependence of these material properties also follows a general trend from researchers which can be carefully employed at the validation stage of the model.

The tested assembly was composed of connections which have been designed according to CAN/CSA 086-09 (2009). The design load capacity of the connections was mostly governed by the splitting resistance of the wooden beam in the joint area. The design load capacities of all the connection configurations were reported by Sabah (2012). In the fire resistance test, a ratio of the design load capacities (load ratio) was applied on the individual connection assemblies which are shown in Table 4.1. The design capacities incorporate material strength factors. These design factors result in a conservative resistance estimate of the connection, which is lower than the actual strength. The actual capacity of a connection is known as the ultimate capacity.

The CN connection assembly was tested at the laboratory in non-fire conditions to verify its ultimate capacity. This assembly was loaded at ambient temperatures until it failed eventually. A total of the two point loads which caused the assembly to fail was approximately $100 \mathrm{kN}$, thus, its 
ultimate load capacity. The design capacity of the beam connection was $71.5 \mathrm{kN}$. The failure mode recorded for the connection during testing was the splitting of the glulam beam in the direction parallel to wood grain, which originated from the connection region (Sabah, 2012).

Table 4.1 Applied Load and Load ratio of Test connections (Sabah, 2012)

\begin{tabular}{|c|c|c|c|c|}
\hline $\begin{array}{c}\text { Connection } \\
\text { Type }\end{array}$ & $\begin{array}{c}\text { Number of } \\
\text { Bolts }\end{array}$ & $\begin{array}{c}\text { Bolt Diameter } \\
(\mathbf{m m})\end{array}$ & $\begin{array}{c}\text { Load ratio } \\
\mathbf{( \% )}\end{array}$ & $\begin{array}{c}\text { Load } \\
(\mathbf{k N})\end{array}$ \\
\hline $\mathrm{CN}$ & 4 & 19.1 & 30 & 21.5 \\
\hline $\mathrm{CN}$ & 4 & 19.1 & 100 & 71.5 \\
\hline EX & 4 & 19.1 & 60 & 37.5 \\
\hline EX & 4 & 19.1 & 100 & 62.5 \\
\hline SE & 1 & 12.7 & 60 & 48 \\
\hline SE & 1 & 12.7 & 100 & 80 \\
\hline
\end{tabular}

\subsubsection{Estimation of the Ultimate Capacity from the Structural Model}

The ambient strength test for the $\mathrm{CN}$ connection assembly was simulated using the structural model. This was done to verify the reliability of the structural model without fire effects. The model assembly was subjected to increasing point loads until failure. The structural damage and failure modelling was employed accordingly as described in Section 3.3.3.3 to determine the point of ultimate failure. The load to failure from the model can then be compared with the ultimate load capacity recorded from the test.

ABAQUS conducts an analysis in steps. Each analysis step contains a procedure to solve the numerical problem within a certain time frame known as "step time". The only analysis step of this simulation is the static analysis step. The load on the assembly model was applied in small 
increments of the step time during the analysis. The numerical problem is solved at each increment of the step time to obtain a converged solution.

The load applied on the assembly during the analysis is proportional to the step time increment. ABAQUS applies the load in increments in order to obtain a converged solution. This concept of time increment and the proportional applied load was used to estimate the load to cause ultimate failure from the ALLDMD curve (see Fig. 4.1). ALLDMD describes the progressive structural damage of the wooden elements in the modelled assembly. ABAQUS computes ALLDMD as an equivalence of the strain energy which results in the initial damage and subsequent propagation of damage in the wood material during analysis. Once a crack forms, the value of the ALLDMD is proportional to the fracture energy imposed on the material. The fracture energy is in turn a function of the accumulated strain energies at crack tips (as already described in section 2.4.1.3). ALLDMD values increase suddenly as cracks form and begin to propagate in wood, which indicates the abrupt brittle failure mode.

The moment (as indicated by time increment) of rapid increase in the ALLDMD was used to estimate the failure load. The time increment at which ultimate failure occurs was estimated as value of 0.82 from Fig. 4.1, and was used to estimate the ultimate failure load from the model as follows:

Pressure applied on plate (140mm sq. $)=3 \mathrm{~N} / \mathrm{mm}^{2}$

Failure load $=0.82 \times 3=2.46 \mathrm{~N} / \mathrm{mm}^{2}$

Load, $\mathrm{P}=2.46 \times 140 \times 140=48.2 \mathrm{kN}$ 
Total load, $2 \mathrm{P}=96.4 \mathrm{kN}$ (Ultimate failure load from model)

The predicted ultimate load from the model is $96.4 \mathrm{kN}$, which is in close approximation to the ultimate load recorded from the test $(100 \mathrm{kN})$. Moreover, the failure mode in the model was the formation of cracks in the wood at the bolt-hole region, hence this provides some level of reliability of the structural model in ambient conditions.

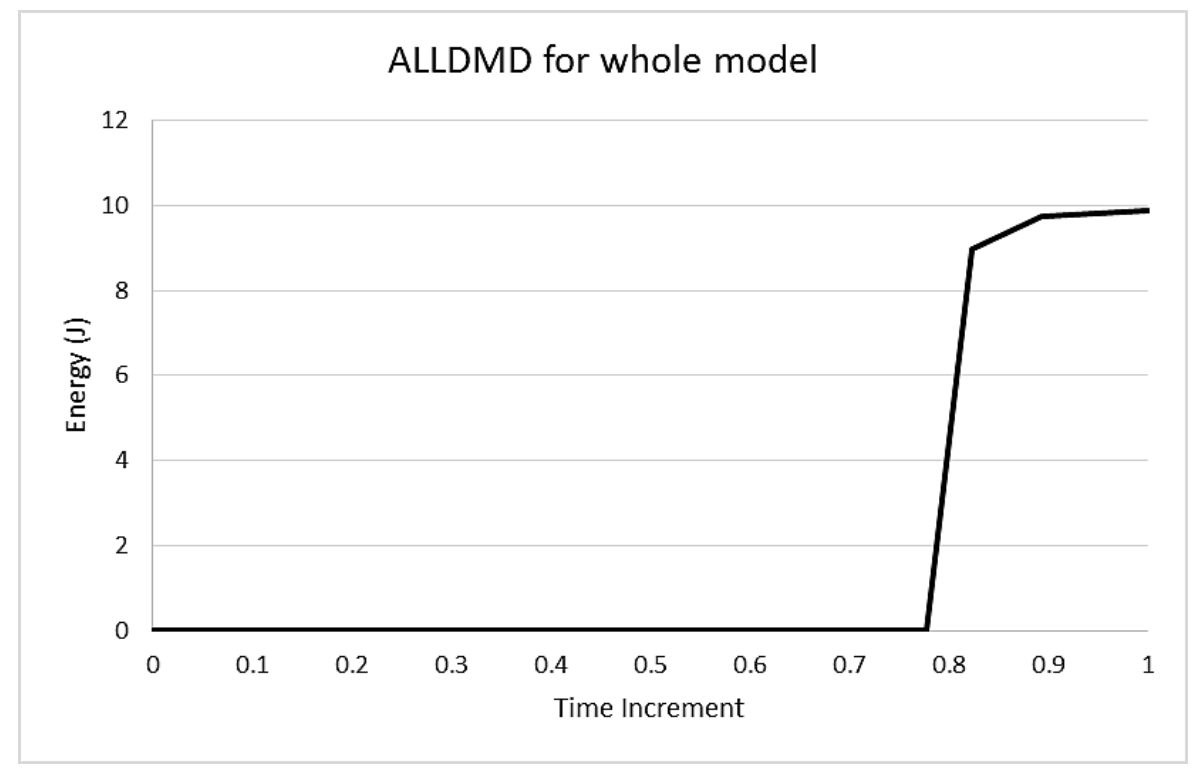

Fig. 4.1 Damage Energy (ALLDMD) against Time Increment

\subsubsection{Thermal Model}

To validate the thermal model, temperatures at various points in the concealed connection assembly (see Fig. 4.2) which were recorded from the test were compared with the predictions from the model. The corresponding locations of the sections in Fig. 4.2 (a), Fig. 4.2 (b) and Fig. 4.2 (c) on the test assembly are shown in Fig. 4.3.

The temperature development at points in the assembly over time of fire exposure indicates the level of heat penetration within the assembly. The temperatures at points $9,10,11$ and 12 are 
selected from the bolt and concealed plate while 25, 26, 27 and 28 are selected from the glulam beam mid-span for validation.

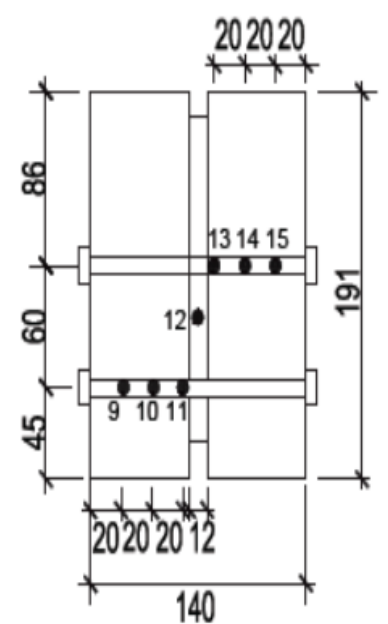

(a) Bolt-plate (Sec II)

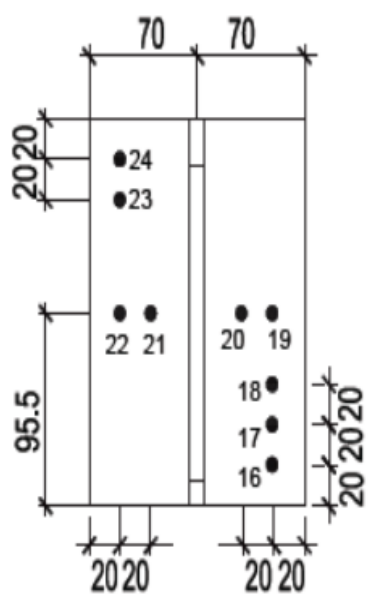

(b) Wood-plate (Sec II)

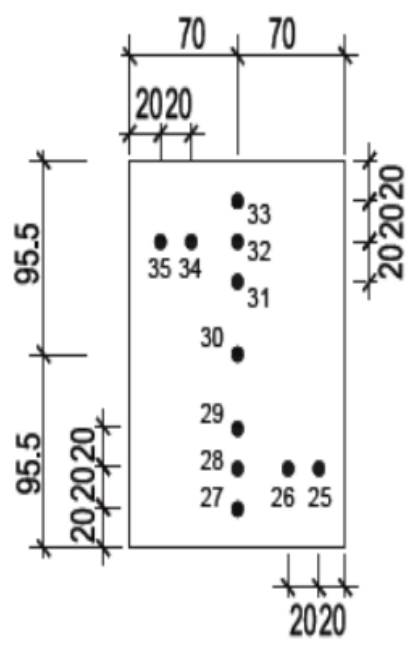

Fig. 4.2 Cross-section of Test Assembly with Thermocouple locations

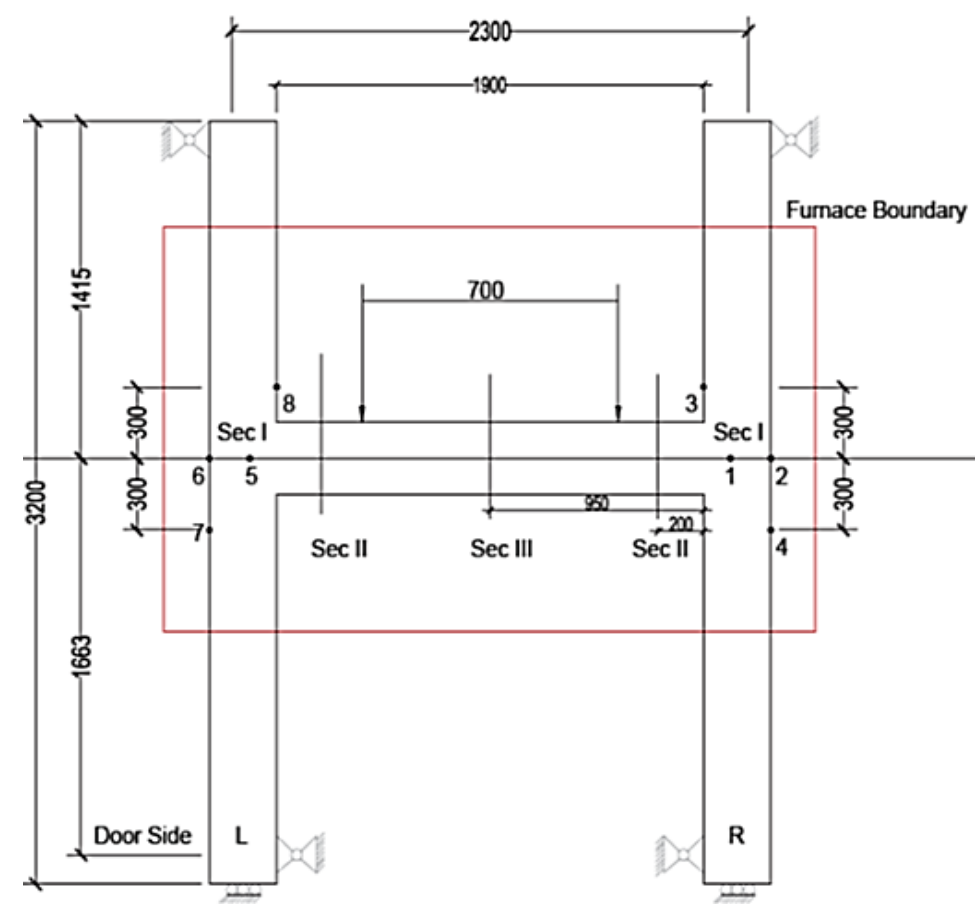

Fig. 4.3 Schematic of the Connection Test Assembly 
The temperature variations at points $9,10,11$ and 12 from the model generally compare well with the test results as seen in Fig. 4.4 (a), (b) and (c). The difference between the model results and the test data are within $\pm 11 \%$ envelope.

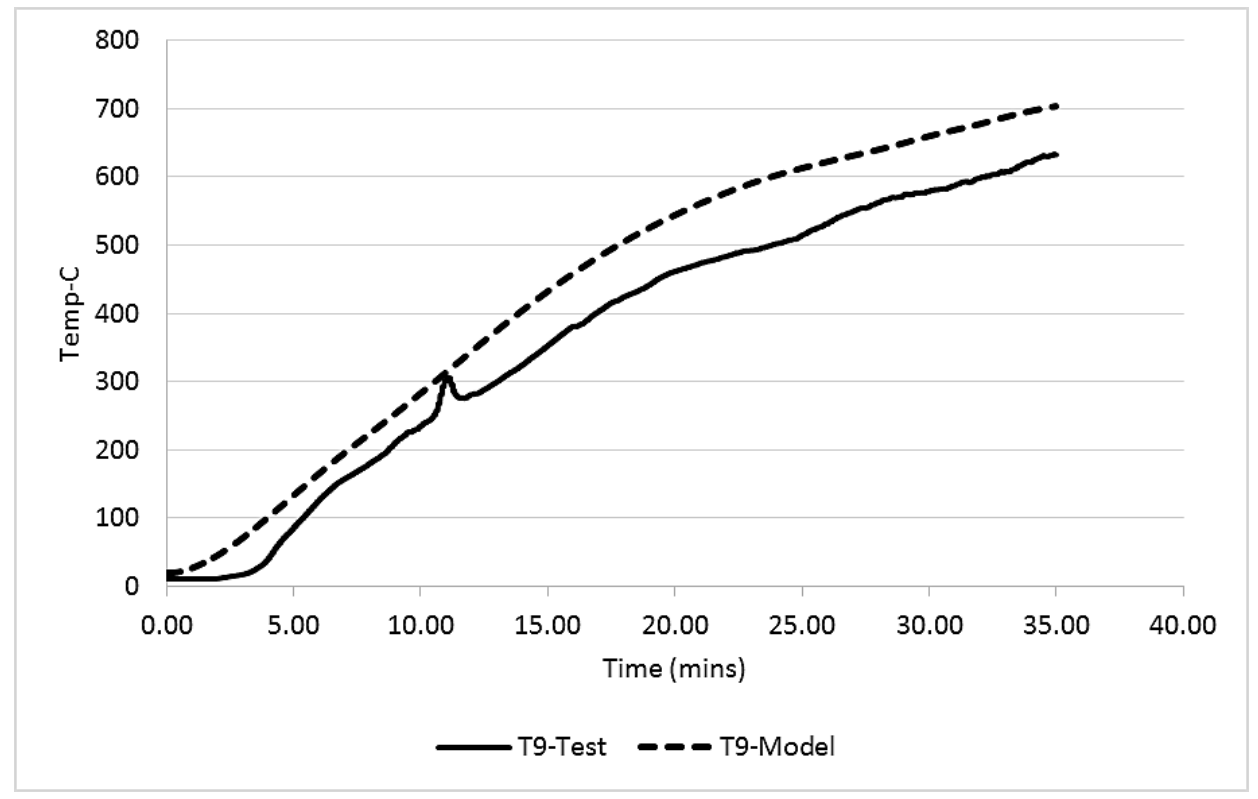

(a) $\mathrm{T9}$

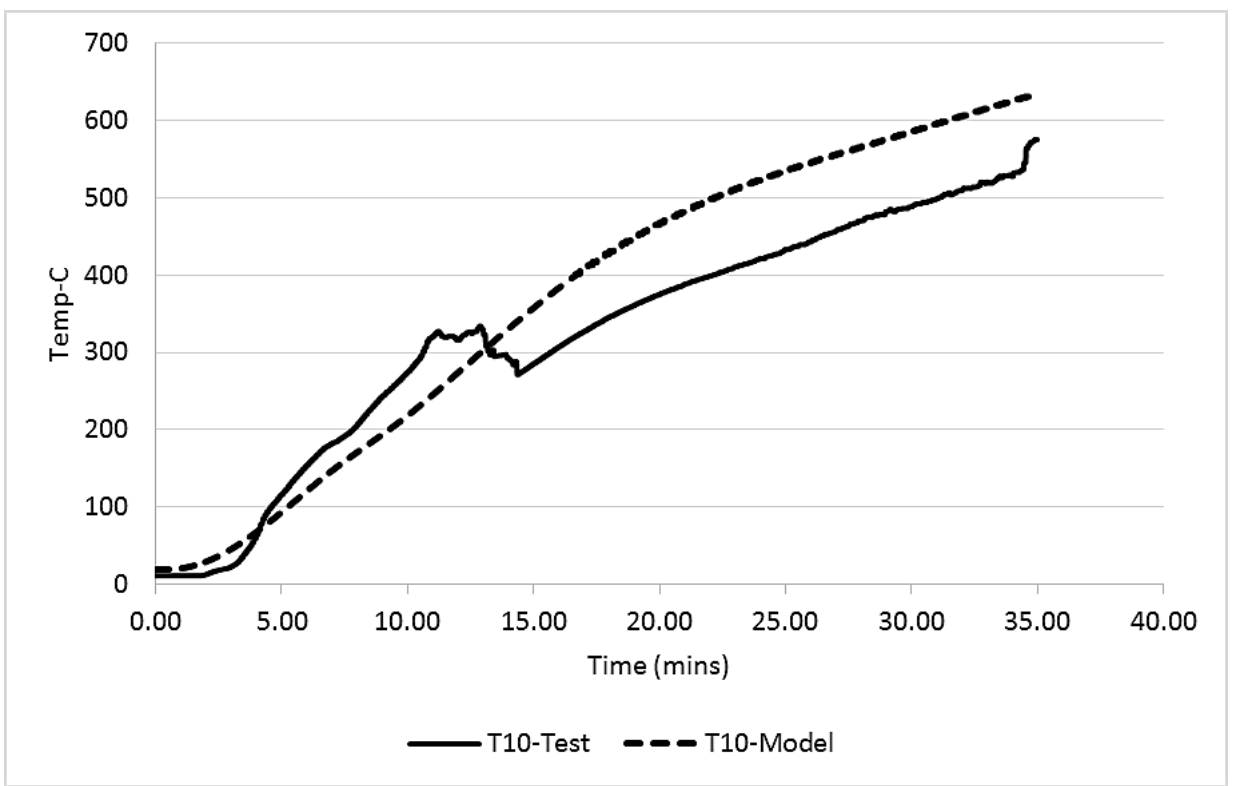

(b) $\mathrm{T} 10$ 


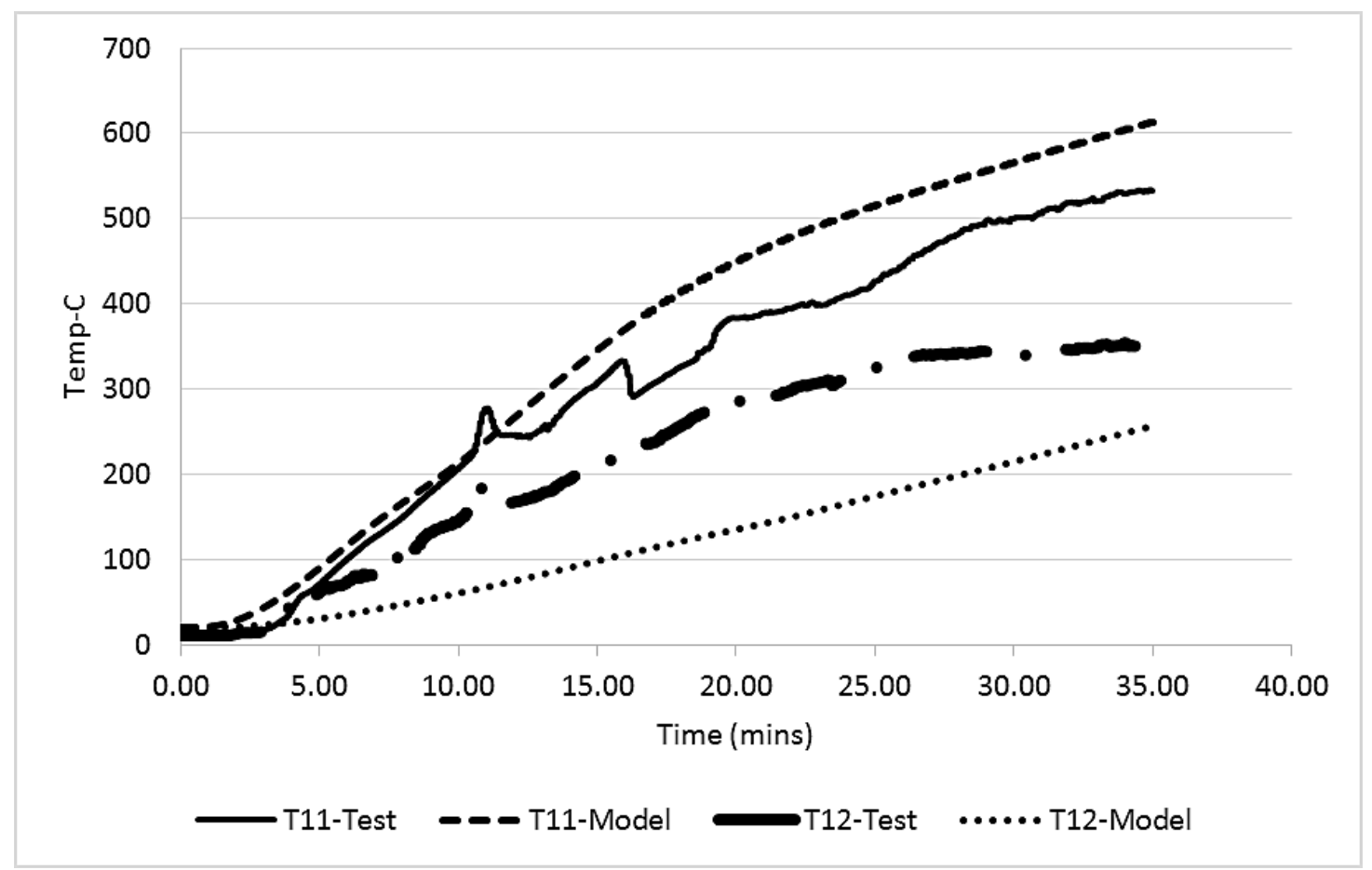

(c) T11 and T12

Fig. 4.4 Temperature-depth variation with time; bolt and concealed plate

The model generally predicts higher temperatures at the above-mentioned points except for point 12. The lower temperature development at point 12 in the model can be attributed to the total absence of heat at the top of the beam (for the model), whereas in the actual test some amount of heat is leaked to the hidden steel plate. This results in relatively higher test temperatures of the plate than what the model could represent (especially around 20 minutes). The temperature results from the model at these points also follow the general decrease in temperature from the surface of the assembly towards its center as observed in the test data.

The temperature development at points 25, 26, 27 and 28 also depicts a good agreement between test and model results as shown in Fig. 4.5 (a) and (b) with only minor variations. The points close to fire exposure (25 and 26) record high temperatures and the temperatures decrease as we 
approach the center of the assembly (27 and 28). The model captures this decreasing trend in temperatures as recorded in the test.

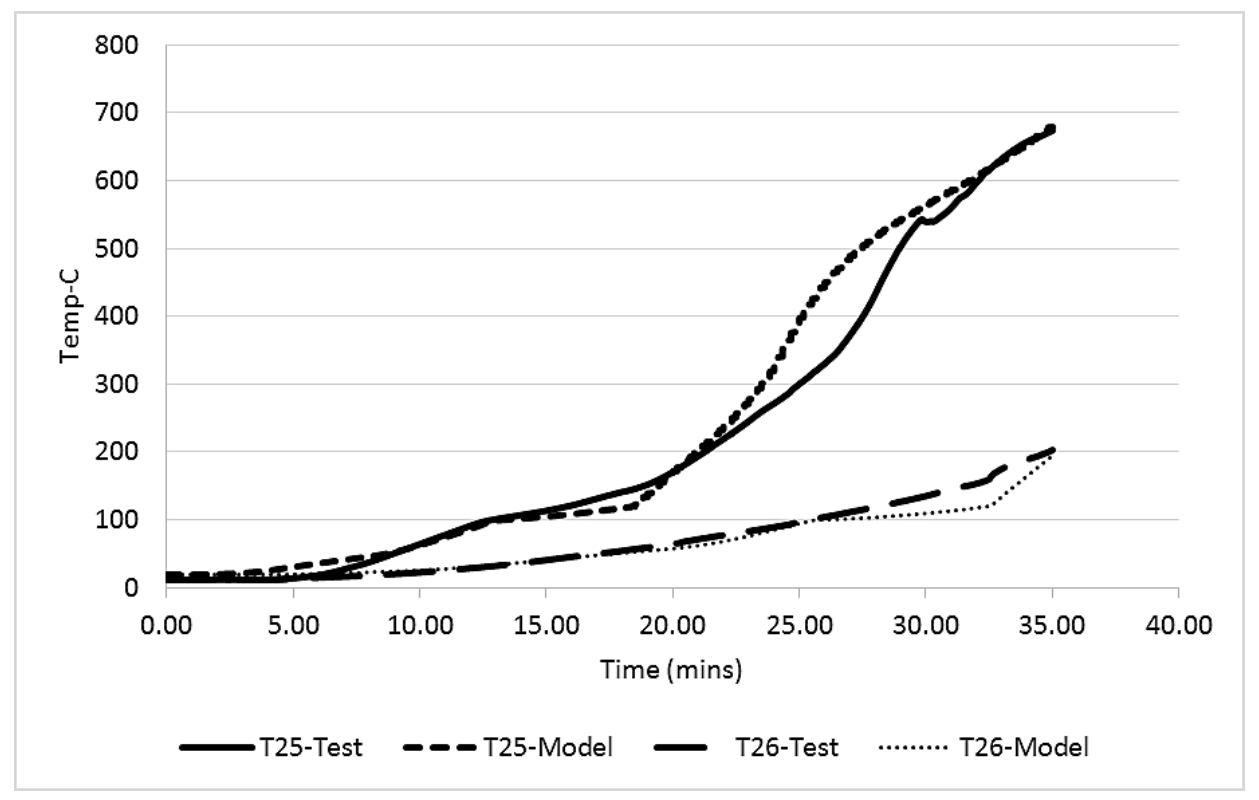

(a) T25 and T26

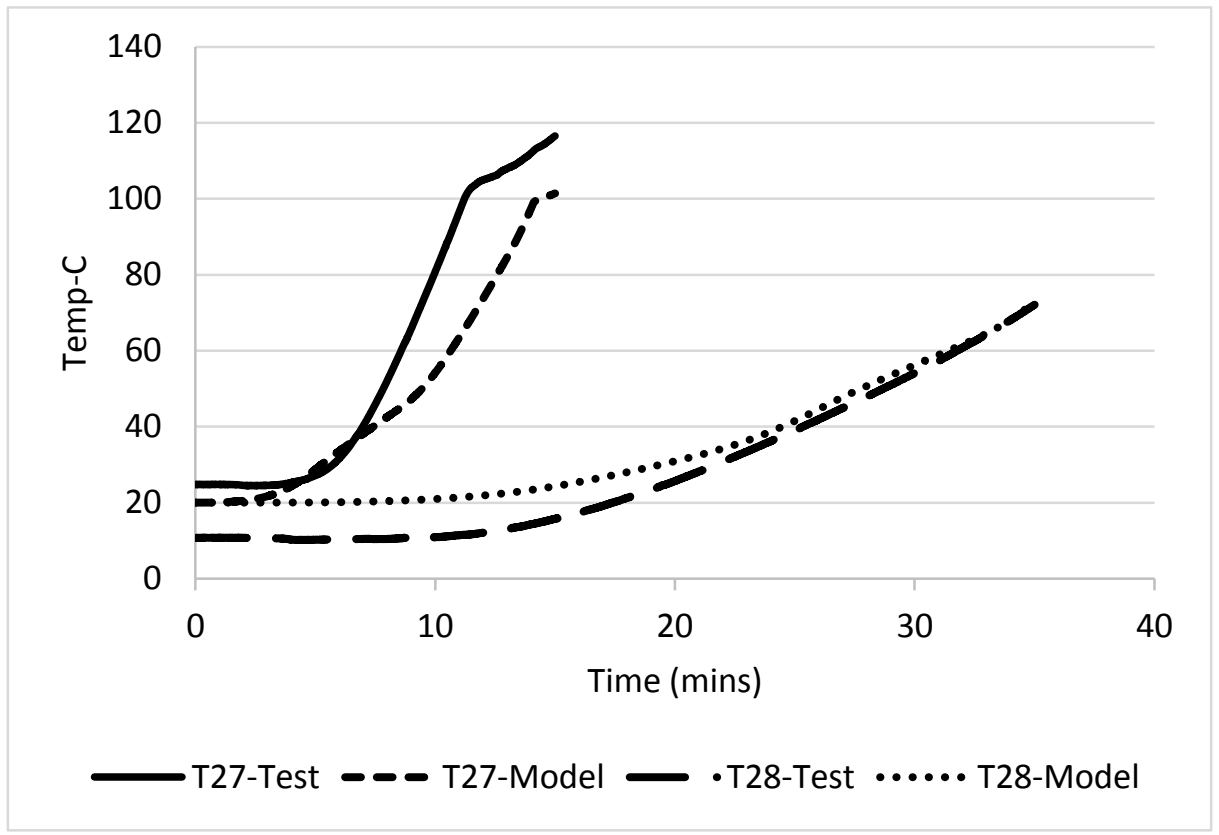

(b) T27 and T28

Fig. 4.5 Temperature-depth variation with time; beam mid-span 
The prediction of the temperature development at the selected depths on the beam section by the thermal model demonstrates the reliability of the material properties and the heat transfer procedure adopted.

A typical graph of the temperature-depth against time from the test is compared with the temperature contour from the model (after 35 minutes of fire exposure) in Fig. 4.6 (a) and Fig. 4.6 (b). A $20-\mathrm{mm}$ depth from the sides lies within the range of $650-750^{\circ} \mathrm{C}$ (see test result in Fig. 4.6 (b)) after 35 minutes of fire exposure and this is also well represented by the yellow to orange temperature contour from the model $\left(631-784^{\circ} \mathrm{C}\right)$. Temperature distribution within a 40 to 100 $\mathrm{mm}$ range of the cross-section depth increases gradually from ambient temperature $\left(20^{\circ} \mathrm{C}\right)$ to about $100^{\circ} \mathrm{C}$ after 35 minutes of fire exposure (see Fig. 4.6) and this is depicted in both the test and model results. The distribution of temperature from the model also depicts the corner rounding which characterize the charring properties of the wood section exposed on its three sides to fire (Buchanan, 2002). This confirms that the heat transfer model can predict well the temperature distribution of the model assembly during the duration of fire exposure.

Comparing the temperature development with time at particular depths of the beam section, uneven heat penetration is observed at the immediate depths $(40 \mathrm{~mm})$ from the left and right side of the beam, which are directly exposed to heat flux on the boundary (see Fig. 4.6b). The unsymmetrical temperature distribution from the test is as a result of the uneven heat flux distribution in the furnace during testing. The model however assumes a uniform heat flux to all the exposed wood surfaces, hence a symmetric distribution of temperature on the wood section as seen in Fig. 4.6a. 


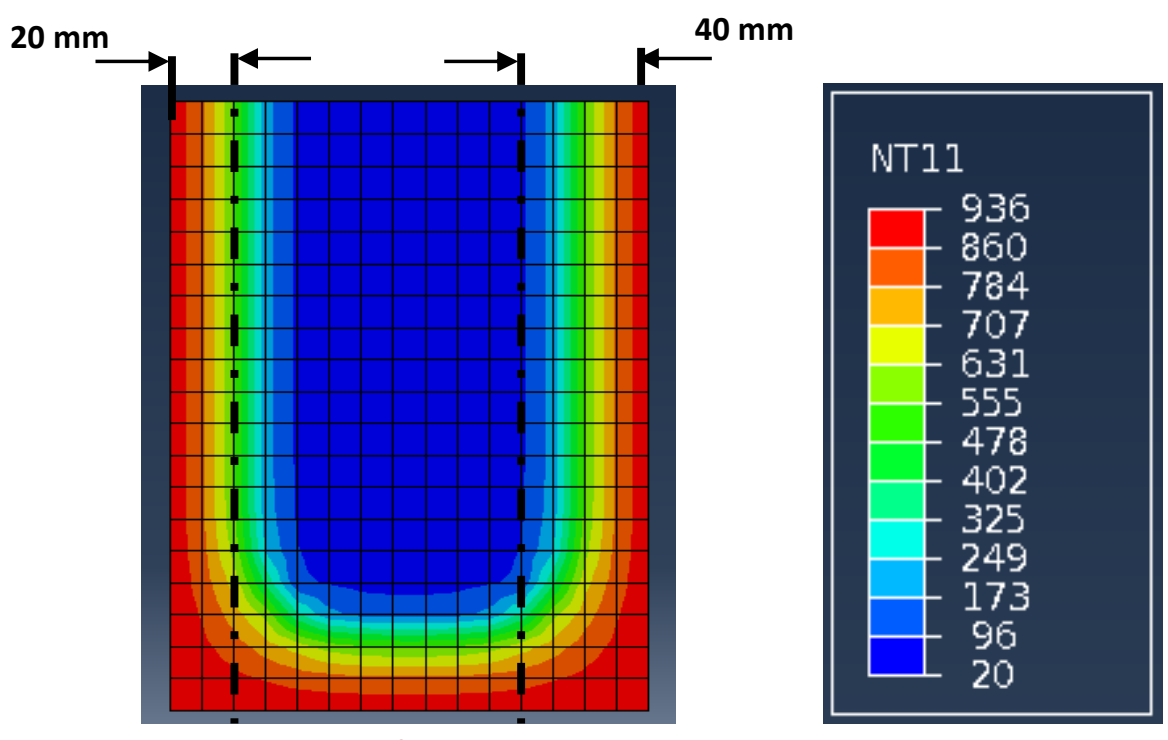

(a) Temperature Distribution from Model after 35 minutes of fire exposure

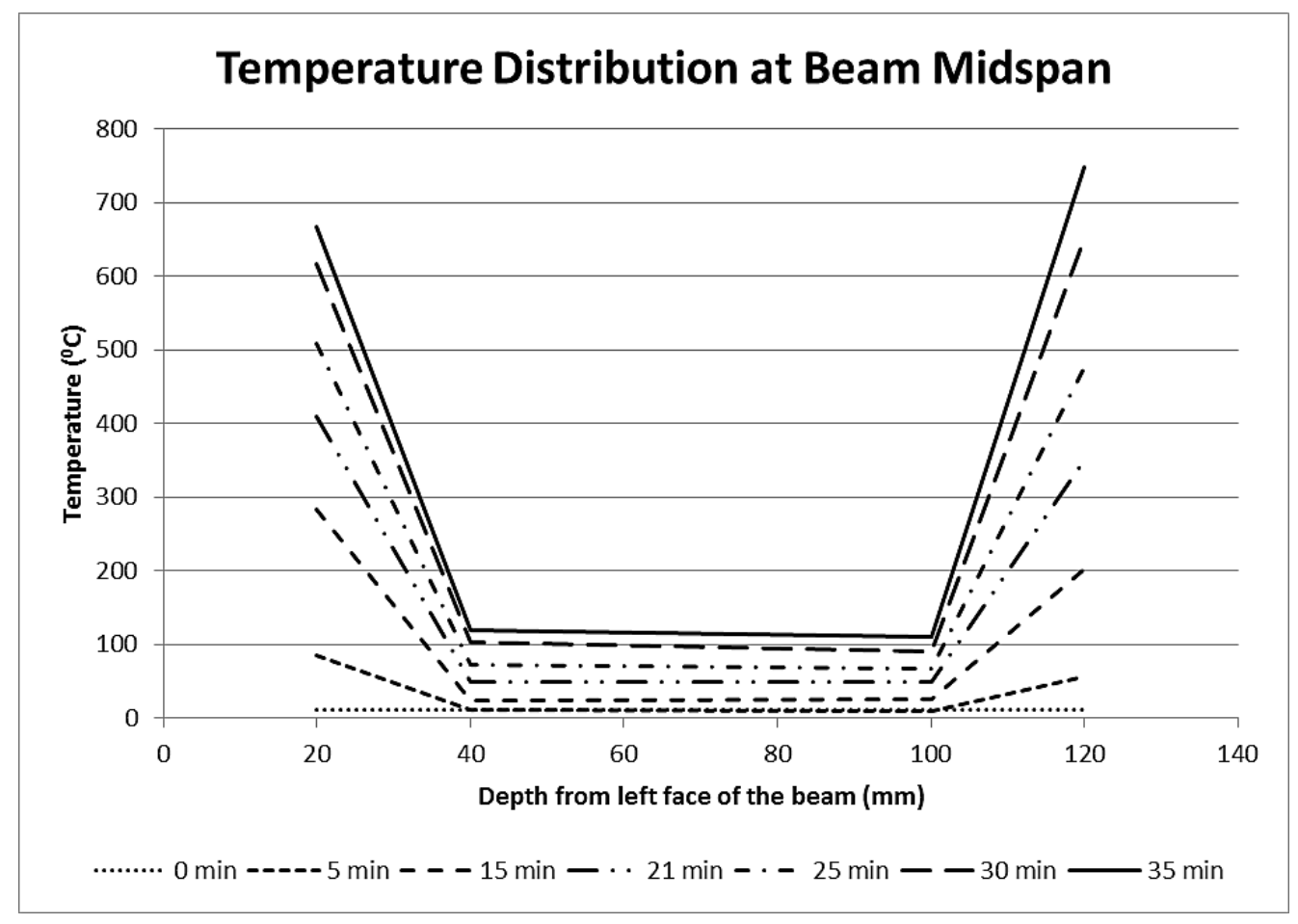

(b) Temperature Distribution on wood section with time (Test)

Fig. 4.6 Temperature-depth Distribution against Time from the Test and Model 


\subsection{Heat Transfer and Temperature Distribution}

The heat penetration within the assembly is a major determining factor of how the assembly responds to fire temperatures. All the test assemblies had the top of the beams covered to simulate the presence of a floor. The columns were also covered while three sides of the beam were exposed; left side, right side and bottom side. The exposure of the connections to fire and their corresponding behaviour are different depending on the configuration and the interaction of steel plates, bolts and wood. The behaviour of each connection type will be discussed in the following.

\subsubsection{Concealed Connection (CN)}

The concealed shear tab connects the beam to the column with the steel plate embedded in a center notch of the wood. The bottom side of the plate and the bolts are exposed and, therefore, heat is conducted directly and quickly to the core of the beam section in the connection region. Fig. 4.7 shows that the temperatures in the wood section are increased due to the influence of the heated steel elements. The bolt and plate contact regions have higher temperatures than the other inner regions of the section.

Influence of steel elements on temperature at the connection



Fig. 4.7 Temperature Distribution at the CN connection after 35 minutes of fire exposure 
The temperature contour plot from the model (on the right side of Fig. 4.7) shows a similar distribution of heat when compared with the charred pattern obtained from the test (shown on the left side of Fig. 4.7). Contact regions are charred while internal regions that remain in the range of ambient temperatures are not yet charred.

The temperature development in the wood at points 16 and 17 (shown in Fig. 4.2) shows a good agreement between the test and the model results as seen in Fig. 4.8. Both points generally record high temperatures during the duration of fire exposure because of the influence of heat from the two directions on the beam sides.

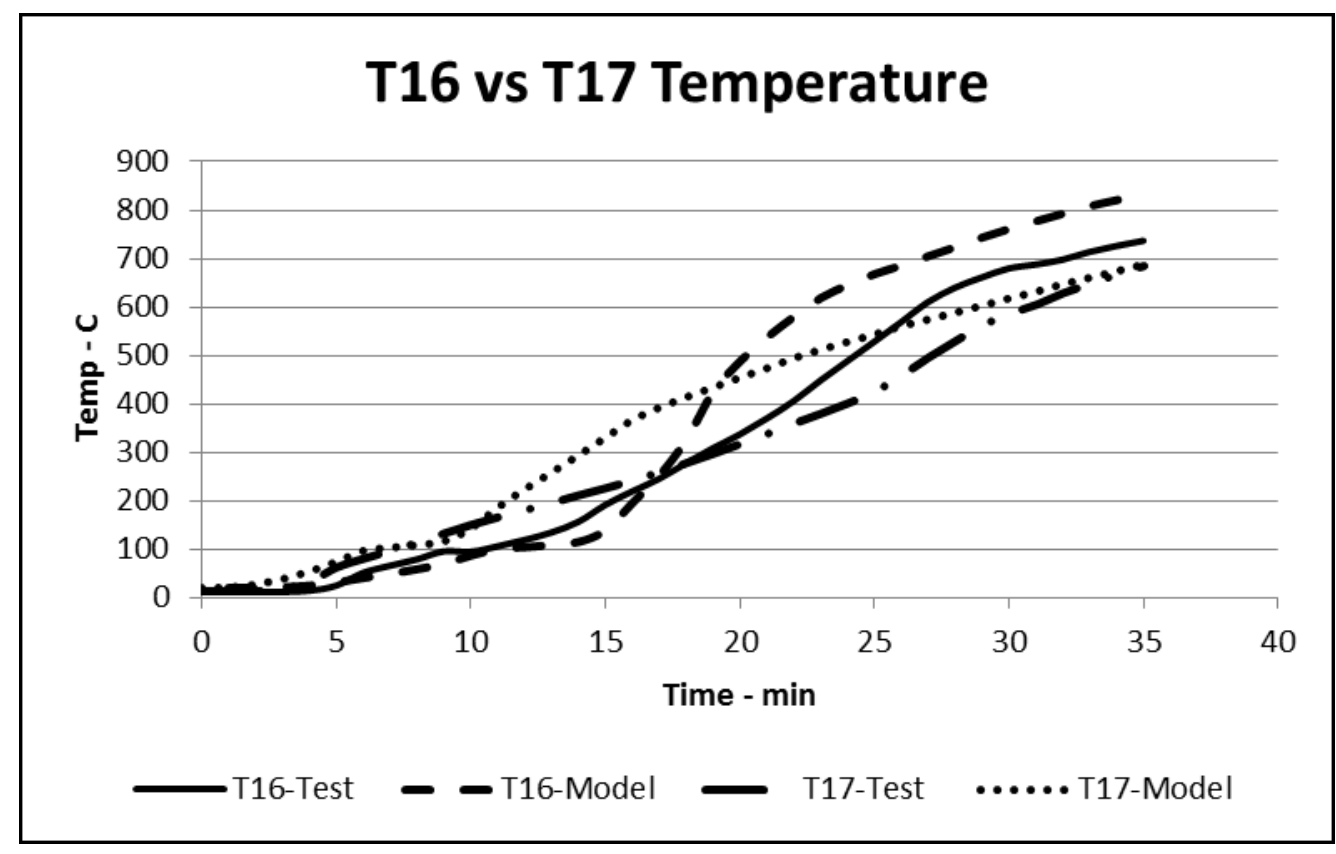

Fig. 4.8 Test vs Model Temperature T16 and T17

The temperatures at points 16 and 17 vary slightly as seen from both the test and model results. This is because points 16 and 17 lie in a region (see Fig. 4.2) of almost uniform temperature, which is affected by the two-directional effect of heat flux from the fire (see Fig.4.7). Comparison of 
temperatures at points 21 and 22 also shows a good correlation between test and model results as seen in Fig. 4.9 and Fig. 4.10 respectively. T22 model temperatures varied significantly from the test after 10 minutes of fire exposure but within the range of recorded temperatures from the two concealed tests. The variation of recorded test temperatures on the assembly can be explained by the natural scatter of material properties and the condition of each test specimen.

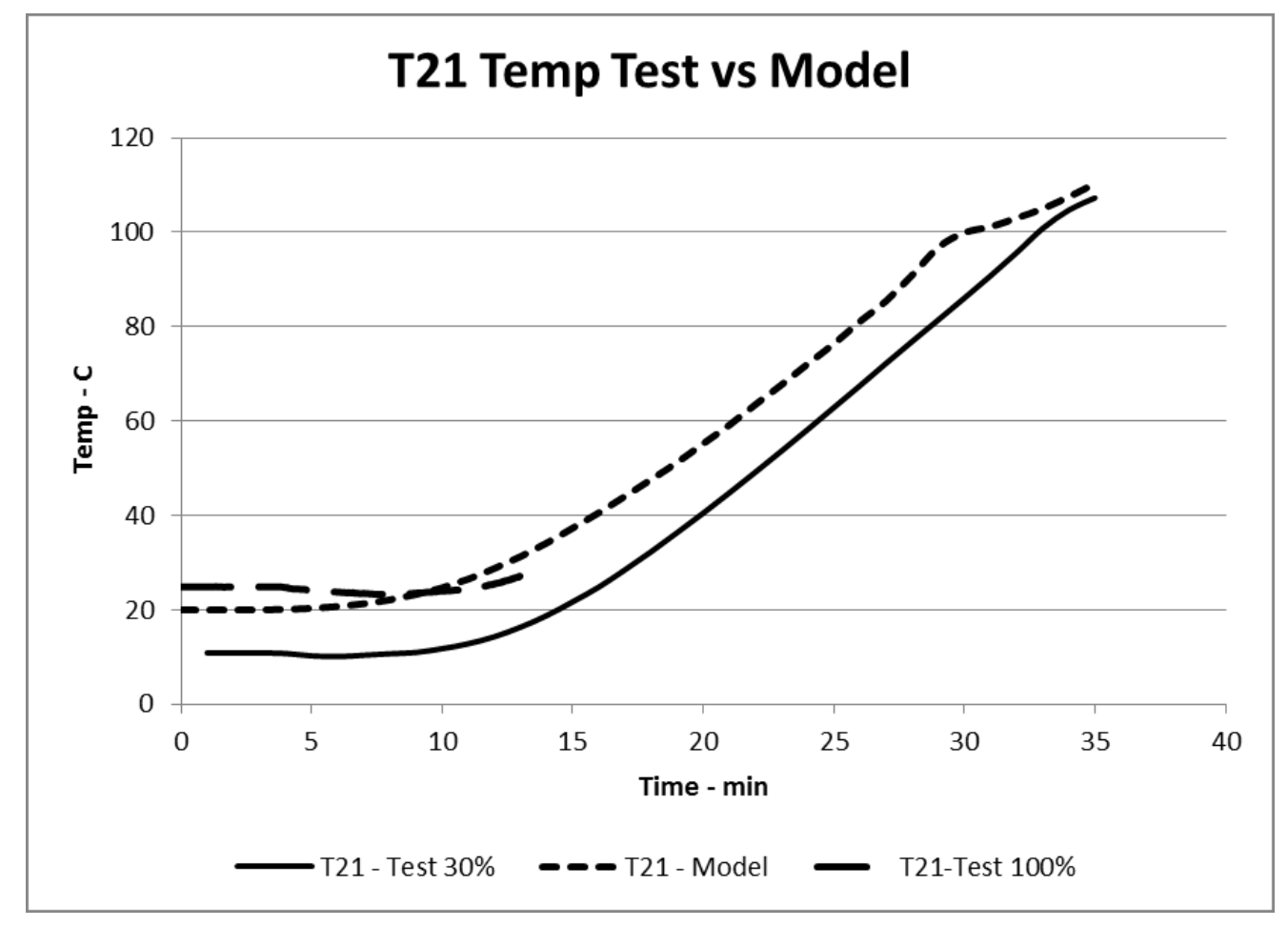

Fig. 4.9 Test vs Model Temperature T21

Temperature development at points 21 and 22 was slightly overestimated by the model at certain times during the fire exposure (see Fig. 4.9 and Fig. 4.10). This can be attributed to the lower ambient temperatures of the test specimens (prior to the start of the test) as compared to the model which assumes a uniform initial temperature of $20{ }^{\circ} \mathrm{C}$. 


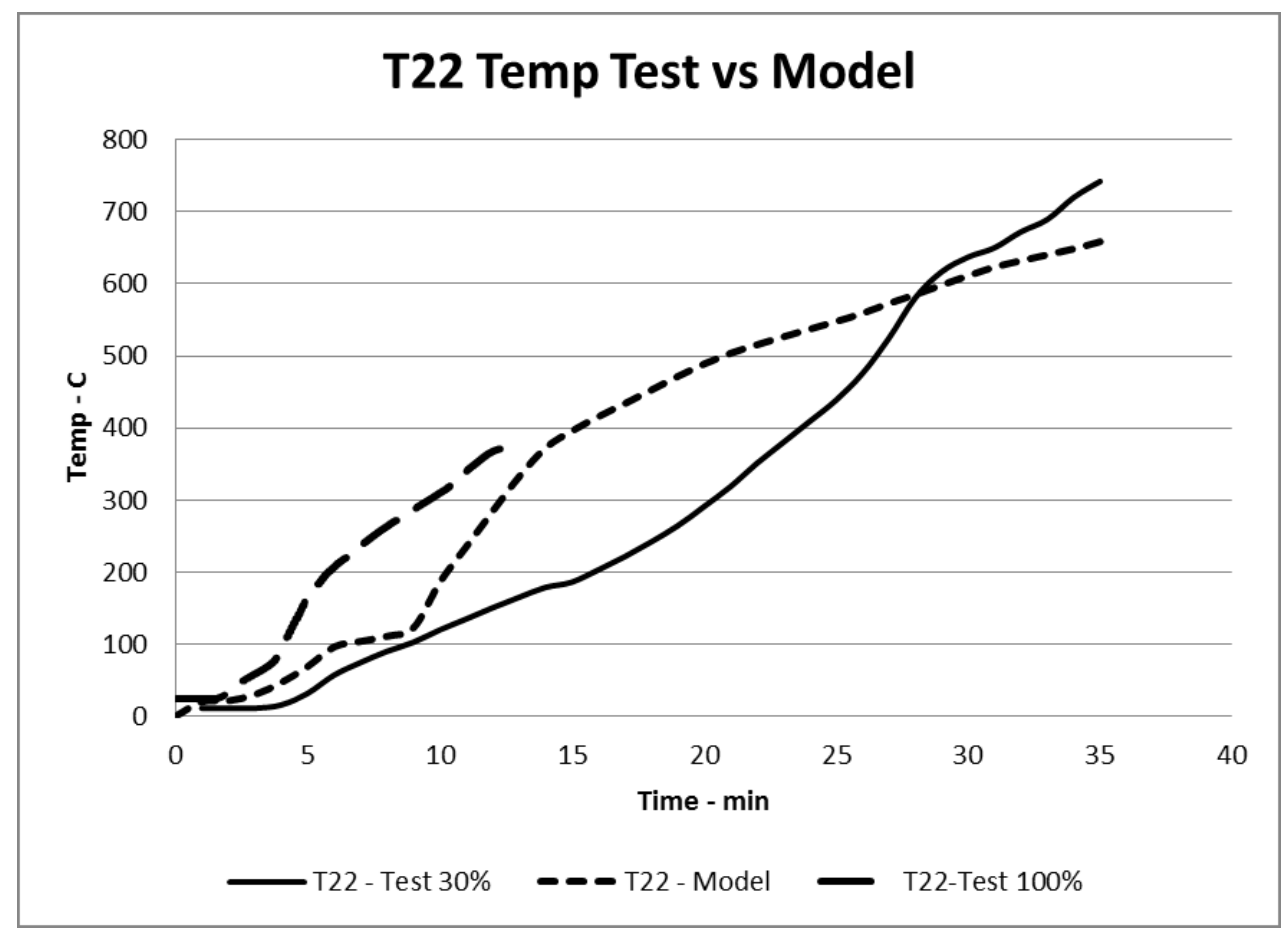

Fig. 4.10 Test vs Model Temperature T22

A comparison of the model temperatures depicts a significant difference between points 16, 19 and 24 in Fig. 4.11. All the three points, which are at the same depth in the wood section record similar temperatures during the early stage of the fire exposure (about 15 minutes). After 15 minutes, point 16 which is strongly influenced by the two-directional heat flux records high temperatures as compared to points 19 and 24, which are exposed to just one-directional heat flux. The effect of protection provided by the floor is seen in Fig. 4.11. T24 temperatures remain generally lower than that of T16. This however represents an ideal situation where the heat flux is absent at the top of the beam (as applied in the model) unlike the test conditions which had some heat flux to the top of the beam. 


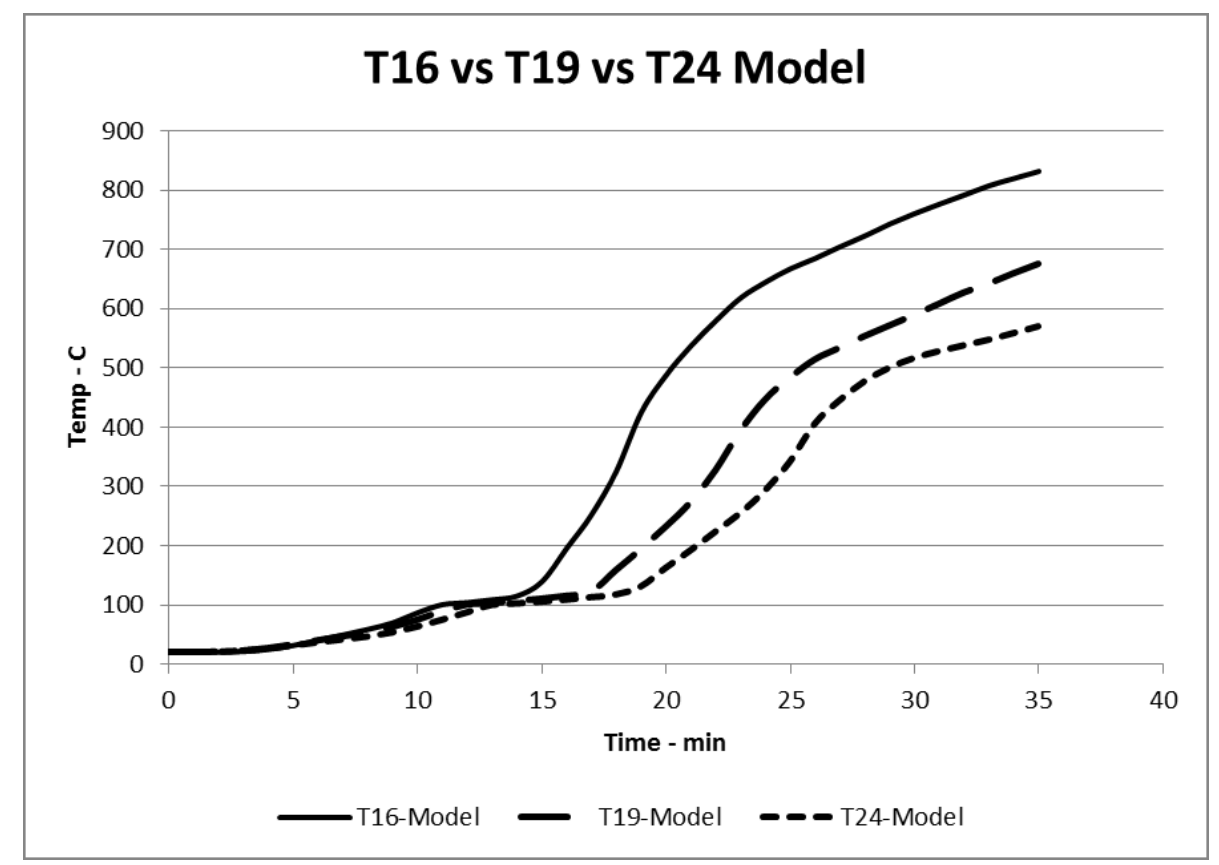

Fig. 4.11 Model Temperature T16, T19 and T24

\subsubsection{Exposed Connection (EX)}

The exposed connection, contrary to the concealed has its steel plates on the outside of the beam section. The influence of the exposed steel plate can be seen in the temperature distribution in Fig. 4.12. Unlike the concealed connection (see Fig. 4.7), the temperature at the core of the beam section remains uniform (at Sec I in Fig. 4.12) at ambient conditions after 30 minutes of fire exposure. The temperatures in the wood increase towards the outside of the beam section due to fire exposure, but areas behind the steel plate have a less penetration of heat as depicted in Fig. 4.12 (b). The presence of the steel plates on the outside of the beams delays the transmission of heat into the wood during fire exposure. Fig. 4.12 (b) also shows that the top regions of the wood section which are not shielded by the steel plate have much penetration of the high temperature contours as compared to the other wood regions below with a cover of the steel plate. 


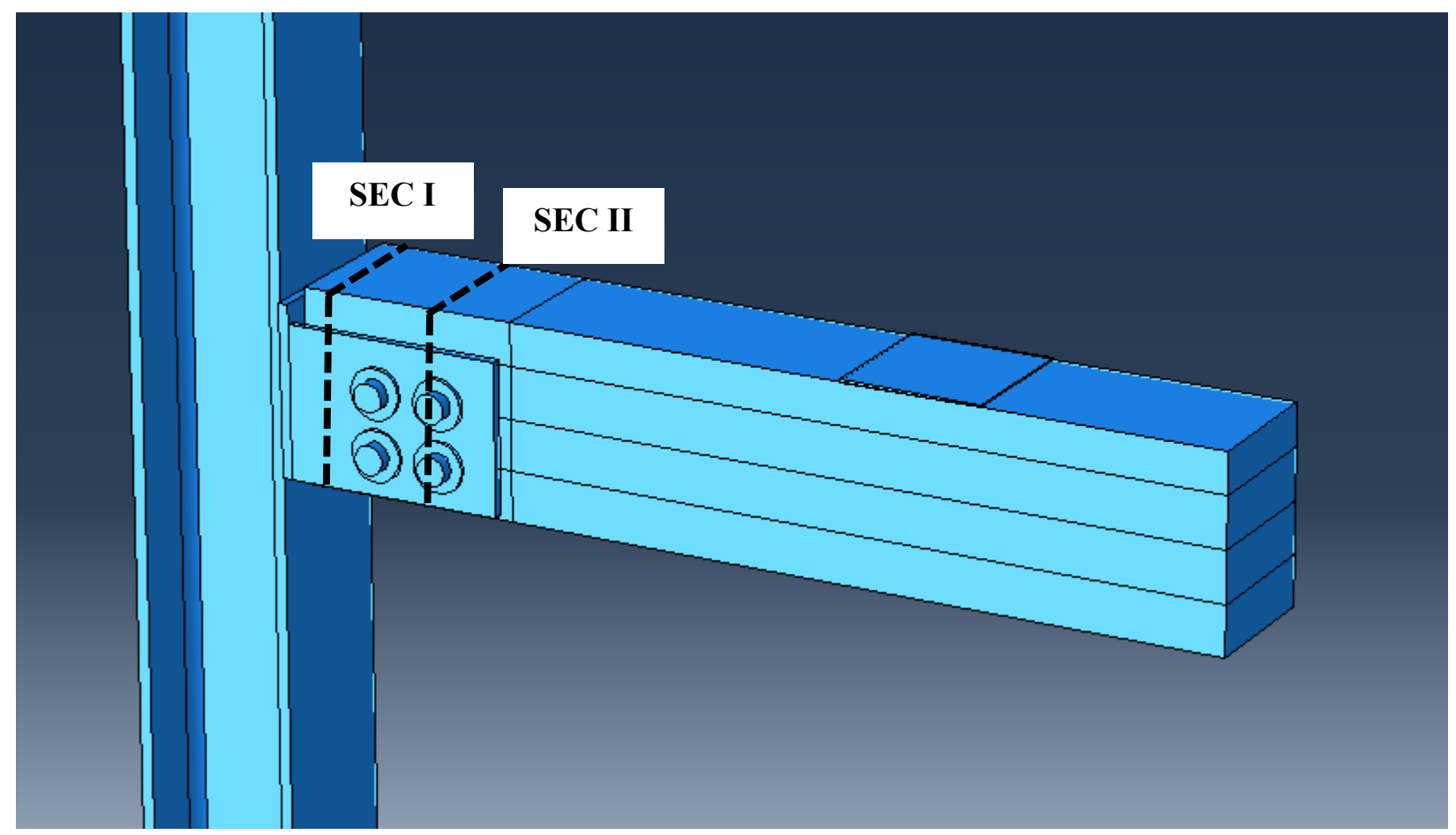

(a) Exposed Connection Assembly
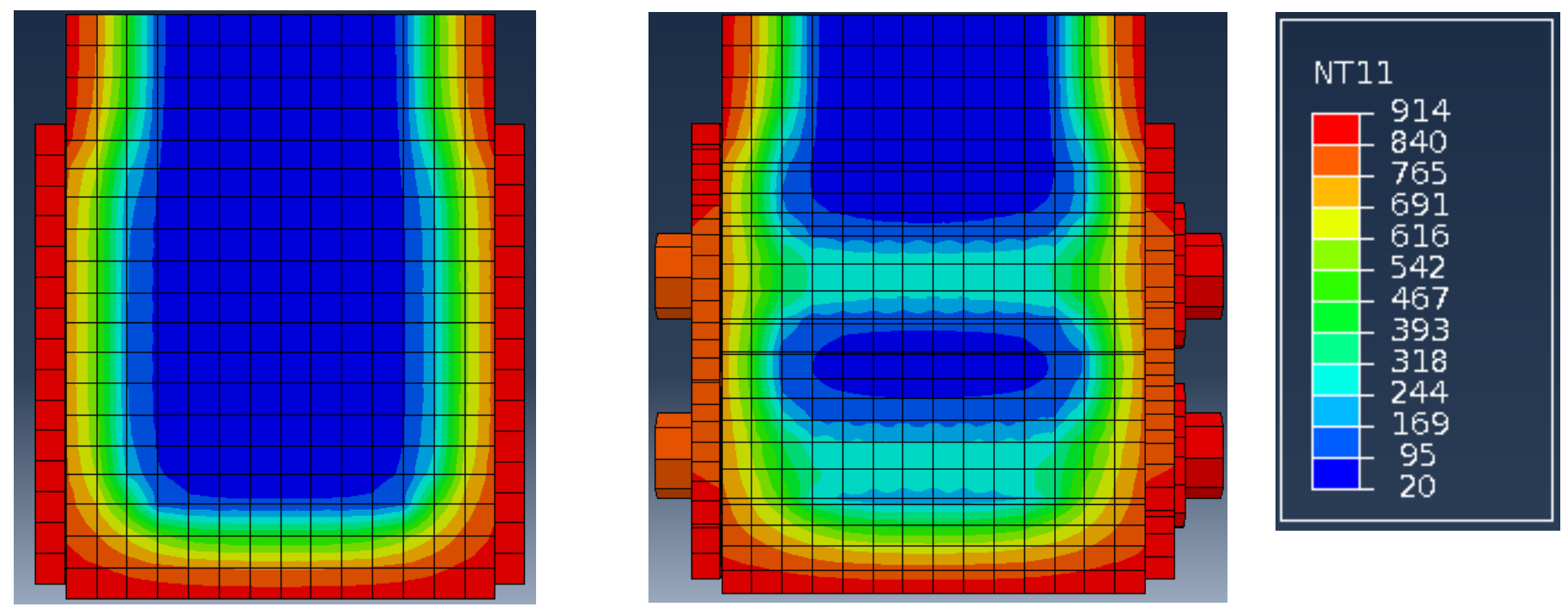

(b) Wood-plate section (SEC I)

(c) Wood-plate-bolt section (SEC II)

Fig. 4.12 Temperature Distribution at the EX Connection after 30 minutes of Fire Exposure 
The temperature distribution at the bolt location for the exposed connection (shown in Fig. 4.12 (c)) shows a similar interior heating effect on the wood which is caused by the bolts as described previously for the $\mathrm{CN}$ connection.

A comparison of the test and model temperature results in Fig. 4.13 shows a good correlation for T16 during the initial stages of the fire. Beyond 10 minutes of fire exposure, the model tends to overestimate the temperatures at point T16. T16 is subjected to heating from the exposed plate which could be delayed by some minor gaps present at the plate-wood surface in the test conditions. The model however assumes a perfect contact condition which results in a faster heating of the wood beneath causing the temperatures to be overestimated.

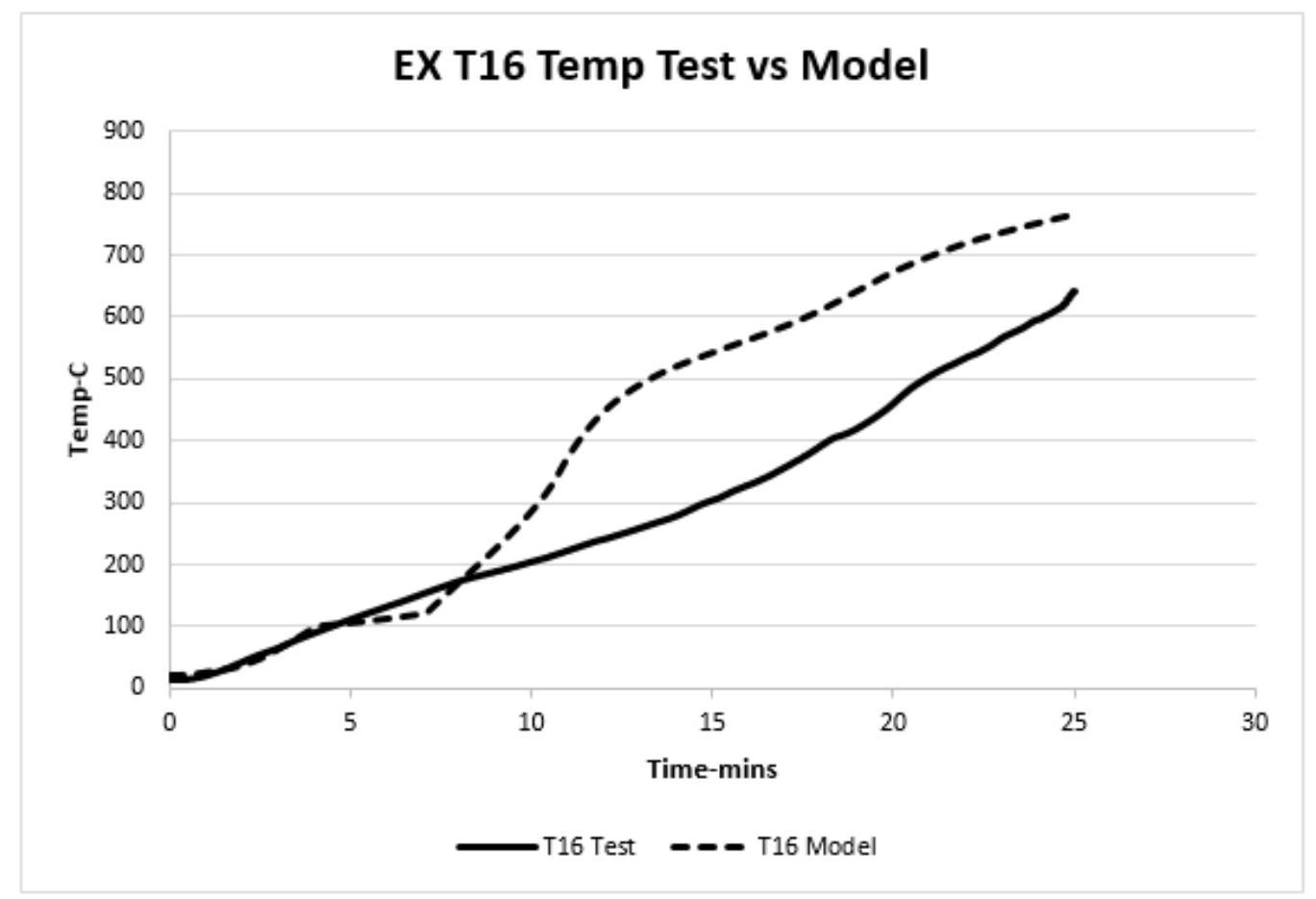

Fig. 4.13 EX Test vs Model Temperature T16 
Fig. 4.14 shows the model and test temperature development at points 18 and 20, which are generally in a good agreement. Point 20 , which is around the middle of the section, records temperatures which are slightly above ambient temperature since it is slowly heated with time during fire exposure from one side of the beam.

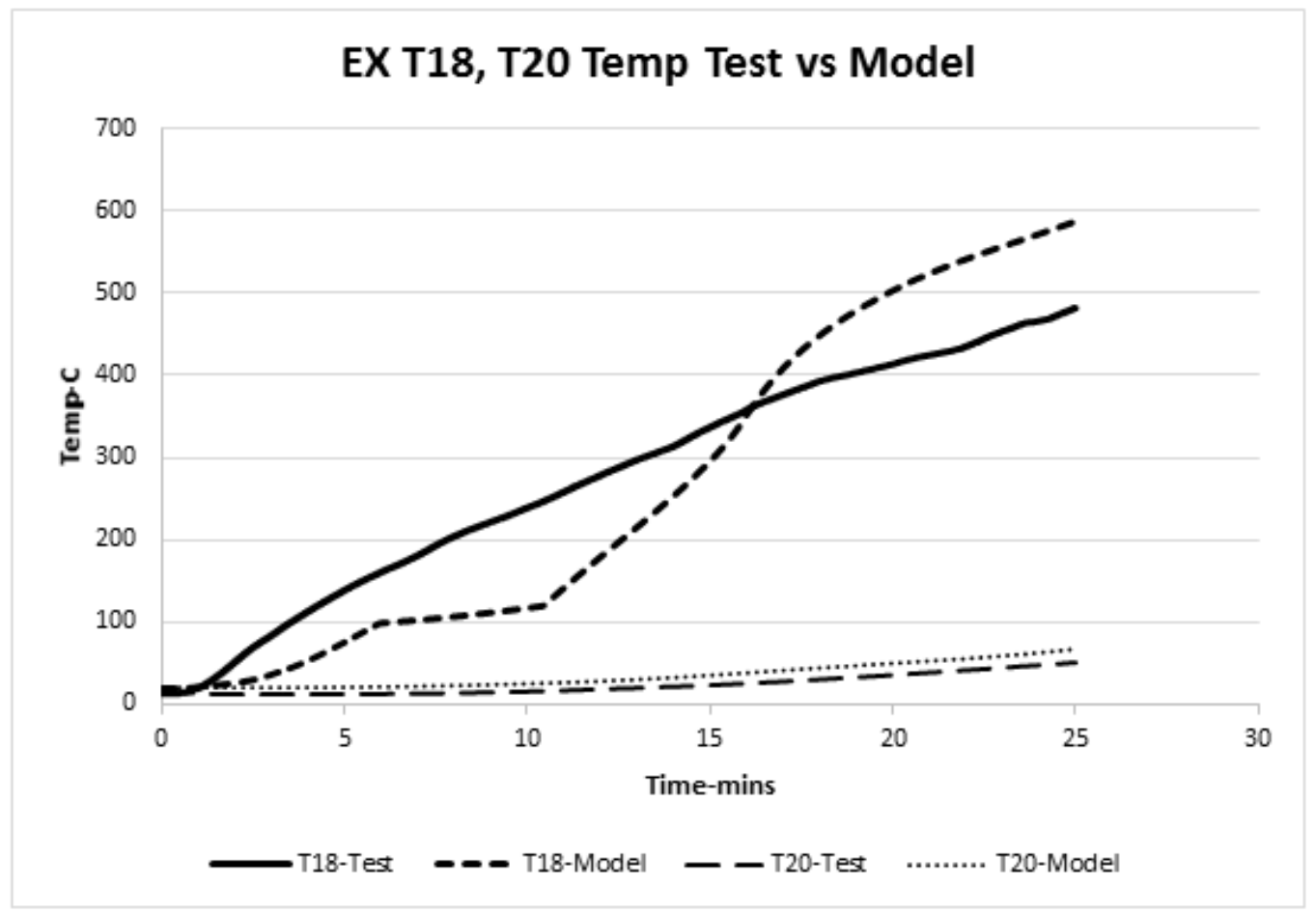

Fig. 4.14 Test vs Model Temperature T18 and T20

\subsubsection{Seated Connection (SE)}

The seated connection is quite similar to the exposed connection because it has outer steel plates, but it also has an additional steel plate at the bottom of the beam, forming a seat. The temperature distribution is hence similar to the exposed connection showing high temperatures in the regions of the exposed wood while the areas behind the steel plates have less penetration of heat during fire exposure. Fig. 4.15 (b) and Fig. 4.15 (c) show the temperature distribution on the section of the assembly at the critical connection area after 35 minutes of fire exposure. 


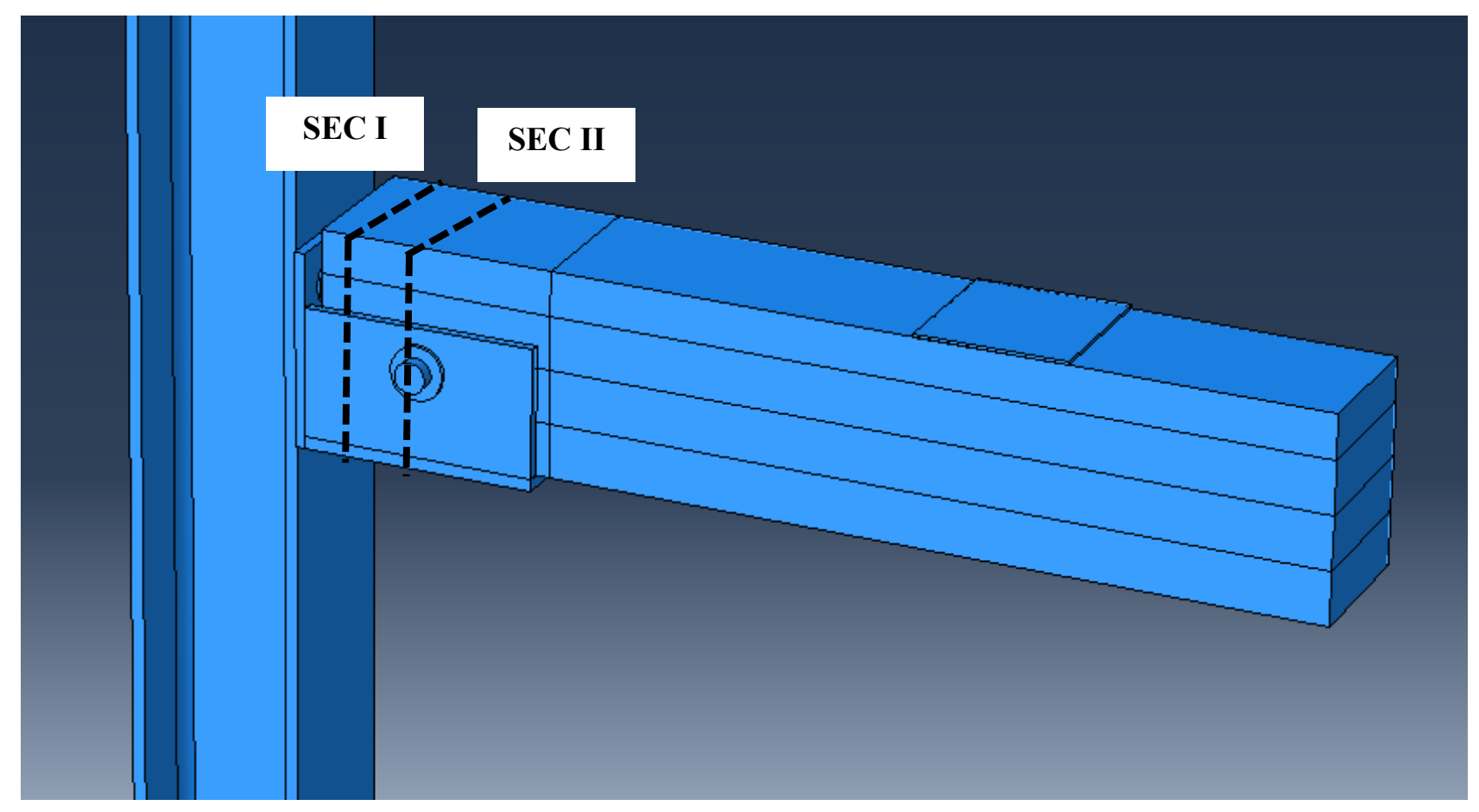

(a) Seated Connection Assembly
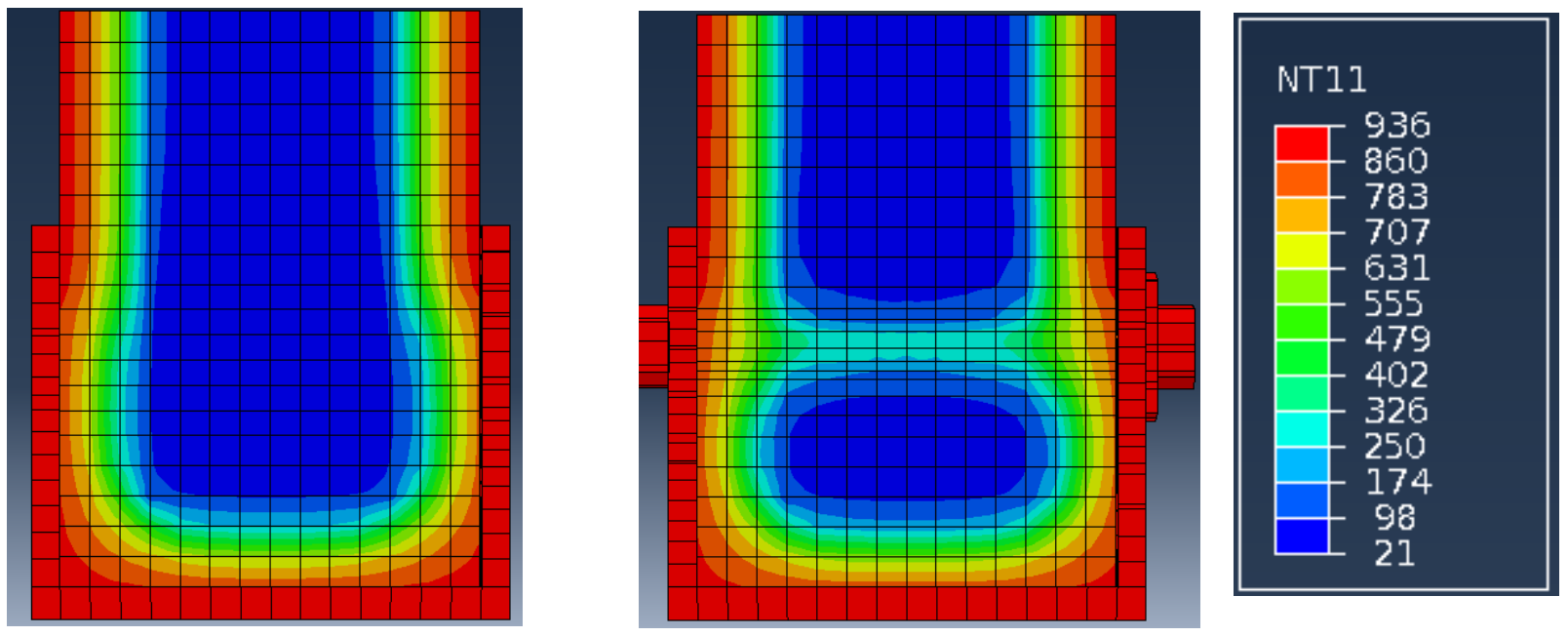

(b) Wood-plate section (SEC I)

(c) Wood-plate-bolt section (SEC II)

Fig. 4.15 Temperature Distribution at the SE Connection after 35 minutes of Fire Exposure 
The presence of the steel plates on the three outer surfaces of the beam section provides a brief partial protection against fire exposure, hence most of the inner regions of the section are at ambient conditions as compared to the exposed connection. The presence of a single bolt further reduces the high temperatures from the fire which could reach the center of the beam section (see Fig. 4.15 (c)).

Comparisons of the model and test temperatures for the SE connection are shown in Fig. 4.16 and Fig. 4.17. The model temperatures compare quite well with those obtained from the test for all points except for the slight variation at T16 and T17 after about 15 minutes of fire exposure. This can again be explained by the perfect contact conditions which were assumed in the model, which heats up the wood faster than what occurs in the normal test conditions, hence the resulting overestimation by the model.

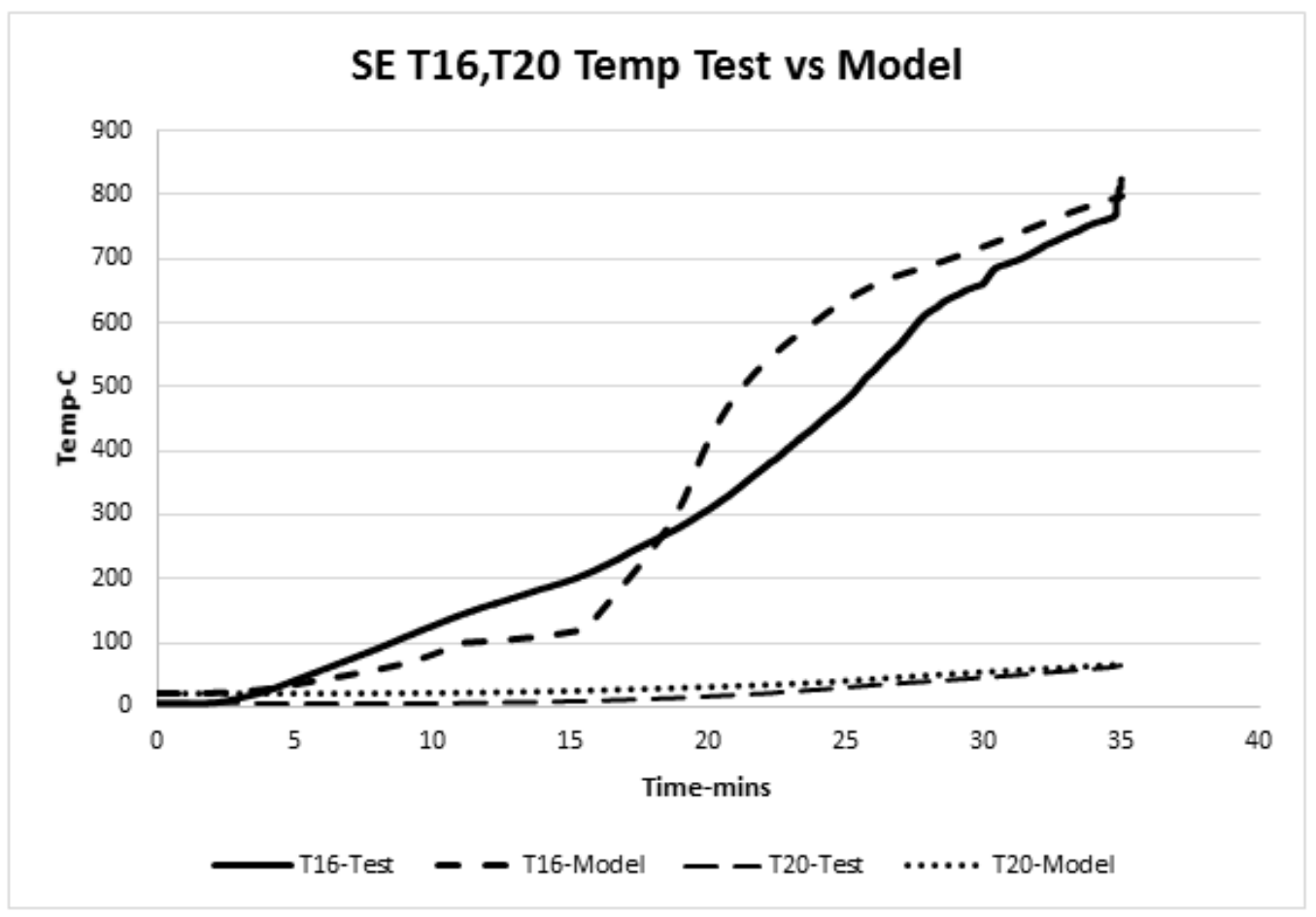

Fig. 4.16 Test vs Model Temperature T18 and T20 


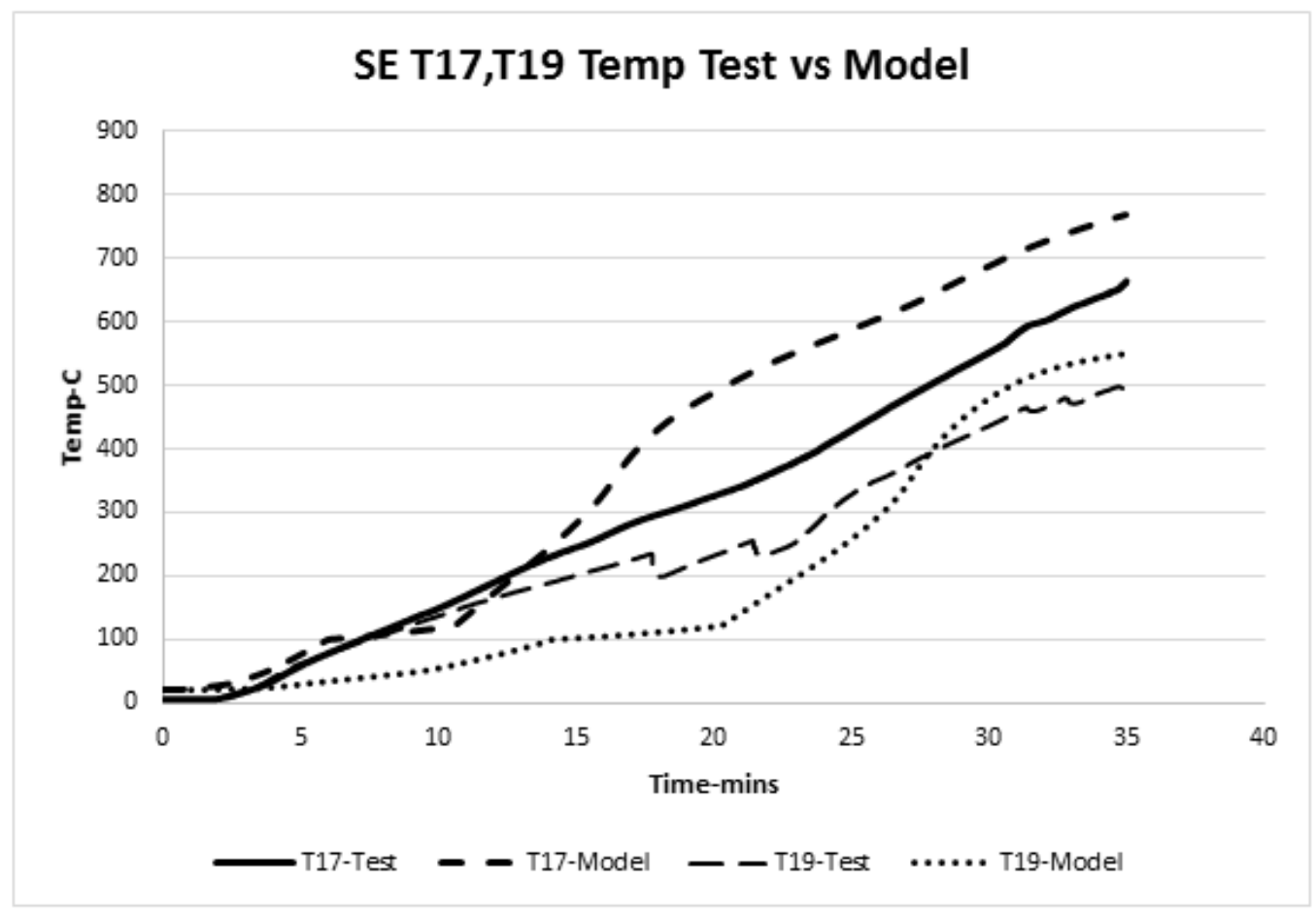

Fig. 4.17 Test vs Model Temperature T17 and T19

\subsection{Charring Rate}

Charring rate is the rate at which wood turns to char after some time of fire exposure. It is normally measured in millimeter per $\min (\mathrm{mm} / \mathrm{min})$. The charring rate of wood is a function of its density and moisture content (Buchanan, 2002). The glulam specimens used in the test had slightly varying density and moisture content thus an average value of the parameters was used in the model.

Apart from the properties of wood, its level of exposure determines the rate at which it chars. Charred wood has negligible structural capacity and so only the residual wood section which is not charred is used to perform structural analysis of timber exposed to fire (Lie, 1977). The need for adequate wood member thickness to account for charring has been demonstrated by the work of various researchers (Noren 1996; Peng and Hadjisophocleous, 2009; Racher et al., 2010) as 
discussed in section 2.3.1.3. In view of this, the need for protection of wood at the connection level is normally critical, which is described by the work of Buchanan and King (1991) and Moss et al. (2009) in section 2.3.1.3. The hybrid connections examined in this research have different levels of wood exposure to fire. The presence of steel plates and bolts and their exposure levels also determine the rate at which heat can reach wood, thus the resulting char produced over time.

Wood chars at a temperature of approximately $280^{\circ} \mathrm{C}$ and above (Buchanan, 2002). Figure 4.18 shows a temperature contour on a cross-section at the beam mid-span from the model alongside a picture of the corresponding charred section from the $\mathrm{CN}$ connection test. An average surrounding thickness of $28 \mathrm{~mm}$ lies within the charring temperature region which was obtained from the model. This leaves a residual section of about $84 \mathrm{~mm}$ from the model as opposed to $85 \mathrm{~mm}$ from the test. In the model, the layer of wood which lies within the charring temperatures of wood is used to estimate the charring rate of wood during the duration of fire exposure and summarised in Table 4.2.
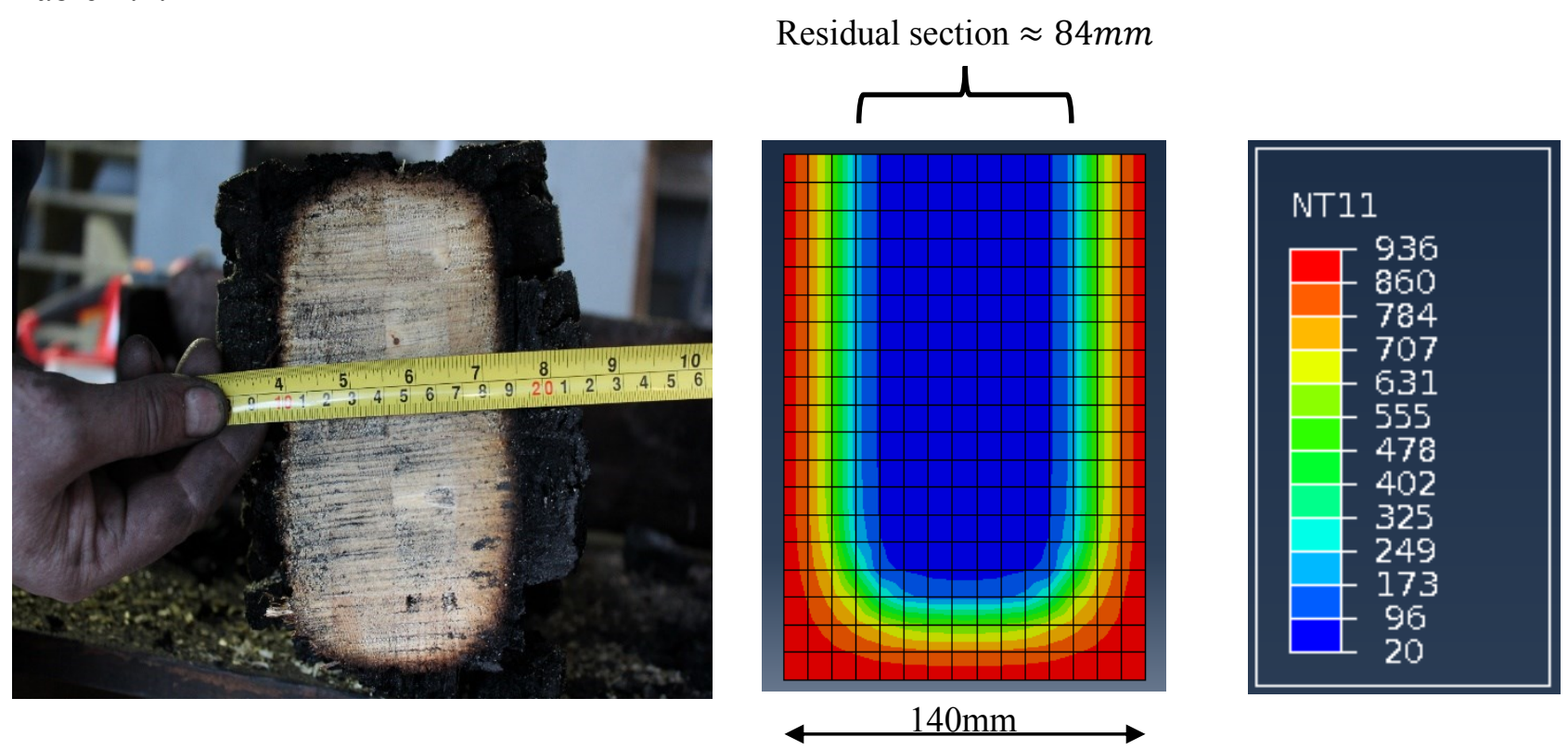

Fig. 4.18 Typical charred section at beam mid-span after 35 minutes 
The model predicted the charring rate of the exposed glulam beam section as $0.8 \mathrm{~mm} / \mathrm{min}$ which is just a $+2.5 \%$ variation from the test result. The average charring rate obtained from both the test and the numerical model is within $\pm 14 \%$ variation of the commonly adopted $0.7 \mathrm{~mm} / \mathrm{min}$ charring rate of wood in standard fires (Buchanan, 2002).

Table 4.2 Charring Rate

\begin{tabular}{|c|c|c|c|c|c|c|}
\hline & $\begin{array}{c}\text { Beam } \\
\text { Midspan } \\
\text { (Average } \\
\text { from Tests) }\end{array}$ & $\begin{array}{c}\text { Meam } \\
\text { Midspan } \\
\text { (Model) }\end{array}$ & $\begin{array}{c}\text { Average } \\
\text { charring rate } \\
\text { of Glulam } \\
\text { (Buchanan, } \\
\text { 2002) }\end{array}$ & $\begin{array}{c}\text { CN at } \\
\text { connection } \\
\text { region } \\
\text { (Model) }\end{array}$ & $\begin{array}{c}\text { EX at } \\
\text { connection } \\
\text { region } \\
\text { (Model) }\end{array}$ & $\begin{array}{c}\text { SE at } \\
\text { connection } \\
\text { region } \\
\text { (Model) }\end{array}$ \\
\hline $\begin{array}{c}\text { Charred layer } \\
\text { (mm) }\end{array}$ & 27.5 & 28 & - & 33 & 19 & 20 \\
\hline $\begin{array}{c}\text { Charring rate } \\
\text { (mm/min) }\end{array}$ & 0.78 & 0.8 & 0.7 & 0.94 & 0.63 & 0.57 \\
\hline
\end{tabular}

The charring at the connection locations is strongly influenced by the bolts and steel plates. For a typical concealed plate connection, the bottom of the plate is subjected to heat flux which transfers heat directly to the center of the beam cross-section, hence increasing the charring rate there.

Bolt influence on charring at the connection

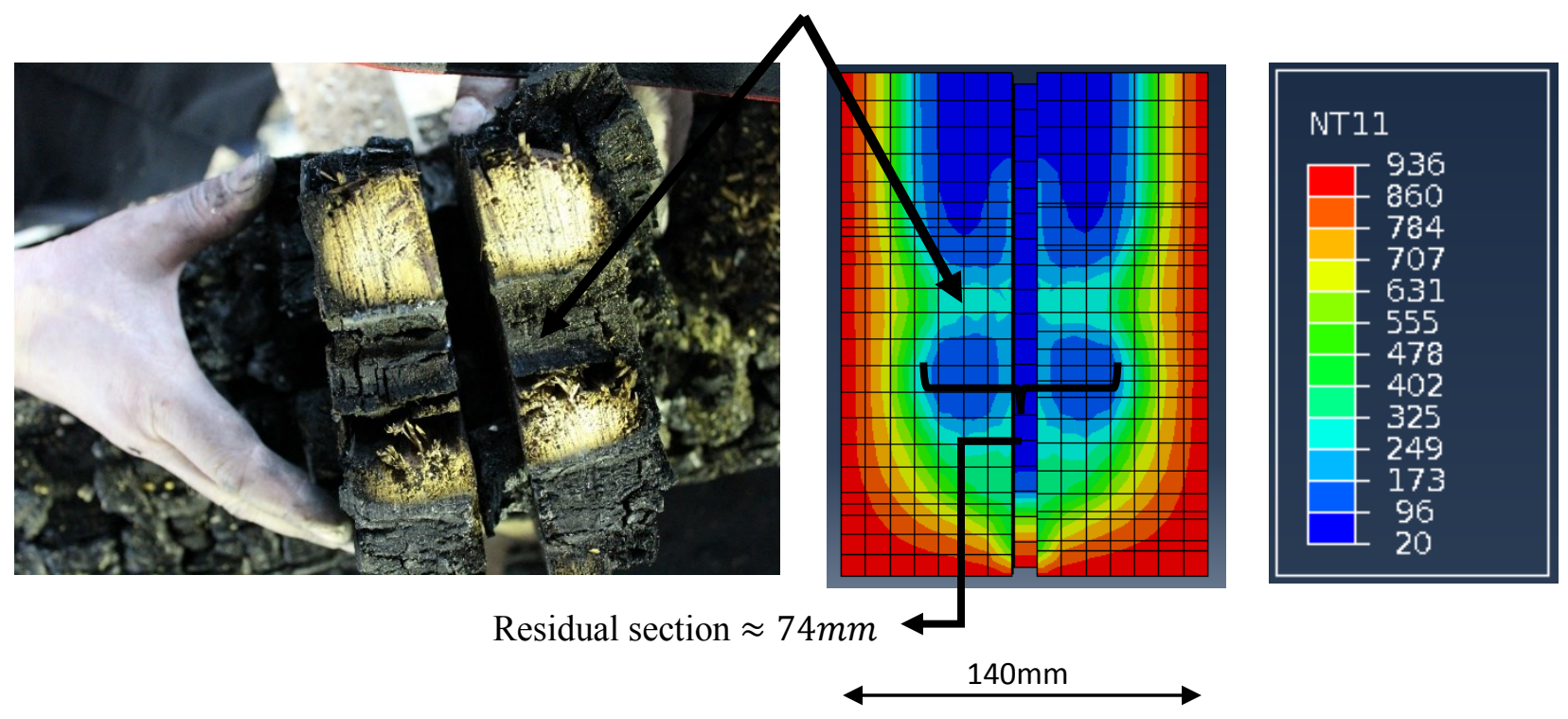

Fig. 4.19 Typical charred section at the CN connection region after 35 minutes of fire exposure 
In Figure 4.19, the bolt and the steel plates increased the charring rate of wood which results in a further reduction of the residual cross section. This produced an average charred layer of $33 \mathrm{~mm}$ and a corresponding charring rate of $0.94 \mathrm{~mm} / \mathrm{min}$.

For the EX test connection, the charring rate at the connection level was further reduced to 0.63 $\mathrm{mm} / \mathrm{min}$. This can be attributed to the partial protection that the steel plates provide to the wood behind them thus delaying its charring (see Fig. 4.20 (a)). A residual section of $122 \mathrm{~mm}$ is obtained after 18 minutes of fire exposure from the test which results in a charring rate of $0.5 \mathrm{~mm} / \mathrm{min}$. (Fig. 4.20 (b)). The model thus predicts the charring rate with $+26 \%$ variation from the test result. The charring front at the bottom of the wood however remains high due to direct exposure to heat.

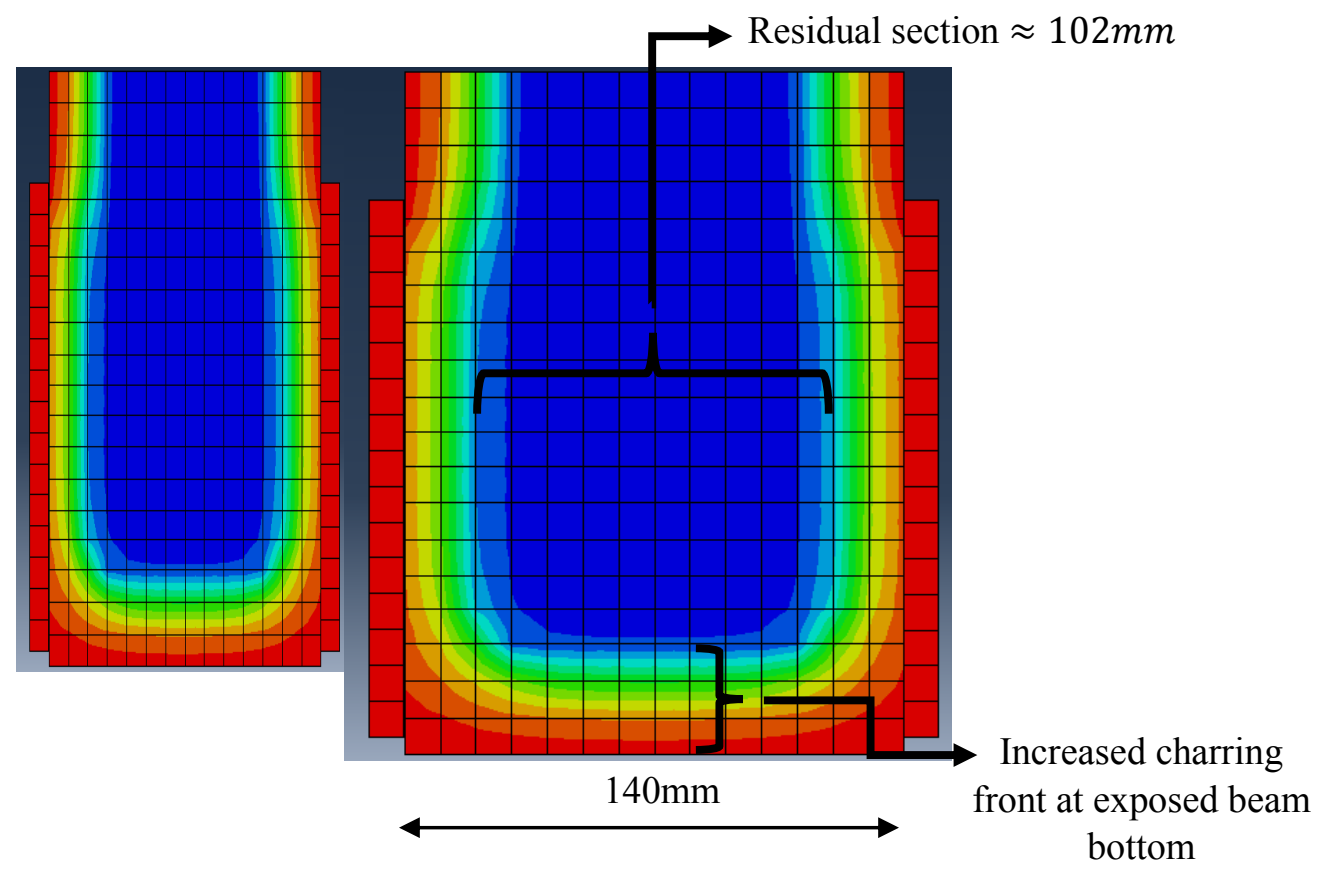

(a) EX after 30 minutes of fire exposure (Model) 


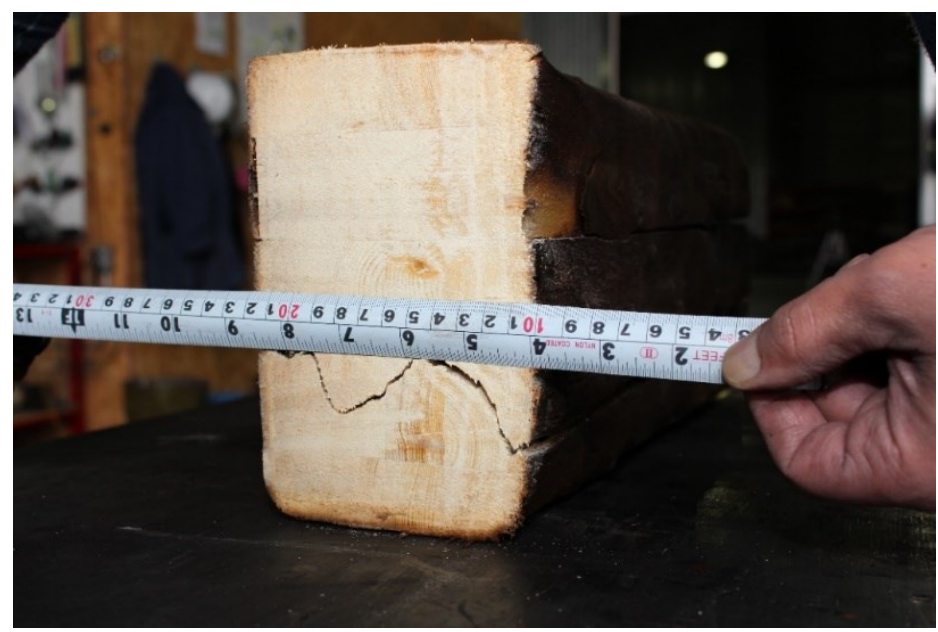

(b) EX after 18 minutes of fire exposure (Test)

Fig. 4.20 Typical charred section at the EX connection region

A similar charring pattern was obtained for the seated connection, which had an additional plate underneath the beam section. A comparison of the residual sections from both the model and the test (see Fig. 4.21), after their respective durations of fire exposure, portrays a good correlation and a negligible variation of the charring rate, which is around $0.57 \mathrm{~mm} / \mathrm{min}$.

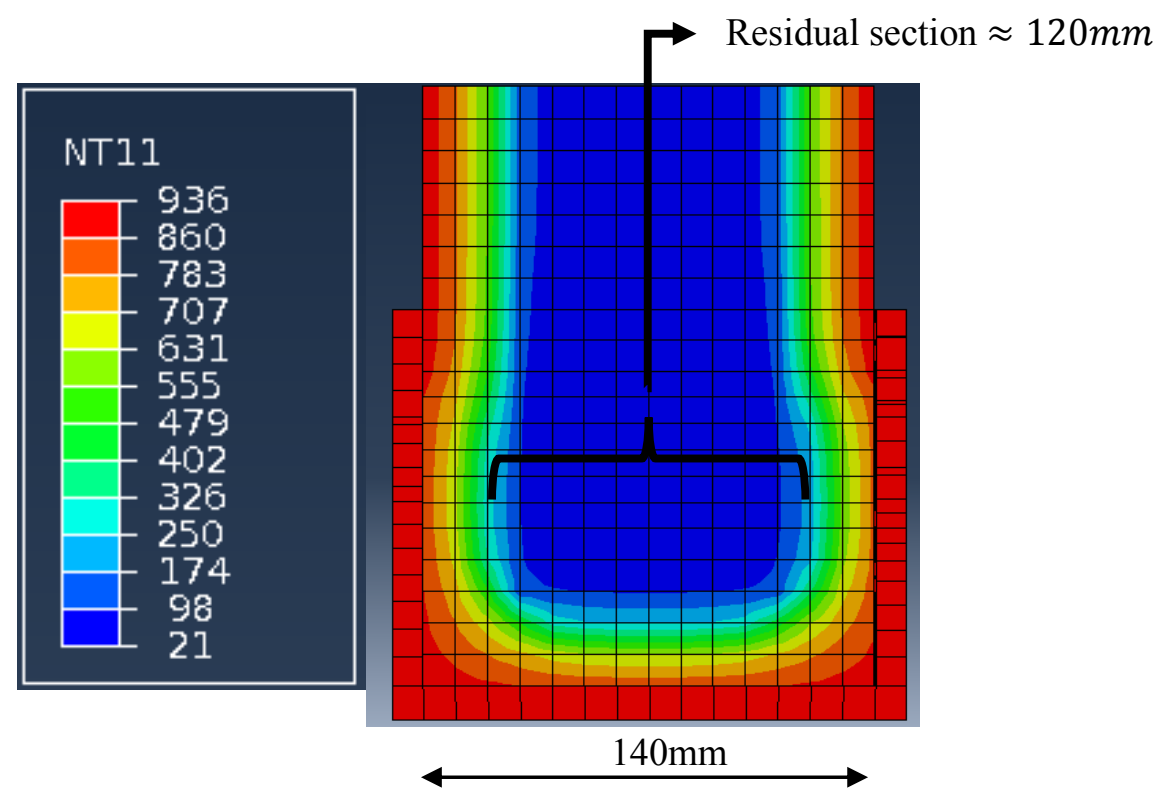

(a) SE after 35 minutes of fire exposure (Model) 


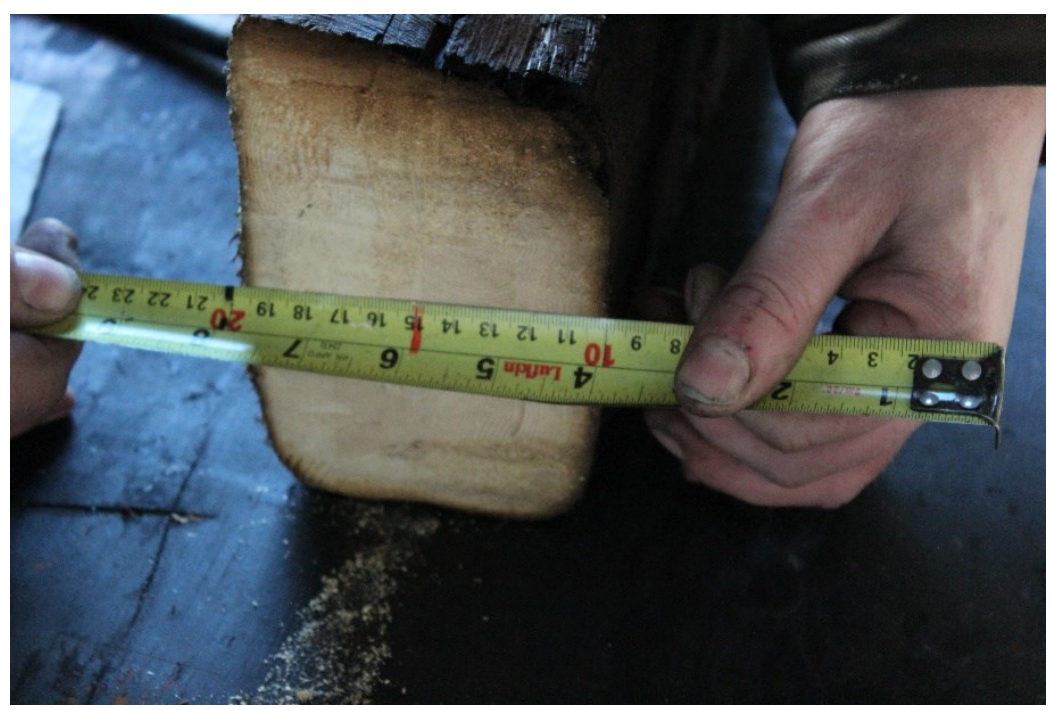

(b) SE after 34.5 minutes of fire exposure (Test)

Fig. 4.21 Typical charred section at the SE connection region

\subsection{Estimation of the Fire Resistance}

Fire resistance is defined as the time it takes for the assembly to reach structural failure when subjected to the standard time-temperature curve. It was therefore necessary to determine the onset of failure in the modelled assembly for a comparison with the test results. The predominant failure mode from the test results was brittle failure (splitting) by crack propagation in the glulam beam which eventually leads to the loss of the assembly's load-carrying capacity at the connection region. The extended Finite Element Method (XFEM) in the Linear Elastic Fracture Mechanics (LEFM) framework (Abaqus 6.112 Manual, 2011) was used to model the formation and propagation of shear cracks in the continuum elements. A crack is initiated when the maximum shear stress criteria within any element is exceeded. The subsequent propagation of cracks is governed by the fracture energies according to Griffith (1921) as described previously in section 3.3.3.3. 
In the simulation of the model, the specimen was first subjected to its corresponding load in the first procedure and followed by applying the transient temperature solution on the assembly for the duration of the fire exposure. The initial application of the full load ratio in the structural model does not lead to failure because the applied load is only a fraction of the assembly's ultimate capacity. In the second part, the heat added to the assembly degrades the stiffness and strength of the elements. This leads to an increase in the internal stresses, damage and eventual failure of the model assembly.

The model tracks the progressive damage in the form of energy dissipated by damage (ALLDMD). Figure 4.22 is an example of a typical ALLDMD curve showing three distinct phases. The first phase is marked by a value of almost zero (before $t_{1}$ ) which indicates no inter-laminar damage (no cracks in the glulam). This is followed by a quick rise which represents the energy released in the formation of cracks and their propagation (between $t_{1}$ and $t_{2}$ ). The third phase which has an almost constant peak value (beyond $t_{2}$ ) means no further energy can be accommodated through damage, indicating that ultimate failure has occurred.

The time to ultimate failure of the model is observed at the point of sudden rise in the ALLDMD value as shown in Figure 4.22. Point $t_{2}$ is the time where no further damage in the assembly occurs, thus an approximation of the fire resistance of the connection. 


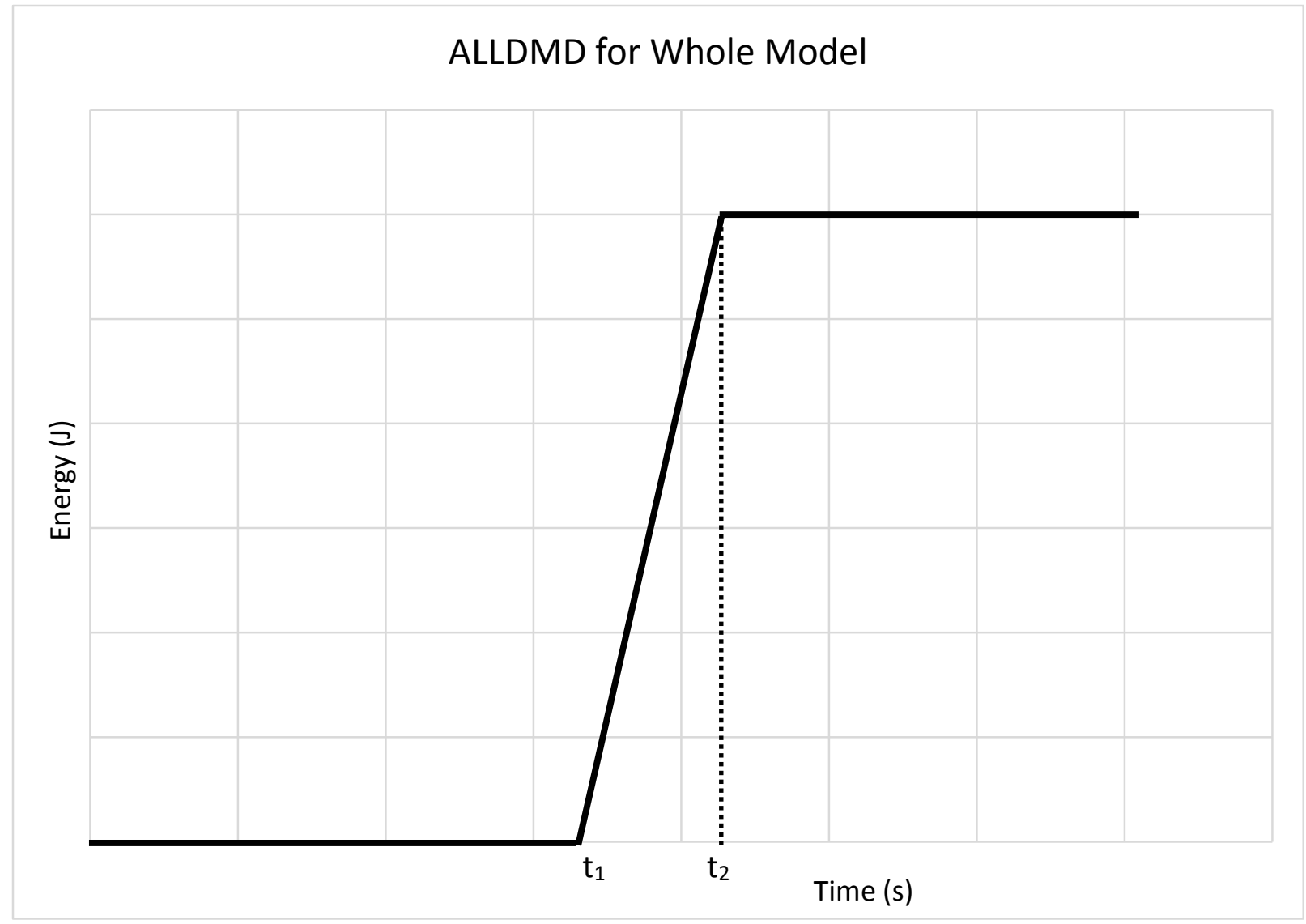

Fig. 4.22 A Typical Damage Energy curve (ALLDMD)

\subsubsection{Concealed Connection}

The time to failure of the concealed plate connection assembly is clearly outlined in the damage energy curves of Fig. 4.23. The time to ultimate failure of the model assembly generally decreases with the application of higher initial loads, a trend which was also observed in the experimental test results. The difference in fire resistance for the $60 \%$ and $100 \%$ load ratios is quite marginal but a significant improvement of about $50 \%$ in fire resistance is obtained when the applied load is further reduced to $30 \%$ of the ambient ultimate capacity. 


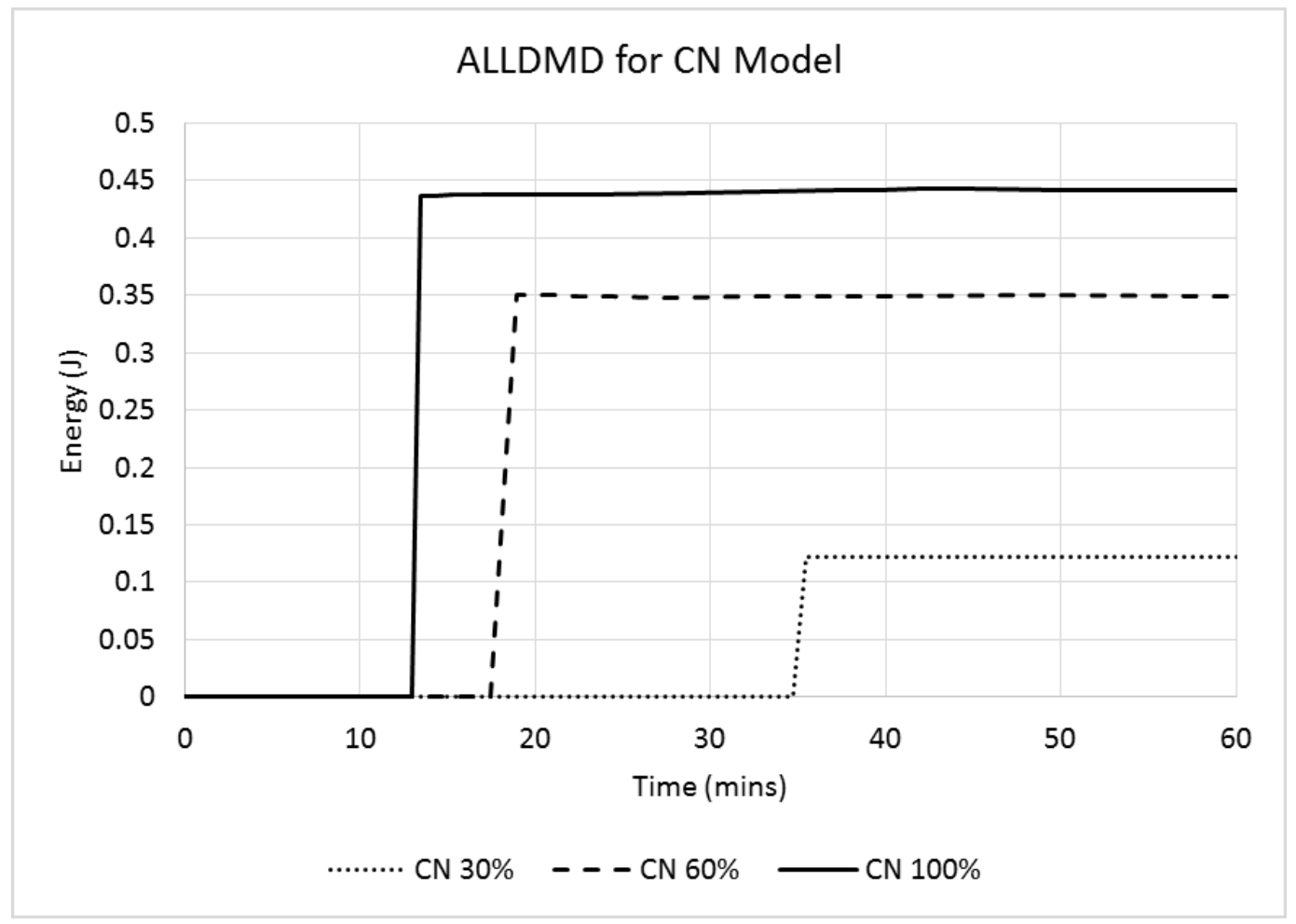

Fig. 4.23 Progressive Damage of the CN Connection

The rate at which the fire degrades the loaded assemblies is also portrayed at the onset of damage (see Fig. 4.23). The ALLDMD curves are generally steep in nature because of the brittle failure which the assembly experiences when subjected to loads. The damage energy of the concealed connection depicts a general trend of decreasing values as the failure times increase (see Fig. 4.23). This can be attributed to the high charring rate $(0.94 \mathrm{~mm} / \mathrm{min})$ of wood at the concealed connection region of wood which produces low-strength charred wood. A high amount of low-strength char was removed by the fire before the latter stage of the fire exposure when the failure was recorded, hence a reduction in the damage energies as the failure times prolonged.

The time to failure of the $\mathrm{CN}$ connection generally agrees with test results as seen in Fig. 4.24, with an average variation of $\pm 7 \%$. The model was also used to predict the response of an assembly 
loaded with a $60 \%$ load ratio and the results seem to be consistent with the other model results. There was no test data for this load ratio.

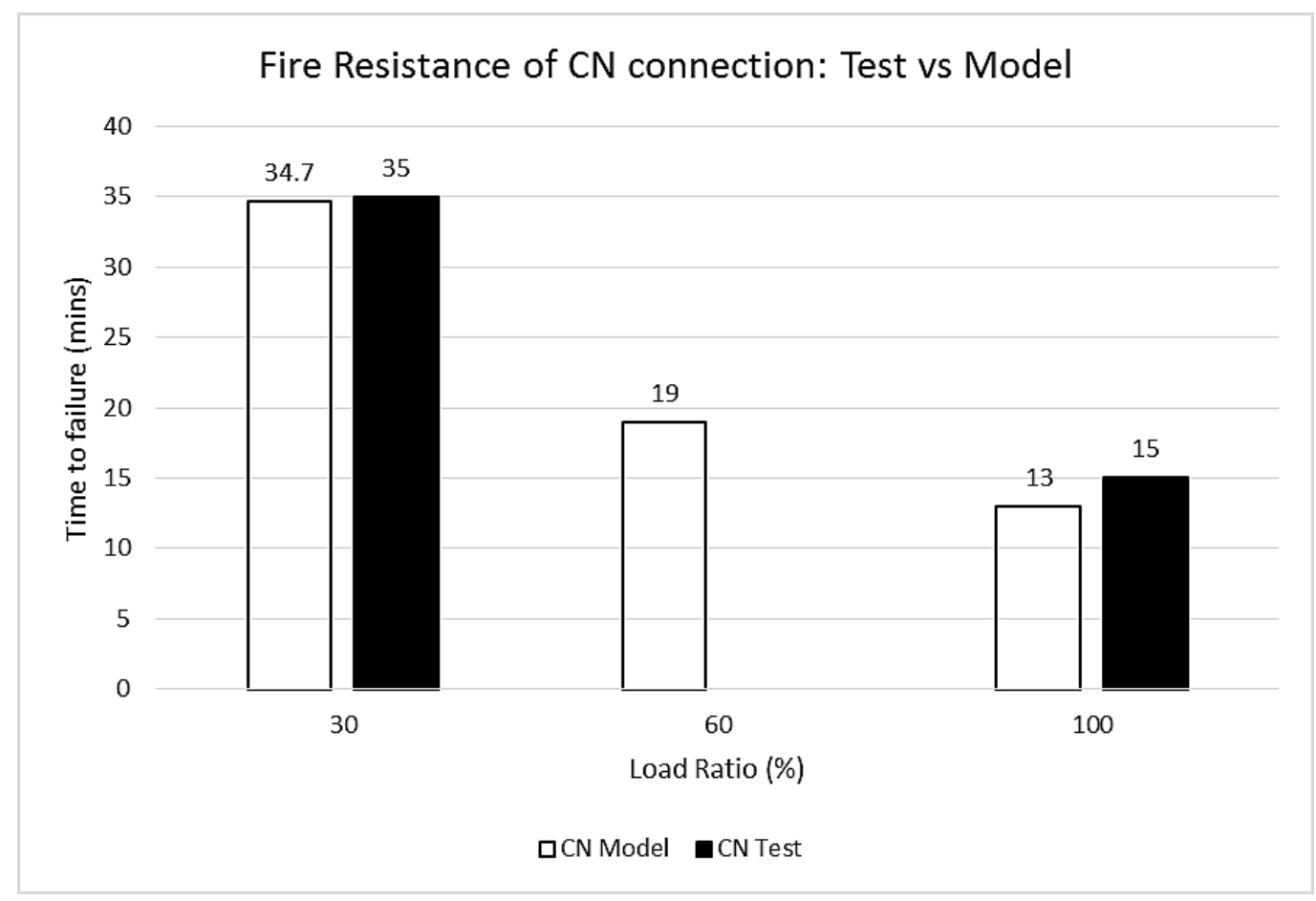

Fig. 4.24 Fire Resistance of the CN Connection

\subsubsection{Exposed Connection}

The model's prediction of an exposed connection's fire resistance is as shown in Fig. 4.25 with the damage curves. Prolonged times of failure under fire are recorded with decreasing applied load ratios on the assembly. The fire resistance of the connection is improved significantly when the load ratio is reduced from $60 \%$ to $30 \%$, as compared to the $100 \%$ load ratio application, which fails in a relatively rapid manner. 


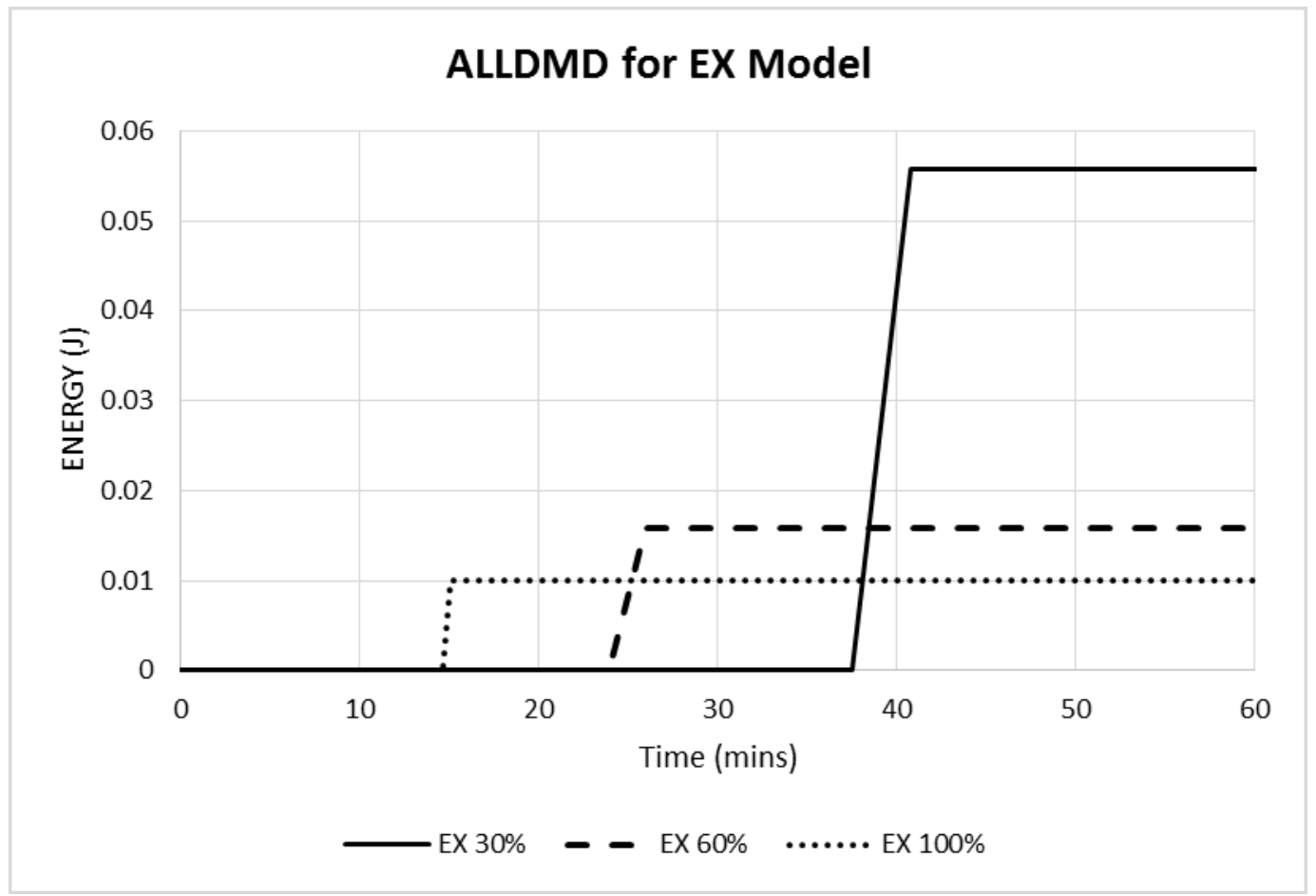

Fig. 4.25 Progressive Damage of the EX Connection

Unlike the concealed connection, the exposed connection recorded an increase in the ALLDMD values as the failure times of the connection increased. This can be explained by the low amount of charred wood produced in the EX connection as opposed to the $\mathrm{CN}$ connection. The partial protection of the beam by the outer steel plates in the EX connection during fire exposure resulted in a wider residual wood section (as compared to the $\mathrm{CN}$ connection) which could accommodate further damage.

The prediction of the fire resistance for the different load ratios is also in a good correlation with the test results as seen in Fig. 4.26. The average variation of the model results from the test results is about $\pm 15 \%$. The model was also used to predict the behaviour of the assembly with a $30 \%$ load ratio. 


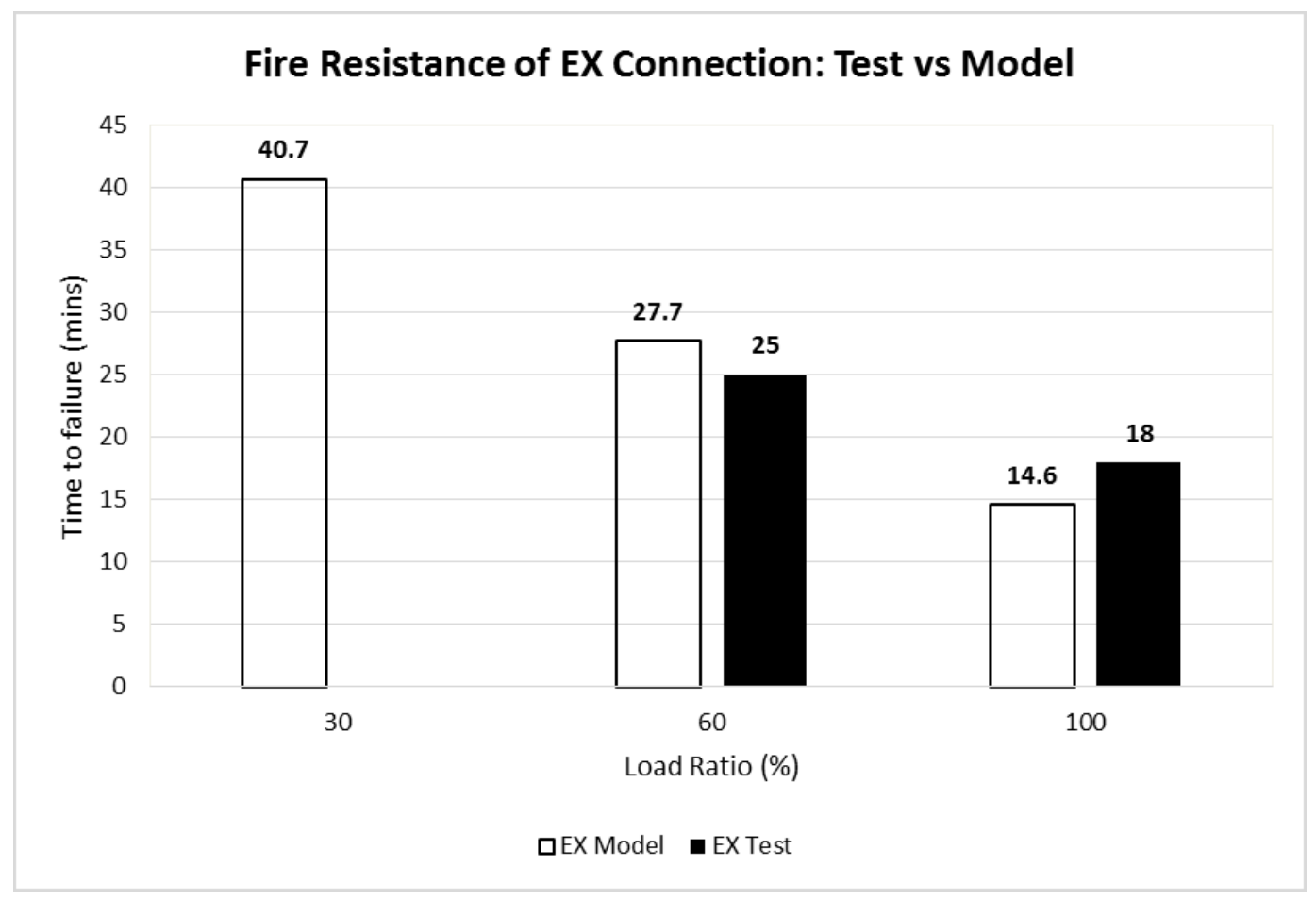

Fig. 4.26 Fire Resistance of the EX Connection

\subsubsection{Seated Connection}

The time to failure of the seated connection is represented by the damage curves in Fig. 4.27. The fire resistance follows the same increasing trend as the load ratios decrease, which have been portrayed in the previous connection configurations. The progressive damage in the SE connection increased as the failure times increased from the $30 \%$ to $60 \%$ load ratio (see Fig. 4.27). This is the same trend observed for the EX connection as discussed previously. The only deviation for the SE connection is the ALLDMD for the 100\% load ratio. With the $100 \%$ load ratio, a high load is applied on the assembly which could result in a mix failure of splitting at the connection area and also bearing failure of the wood on the seated plate, hence the corresponding higher damage recorded. 


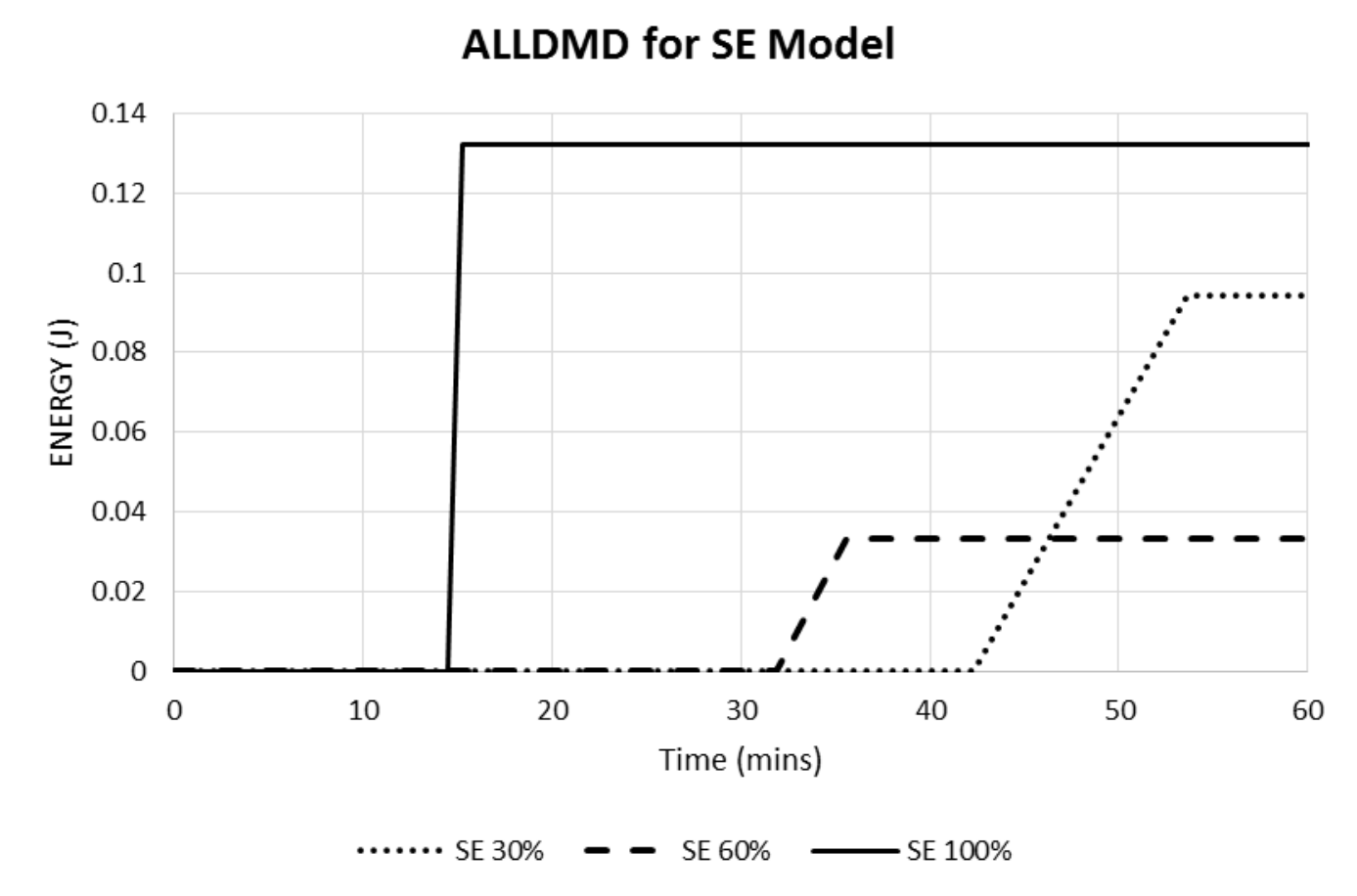

Fig. 4.27 Progressive Damage of the SE Connection

Fire Resistance of SE Connection: Test vs Model

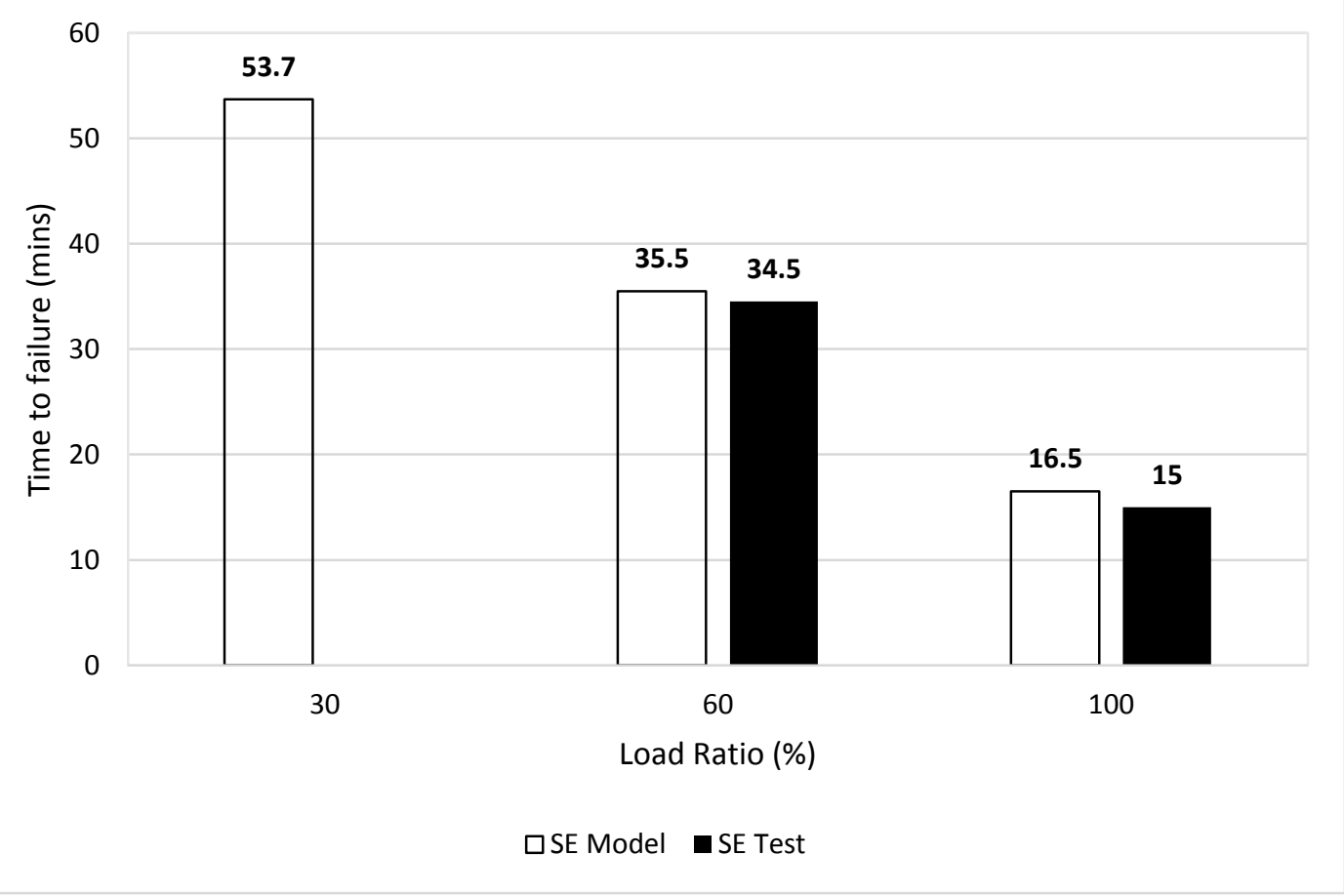

Fig. 4.28 Fire Resistance of the SE Connection 
The predictions of the fire resistance by the model is within an average variation of $\pm 6 \%$ as seen in Fig. 4.28. The model was again able to predict the fire resistance of the assembly with a $30 \%$ load ratio.

\subsubsection{Relative Fire Resistance of the Connections}

In this section, the different connection configurations will be compared to see their relative performance under the respective load ratios. Load ratio is the ratio of the load which is estimated to be on the structure during fire to the normal temperature design load capacity of the members (Buchanan, 2002). In the event of fire, the likely applied loads on the structure can be much less than the design loads adopted in normal temperatures. This is because majority of the occupancy loads would be absent during a fire event. Buchanan (2002) noted that a building would normally have a load ratio of 0.5 , hence it will lose about $50 \%$ or more of its strength before structural collapse will occur.

The load ratio concept is equally an important parameter like the time-temperature curves which are specified by the design standards. Design Standards such as ASTM E119 (1988) and ISO 134 (1975) recommend that the building elements should be subjected to their "maximum load condition" during a fire resistance test (Buchanan, 2002). The maximum load condition should be according to "nationally recognized structural design criteria" (ASTM E119 (1988)). Lower load ratios can be applied if the design criteria are clearly specified for the building element being tested (ASTM E119 (1988)). Higher load ratios result in a reduced fire resistance and very low load ratios on the building elements tend to improve their fire resistance. 


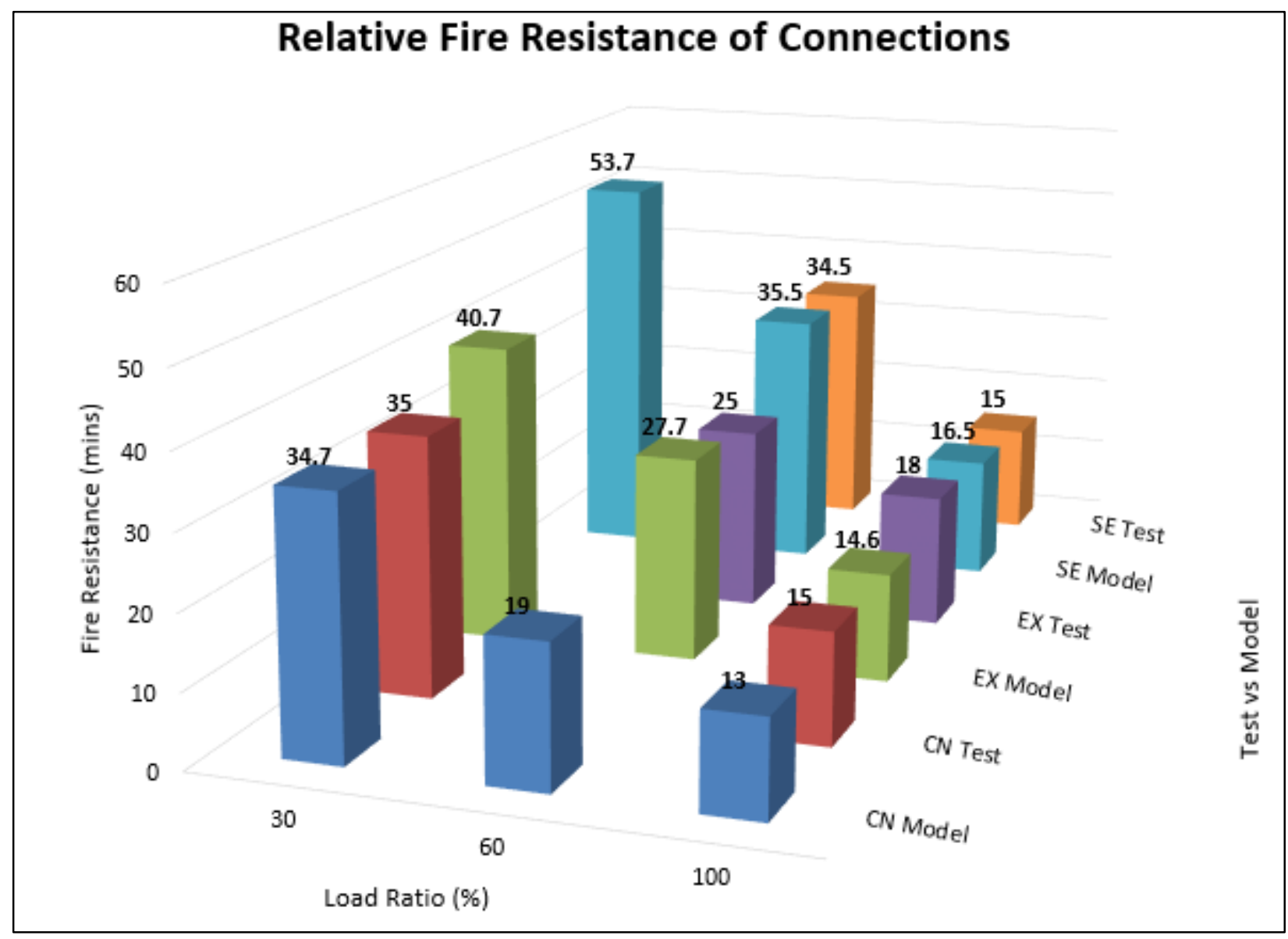

Fig. 4.29 Relative Fire Resistance of the Connections

Fig. 4.29 summarizes the fire resistance of the CN, EX and SE connections under their respective load ratios from both the test and the model. The influence of load ratios is clearly demonstrated for the individual connections. Both the test and model results illustrate that the fire resistance of the connections decreases as the applied load increases. Table 4.3 summarizes the model's prediction of fire resistance of the connections compared with the results obtained from the tests conducted by Sabah (2012). The variation of the model results from that of the tests ranged from $-18.9 \%$ to $+10.8 \%$, which is generally in a good agreement. 
Table 4.3 Fire Resistance of the Connections

\begin{tabular}{|c|c|c|c|c|c|}
\hline \multirow{2}{*}{$\begin{array}{c}\text { Connection } \\
\text { Type }\end{array}$} & \multirow{2}{*}{$\begin{array}{c}\text { Bolt Diameter } \\
\text { (mm) }\end{array}$} & \multirow{2}{*}{$\begin{array}{c}\text { Load ratio } \\
\text { (\%) }\end{array}$} & \multicolumn{2}{|c|}{$\begin{array}{c}\text { Failure Time } \\
\text { (mins) }\end{array}$} & \multirow[t]{2}{*}{ Variation $(\%)$} \\
\hline & & & Test & Model & \\
\hline \multirow{3}{*}{$\mathbf{C N}$} & \multirow{3}{*}{19.1} & 30 & 35 & 34.7 & -0.86 \\
\hline & & 60 & - & 19 & - \\
\hline & & 100 & 15 & 13 & -13.3 \\
\hline \multirow{3}{*}{ EX } & \multirow{3}{*}{19.1} & 30 & - & 40.7 & - \\
\hline & & 60 & 25 & 27.7 & +10.8 \\
\hline & & 100 & 18 & 14.8 & -18.9 \\
\hline \multirow{3}{*}{ SE } & \multirow{3}{*}{12.7} & 30 & - & $\begin{array}{l}53.7 \\
\end{array}$ & - \\
\hline & & 60 & 34.5 & 35.5 & +2.9 \\
\hline & & 100 & 15 & 16.5 & +10.0 \\
\hline
\end{tabular}

It can also be observed in Fig. 4.29 that not much improvement of fire resistance can be obtained among the connections as the applied load tends to approach the ultimate ambient capacity. In Fig. 4.30, the standard deviation of the fire resistance results is an average of 1.4 at the $100 \%$ load ratio (from both test and model) but increases to 6.74 and 7.93 for the $30 \%$ and $60 \%$ load ratios respectively. This means that all the connections perform similarly in fire when highly loaded.

At the $100 \%$ load ratio, the differences in the gradual degradation by fire for the different connections cannot really be distinguished since they all fail in a relatively short time. The high mechanical stresses initially applied on the assembly seems to dominate the assembly failure rather than the gradual degradation of the assembly strength expected from the fire. 
This is based on the premise that not much char is produced within the short duration when the connections were exposed to fire. The difference in failure times are however clear at lower load ratios $(30 \%$ and $60 \%)$ where the long duration of fire exposure are expected to produce significant amounts of charred wood.

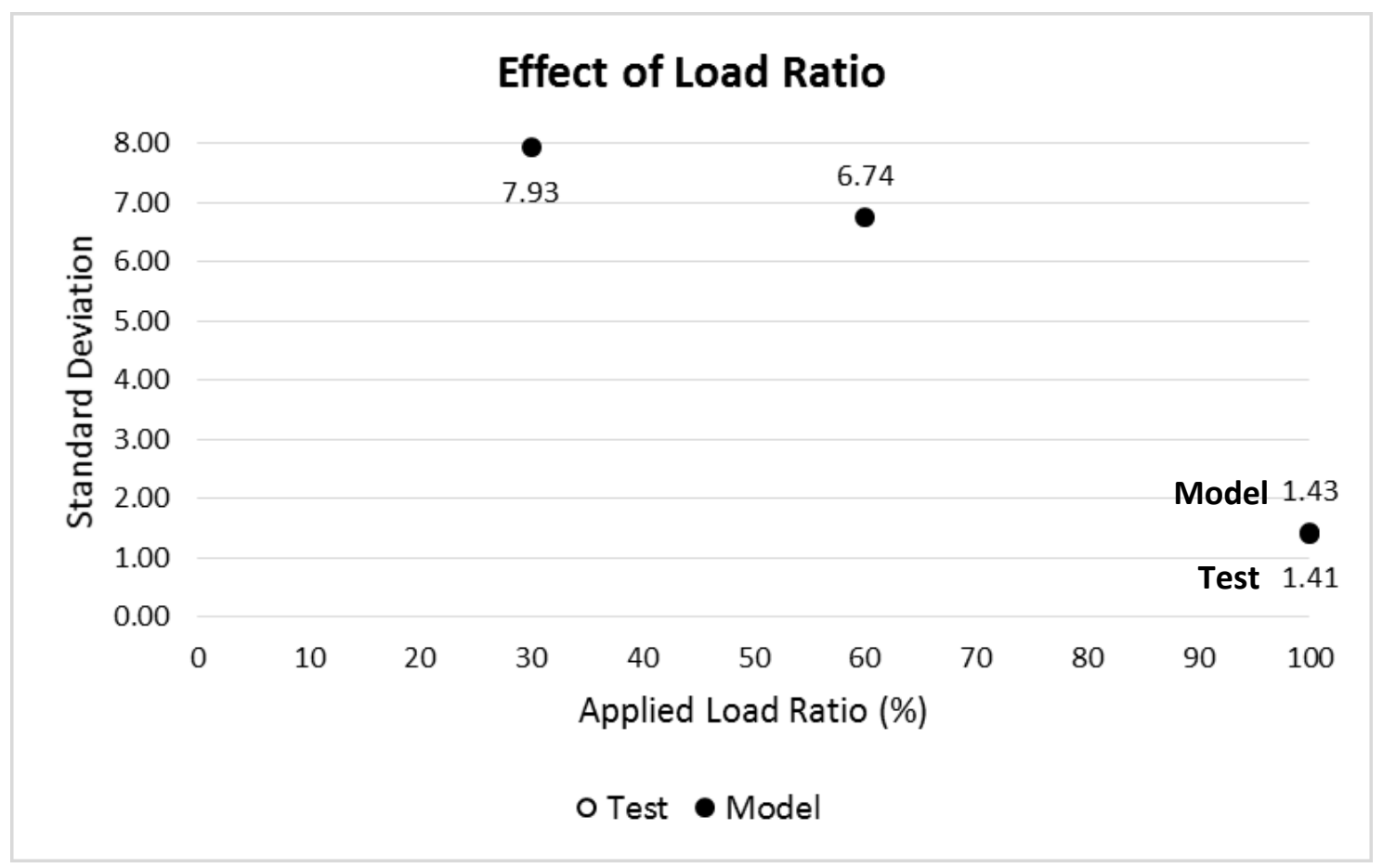

Fig. 4.30 Effect of Load Ratio on the Relative Fire Resistance of the Connections

Fig. 4.30 also describes the sensitivity of the fire resistance results to load levels applied, which is depicted in both the test and the model results. Since the range of $30 \%-60 \%$ load ratio produced a representative fire performance of the different connections, the $50 \%$ load ratio suggested by Buchanan (2002) could be a useful "rule of thumb" when lower load ratios need to be selected in a fire resistance test.

The relative performance of the connections in fire is clearly distinguished as lower load ratios $(30 \%-60 \%)$ are maintained on the individual connection assemblies. The fire resistance is 
significantly increased in the order from $\mathrm{CN}$ to EX to SE when lower loads are maintained on the assembly. As shown in Fig. 4.29, the fire resistance can be improved by as much as $50 \%-80 \%$ when the seated connection is used instead of the concealed connection.

For lower load ratios, the SE connection has a much better fire resistance compared to both the $\mathrm{CN}$ and EX connections. The model predicts a fire resistance of more than 45 minutes which is quite remarkable considering the provision of no protection of the connection. The steel plates which are exterior to the beam are known to provide a brief partial protection to the wood, thus reducing the production of low-strength char. The EX connection, hence has a marginal improvement (about 5 minutes) of its fire resistance from the $\mathrm{CN}$ connection. With additional steel plate underneath the beam as in the SE connection, the connection's capacity in fire conditions is further enhanced, resulting in a significant improvement in the order of 20 minutes fire resistance.

The fire resistance results of the $\mathrm{CN}$, EX and SE connections from both the test and model suggest a better fire resistance for the connections with the exposed plates (i.e. EX and SE). The result of other previous research works (Peng, 2010; Moss et al., 2010) however demonstrate a better fire resistance when the plate sections are concealed in the timber member. These previous works are based on tested timber connections under pure tensile loading. The shear failure of those connections were due to only tensile forces. The mechanism of shear failure in the $\mathrm{CN}, \mathrm{EX}$ and SE connections in this research is due to tensile, compressive and shear stresses in the wooden beam. The compressive resistance provided by the beam can enhance the fire resistance of the connections as compared to the more brittle failure that will occur in the pure tensile-loaded connections. This compressive capacity which could be utilised by the beam connections is 
expected to increase for the EX and SE connections since they have bigger residual sections, thus their enhanced fire resistance as compared to the $\mathrm{CN}$ connection.

Seated connections are normally constructed with a single bolt since the beam already rests well in position on the plate underneath. A half-inch $(12.7 \mathrm{~mm})$ bolt was used for the SE connection during the fire resistance test. An alternative model was created to investigate the behaviour of the connection if there was no bolt. It was noticed that the typical wood brittle failure in the connections was improved since much of the bearing resistance was provided by the "plate seat", hence shifting the splitting occurrence near the mid-span of the beam (see discussion in section 4.6). Fig. 4.31 illustrates the model's record of progressive damage and the estimated fire resistance level of the connection subjected to a $60 \%$ load ratio. A fire resistance of 57.2 minutes was obtained, which is a dramatic improvement of the connection's fire resistance with a bolt (40.7 minutes).

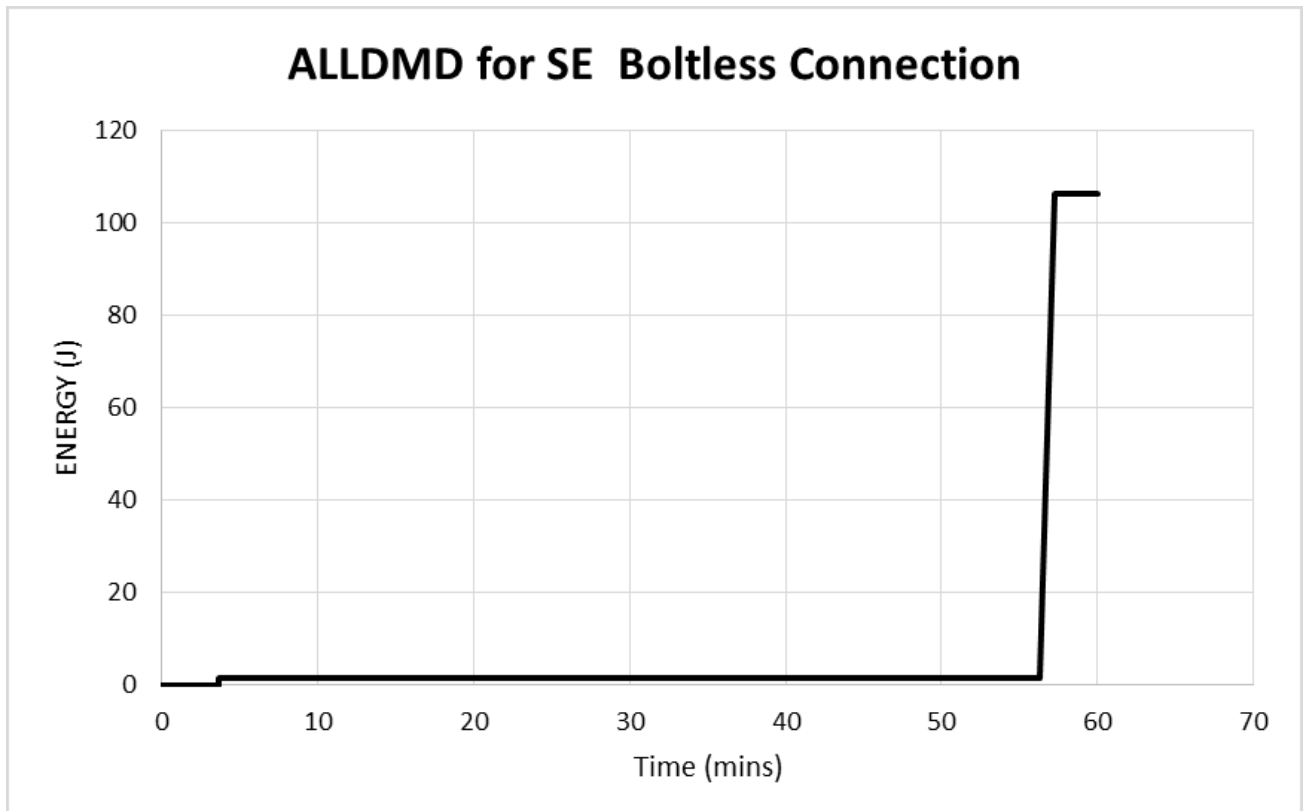

Fig. 4.31 Progressive Damage of the SE Boltless Connection 
The presence of the bolt in the SE connection increases heat transmission to the core of the wood section (as discussed in section 4.3.3) which causes charring and reduction of the connection's capacity in fire. This was also observed by Audebert et al. (2011) in examining the load distribution among fasteners of a steel-timber connection in fire. It was noticed that the bolts transmitted twice as much heat to the connection region as compared to the dowels which were used (Audebert et al., 2011). This was attributed to the exposure of the large area of bolt heads, nuts and washers to fire, which quickly conducted heat to the wood section.

From the fire resistance perspective, the presence of bolts in the SE connection can undermine its capacity in fire. Since the bolt is needed in the SE connection to hold the beam in position, it can be replaced with dowels or smaller diameters of fasteners which transmit less heat to the connection assembly.

\subsection{Structural Damage and Failure}

The extent of damage sustained by an assembly is determined by the level of the applied load and the effects of elevated temperatures on the material strengths. The initial application of loads increases the internal stresses within the elements of the assembly. The imposed stresses at this stage are however lower than the assembly's structural capacity since the load applied is a small proportion of the load that could initiate any damage and cause subsequent failure.

During the second stage of the fire resistance test, the stresses will increase due to a loss of the wood cross-section. So even though the applied load is constant, the stresses will increase, causing failure. What could initiate damage at any point in the material is the degradation of its strength 
due to elevated temperatures. The time-varying temperature distribution in the assembly softens the component materials and indirectly increases the internal imposed stresses. The material becomes both flexible and weak in strength with increasing temperatures. This leads to the initiation of damage in the material once its structural capacity is exceeded.

Damage in the wood element is by the formation and propagation of cracks, often preceded by some amount of deformations of the beam section. The extent of deformation in the wood material depends on its ductility when stressed. Since the plasticity of wood wasn't modelled, the wood failed in a very brittle manner and the recorded deformations were quite significant from the test results. Fig. 4.32 shows a comparison of the model and test results of deformations at the bottom of the beam midspan for a sample connection assembly. The variation of the test from the model is very significant in the order of $-70 \%$ after 30 minutes of fire exposure. This shows the limitation of the current model, which excludes wood plasticity, whereas some amount of wood plasticity was depicted in the test results.

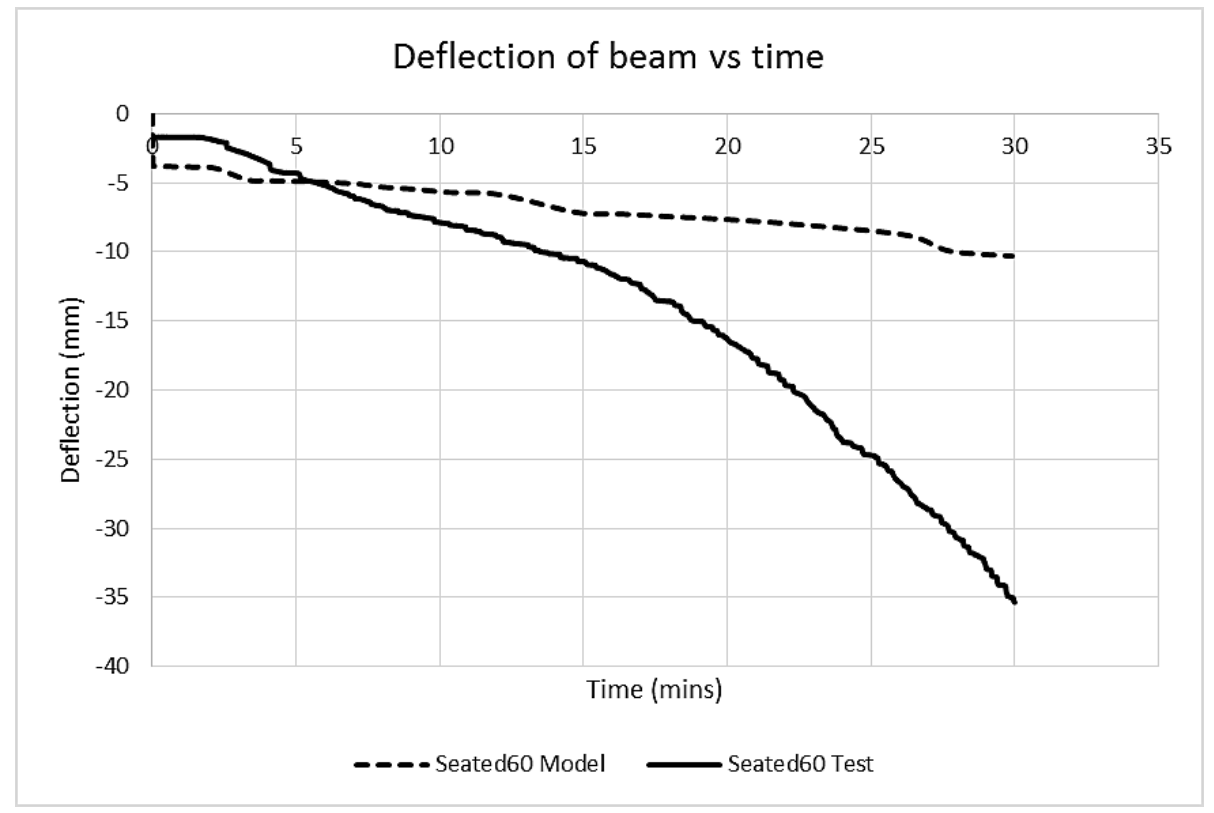

Fig. 4.32 Midspan deflection of beam against time of fire exposure 
The predominant failure mode in the assembly was the splitting of wood parallel to grain and this was noticed in both the test and the numerical model. These splits originated at the bolt-hole edges, which are regions of high stress concentration. Under loading, the bolt shank transfers compressive stresses to the wood below, which acts as a wedge imposing lateral stresses parallel to wood grain to form cracks. Once the localized crack at the connection level is formed, it propagates along the beam and eventually leads to splitting failure. This failure mode of the test and model are shown in Figure 4.33, which was typical of the $\mathrm{CN}$ and EX connections.

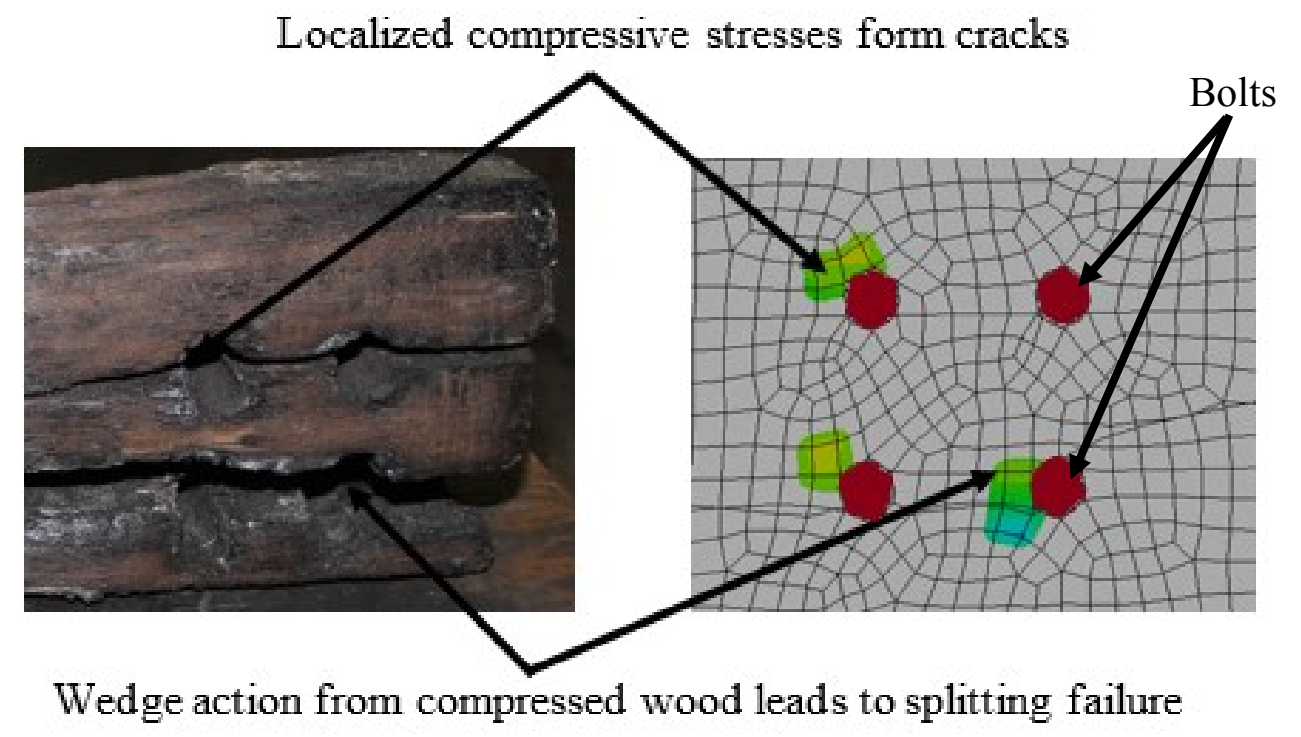

Fig. 4.33 Origination of Failure from the bolted regions

For the seated connection, the stress concentration at the bolt region is limited due to the additional support of the beam on the steel plate. This shifts the splitting failure of wood to the mid-span sections of the beam and around the regions where the point loads are applied (see Fig. 4.34). The exclusion of bolt in the model also illustrates this physical observation. In Fig. 4.35 and Fig. 4.36, the stress concentration in the wood element occurs near the beam mid-span which causes the initiation of damage there. 


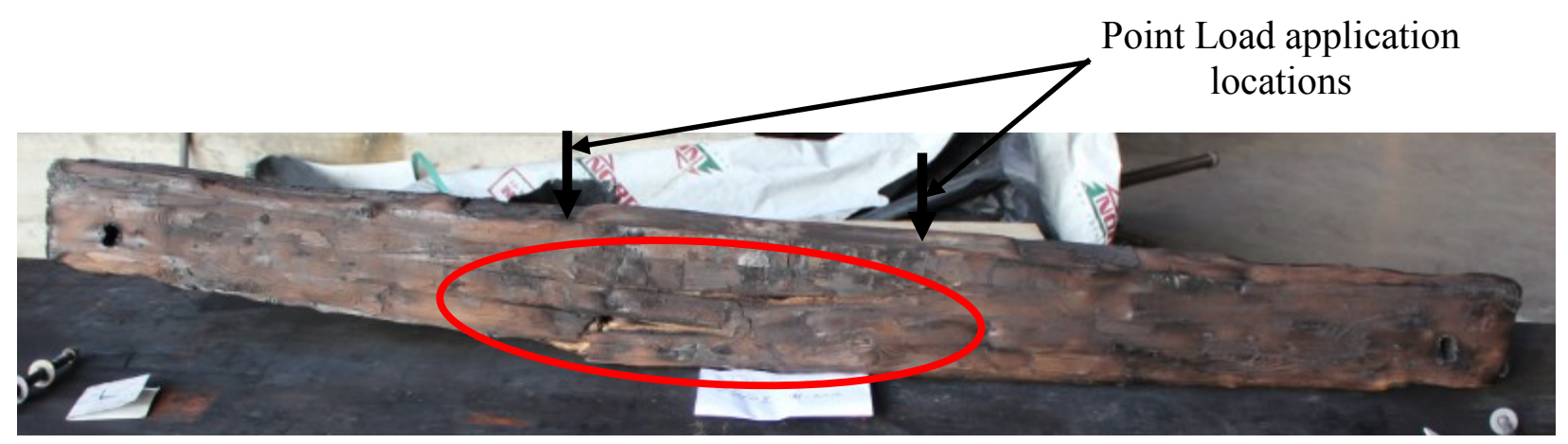

Fig. 4.34 Splitting at the beam mid-span for the SE connection

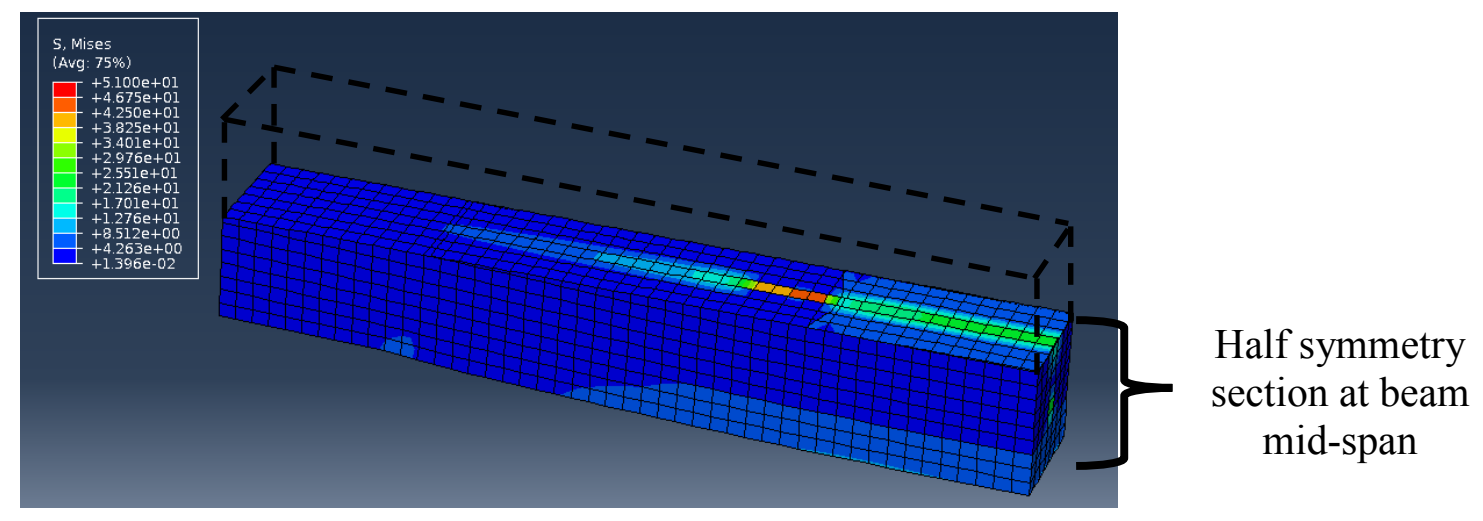

Fig. 4.35 Stress concentration at the mid-span and mid-height of the half symmetry beam section

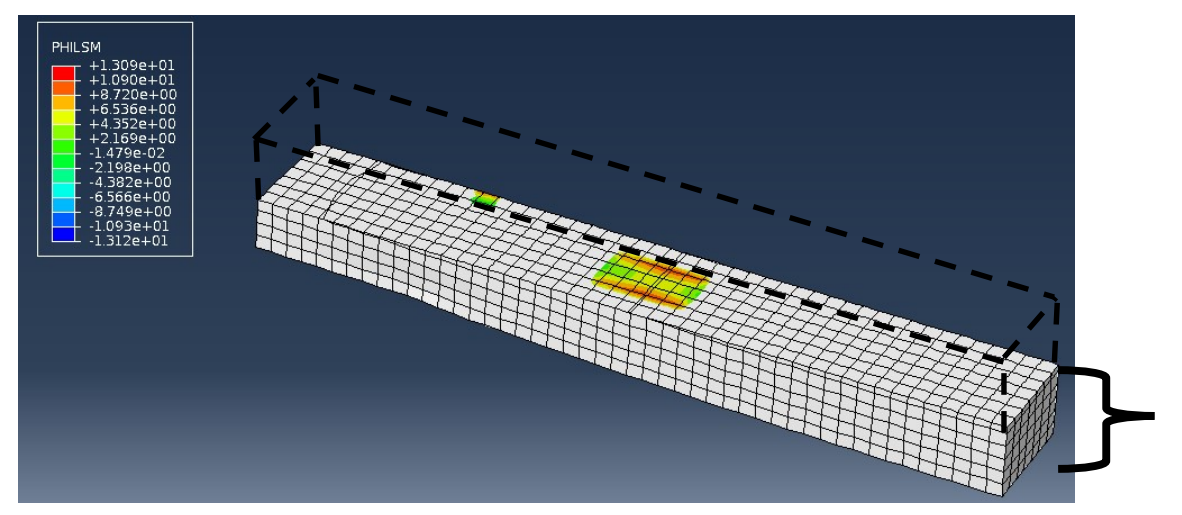

Half symmetry section at beam mid-span

\section{Fig. 4.36 Damage and Failure at the mid-span and mid-height of the half symmetry beam section}

The model underestimates the extent of crack propagation which were observed in the test. While the model does not account for the influence of glue between the lamellae of the glulam beam, inter-lamellae splitting was recorded in the test. These inter-lamellae splits and also splitting at the 
finger joints of the glulam beam were observed in the test (see Fig. 4.33 and Fig. 4.34) and this contributed to the difference in crack propagation which the model could predict.

For the steel bolts and plates in the assembly, they remained stiffer in elevated temperatures compared to the wooden beam. The damage which occurred in the steel sections was some minimal yielding at certain regions. Fig. 4.37 shows the recorded yielding of bolts and steel plates from the test and the model.
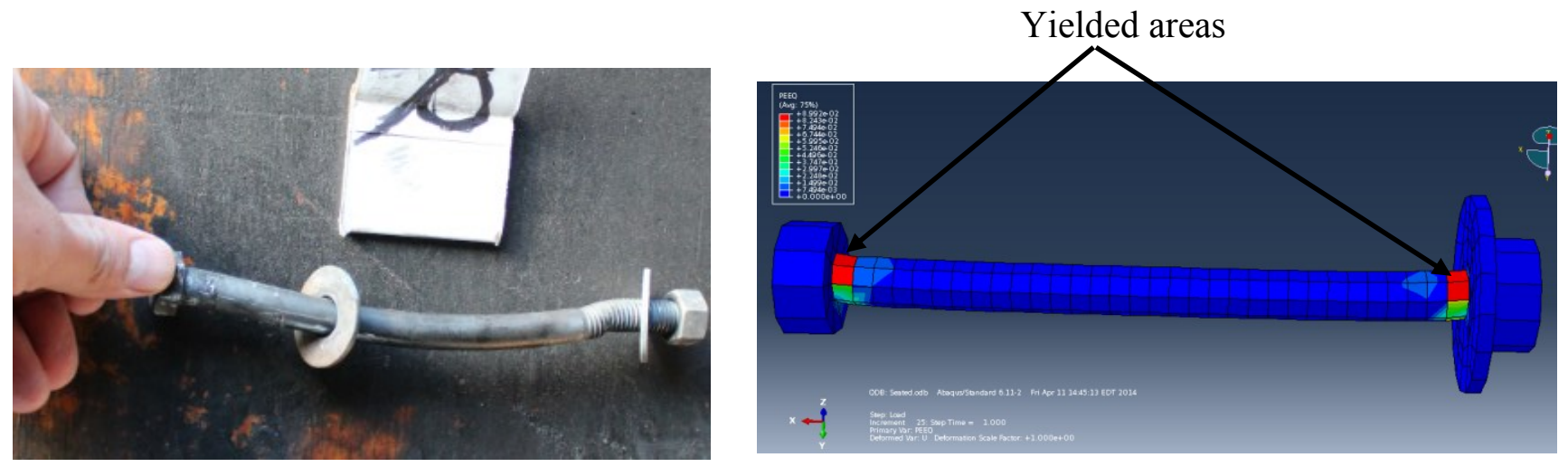

(a) Yielding of the Bolts

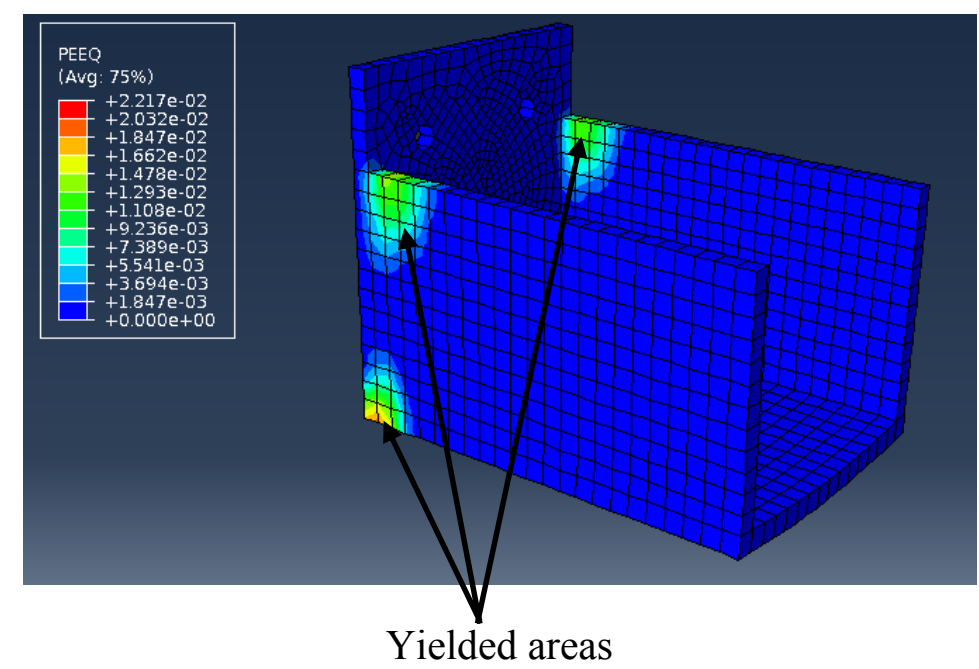

(b) Yielding of the plate

Fig. 4.37 Yielding of the Steel Elements 


\subsection{Conclusion}

A finite element model to simulate the fire resistance of three different shear tab connections has been developed in ABAQUS. The sequentially coupled thermal stress procedure which was adopted in the model was able to represent the overall behaviour of the connections in fire. The comparison of the model with the test results are generally in good agreement. The important parameters which were distinguished in the individual connections were the heat transfer and temperature development, charring rate of wood, and structural damage and failure during the duration of fire exposure. It was noticed that the amount of heat transmitted to the connection and the applied load on the connection assembly during fire exposure determined the fire resistance which was recorded. In conclusion, the seated shear tab connection had a better fire resistance than the concealed and exposed shear tab connections. 


\section{Chapter 5: Summary, Conclusions and Recommendations}

\subsection{Research Summary}

Following the objectives of this research, a finite element model has been developed in ABAQUS/Standard V6.112 which can simulate the behaviour of hybrid steel-timber connections in fire conditions. Three different types of connections: Concealed, Exposed and Seated shear tabs were investigated in the numerical model to see their correlation with full-scale fire resistance test results. In this preliminary study, which was focused on developing a reliable numerical model, the connection type and the load ratios were the primary parameters which were varied. The loads applied on the connection assemblies were $30 \%, 60 \%$ and $100 \%$ of their ambient design capacities according to CAN/CSA-O86-09 (2009). The time to structural failure of the individual connection configurations in fire was the primary concern.

A three-dimensional thermo-mechanical model was developed and used to simulate the individual connections in fire. The model couples heat and structural effects on the assembly which are both caused by a fire resistance test. A sequentially coupled thermal-stress procedure was adopted in ABAQUS, capable of conducting a structural analysis which follows a successful heat transfer analysis on the model assembly.

The thermal behaviour of the assembly in terms of the heat transfer, temperature distribution with time as well as the charring characteristics of the wooden beam obtained from the model generally correlates well with the test results. The concealed connection generally transmits more heat into the connection region as compared to the exposed and seated connections. This is attributed to the direct fire exposure of the wood side members and the presence of the steel plate at the beam center 
for the concealed connection. In contrast, the exposed and seated connections had the steel plates exposed, which delayed the heating of the wood behind. The relative exposure of the wood to fire was reflected in the heat propagation at the connection regions and the corresponding charring rates that were recorded. The concealed connection level recorded a charring rate which was $50 \%$ higher than it was on average for the exposed and seated connections. The test and model charring rates of the glulam wood section varied by $2.5 \%$. The average of the test and model values of charring rate was within $14 \%$ of the charring rate of wood in standard fires $(0.7 \mathrm{~mm} / \mathrm{min})$.

The structural damage and failure of the assembly occurred when its strength and stiffness were degraded by fire temperatures. The gradual structural damage and failure during the duration of fire exposure was used to estimate the fire resistance of all the connections in the model. All the connection types followed a decreasing trend in the fire resistance as they were subjected to higher load ratios. All the connections, when subjected to the $100 \%$ load ratio, demonstrated a similar fire resistance which was around 15 minutes. The model predictions of the fire resistance were generally within $\pm 11 \%$ variation of the recorded test results. The seated connection recorded a fire resistance level in the range of $50 \%-80 \%$ higher than that of the concealed and exposed connections.

\subsection{Conclusions}

Based on the findings of this research, the following conclusions can be drawn on the behaviour of the three connections in fire conditions:

- A sequentially coupled thermal-stress analysis procedure in a finite element model can generally represent the thermo-mechanical response of the steel-timber connections in fire 
conditions. Numerical simulation can be used to assess the fire resistance of the connections, as an alternative to full-scale fire resistance tests, following a successful model validation. The model's predictions for the fire resistance of these connections were within $\pm 11 \%$ of the test results.

- The connection configuration determines the level of fire safety which can be achieved. The rate of heat penetration within the connection region is dependent on the relative exposure of wood and steel elements. At constant low load ratios, the seated connection can achieve $50 \%$ - $80 \%$ higher fire resistance levels compared to the concealed connection. The seated connection had a better fire resistance than both the concealed and exposed connections while the exposed connection performed slightly better than the concealed connection.

- Increasing the load ratio on the connection assembly resulted in a decrease of the fire resistance. This observation was typical of all the connections in both the model and the test. Applying a load ratio close to the ultimate ambient capacity however resulted in a slim variation of the fire resistance of the connections. An average of 15 minutes fire resistance was obtained for all the connections, which is quite insignificant. The application of lower load ratios $(30 \%-60 \%)$ however can show the distinction between the various connections' performance in fire.

- The charring rate of timber increased as it becomes more exposed directly to fire. The model's estimation of wood charring rate was only a $2.5 \%$ variation from the test result. 
Both the model and test had an average of $14 \%$ variation from the charring rate of glulam wood sections in standard fires. The concealed connection recorded an average of 50\% higher charring rate than that obtained for the exposed and seated connections because it had more exposure of the wood compared to the other connections.

- The material properties from Eurocode 5 (2004) provided the temperature-dependent properties of wood and steel for both the thermal and structural analysis. The validation of the thermal model showed the reliability of these reduction factors especially in accounting for the effect of charred wood.

\subsection{Recommendations for Future Work}

For future further studies on the numerical simulation of hybrid steel-timber connections in fire, the following recommendations could be of help.

- The wood was modelled as a linear elastic material, whereby its fracture tendencies were modelled. This is because the approach adopted was the Linear Elastic Fracture Mechanics method which could accommodate only linear elastic materials. The model could not model the plastic deformations of the wood material and the extent of wood crack propagation. To improve the wood material model, it is recommended that the Concrete Damage Plasticity (CDP) model in ABAQUS be incorporated in the current modelling approach. The CDP model is capable of representing well both the linear elastic brittle behaviour of wood in tension and its linear elastic-plastic behaviour in compression, once the timber tension and compressive properties are substituted for concrete properties 
(Klippel and Frangi, 2014). The CDP model, when included in the current modelling approach, can potentially improve the simulation results.

- One important input in the numerical model is the material properties. The steel properties are quite composed in nature unlike wood which is subject to a large scatter of many dependencies; species, directionality, density, moisture content, etc. The wood properties which was used in the model were combined values from the manufacturer and literature. To account for the reliability of wood structural properties it is suggested that some specimen samples be tested for their strength and elastic properties to confirm the given values. In addition, pure structural tests on the connection assemblies can be conducted to aid in the validation stage of the numerical model. A single test for each connection configuration can be conducted without fire to confirm their ultimate structural capacities against designed capacities.

- During the simulation, it was also realized that the application of higher loads could not properly depict the relative fire resistance of the individual connections. It is advised to keep the load ratios below $50 \%$.

- From both the test and model results, it was observed that the seated connection with bolt resulted in an increased transmission of heat to the wood section, thus reducing the connection's capacity. The model conducted for the seated connection without bolt demonstrated an improved fire resistance of $40 \%$ higher (extra 16.5 minutes). It is recommended that dowels or smaller diameters of bolts should be used to stabilise the beam, where necessary, since they conduct less heat to the wood. 
- Lastly, fire protection on the connections can be examined to see how that will improve the fire resistance level recorded. This is because the partial protection provided by the steel elements to the wood section in the exposed and seated connections made a difference in the heat penetration and the resulting char of wood over the duration of fire exposure, and this could have also enhanced connection's fire resistance that were recorded. 


\section{Appendix: Input of the Model}

\section{Thermal Properties of the Materials}

\begin{tabular}{|c|c|c|c|}
\hline \multicolumn{4}{|c|}{ Glulam (at 12\% initial moisture content) } \\
\hline Temperature $\left.\mathbf{(}^{\mathbf{0}} \mathbf{C}\right)$ & $\begin{array}{c}\text { Conductivity } \\
(\mathbf{W} / \mathbf{m} / \mathbf{K})\end{array}$ & $\begin{array}{c}\text { Density } \\
\left(\mathbf{k g} / \mathbf{m}^{\mathbf{3}}\right)\end{array}$ & $\begin{array}{c}\text { Specific Heat Capacity } \\
(\mathbf{J} / \mathbf{k g} / \mathbf{K})\end{array}$ \\
\hline 20 & 0.12 & 627.2 & 1530 \\
\hline 99 & & 560.0 & 1760 \\
\hline 100 & & 560.0 & 13500 \\
\hline 120 & & 560.0 & 13500 \\
\hline 200 & 0.15 & 560.0 & 2000 \\
\hline 250 & & 520.8 & 1620 \\
\hline 300 & & 425.6 & 1360 \\
\hline 350 & 0.07 & 291.2 & 990 \\
\hline 400 & & 212.8 & 1390 \\
\hline 600 & & 156.8 & 1950 \\
\hline 800 & 0.35 & 145.6 & 2120 \\
\hline 1200 & 1.5 & 56.0 & 2120 \\
\hline
\end{tabular}

\begin{tabular}{|c|c|c|c|}
\hline \multicolumn{4}{|c|}{ Steel } \\
\hline Temperature $\left({ }^{0} \mathrm{C}\right)$ & $\begin{array}{l}\text { Conductivity } \\
(\mathbf{W} / \mathbf{m} / \mathbf{K})\end{array}$ & $\begin{array}{l}\text { Density } \\
\left(\mathrm{kg} / \mathrm{m}^{3}\right)\end{array}$ & $\begin{array}{c}\text { Specific Heat Capacity } \\
(\mathrm{J} / \mathrm{kg} / \mathrm{K})\end{array}$ \\
\hline 20 & 53.3 & \multirow{12}{*}{7850} & 439.8 \\
\hline 100 & 50.7 & & 487.6 \\
\hline 200 & 47.3 & & 529.8 \\
\hline 250 & & & 547.3 \\
\hline 300 & 44.0 & & 564.7 \\
\hline 350 & & & 583.7 \\
\hline 400 & 40.7 & & 605.9 \\
\hline 500 & 37.4 & & 666.5 \\
\hline 600 & 34.0 & & 760.2 \\
\hline 700 & 30.7 & & 1008.2 \\
\hline 800 & 27.4 & & 803.3 \\
\hline 900 & 27.4 & & 650.0 \\
\hline
\end{tabular}


DFLUX User subroutine (Adapted from Peng, 2010)

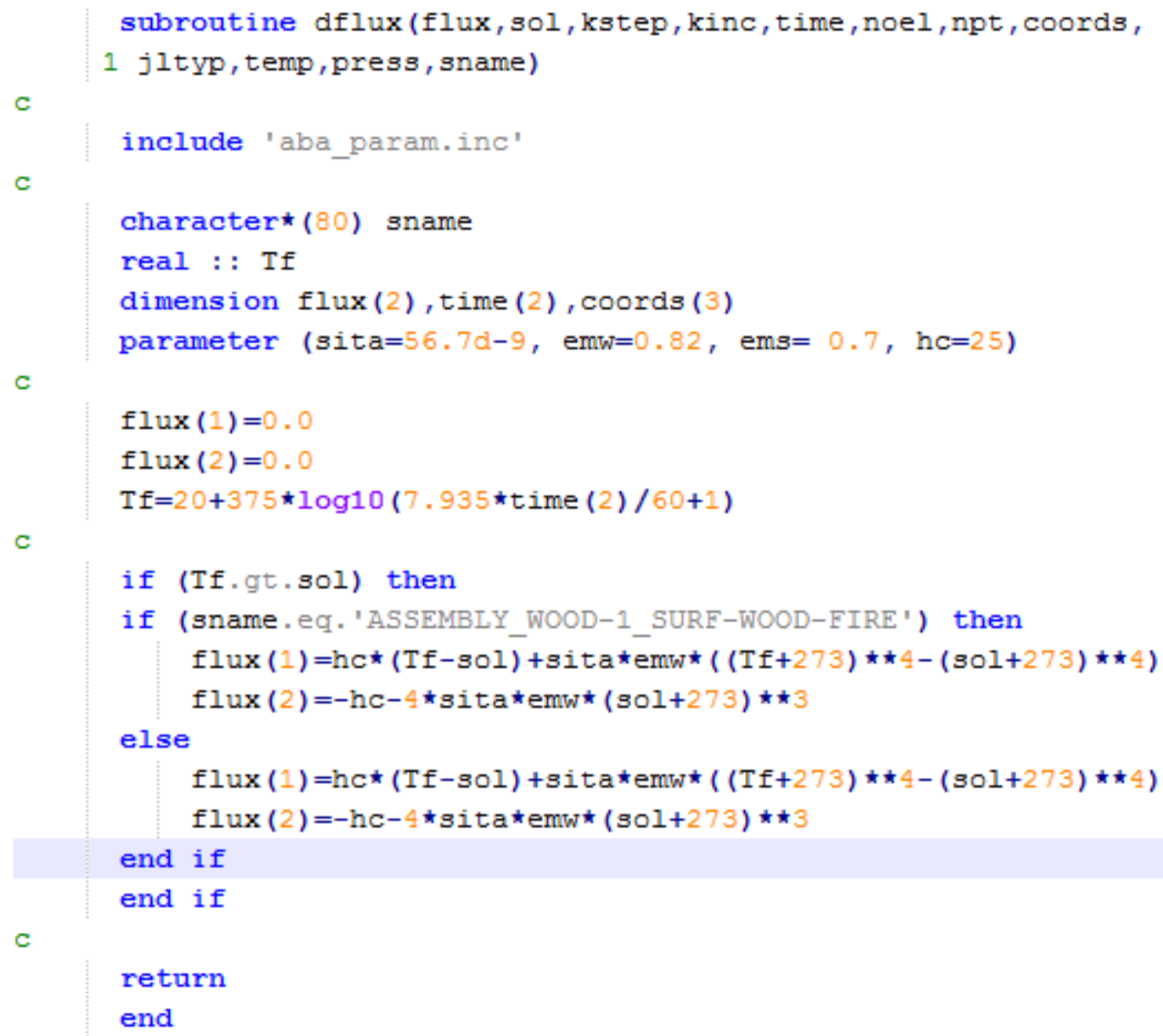

Mechanical Properties of the Materials at Elevated Temperatures

\begin{tabular}{|c|c|c|c|}
\hline \multicolumn{4}{|c|}{ Steel-Elasticity } \\
\cline { 1 - 3 } Temperature $\left({ }^{\mathbf{0}} \mathbf{C}\right)$ & $\begin{array}{c}\text { Reduction } \\
\text { Factor }\end{array}$ & $\begin{array}{c}\text { Elastic Modulus } \\
\text { (MPa) }\end{array}$ & \multirow{2}{*}{ Poisson Ratio } \\
\hline 20 & 1.0 & 200,000 & \\
\hline 99 & 1.0 & 200,000 & \\
\hline 100 & 1.0 & 200,000 & \multirow{2}{*}{0.3} \\
\hline 120 & 1.0 & 200,000 & \\
\hline 200 & 1.0 & 200,000 & \\
\hline 250 & 1.0 & 200,000 & \\
\hline 300 & 1.0 & 200,000 & \\
\hline 350 & 1.0 & 200,000 & \\
\hline 400 & 1.0 & 200,000 & \\
\hline & \multicolumn{2}{|c|}{} \\
\hline
\end{tabular}




\begin{tabular}{|c|c|c|}
\hline 500 & 0.78 & 156,000 \\
\hline 600 & 0.48 & 95,000 \\
\hline 700 & 0.22 & 44,000 \\
\hline 800 & 0.11 & 22,000 \\
\hline 900 & 0.07 & 14,000 \\
\hline 1000 & 0.035 & 7,000 \\
\hline 1200 & 0.02 & 4,000 \\
\hline
\end{tabular}

\begin{tabular}{|c|c|c|c|}
\hline \multicolumn{4}{|c|}{ Steel-Plasticity } \\
\hline Temperature $\left({ }^{0} \mathrm{C}\right)$ & $\begin{array}{l}\text { Reduction } \\
\text { Factor }\end{array}$ & $\begin{array}{c}\text { Yield Strength } \\
(\mathrm{MPa})\end{array}$ & Plastic strain \\
\hline 20 & 1.0 & 400 & 0 \\
\hline 20 & 1.0 & 400 & 0.03 \\
\hline 20 & 1.0 & 460 & 0.05 \\
\hline 20 & 1.0 & 500 & 0.08 \\
\hline 50 & 1.0 & 400 & 0 \\
\hline 50 & 1.0 & 400 & 0.03 \\
\hline 50 & 1.0 & 460 & 0.05 \\
\hline 50 & 1.0 & 500 & 0.08 \\
\hline 400 & 1.0 & 400 & 0 \\
\hline 400 & 1.0 & 400 & 0.03 \\
\hline 400 & 1.0 & 460 & 0.05 \\
\hline 400 & 1.0 & 500 & 0.08 \\
\hline 500 & 0.85 & 340 & 0 \\
\hline 500 & 0.85 & 340 & 0.03 \\
\hline 500 & 0.85 & 391 & 0.05 \\
\hline 500 & 0.85 & 425 & 0.08 \\
\hline 600 & 0.55 & 220 & 0 \\
\hline 600 & 0.55 & 220 & 0.03 \\
\hline 600 & 0.55 & 253 & 0.05 \\
\hline 600 & 0.55 & 275 & 0.08 \\
\hline 700 & 0.20 & 80 & 0 \\
\hline 700 & 0.20 & 80 & 0.03 \\
\hline 700 & 0.20 & 92 & 0.05 \\
\hline 700 & 0.20 & 100 & 0.08 \\
\hline 800 & 0.1 & 40 & 0 \\
\hline 800 & 0.1 & 40 & 0.03 \\
\hline 800 & 0.1 & 46 & 0.05 \\
\hline 800 & 0.1 & 50 & 0.08 \\
\hline
\end{tabular}




\begin{tabular}{|c|c|c|c|c|c|c|c|c|c|c|c|}
\hline \multicolumn{12}{|c|}{ Wood-Elasticity } \\
\hline \multirow{2}{*}{$\begin{array}{c}\text { Temp } \\
\left({ }^{0} \mathrm{C}\right)\end{array}$} & \multicolumn{2}{|c|}{ Reduction Factor } & \multicolumn{3}{|c|}{ Elastic Modulus (MPa) } & \multicolumn{3}{|c|}{ Poisson Ratio } & \multicolumn{3}{|c|}{ Shear Modulus (MPa) } \\
\hline & $\bar{E}$ & G & $\overline{E_{1}}$ & $E_{2}$ & $\overline{E_{3}}$ & $v_{12}$ & $v_{13}$ & $v_{23}$ & $G_{12}$ & $G_{13}$ & $G_{23}$ \\
\hline 20 & 1 & 1 & 860 & 860 & 13000 & 0.555 & 0.038 & 0.014 & 59 & 810 & 810 \\
\hline 50 & 0.98 & 0.8 & 842.8 & 842.8 & 12740 & 0.555 & 0.038 & 0.014 & 47.2 & 648 & 648 \\
\hline 100 & 0.97 & 0.4 & 834.2 & 834.2 & 12610 & 0.555 & 0.038 & 0.014 & 23.6 & 324 & 324 \\
\hline 150 & 0.95 & 0.3 & 817 & 817 & 12350 & 0.555 & 0.038 & 0.014 & 17.7 & 243 & 243 \\
\hline 200 & 0.93 & 0.2 & 799.8 & 799.8 & 12090 & 0.555 & 0.038 & 0.014 & 11.8 & 162 & 162 \\
\hline 250 & 0.1 & 0.1 & 86 & 86 & 1300 & 0.555 & 0.038 & 0.014 & 5.9 & 81 & 81 \\
\hline 300 & 0.1 & 0.1 & 86 & 86 & 1300 & 0.555 & 0.038 & 0.014 & 5.9 & 81 & 81 \\
\hline 400 & 0.1 & 0.1 & 86 & 86 & 1300 & 0.555 & 0.038 & 0.014 & 5.9 & 81 & 81 \\
\hline 500 & 0.1 & 0.1 & 86 & 86 & 1300 & 0.555 & 0.038 & 0.014 & 5.9 & 81 & 81 \\
\hline 600 & 0.1 & 0.1 & 86 & 86 & 1300 & 0.555 & 0.038 & 0.014 & 5.9 & 81 & 81 \\
\hline 700 & 0.1 & 0.1 & 86 & 86 & 1300 & 0.555 & 0.038 & 0.014 & 5.9 & 81 & 81 \\
\hline 800 & 0.1 & 0.1 & 86 & 86 & 1300 & 0.555 & 0.038 & 0.014 & 5.9 & 81 & 81 \\
\hline 900 & 0.1 & 0.1 & 86 & 86 & 1300 & 0.555 & 0.038 & 0.014 & 5.9 & 81 & 81 \\
\hline 1000 & 0.1 & 0.1 & 86 & 86 & 1300 & 0.555 & 0.038 & 0.014 & 5.9 & 81 & 81 \\
\hline 1100 & 0.1 & 0.1 & 86 & 86 & 1300 & 0.555 & 0.038 & 0.014 & 5.9 & 81 & 81 \\
\hline 1200 & 0.1 & 0.1 & 86 & 86 & 1300 & 0.555 & 0.038 & 0.014 & 5.9 & 81 & 81 \\
\hline
\end{tabular}

\begin{tabular}{|c|c|c|c|c|}
\hline \multicolumn{5}{|c|}{ Glulam-Shear Stress Damage } \\
\hline $\begin{array}{c}\text { Temperature } \\
\left({ }^{\circ} \mathrm{C}\right)\end{array}$ & $\begin{array}{c}\text { Reduction } \\
\text { Factor }\end{array}$ & $\begin{array}{c}\text { Nominal Stress } \\
\text { Normal-only mode } \\
\left(t_{n}^{o}\right)(\mathrm{MPa})\end{array}$ & $\begin{array}{l}\text { Nominal Stress } \\
\text { First direction } \\
\left(t_{s}^{o}\right)(\mathrm{MPa})\end{array}$ & $\begin{array}{c}\text { Nominal Stress } \\
\text { Second direction } \\
\left(t_{t}^{o}\right)(\mathrm{MPa})\end{array}$ \\
\hline 20 & 1.0 & 50 & 50 & 4 \\
\hline 50 & 0.8 & 40 & 40 & 3.2 \\
\hline 100 & 0.4 & 15 & 15 & 1.6 \\
\hline 150 & 0.3 & 12.5 & 12.5 & 1.2 \\
\hline 200 & 0.2 & 10 & 10 & 0.8 \\
\hline 250 & 0.1 & 5 & 5 & 0.4 \\
\hline 300 & 0.1 & 5 & 5 & 0.4 \\
\hline 500 & 0.1 & 5 & 5 & 0.4 \\
\hline 750 & 0.1 & 5 & 5 & 0.4 \\
\hline 1000 & 0.1 & 5 & 5 & 0.4 \\
\hline
\end{tabular}

\begin{tabular}{|c|c|c|}
\hline \multicolumn{3}{|c|}{ Fracture Criteria, Critical Fracture Energies of Wood $\left(\boldsymbol{G}_{\boldsymbol{C}}\right)$} \\
\hline $\begin{array}{c}\text { Mode I } \\
\text { Critical Energy Release Rate } \\
\left(\boldsymbol{G}_{\boldsymbol{I C}}\right)(\mathbf{N} / \mathbf{m m})\end{array}$ & $\begin{array}{c}\text { Mode II } \\
\text { Critical Energy Release Rate } \\
\left(\boldsymbol{G}_{\boldsymbol{I I C}}\right)(\mathbf{N} / \mathbf{m m})\end{array}$ & $\begin{array}{c}\text { Mode III } \\
\text { Critical Energy Release Rate } \\
\left(\boldsymbol{G}_{\boldsymbol{I I I C}}\right)(\mathbf{N} / \mathbf{m m})\end{array}$ \\
\hline 0.179 & 0.737 & 10.0 \\
\hline
\end{tabular}




\section{References}

ABAQUS/CAE Version 6.11 Standard Manual, 2011, Dassault Systemes, Rhode Island, USA

ASM Handbook (1992), "Friction, Lubrication, and Wear Technology", ASM International, Vol. 18

ASTM E119 (1988 (a)), "Standard Tests and Methods for Fire Tests of Building Construction and Materials", American Society for Testing Materials

Audebert M., Dhima D., Taazount M., Bouchair A. (2011), "Numerical Investigations on the Thermo-mechanical behaviour of Steel-to-Timber Joints exposed to Fire", Engineering Structures, Vol. 33, pp. $3257-3268$

Ballerini M., Mares F., Sommavilla D. (2006), "Dowel timber connections with two shear planes loaded parallel to grain: reliability of the new European design code by means of experimental tests", World Conference on Timber Engineering, Portland, OR, USA

Barrett J. D. (1981), "Fracture Mechanics and the Design of Wood Structures", Philosophical Transactions of the Royal Society of London, Series A, Vol. 299, pp. $217-226$

Bartunkova E. (2012), “Constitutive Model of Timber”, Master's Thesis, Czech Technical University in Prague, Czech Republic

Bathe K. (1996), "Finite Element Procedures”, Prentice-Hall, Inc., New Jersey, USA

Benabou L. (2012), "Finite Strain Analysis of Wood Species under Compressive Failure due to Kinking", International Journal of Solids and Structures, Vol. 40, pp. $408-419$

Blass J., Schädle P. (2011), "Ductility aspects of reinforced and non-reinforced timber joints", Journal of Engineering Structures, Vol. 33, pp. 3018-3026

BSI (1987), "Fire Tests on Building Materials and Structures", British Standards Institution, UK

Buchanan, A.H. (2002), "Structural Design for Fire Safety”, John Wiley and Sons Ltd., Chichester, UK

Buchanan A. H., King A. B. (1991), "Fire Performance of Gusset Connections in Glue-laminated Timber", Fire and Materials, Vol. 13, pp. 137-143 
CAN/CSA-O86-09 (2009), "Engineering Design in Wood", Canadian Standards Association, Rexdale, Ontario, Canada

CAN/ULC-S101 (2007), "Standard Methods of Fire Endurance Tests of Building Construction and Materials", Underwriter's Laboratories of Canada, Scarborough, Canada

Cofer W. F., Du Y., Hermanson J. C. (1999), "The Development of a Simple Three Dimensional Constitutive Model for the Analysis of Wood", AMD Applied Mechanics Division; Mechanics of Cellulosic Materials, Vol. 85, pp. $107-124$

Dickof C., Stiemer S. F., Tesfamariam S. (2012), "Wood-Steel Hybrid Seismic Force Resisting Systems: Seismic Ductility", World Conference on Timber Engineering, Auckland, New Zealand

EN 1993-1-2 (2001), "Eurocode 3 - Design of Steel Structures. Part 1.2: General rules - Structural Fire Design"

EN 1995-1-1 (2004), "Eurocode 5 - Design of Timber Structures. Part 1-1: General-Common rules and rules for buildings". CEN/TC 250/SC5, 2004-11-01

Erchinger C., Frangi A., Fontana M. (2010), "Fire design of steel-to-timber dowelled connections", Journal of Engineering Structures, Vol. 32, pp. $580-589$

Griffith A. A. (1921), "The Phenomena of Rupture and Flows in Solids", Philosophical Transactions of the Royal Society of London. Series A, Containing Papers of a Mathematical or Physical Character, Vol. 221, pp. $163-198$

Haller P., Putzger R. (2006), "Fracture Energy in Mode I and Mode II of Textile Reinforced Wood", Fracture of Nano and Engineering Materials and Structures, Proceedings of the $16^{\text {th }}$ European Conference of Fracture, Vol. 10, pp. 453 - 454, Alexandroupolis, Greece

He M., Li Z., (2012), "Evaluation of Lateral Performance of Timber-Steel Hybrid Lateral Restraint System through Experimental Approach", World Conference on Timber Engineering, Auckland, New Zealand

ICC ICBC (2012), “International Building Code”, International Code Council, USA

Inglis C. (1913), "Stresses in a Plate due to the presence of Cracks and Sharp corners", Transactions of the institute of Naval architects", Vol. 55, pp. $219-241$ 
Irwin G. R. (1958), “Fracture”, Encyclopedia of Physics, Springer, Berlin, Vol. VI, pp. 551 - 590

ISO 834 (1975), "Fire Resistance Tests - Elements of Building Construction", International Organisation for Standardization

Johansson H., Stehn L. (2002), "Effects of Joint Geometry on the Shear-Plug Failure in Nailed Timber Connections", World Conference on Timber Engineering, Shah Alam, Malaysia

Jorissen A., Fragiacomo M. (2011), "General Notes on Ductility of Timber Structures", Journal of Engineering Structures, Vol. 33, pp. 2987-2997

Kharouf N., McClure G., Smith I. (2003), "Elasto-plastic Modelling of Wood Bolted Connections", Computers and Structures, Vol. 81, pp. $747-754$

Khorasan S. R. (2012), "Finite-Element Simulations of Glulam Beams with Natural Cracks", Master's Degree Thesis, Department of Mechanical Engineering, Blekinge Institute of Technology, Karlskrona, Sweden

Khorasani, Y. (2011), "Feasibility Study of Hybrid Wood Steel Structures", Masters' Thesis, University of British Columbia, Vancouver, Canada

Klippel M., Frangi A. (2014), "Numerical Investigations on the Fire Behaviour of GluedLaminated Timber Beams Taking into Account the Influence of Adhesives", Proceedings of the $8^{\text {th }}$ International Conference on Structures in Fire, Shanghai, China

Kollmann, F.F.P. and Côté, W.A. (1984), "Principles of Wood Science and Technology", Vol. 1 Solid wood. Berlin, Springer

Lie T. T. (1977), "A Method for Assessing the Fire Resistance of Laminated Timber Beams and Columns", Canadian Journal of Civil Engineering, Vol. 4, pp. 161 - 169

Moss P. J., Buchanan A. H., Fragiacomo M., Lau P. H., Chuo T. (2009), "Fire Performance of bolted connections in laminated veneer lumber", Fire and Materials, Vol. 33, pp. 223-243

NBCC (2005), "National Building Code of Canada", Canadian Commission on Building and Fire Code National Research Council of Canada, Ottawa, ON, Canada

NEN-EN 338:2009. Structural timber - Strength classes. Brussels, CEN, 2009

Norén J. (1996), "Load-bearing Capacity of Nailed Joints Exposed to Fire", Fire and Materials, Vol. 20, pp. 133-143 
Oudjene M., Khelifa M. (2009), "Elasto-plastic Constitutive Law for Wood Behaviour under Compressive Loadings”, Construction and Building Materials, Vol. 23, pp. 3359 - 3366

Oudjene M., Khelifa M. (2009), "Finite Element Modelling of Wooden Structures at Large Deformations and Brittle Failure Prediction”, Materials and Design, Vol. 30, pp. 4081 4087

Palermo A., Pampanin S., Buchanan A., Fragiacomo M., Deam B. (2006), "Code Provisions for Seismic Design of Multi-Storey Post-Tensioned Timber Buildings”, International Council for Research and Innovation in Building and Construction, Working Commission W18 Timber Structures, Florence, Italy

Peng L., Hadjisophocleous G. (2009), "Predicting the Fire Resistance of Wood-Steel-Wood Timber Connections”, Fire Technology, Vol. 47, pp. 1101 - 1119

Peng L. (2010), "Performance of Heavy Timber Connections in Fire”, Ph.D Thesis, Carleton University, Ottawa, Canada

Racher P., Bocquet J. F. (2005), "Non-linear Analysis of Dowelled Timber Connections: A new approach for Embedding Modelling”, Electronic Journal of Structural Engineering, 5 (2005)

Racher P., Laplanche K., Bouchäir A. (2010), "Thermo-mechanical analysis of the fire performance of dowelled timber connection", Journal of Engineering Structures, Vol. 32, pp. $1148-1157$

Reddy J. N. (1993), “An Introduction to the Finite Element Method”, McGraw-Hill, Inc., New York, USA

Reichert T. (2009), "Development of 3D Lattice Models for Predicting Non-linear Timber Joint Behaviour", PhD Thesis, Edinburgh Napier University

Sabah A., Hadjisophocleous G. (2012), "Full Scale Tests to Study the Influence of Various Parameters on the Fire Performance of Hybrid Timber Connections", Proceedings of the $13^{\text {th }}$ International Fire Science and Engineering Conference, UK, Interflam 2013, Vol. 1

Salem O. F. (2012), "Structural Fire Performance of Beam-to-Column Moment Connections Joining Tubular Steel Members", PhD Thesis, Carleton University, Ottawa, Ontario, Canada 
Sandhaas C. (2012), "Mechanical Behaviour of Timber Joints with Slotted-in Steel Plates", Master's Thesis, Delft University of Technology, Netherlands

Smith I., Snow M., Asiz A., Vasic S., (2006), "Failure Mechanisms in Wood-based Materials: A Review of Discrete, Continuum, and Hybrid Finite-element representations", $7^{\text {th }}$ World Congress on Computational Mechanics, Los Angeles, USA

Stiemer S., Khorasani Y., Siadat Z. (2010), “Steel Timber Hybrid Structures”, 510 Report Final Proper, Canada

Stiemer S., Tesfamariam S., Karacabayeli E., Popovs M. (2013), "Timber-Steel Hybrid Systems", From Tree to Buildings Workshop, Quebec City, Quebec

Surprenant D. (2010), "The National Building Code of Canada: A Tool for Recovery in the Forest Industry”, Library of Parliament, Publication No. 2010-27-E, Ottawa, Canada

Wiedenhoeft A. (2010), "Structure and Function of Wood", Wood Handbook-Wood as an engineering material, General Technical Report FPL-GTR-190, Madison, WI: U.S., Department of Agriculture, Forest Service, Forest Products Laboratory, Chapter 3

Winandy J. E. (1994), “Wood Properties”, USDA-Forest Service, Forest Products Laboratory, Encyclopedia of Agricultural Science, Volume 4, pp. 549-561

Wood Design Manual (2005), "Structural Wood Design, A Practice-Oriented Approach Using the ASD Method", John Wiley and Sons Inc., Hoboken, New Jersey, USA

Wood Handbook (2010), Wood Handbook: Wood as an Engineering Material, United States Department of Agriculture Forest Service, Forest Products Laboratory, Madison, Wisconsin, USA. 